\title{
Palliative care needs of patients with advanced chronic organ failure
}

Citation for published version (APA):

Janssen, D. J. A. (2012). Palliative care needs of patients with advanced chronic organ failure. [Doctoral Thesis, Maastricht University]. Datawyse / Universitaire Pers Maastricht.

https://doi.org/10.26481/dis.20120322dj

Document status and date:

Published: 01/01/2012

DOI:

10.26481/dis.20120322dj

Document Version:

Publisher's PDF, also known as Version of record

\section{Please check the document version of this publication:}

- A submitted manuscript is the version of the article upon submission and before peer-review. There can be important differences between the submitted version and the official published version of record.

People interested in the research are advised to contact the author for the final version of the publication, or visit the DOI to the publisher's website.

- The final author version and the galley proof are versions of the publication after peer review.

- The final published version features the final layout of the paper including the volume, issue and page numbers.

Link to publication

\footnotetext{
General rights rights.

- You may freely distribute the URL identifying the publication in the public portal. please follow below link for the End User Agreement:

www.umlib.nl/taverne-license

Take down policy

If you believe that this document breaches copyright please contact us at:

repository@maastrichtuniversity.nl

providing details and we will investigate your claim.
}

Copyright and moral rights for the publications made accessible in the public portal are retained by the authors and/or other copyright owners and it is a condition of accessing publications that users recognise and abide by the legal requirements associated with these

- Users may download and print one copy of any publication from the public portal for the purpose of private study or research.

- You may not further distribute the material or use it for any profit-making activity or commercial gain

If the publication is distributed under the terms of Article $25 \mathrm{fa}$ of the Dutch Copyright Act, indicated by the "Taverne" license above, 


\section{Palliative care needs of patients with advanced chronic organ failure}


ISBN 9789461591241

(C) copyright Daisy J.A. Janssen, Maastricht 2012

Printing: Datawyse | Universitaire Pers Maastricht

The research presented in this thesis was conducted at $\mathrm{CIRO}+$, centre of expertise for chronic organ failure, Proteion Thuis, and the School for Public Health and Primary Care: CAPHRI, Maastricht University. CAPHRI participates in the Netherlands School of Primary Care Research CaRe. CAPHRI was classified as 'excellent' by the external evaluation committee of leading international experts that reviewed CAPHRI in December 2010.

The study presented in this thesis was supported by: Proteion Thuis, Horn, The Netherlands; CIRO+, centre of expertise for chronic organ failure, Horn, The Netherlands; Grant 3.4.06.082 of the Netherlands Asthma Foundation, Leusden, The Netherlands; The Weijerhorst Foundation, Maastricht, The Netherlands; Stichting Wetenschapsbevordering Verpleeghuiszorg (SWBV), Utrecht, The Netherlands.

Printing of this thesis was financially supported by $\mathrm{CIRO}+$, centre of expertise for chronic organ failure; Proteion Thuis; Boehringer Ingelheim; Novartis Pharma, and GlaxoSmithKline. 


\title{
Palliative care needs of patients with advanced chronic organ failure
}

\author{
DISSERTATION \\ to obtain the degree of Doctor at the Maastricht University, \\ on the authority of the Rector Magnificus Prof. dr. G.P.M.F. Mols, \\ in accordance with the decision of the Board of Deans, \\ to be defended in public on Thursday, March 22, 2012 at 16.00 hours
}

by

Daisy J.A. Janssen

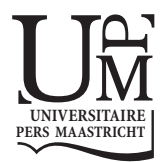




\section{Supervisors}

Prof. dr. E.F.M. Wouters

Prof. dr. J.M.G.A. Schols

\section{Co-supervisor}

Dr. M.A. Spruit

\section{Assessment Committee}

Prof. dr. H.P. Brunner-La Rocca (chairman)

Prof. dr. J.E. Ellershaw

Prof. dr. R.T.C.M. Koopmans

Prof. dr. K. Leunissen

Prof. dr. J.F.M. Metsemakers 
Voor Pap en Mam 



\section{Table of contents}

Chapter 1 General introduction 9

Chapter 2 A patient's journey: The last wish of a patient with end stage 29 chronic obstructive pulmonary disease

Chapter 3 Daily symptom burden in end-stage chronic organ failure: a systematic review

Chapter 4 Self-perceived symptoms and care needs of patients with severe to very severe chronic obstructive pulmonary disease, congestive heart failure or chronic renal failure and the consequences for their closest relatives: the research protocol

Chapter 5 Symptoms, comorbidities and healthcare in patients with advanced chronic obstructive pulmonary disease or chronic heart failure

Chapter $6 \quad$ Impaired health status and care dependency in patients with advanced COPD or chronic heart failure

Chapter 7 Family caregiving in advanced chronic organ failure

Chapter 8 A call for high-quality advance care planning in outpatients with severe COPD or chronic heart failure

Chapter 9 Predicting changes in preferences for life-sustaining treatment among patients with advanced chronic organ failure

Chapter 10 Patient-clinician communication about end-of-life care for Dutch and US patients with COPD

Chapter 11 General Discussion

Summary

Samenvatting

Dankwoord 209

Curriculum vitae

List of publications 



\section{CHAPTER 1}

\section{General introduction}

Part of the General introduction was published as:

Daisy J.A. Janssen, Ruth A. Engelberg, Emiel F.M. Wouters, and J. Randall Curtis Advance care planning for patients with COPD: past, present and future.

Patient Educ Couns, 2012. 86(1): 19-24. 
10 | CHAPTER 1 


\section{General introduction}

\section{Chronic organ failure}

A century ago, most deaths occurred suddenly due to infectious diseases, accidents and childbirth. ${ }^{1}$ Nowadays, demographic transitions like ageing of the population and a shift in causes of death to chronic diseases, have major consequences for the experience of dying and end-of-life care needs. ${ }^{2,3}$ The experience of dying becomes increasingly a feature of old age. ${ }^{2}$ Many people acquire progressive chronic diseases towards the end of life, like chronic organ failure. ${ }^{1,2}$ Indeed, chronic organ failure is a major cause of mortality, as well as a major cause of morbidity, worldwide. ${ }^{3}$

The present thesis focuses on palliative care needs of patients with advanced chronic organ failure, like Chronic Obstructive Pulmonary Disease (COPD), Chronic Heart Failure (CHF) and Chronic Renal Failure (CRF) and the needs of their closest relatives. This introduction starts with background information about COPD, CHF and $\mathrm{CRF}$, followed by an introduction to palliative care, including the disease trajectory and the palliative care model for patients with chronic organ failure. An overview is provided about the available knowledge at the start of the study concerning symptom burden, care needs, family caregiving and advance care planning. This chapter concludes with the research questions and outline of the thesis.

\section{COPD}

COPD is defined as: 'a preventable and treatable disease with some significant extra pulmonary effects that may contribute to the severity in individual patients. Its pulmonary component is characterized by airflow limitation that is not fully reversible. The airflow limitation is usually progressive and associated with an abnormal inflammatory response of the lung to noxious particles or gases'. ${ }^{4}$ The Global Initiative for Chronic Obstructive Lung Disease (GOLD) graded severity of COPD according to the degree of airflow limitation into mild, moderate, severe and very severe. ${ }^{4}$ The worldwide prevalence of moderate to very severe COPD is estimated around $10 \%$ in persons aged 40 years and older. ${ }^{5}$ A Dutch study has shown that the risk for developing COPD over the next 40 years was $24 \%$ for a 55 -year old man and $16 \%$ for a 55 year old woman. ${ }^{6}$ Almost $20 \%$ of the Dutch patients in general practice with a physician diagnosis of COPD suffered from severe to very severe COPD. ${ }^{7}$ COPD is expected to be the third leading cause of death by 2020 worldwide. ${ }^{3}$ The mortality within one year after hospitalization for an acute exacerbation of COPD is $23 \%{ }^{8}$ Progressive respiratory failure is the primary cause of death in patients with COPD 
hospitalized for an exacerbation. ${ }^{8}$ In addition, patients with COPD often suffer from co-morbidities which may further compromise survival. ${ }^{9}$ Indeed, cardiovascular events are an important cause of death for patients with COPD. ${ }^{10}$ Management of COPD includes reduction of risk factors, like smoking cessation; pharmacological treatment, like inhaled bronchodilators and glucocorticosteroids; and nonpharmacological treatment, such as pulmonary rehabilitation, long-term oxygen therapy and surgical treatment. ${ }^{4}$ Pulmonary rehabilitation is indicated for patients who are symptomatic or who complain of having decreased daily life activities. ${ }^{11,12}$ Long-term oxygen therapy has been shown to increase survival in patients with chronic respiratory failure. ${ }^{4}$ Surgical treatments like bullectomy, lung volume reduction surgery and lung transplantation can improve outcomes for carefully selected patients with very severe COPD. ${ }^{4}$

\section{CHF}

The European Society of Cardiology (ESC) guidelines defined heart failure as: ' $a$ clinical syndrome in which patients have the following features: symptoms typical of heart failure (breathlessness at rest or on exercise, fatigue, tiredness, ankle swelling); and signs typical of heart failure (tachycardia, tachypnea, pulmonary rales, pleural effusion, raised jugular venous pressure, peripheral edema, hepatomegaly); and objective evidence of a structural or functional abnormality of the heart at rest (cardiomegaly, third heart sound, cardiac murmurs, abnormality on the echocardiogram, raised natriuretic peptide concentration) $)^{13}$ Heart failure is categorized in new-onset, transient, and CHF. Worsening heart failure in a patient suffering from $\mathrm{CHF}$ is the most common form of heart failure leading to hospital admission. ${ }^{13}$ The New York Heart Association (NYHA) functional classification defined four classes of disease severity, based on symptoms and physical activity. ${ }^{13}$ The overall prevalence of $\mathrm{CHF}$ is rising and is estimated between $2 \%$ and $3 \%$ in all age groups and between $10 \%$ and $20 \%$ in persons aged 70 to 80 years. ${ }^{13}$ In the Netherlands, almost one-third of the persons aged 55 , will develop heart failure during their remaining life. ${ }^{14}$ The prognosis of $\mathrm{CHF}$ is worse than in many of the common malignant diseases. ${ }^{15}$ Fiveyear mortality after the onset of CHF is estimated at $59 \%$ for men and $45 \%$ for women. ${ }^{16} \mathrm{CHF}$ management consists of pharmacological and non-pharmacological therapy. ${ }^{13}$ Pharmacological therapy includes for example angiotensin-converting enzyme inhibitors, ß-Blockers, aldosterone antagonists, diuretics and digoxin. Nonpharmacological treatment components are weight monitoring, regular daily activity, smoking cessation, sodium restriction and fluid restriction in patients with severe symptoms. Heart transplantation can be considered in patients with end-stage CHF. $^{13}$ 


\section{CRF}

Chronic renal failure is defined as: 'kidney damage for three months or more (structural or functional abnormalities of the kidney, with or without decreased Glomerular Filtration Rate (GRF)) or a decreased GFR with or without kidney damage.17 Decreased GFR is associated with a wide range of complications, such as hypertension, anemia, malnutrition, bone disease, neuropathy, which can be prevented or ameliorated by treatment at early stages. ${ }^{18}$ Therapeutic interventions include treatment of the underlying renal disease, treatment of co-morbidities, treatment of complications, preparation for replacement and finally renal replacement therapy with dialysis or transplantation. ${ }^{17}$ The decision to start dialysis should be based on the GFR, the presence of symptoms or signs of uraemia, the inability to control hydration status or blood pressure, the presence of progressive deterioration in nutritional status and co-morbidities. ${ }^{19,20}$ The decision to start dialysis or to offer conservative management is complex. Patient's preferences, prognosis, expected quality of life with and without dialysis and burden of treatment contribute to decision-making. ${ }^{20}$ The prevalence of renal replacement therapy increases in Europe. ${ }^{21}$ In the Netherlands, the prevalence was 767.9 per million population in the year 2006. ${ }^{21}$ Mortality is high in dialysis patients. Indeed, five-year mortality for patients on haemodialysis is $64 \%$ and for patients on peritoneal dialysis $57 \% .{ }^{21}$ Important causes of death in people on dialysis are cardiac disease, infection, malignancy, stroke and treatment withdrawal. ${ }^{22}$ About one in four deaths is preceded by a decision to discontinue dialysis. ${ }^{23}$

\section{Palliative care for patients with chronic organ failure}

\section{Definition of palliative care}

Palliative care is defined by the World Health Organization as "an approach that improves the quality of life of patients and their families facing the problem associated with life-threatening illness, through the prevention and relief of suffering by means of early identification and impeccable assessment and treatment of pain and other problems, physical, psychosocial and spiritual. Palliative care: provides relief from pain and other distressing symptoms; affirms life and regards dying as a normal process; intends neither to hasten or postpone death; integrates the psychological and spiritual aspects of patient care; offers a support system to help patients live as actively as possible until death; offers a support system to help the family cope during the patients illness and in their own bereavement; uses a team approach to address the needs of patients and their families, including bereavement counseling, if indicated; will enhance quality of life, and may also positively influence the course 
of illness; is applicable early in the course of illness, in conjunction with other therapies that are intended to prolong life, such as chemotherapy or radiation therapy, and includes those investigations needed to better understand and manage distressing clinical complications." ${ }^{24}$

\section{Disease trajectories of patients with chronic organ failure}

During the last decade, several authors have suggested that palliative care has an important role in chronic non-malignant diseases. ${ }^{25-29}$ Indeed, previous research has shown that quality of life of patients with CHF, COPD or CRF is equally or even more greatly affected by their disease than quality of life of patients with cancer. ${ }^{27,30,31}$ However, until now palliative care has been reserved mostly for patients with malignant disease as evidenced by the limited access to palliative care for patients with non-malignant disease. ${ }^{27,32}$ This disparity in care, despite evidence to the contrary, likely reflects the uncertainty in the prognosis in terms of survival in patients with chronic organ failure. ${ }^{33}$ The course of end-stage COPD and CHF is typically marked by a gradual decline in health status and punctuated by acute exacerbations (Figure 1.1, middle panel). ${ }^{1}$ Every exacerbation can be life threatening and is associated with an increased risk of dying. ${ }^{1}$ In CRF, it is more complex to describe the disease trajectory. CRF patients can follow a trajectory comparable with the trajectories of patients with COPD or CHF. CRF patients may have recurrent episodes like cardiovascular events, infections or fluid overload, without complete recovery after such episode. ${ }^{34}$ However, patients who withdraw from dialysis or who are managed conservatively, are likely to follow a trajectory comparable with cancer patients: a short period of rapid decline at the end of life (Figure 1.1, upper panel). ${ }^{34,35}$ Other CRF patients may follow a disease trajectory characterized by a steady decline in which the rate of decline depends on the underlying renal disease and co-morbidities (Figure 1.1, lower panel). ${ }^{36}$ Unfortunately, even the best models of six-month survival in patients with non-malignant diseases have a limited ability to predict death for individual patients. ${ }^{33,37}$ Therefore, predicting prognosis of survival is a continuous challenge for the treating physicians of patients with advanced COPD, CHF or CRF.

\section{Palliative care model}

Based on the described disease trajectories, the traditional dichotomous model of curative and palliative care in which curative care ends and palliative care starts at a certain moment, is not appropriate for patients with COPD, CHF or CRF. The Official American Thoracic Society Clinical Policy Statement: Palliative Care for Patients with Respiratory Diseases and Critical Illnesses describes an individualized integrated 
model of palliative care in which palliative care starts when a patient suffering from a progressive respiratory disease becomes symptomatic. ${ }^{39}$

Figure 1.1 Disease trajectories at the end of life
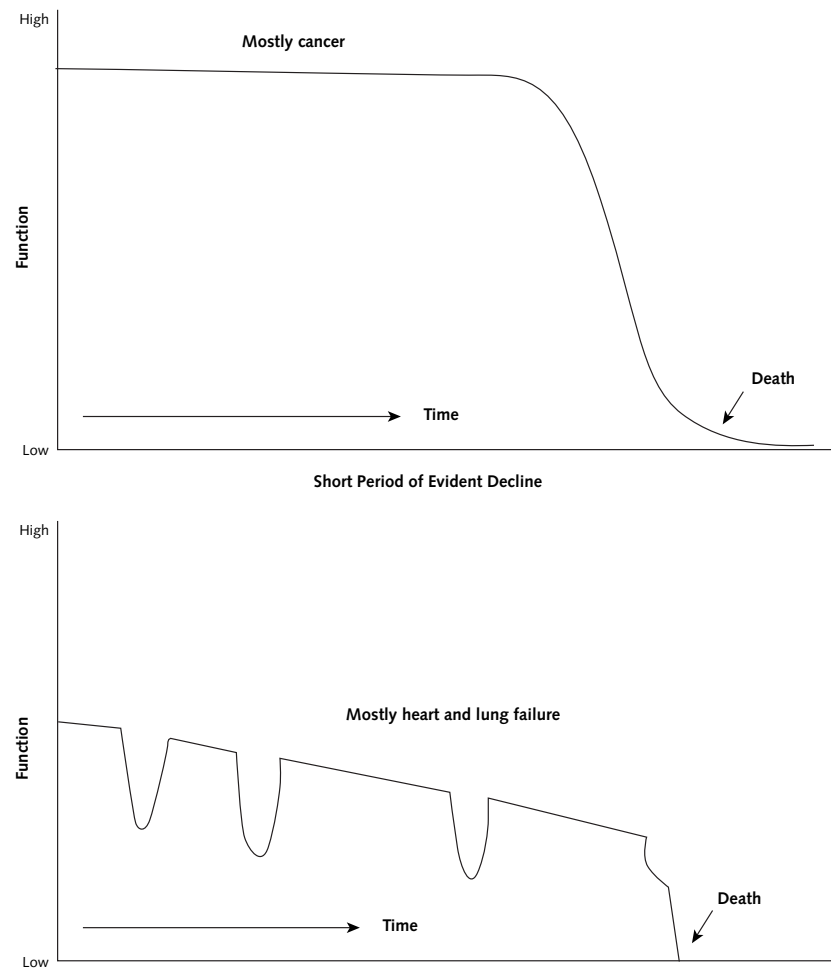

Long-Term Limitations with Intermittent Serious Episodes

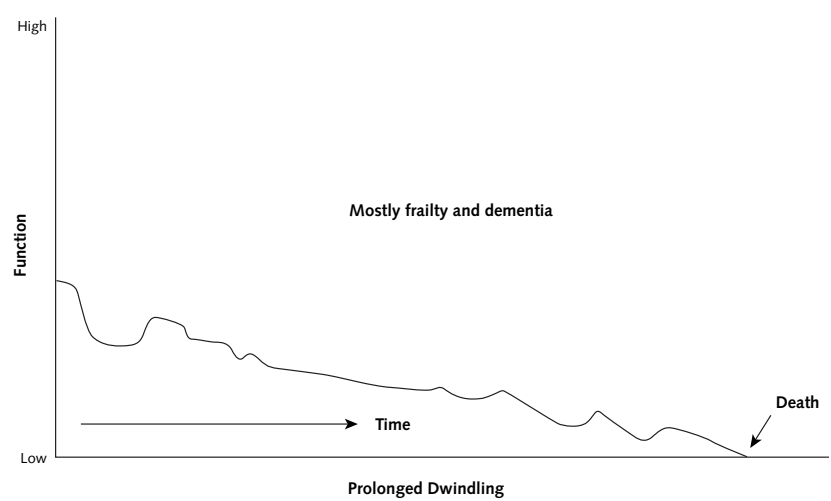

Disease trajectories at the end of life: a short period of evident decline (upper panel); long-term limitations with intermittent episodes (middle panel); and a gradual decline (lower panel). Reproduced with permission. ${ }^{38}$ 
Palliative care needs to be offered concurrent with curative-restorative care and the intensity of palliative care is titrated to the needs of the patient and the patient's family. ${ }^{39}$ The position statement from the palliative care workshop of the Heart Failure Association of the European Society of Cardiology describes that palliative care should be available to all CHF patients along the whole disease trajectory. ${ }^{40}$ Also for CRF patients, the importance of offering palliative care early in the course of the disease has recently been recognized. While the first edition of the Renal Physicians Association (RPA) and the American Society of Nephrology (ASN) 'Clinical Practice Guideline on Shared Decision-Making in the Appropriate Initiation of and Withdrawal from Dialysis' only recommended to offer palliative care to patients who decided to forego dialysis, ${ }^{41}$ the most recent edition of this guideline recommends to offer palliative care to all CRF patients who suffer from burdens of their disease. ${ }^{42}$ These include patients who have chosen not to start dialysis or withdraw from dialysis, but also patients who chose to undergo or remain on dialysis. This guideline recommends that a multi-professional team with expertise in renal palliative care should be involved in managing the physical, psychological, social, and spiritual aspects of treatment for these patients, including end-of-life care. ${ }^{42}$

\section{Symptoms}

Palliative care should improve the quality of life of patients by early identification, assessment and treatment of physical and psychological symptoms. ${ }^{24}$ Previous research has shown that symptom burden of patients with COPD, CHF and CRF is comparable with symptom burden of patients with cancer. ${ }^{29-31,43}$

According to bereaved relatives, common symptoms experienced by patients with chronic lung disease in their last year of life are dyspnea (94\%), pain (77\%), low mood (71\%), anorexia (67\%), insomnia (65\%) and cough (59\%). ${ }^{29}$ In-depth interviews with bereaved relatives of COPD patients showed that dyspnea had major consequences in terms of physical functioning, lifestyle restrictions and anxiety. ${ }^{44} \mathrm{~A}$ questionnaire survey including bereaved relatives, suggests that symptom control is poor in the last year of life of patients with COPD. Moreover, patients may receive inadequate services from primary and secondary care. ${ }^{45}$

A retrospective review examined medical and nursing records of 80 elderly patients with CHF who had been hospitalized during the last six months of life. This study showed that on average, 6.7 symptoms were reported for each patient. ${ }^{46}$ An interview survey of bereaved relatives showed that in their last year of life, $78 \%$ of $\mathrm{CHF}$ patients experienced pain, $61 \%$ dyspnea, $59 \%$ low mood, $45 \%$ sleeplessness, $43 \%$ anxiety and $43 \%$ loss of appetite. ${ }^{47}$ In addition, $87 \%$ of elderly hospitalized CHF pa- 
tients have expressed worries about control of pain, shortness of breath and other symptoms. $^{48}$

A cross-sectional pilot study compared symptom burden of 11 patients with CRF and 11 patients with incurable cancer. CRF patients included patients who declined dialysis or patients who had not yet started dialysis. ${ }^{30}$ The median number of symptoms (assessed using the Memorial Symptom Assessment Scale Short Form (MSASSF)) was 17 for CRF patients and 15 for cancer patients. The most frequently reported symptoms by CRF patients were lack of energy, sleeplessness, dyspnea, edema and pain. ${ }^{30} \mathrm{~A}$ pilot study assessing symptom burden, as well as the acceptability of palliative care for CRF patients, included 19 haemodialysis patients with co-morbidities. This study showed that while patients experienced a mean number of 10.5 symptoms (assessed with the MSAS-SF), only 4.1 symptoms were recorded by the treating nephrologists in the medical record. With the exception of pain, nephrologists did not report the most common symptoms. ${ }^{26}$

These studies suggest that symptom burden is high in patients with advanced COPD, CHF or CRF and symptom management may be inadequate. However, most studies were retrospective, or included a limited number of patients. Therefore, at the start of this study, knowledge concerning severity of symptom burden in advanced COPD, CHF or CRF was scarce. Moreover, the presence of symptom-related interventions was unknown. For development of palliative care programs for patients with advanced chronic organ failure which adequately address symptoms, it is necessary to know the severity of symptoms, the presence of symptom-related interventions and utilization of healthcare.

\section{Care needs and consequences for family caregivers}

Patients with advanced chronic organ failure often experience impairment in performing normal daily tasks. ${ }^{49,50}$ A study of COPD and CHF patients admitted to the hospital showed that patients may need assistance with instrumental activities of daily living, like grocery shopping, house working, doing laundry and travelling, but also with basic activities of daily living, like bathing and dressing. ${ }^{50}$ Family caregivers have a crucial role in providing care for patients with advanced chronic organ failure. $^{45,51,52}$ A qualitative study of bereaved relatives of COPD patients showed that patients with COPD became increasingly dependent on their loved ones towards the end of life. ${ }^{44}$ Caring for a loved one with advanced disease may have significant consequences for the family caregiver(s). Qualitative studies have shown that a decline in patients' health status can lead to a range of physical, social, and emotional consequences for family caregivers of patients with COPD, CHF or CRF. ${ }^{49,53-55}$ 
Indeed, unstructured interviews with 18 patients with end-stage respiratory disease, CHF or CRF and their closest relatives showed that deteriorating health status led to care dependency, social isolation and burden for family caregivers. Patients often experienced feelings of frustration because of their inability to perform normal daily tasks. Adapting to their functional limitations may be difficult for patients, but also for family caregivers. ${ }^{49}$ Moreover, previous studies have shown that health status and emotional well-being of family caregivers of patients with chronic organ failure can be impaired. ${ }^{56-61}$ Nevertheless, family caregiving may not only cause a burden, but can also be a positive experience for family caregivers. ${ }^{62}$ A study including family caregivers of cancer patients has shown that positive aspects of caregiving may enhance quality of life of family caregivers. ${ }^{63}$

Palliative care should not only improve quality of life of patients confronted with life-threatening illness, but also of their loved ones. ${ }^{24}$ Further understanding of burden of family caregiving for patients with advanced chronic organ failure and insight in positive aspects of caregiving are important to provide adequate support to family caregivers and to improve their quality of life.

\section{Advance care planning}

Decisions about end-of-life care often occur at a time when patients lack the capacity to make these decisions. ${ }^{64,65}$ Therefore, advance directives were advanced in the 1990 s as an important tool for improving end-of-life care. ${ }^{65-67}$ Early studies of advance directives proved to be disappointing and many in the healthcare community grew disillusioned with their potential. ${ }^{68}$ However, advance directives, within the context of advance care planning, has again received increasing attention in the last few years. ${ }^{64}$ In the previous decade, advance care planning was seen as the process by which persons can indicate the type of treatment they would want to receive in the future if they were no longer able to participate in the decision-making process; it was often seen as synonymous with the completion of advance directives. ${ }^{69}$ However, more recently advance care planning is seen as a process of communication between patients and professional caregivers that includes, but is not limited to, the completion of advance directives. ${ }^{69}$ Communication about end-of-life care is an essential part of advance care planning. In contrast to the early research on advance directives, recent studies have shown that advance care planning can be effective in changing outcomes for patients and their loved ones and provide support for the use of advance directives. An observational study showed that patients who had completed advance directives, and subsequently died, were less likely to receive life-sustaining treatments at the end of life than patients without advance directives. ${ }^{70}$ Family members of these patients were also surveyed and those whose 
loved one completed advance directives reported fewer concerns with physician communication and felt better prepared for their family member's death. ${ }^{70}$ Another observational study, the Health and Retirement study, examined individuals of 60 years of age or older and showed that patients who had prepared advance directives received care that was strongly associated with their preferences. ${ }^{64}$ In fact, patients with a living will were more likely to receive palliative care before dying than patients without a living will. ${ }^{64}$ Data from patients with cancer show that patient-physician communication about end-of-life care is not associated with any increase in anxiety or depression, but is associated with improved quality of life at the end of life and decreased intensive care resource use at the end-of-life. ${ }^{71}$

Because of the trajectory of illness among patients with chronic organ failure and the prognostic uncertainty ${ }^{1}$, advance care planning may be particularly important for these patients. ${ }^{72,73}$ The SUPPORT study has shown that patients with COPD were much more likely than patients with lung cancer to receive invasive mechanical ventilation, cardiopulmonary resuscitation or tube feeding before dying despite the fact that an equal proportion, and the majority, of hospitalized patients with advanced COPD or lung cancer preferred care focused on comfort rather than extending life. ${ }^{74}$ Similarly, a retrospective study has shown that patients who died in the hospital from CHF were more likely than patients who died of metastatic cancer to receive life-sustaining interventions before death. ${ }^{75}$ In addition, a qualitative study of bereaved family caregivers demonstrated differences in the experiences of family caregivers of patients with COPD and patients with cancer with respect to the need for decision-making about life-sustaining treatments. ${ }^{69}$ Bereaved caregivers of patients with cancer reported that patients reached a point in their illness when it was accepted that there were no longer any treatment options available to prolong the patient's life. In contrast, the family caregivers of patients with COPD experienced the need to make specific treatment decisions about life-sustaining treatment at the end of life. ${ }^{69}$ Therefore, timely discussions are needed to allow patients to participate actively in the decision making process. ${ }^{76}$

Despite this, a qualitative study has shown that patients with advanced COPD demonstrate a poor understanding of their disease. ${ }^{77}$ Most patients were unaware of the progressive course of COPD and the possibility they could die from COPD. If patients were aware of the fact that they could die from their disease, they often gained this information from personal experiences or the media rather than from conversations with their clinician. Nevertheless, patients with COPD expressed concerns about their dying. They were afraid of dying of breathlessness or suffocation and none of them had discussed their fears with their clinician. ${ }^{77}$ Also patients with CHF lacked understanding of their disease. ${ }^{78}$ In a qualitative study of 20 patients with advanced $\mathrm{CHF}$, none of them had discussed disease progression or advance 
care planning with their healthcare professionals. ${ }^{78}$ Patients admitted to the hospital with decompensated heart failure expressed concerns about the inappropriate prolongation of life. $^{48}$

Despite patients' and families' requests for increased and improved advance care planning, data from both patients and their physicians suggest that advance care planning is uncommon and often poorly done. ${ }^{79,80}$ Although patients with severe COPD rated their clinicians' general communication skills highly (e.g., listening, answering questions), they rated their clinicians' skills at discussing end-of-life topics as poor and reported that many topics are not discussed at all (e.g., prognosis, what dying might be like, spiritual issues). ${ }^{81}$

Clinicians have similarly reported that they often fail to discuss end-of-life care with their patients. ${ }^{76}$ They have also reported that patients with COPD are frequently not informed about the fact that they have a life-limiting illness. ${ }^{76}$ Indeed, only $31 \%$ of the patients with advanced COPD estimated their life-expectancy to be less than one year in the month before they died. ${ }^{82}$ This failure to understand the likelihood of death from COPD is an important barrier to initiating discussions about end-oflife care. ${ }^{76}$ Healthcare professionals identified the unpredictable disease trajectory as a reason why future care options are not discussed in $\mathrm{CHF}^{78}$

In conclusion, the currently available literature shows that advance care planning is important for patients with advanced chronic organ failure and suggests that advance care planning is poorly done. However, most of the studies concerning advance care planning are performed in the USA. European data concerning advance care planning for patients with advanced COPD, CHF or CRF are scarce. At the start of this study, the status of advance care planning for clinically stable outpatients with advanced chronic organ failure was unknown. Moreover, it was unknown whether and to what extent international differences exist in advance care planning. 


\section{Aims of the thesis}

Aim of this thesis was to understand the palliative care needs of patients with advanced chronic organ failure and the needs of their closest relatives. A better understanding of the palliative care needs of patients with advanced chronic organ failure and the needs of their closest relatives may eventually result in the development of interventions aimed at improving quality of life of patients and their closest relatives.

A longitudinal observational study was designed to answer the following research questions:

1. What are the self-perceived symptoms and care needs of patients with advanced chronic organ failure and whether and to what extent does current healthcare address these symptoms and care needs?

2. How do patients with advanced chronic organ failure perceive their health status and what are the correlates of impaired health status?

3. Whether and to what extent do closest relatives of patients with advanced chronic organ failure perceive family caregiving as a burden and/or a positive experience?

4. What are the life-sustaining treatment preferences of patients with advanced chronic organ failure?

5. How do patients with advanced chronic organ failure perceive advance care planning, including quality of patient-clinician communication about end-of-life care?

6. How do life-sustaining treatment preferences of patients with advanced chronic organ failure change over time and what are possible predictors of change in life-sustaining treatment preferences?

7. Whether and to what extent is the quality of patient-clinician communication about end-of-life care comparable between the Netherlands and USA for patients with COPD? 


\section{Outline of the thesis}

Chapter 2 describes the story of a patient with end-stage COPD and shows the consequences of the disease from a patient's individual perspective. Chapter 3 describes the results of a systematic review of the peer-reviewed literature, at the start of the current project, which addresses daily symptom burden of patients with advanced CHF, COPD or CRF. This chapter describes what was known about symptom burden in advanced COPD, CHF or CRF and identifies which knowledge was lacking. Chapter $\mathbf{4}$ describes the methodology of the prospective longitudinal study we performed for this thesis in detail. For development of palliative care programs which adequately address symptoms of patients with COPD or CHF, it is necessary to know severity of symptom distress and to gain insight in co-morbidities and current provision of healthcare. Therefore, Chapter 5 shows the results of the crosssectional part of our study that investigated severity of symptoms, presence of comorbidities and current provision of healthcare in outpatients with advanced COPD or CHF. The aim of palliative care is to improve quality of life of patients with lifelimiting illness. So, Chapter 6 focuses on health status, correlates of impaired health status and care dependency of patients with advanced COPD or CHF. Chapter 7 focuses on caregiver burden as well as positive aspects of family caregiving in advanced chronic organ failure. Especially in chronic organ failure, an important aspect of palliative care is advance care planning, including communication about end-oflife care. Therefore, Chapter $\mathbf{8}$ shows the life-sustaining treatment preferences, the current status of advance care planning and quality of end-of-life care communication in outpatients with clinically stable, but severe COPD or CHF. Chapter 9 focuses on stability of life-sustaining treatment preferences to know the need for reevaluation of advance care planning. Future efforts to improve communication about end-of-life care may benefit from an understanding of international differences in quality of communication about end-of-life care. Chapter 10 compared quality of patient-clinician communication about end-of-life care and endorsement of barriers and facilitators to this communication between the Netherlands and USA. Chapter 11 is the general discussion and discusses the clinical implications of this thesis and future directions for research. 


\section{References}

1. Murray, S.A., M. Kendall, K. Boyd, and A. Sheikh, Illness trajectories and palliative care. Bmj. 2005;330(7498):1007-11.

2. Seale, C., Changing patterns of death and dying. Soc Sci Med. 2000;51(6):917-30.

3. Murray, C.J. and A.D. Lopez, Alternative projections of mortality and disability by cause 1990-2020: Global Burden of Disease Study. Lancet. 1997;349(9064):1498-504.

4. Rabe, K.F., S. Hurd, A. Anzueto, P.J. Barnes, S.A. Buist, P. Calverley, Y. Fukuchi, C. Jenkins, R. Rodriguez-Roisin, C. van Weel, and J. Zielinski, Global strategy for the diagnosis, management, and prevention of chronic obstructive pulmonary disease: GOLD executive summary. Am J Respir Crit Care Med. 2007;176(6):532-55.

5. Buist, A.S., M.A. McBurnie, W.M. Vollmer, S. Gillespie, P. Burney, D.M. Mannino, A.M. Menezes, S.D. Sullivan, T.A. Lee, K.B. Weiss, R.L. Jensen, G.B. Marks, A. Gulsvik, and E. Nizankowska-Mogilnicka, International variation in the prevalence of COPD (the BOLD Study): a population-based prevalence study. Lancet. 2007;370(9589):741-50.

6. van Durme, Y.M., K.M. Verhamme, T. Stijnen, F.J. van Rooij, G.R. Van Pottelberge, A. Hofman, G.F. Joos, B.H. Stricker, and G.G. Brusselle, Prevalence, incidence, and lifetime risk for the development of COPD in the elderly: the Rotterdam study. Chest. 2009;135(2):368-77.

7. Hoogendoorn, M., T.L. Feenstra, T.R. Schermer, A.E. Hesselink, and M.P. Rutten-van Molken, Severity distribution of chronic obstructive pulmonary disease (COPD) in Dutch general practice. Respir Med. 2006;100(1):83-6.

8. Groenewegen, K.H., A.M. Schols, and E.F. Wouters, Mortality and mortality-related factors after hospitalization for acute exacerbation of COPD. Chest. 2003;124(2):459-67.

9. Wouters E.F., C.P.C., M.K. Breyer, E.P. Rutten, L. Graat-Verboome, and M.A. Spruit, Co-morbid manifestations in COPD. Resp Med COPD Update. 2007;3:135-151.

10. Sin, D.D., N.R. Anthonisen, J.B. Soriano, and A.G. Agusti, Mortality in COPD: Role of comorbidities. Eur Respir J. 2006;28(6):1245-57.

11. Nici, L., C. Donner, E. Wouters, R. Zuwallack, N. Ambrosino, J. Bourbeau, M. Carone, B. Celli, M. Engelen, B. Fahy, C. Garvey, R. Goldstein, R. Gosselink, S. Lareau, N. Maclntyre, F. Maltais, M. Morgan, D. O'Donnell, C. Prefault, J. Reardon, C. Rochester, A. Schols, S. Singh, and T. Troosters, American Thoracic Society/European Respiratory Society statement on pulmonary rehabilitation. Am J Respir Crit Care Med. 2006;173(12):1390-413.

12. Spruit, M.A., I. Vanderhoven-Augustin, P.P. Janssen, and E.F. Wouters, Integration of pulmonary rehabilitation in COPD. Lancet. 2008;371(9606):12-3.

13. Dickstein, K., A. Cohen-Solal, G. Filippatos, J.J. McMurray, P. Ponikowski, P.A. Poole-Wilson, A. Stromberg, D.J. van Veldhuisen, D. Atar, A.W. Hoes, A. Keren, A. Mebazaa, M. Nieminen, S.G. Priori, and K. Swedberg, ESC guidelines for the diagnosis and treatment of acute and chronic heart failure 2008: the Task Force for the diagnosis and treatment of acute and chronic heart failure 2008 of the European Society of Cardiology. Developed in collaboration with the Heart Failure Association of the ESC (HFA) and endorsed by the European Society of Intensive Care Medicine (ESICM). Eur J Heart Fail. 2008;10(10):933-89.

14. Bleumink, G.S., A.M. Knetsch, M.C. Sturkenboom, S.M. Straus, A. Hofman, J.W. Deckers, J.C. Witteman, and B.H. Stricker, Quantifying the heart failure epidemic: prevalence, incidence rate, lifetime risk and prognosis of heart failure The Rotterdam Study. Eur Heart J. 2004;25(18):1614-9.

15. Stewart, S., K. MacIntyre, D.J. Hole, S. Capewell, and J.J. McMurray, More 'malignant' than cancer? Five-year survival following a first admission for heart failure. Eur J Heart Fail. 2001;3(3):315-22.

16. Levy, D., S. Kenchaiah, M.G. Larson, E.J. Benjamin, M.J. Kupka, K.K. Ho, J.M. Murabito, and R.S. Vasan, Long-term trends in the incidence of and survival with heart failure. $\mathrm{N} \mathrm{Engl} \mathrm{J} \mathrm{Med.}$ 2002;347(18):1397-402. 
17. K/DOQI clinical practice guidelines for chronic kidney disease: evaluation, classification, and stratification. Am J Kidney Dis. 2002;39(2 Suppl 1):S1-266.

18. Levey, A.S., J. Coresh, E. Balk, A.T. Kausz, A. Levin, M.W. Steffes, R.J. Hogg, R.D. Perrone, J. Lau, and G. Eknoyan, National Kidney Foundation practice guidelines for chronic kidney disease: evaluation, classification, and stratification. Ann Intern Med. 2003;139(2):137-47.

19. ERA-EDTA. European Best Practice Guidelines. Section I. Measurement of renal function, when to refer and when to start dialysis. Nephrol Dial Transplant. 2002;17 Suppl 7:7-15.

20. Murtagh, F.E., J.E. Marsh, P. Donohoe, N.J. Ekbal, N.S. Sheerin, and F.E. Harris, Dialysis or not? A comparative survival study of patients over 75 years with chronic kidney disease stage 5 . Nephrol Dial Transplant. 2007;22(7):1955-62.

21. Kramer, A., V. Stel, C. Zoccali, J. Heaf, D. Ansell, C. Gronhagen-Riska, T. Leivestad, K. Simpson, R. Palsson, M. Postorino, and K. Jager, An update on renal replacement therapy in Europe: ERA-EDTA Registry data from 1997 to 2006. Nephrol Dial Transplant. 2009;24(12):3557-66.

22. The Renal Association. UK Renal Registry The Twelfth Annual Report. http://www.renalreg.com/ Reports/2009.html. Accessed 24/01/2011.

23. Murtagh, F., L.M. Cohen, and M.J. Germain, Dialysis discontinuation: quo vadis? Adv Chronic Kidney Dis. 2007;14(4):379-401.

24. World Health Organisation. WHO definition of palliative care. http://www.who.int/cancer/palliative/ definition/en Accessed 12/01/2011.

25. Curtis, J.R., Palliative and End-of-life Care for Patients with Severe COPD. Eur Respir J. 2008; 32(3): 796-803.

26. Weisbord, S.D., S.S. Carmody, F.J. Bruns, A.J. Rotondi, L.M. Cohen, M.L. Zeidel, and R.M. Arnold, Symptom burden, quality of life, advance care planning and the potential value of palliative care in severely ill haemodialysis patients. Nephrol Dial Transplant. 2003;18(7):1345-52.

27. Gore, J.M., C.J. Brophy, and M.A. Greenstone, How well do we care for patients with end stage chronic obstructive pulmonary disease (COPD)? A comparison of palliative care and quality of life in COPD and lung cancer. Thorax. 2000;55(12):1000-6.

28. Hauptman, P.J. and E.P. Havranek, Integrating palliative care into heart failure care. Arch Intern Med. 2005;165(4):374-8.

29. Edmonds, P., S. Karlsen, S. Khan, and J. Addington-Hall, A comparison of the palliative care needs of patients dying from chronic respiratory diseases and lung cancer. Palliat Med. 2001;15(4):287-95.

30. Saini, T., F.E. Murtagh, P.J. Dupont, P.M. McKinnon, P. Hatfield, and Y. Saunders, Comparative pilot study of symptoms and quality of life in cancer patients and patients with end stage renal disease. Palliat Med. 2006;20(6):631-6.

31. O'Leary, N., N.F. Murphy, C. O'Loughlin, E. Tiernan, and K. McDonald, A comparative study of the palliative care needs of heart failure and cancer patients. Eur J Heart Fail. 2009;11(4):406-12.

32. Grande, G.E., M.C. Farquhar, S.I. Barclay, and C.J. Todd, The influence of patient and carer age in access to palliative care services. Age Ageing. 2006;35(3):267-73.

33. Fox, E., K. Landrum-McNiff, Z. Zhong, N.V. Dawson, A.W. Wu, and J. Lynn, Evaluation of prognostic criteria for determining hospice eligibility in patients with advanced lung, heart, or liver disease. SUPPORT Investigators. Study to Understand Prognoses and Preferences for Outcomes and Risks of Treatments. Jama. 1999;282(17):1638-45.

34. Murtagh, F.E., E. Murphy, and N.S. Sheerin, Illness trajectories: an important concept in the management of kidney failure. Nephrol Dial Transplant. 2008;23(12):3746-8.

35. Murtagh, F.E., J.M. Addington-Hall, and I.J. Higginson, End-Stage Renal Disease: A New Trajectory of Functional Decline in the Last Year of Life. J Am Geriatr Soc. 2011;59(2):304-8

36. Murtagh, F.E., M. Preston, and I. Higginson, Patterns of dying: palliative care for non-malignant disease. Clin Med. 2004;4(1):39-44.

37. Coventry, P.A., G.E. Grande, D.A. Richards, and C.J. Todd, Prediction of appropriate timing of palliative care for older adults with non-malignant life-threatening disease: a systematic review. Age Ageing. 2005;34(3):218-27. 
38. Lorenz, K.A., J. Lynn, S.M. Dy, L.R. Shugarman, A. Wilkinson, R.A. Mularski, S.C. Morton, R.G. Hughes, L.K. Hilton, M. Maglione, S.L. Rhodes, C. Rolon, V.C. Sun, and P.G. Shekelle, Evidence for improving palliative care at the end of life: a systematic review. Ann Intern Med. 2008;148(2):147-59.

39. Lanken, P.N., P.B. Terry, H.M. Delisser, B.F. Fahy, J. Hansen-Flaschen, J.E. Heffner, M. Levy, R.A. Mularski, M.L. Osborne, T.J. Prendergast, G. Rocker, W.J. Sibbald, B. Wilfond, and J.R. Yankaskas, An official American Thoracic Society clinical policy statement: palliative care for patients with respiratory diseases and critical illnesses. Am J Respir Crit Care Med. 2008;177(8):912-27.

40. Jaarsma, T., J.M. Beattie, M. Ryder, F.H. Rutten, T. McDonagh, P. Mohacsi, S.A. Murray, T. Grodzicki, I. Bergh, M. Metra, I. Ekman, C. Angermann, M. Leventhal, A. Pitsis, S.D. Anker, A. Gavazzi, P. Ponikowski, K. Dickstein, E. Delacretaz, L. Blue, F. Strasser, and J. McMurray, Palliative care in heart failure: a position statement from the palliative care workshop of the Heart Failure Association of the European Society of Cardiology. Eur J Heart Fail. 2009;11(5):433-443.

41. Galla, J.H., Clinical practice guideline on shared decision-making in the appropriate initiation of and withdrawal from dialysis. The Renal Physicians Association and the American Society of Nephrology. J Am Soc Nephrol. 2000;11(7):1340-2.

42. Shared decision-making in the appropriate initiation of and withdrawal from dialysis. Clinical Practice Guideline. Second edition. The Renal Physicians Association and the American Society of Nephrology. 2010.

43. Solano, J.P., B. Gomes, and I.J. Higginson, A comparison of symptom prevalence in far advanced cancer, AIDS, heart disease, chronic obstructive pulmonary disease and renal disease. J Pain Symptom Manage. 2006;31(1):58-69.

44. Elkington, H., P. White, J. Addington-Hall, R. Higgs, and C. Pettinari, The last year of life of COPD: a qualitative study of symptoms and services. Respir Med. 2004;98(5):439-45.

45. Elkington, H., P. White, J. Addington-Hall, R. Higgs, and P. Edmonds, The healthcare needs of chronic obstructive pulmonary disease patients in the last year of life. Palliat Med. 2005;19(6):485-91.

46. Nordgren, L. and S. Sorensen, Symptoms experienced in the last six months of life in patients with end-stage heart failure. Eur J Cardiovasc Nurs. 2003;2(3):213-7.

47. McCarthy, M., M. Lay, and J. Addington-Hall, Dying from heart disease. J R Coll Physicians Lond. 1996;30(4):325-8.

48. Formiga, F., D. Chivite, C. Ortega, S. Casas, J.M. Ramon, and R. Pujol, End-of-life preferences in elderly patients admitted for heart failure. QJM. 2004;97(12):803-8.

49. Fitzsimons, D., D. Mullan, J.S. Wilson, B. Conway, B. Corcoran, M. Dempster, J. Gamble, C. Stewart, S. Rafferty, M. McMahon, J. MacMahon, P. Mulholland, P. Stockdale, E. Chew, L. Hanna, J. Brown, G. Ferguson, and D. Fogarty, The challenge of patients' unmet palliative care needs in the final stages of chronic illness. Palliat Med. 2007;21(4):313-22.

50. Incalzi, R.A., A. Corsonello, C. Pedone, F. Corica, P. Carbonin, and R. Bernabei, Construct validity of activities of daily living scale: a clue to distinguish the disabling effects of COPD and congestive heart failure. Chest. 2005;127(3):830-8.

51. Hwang, B., M.L. Luttik, K. Dracup, and T. Jaarsma, Family caregiving for patients with heart failure: types of care provided and gender differences. J Card Fail. 16(5):398-403.

52. Emanuel, E.J., D.L. Fairclough, J. Slutsman, H. Alpert, D. Baldwin, and L.L. Emanuel, Assistance from family members, friends, paid care givers, and volunteers in the care of terminally ill patients. $\mathrm{N}$ Engl J Med. 1999;341(13):956-63.

53. Hasson, F., A. Spence, M. Waldron, G. Kernohan, D. McLaughlin, B. Watson, and B. Cochrane, Experiences and needs of bereaved carers during palliative and end-of-life care for people with chronic obstructive pulmonary disease. J Palliat Care. 2009;25(3):157-63.

54. Boyd, K.J., S.A. Murray, M. Kendall, A. Worth, T. Frederick Benton, and H. Clausen, Living with advanced heart failure: a prospective, community based study of patients and their carers. Eur J Heart Fail. 2004;6(5):585-91.

55. Luttik, M.L., A. Blaauwbroek, A. Dijker, and T. Jaarsma, Living with heart failure: partner perspectives. J Cardiovasc Nurs. 2007;22(2):131-7. 
56. Barnes, S., M. Gott, S. Payne, C. Parker, D. Seamark, S. Gariballa, and N. Small, Characteristics and views of family carers of older people with heart failure. Int J Palliat Nurs. 2006;12(8):380-9.

57. Pinto, R.A., M.A. Holanda, M.M. Medeiros, R.M. Mota, and E.D. Pereira, Assessment of the burden of caregiving for patients with chronic obstructive pulmonary disease. Respir Med. 2007;101(11):24028.

58. Dracup, K., L.S. Evangelista, L. Doering, D. Tullman, D.K. Moser, and M. Hamilton, Emotional wellbeing in spouses of patients with advanced heart failure. Heart Lung. 2004;33(6):354-61.

59. Luttik, M.L., T. Jaarsma, I. Lesman, R. Sanderman, and M. Hagedoorn, Quality of life in partners of people with congestive heart failure: gender and involvement in care. J Adv Nurs. 2009;65(7):144251.

60. Pressler, S.J., I. Gradus-Pizlo, S.D. Chubinski, G. Smith, S. Wheeler, J. Wu, and R. Sloan, Family caregiver outcomes in heart failure. Am J Crit Care. 2009;18(2):149-59.

61. Belasco, A., D. Barbosa, A.R. Bettencourt, S. Diccini, and R. Sesso, Quality of life of family caregivers of elderly patients on hemodialysis and peritoneal dialysis. Am J Kidney Dis. 2006;48(6):955-63.

62. Yamamoto-Mitani, N., K. Ishigaki, M. Kuniyoshi, N. Kawahara-Maekawa, K. Hayashi, K. Hasegawa, and C. Sugishita, Subjective quality of life and positive appraisal of care among Japanese family caregivers of older adults. Qual Life Res. 2004;13(1):207-21.

63. Kim, Y., F. Baker, and R.L. Spillers, Cancer caregivers' quality of life: effects of gender, relationship, and appraisal. J Pain Symptom Manage. 2007;34(3):294-304.

64. Silveira, M.J., S.Y. Kim, and K.M. Langa, Advance directives and outcomes of surrogate decision making before death. N Engl J Med. 2010;362(13):1211-8.

65. Wenger, N.S., R.K. Oye, P.E. Bellamy, J. Lynn, R.S. Phillips, N.A. Desbiens, P. Kussin, and S.J. Youngner, Prior capacity of patients lacking decision making ability early in hospitalization: implications for advance directive administration. The SUPPORT Investigators. Study to Understand Prognoses and Preferences for Outcomes and Risks of Treatments. J Gen Intern Med. 1994;9(10):539-43.

66. Guidelines for the appropriate use of do-not-resuscitate orders. Council on Ethical and Judicial Affairs, American Medical Association. JAMA. 1991;265(14):1868-71.

67. Emanuel, L.L., M.J. Barry, J.D. Stoeckle, L.M. Ettelson, and E.J. Emanuel, Advance directives for medical care--a case for greater use. N Engl J Med. 1991;324(13):889-95.

68. Tonelli, M.R., Pulling the plug on living wills. A critical analysis of advance directives. Chest. 1996;110(3):816-22.

69. Fried, T.R. and J.R. O'Leary, Using the experiences of bereaved caregivers to inform patient- and caregiver-centered advance care planning. J Gen Intern Med. 2008;23(10):1602-7.

70. Teno, J.M., A. Gruneir, Z. Schwartz, A. Nanda, and T. Wetle, Association between advance directives and quality of end-of-life care: a national study. J Am Geriatr Soc. 2007;55(2):189-94.

71. Wright, A.A., B. Zhang, A. Ray, J.W. Mack, E. Trice, T. Balboni, S.L. Mitchell, V.A. Jackson, S.D. Block, P.K. Maciejewski, and H.G. Prigerson, Associations between end-of-life discussions, patient mental health, medical care near death, and caregiver bereavement adjustment. JAMA. 2008;300(14):166573.

72. Curtis, J.R., Palliative and end-of-life care for patients with severe COPD. Eur Respir J. 2008;32(3):796-803.

73. Davison, S.N. and C. Torgunrud, The creation of an advance care planning process for patients with ESRD. Am J Kidney Dis. 2007;49(1):27-36.

74. Claessens, M.T., J. Lynn, Z. Zhong, N.A. Desbiens, R.S. Phillips, A.W. Wu, F.E. Harrell, Jr., and A.F. Connors, Jr., Dying with lung cancer or chronic obstructive pulmonary disease: insights from SUPPORT. Study to Understand Prognoses and Preferences for Outcomes and Risks of Treatments. J Am Geriatr Soc. 2000;48(5 Suppl):S146-53.

75. Tanvetyanon, T. and J.C. Leighton, Life-sustaining treatments in patients who died of chronic congestive heart failure compared with metastatic cancer. Crit Care Med. 2003;31(1):60-4.

76. Gott, M., C. Gardiner, N. Small, S. Payne, D. Seamark, S. Barnes, D. Halpin, and C. Ruse, Barriers to advance care planning in chronic obstructive pulmonary disease. Palliat Med. 2009;23(7):642-8. 
77. Gardiner, C., M. Gott, N. Small, S. Payne, D. Seamark, S. Barnes, D. Halpin, and C. Ruse, Living with advanced chronic obstructive pulmonary disease: patients concerns regarding death and dying. Palliat Med. 2009;23(8):691-7.

78. Harding, R., L. Selman, T. Beynon, F. Hodson, E. Coady, C. Read, M. Walton, L. Gibbs, and I.J. Higginson, Meeting the communication and information needs of chronic heart failure patients. J Pain Symptom Manage. 2008;36(2):149-56.

79. Heffner, J.E., B. Fahy, L. Hilling, and C. Barbieri, Attitudes regarding advance directives among patients in pulmonary rehabilitation. Am J Respir Crit Care Med. 1996;154(6 Pt 1):1735-40.

80. Knauft, E., E.L. Nielsen, R.A. Engelberg, D.L. Patrick, and J.R. Curtis, Barriers and facilitators to end-oflife care communication for patients with COPD. Chest. 2005;127(6):2188-96.

81. Curtis, J.R., R.A. Engelberg, E.L. Nielsen, D.H. Au, and D.L. Patrick, Patient-physician communication about end-of-life care for patients with severe COPD. Eur Respir J. 2004;24(2):200-5.

82. Fried, T.R., E.H. Bradley, and J. O'Leary, Changes in prognostic awareness among seriously ill older persons and their caregivers. J Palliat Med. 2006;9(1):61-9. 



\section{CHAPTER 2}

\section{A patient's journey:}

\section{The last wish of a patient with end stage chronic obstructive pulmonary disease}

Daisy J.A. Janssen, Ton P.G. Alsemgeest, Guy A.M. Widdershoven, Emiel F.M. Wouters, Jos M.G.A. Schols and Martijn A. Spruit BMJ, 2008. 337:a2701. 
30 | CHAPTER 2 


\section{At her explicit request, euthanasia allowed a $\mathbf{5 5}$ year old woman in the Nether- lands with end stage chronic obstructive pulmonary disease to end her life.}

Our patient was 55 years old when she was admitted to the nursing home with endstage chronic obstructive pulmonary disease (COPD) in November 2007. She had had the disease since 1997 and had participated in a pulmonary rehabilitation programme seven times (in 1998, 2000, 2001, 2002, 2005 (2x) and 2006). In 2000 she underwent lung volume reduction surgery. That same year, she also had a stroke which resulted in paralysis of her left arm and pain in the left side of her body. She was prescribed long term oxygen therapy in 2006.

In February 2007, she was admitted to the nursing home for an intensive patienttailored interdisciplinary management programme which improved her health status and daily functioning. She was sent home in April of that year. After discharge, however, she was admitted to the hospital several times because of acute exacerbations. She was prescribed non-invasive positive pressure ventilation because of progressive respiratory failure.

At her second admission to the nursing home in November 2007, she was hopeful that intensive treatment and physical training would again enable her to improve her daily functioning and allow her to live in her own home. However, within two months, she deteriorated progressively, despite an intensive patient tailored interdisciplinary management programme aimed at improving health status and daily functioning. Discharge was not possible.

Because of the progressive decline in her health status and increasing daily burden of symptoms, a palliative approach was increasingly offered alongside curative treatment. It consisted of managing daily symptoms and care needs, and discussing prognosis and advance directives. She already had decided to refuse resuscitation or admission to an intensive care unit. Now, she also refused admission to hospital in case of acute illness.

Two months after her second admission to the nursing home, she first expressed her wish for euthanasia to her treating physician at the nursing home, in the presence of her closest family. She wrote in her living will:

"Since 1997, I am a COPD patient. In 2000, I had a stroke. Since 1997, I have been constantly going in and out of hospital. Every three weeks I have an infection and every time I have to fight to recover. Every time I get worse. I can't fight any more. I am so tired. My shortness of breath becomes worse every time. If I have to go to the bathroom, I have to wait for half an hour before I am able to leave. I am afraid of 
going to the bathroom. Also the pain becomes worse. I have always said that my disease should not become unbearable. Now the moment has come that my life is nothing but suffering, I want this to end. My greatest wish is not to suffer any more."

Because of her increased pain and dyspnoea, the management of symptoms was intensified in the days after her request. Psychosocial and spiritual end of life needs were also dealt with. Thirteen days after she expressed her wish to die, euthanasia was performed in the presence of her closest family, after consultation with a psychiatrist and an independent doctor.

\section{A sister's perspective}

Since 1997 my sister has had lung disease. Gradually, her situation became worse. However, she never complained. She was always grateful for everything we, as a family, did for her. Living in her own home became more difficult during the last years. She was anxious at home and called me almost every day. In the nursing home she felt safe.

On the day she told me that she wanted to ask her doctor for euthanasia I was angry with her. I told her that I didn't want her to do that. I did not understand her wish. I told her that I wanted to do everything for her, that I didn't mind the travelling to the nursing home. I loved her and wanted to take care of her. However, she kept saying she did not want to live like this any more.

In the days after we talked about this, I gradually started to understand her wish. She was suffering every day. Every day she had to fight against her breathlessness and her pain. She did not want to ask other people to help her with everything she had to do. Although it was difficult, I accepted her wish.

The night before the euthanasia was very difficult. I was constantly watching the clock and counting the hours - the hours she had left. On the morning that euthanasia was carried out we went for her last cigarette together. It hurt me to see how much effort it took to smoke just a little bit of this cigarette.

I was sitting next to her when she died. She died very quickly and quietly. I am grateful that her last wish was honoured, that she does not have to suffer any more, and that she died the way she wanted. However, I miss my sister so much, I miss her calling me and I miss taking care of her, every day. 


\section{A medical perspective}

In the Netherlands, euthanasia is defined as termination of life by a medical practitioner at the explicit request of the patient. Euthanasia may allow a patient to end his or her life in dignity after having received every available type of curative and palliative care.

However, euthanasia is legal only in a patient who is suffering unbearably, with no prospect of improvement, and if the following statutory criteria of due care are fulfilled.

\section{Explicit request of the patient}

The attending doctor must be satisfied that the patient has made a voluntary and carefully considered request. Our patient had discussed euthanasia years ago with her treating chest physician and her general practitioner. Since then, she repeatedly said she wished to die if her life was unbearable with no chance of improvement. Two weeks before her death, she asked explicitly for euthanasia. Her request was not made under pressure from or influence by other people, such as her family or friends. She expressed her wish in the presence of her partner, mother, sisters and daughters, who respected her wish. She completed a living will in which she declared that she wished to die of euthanasia because her suffering was no longer bearable. A week after her explicit request she saw a psychiatrist to exclude the possibility that her wish to die was a symptom of a depressive disorder. The psychiatrist declared that she had no symptoms of a psychiatric disease that could have influenced her wish for euthanasia. Moreover, the psychiatrist declared that her request was voluntary and well considered.

In the 13 days between her request and her death she discussed her wish to die, the possibilities for end-of-life care and the things that were important in her life with her doctor almost every day.

\section{Suffering and no prospect of improvement}

The attending doctor must be satisfied that the patient's suffering is unbearable, and that no prospect of improvement exists. Our patient clearly had no chance of improving, and her suffering was unbearable. The main reason for this was her progressive decline in daily functioning and increasing dependency on care givers and loved ones. She needed help with almost all tasks of daily living. She had dyspnoea at minimal exercise and sometimes even at rest. Since she had a stroke in 2000 , she had neuropathic pain in the left side of her body, which was hard to treat effectively. For several months she also had thoracic pain. 


\section{An informed patient}

The attending doctor must have informed the patient about his or her situation and prospects. In the nursing home our patient talked with her doctor about her disease and its expected trajectory, which would probably be characterized by a further decline and punctuated by acute deteriorations in health status and daily functioning. She fully understood the nature of her condition, her prospects and the possibilities for treatment.

\section{No reasonable alternative}

The attending doctor must have concluded, along with the patient, that no reasonable alternative exists in the light of the patient's situation. The main reason for our patient's wish for euthanasia was her progressive decline in daily functioning and increasing dependency on care givers and loved ones. There was no possibility that her daily functioning would improve.

Her lung function had deteriorated over the past few years. A year before she expressed her wish for euthanasia, her forced expiratory volume in the first second was only $26 \%$ of predicted values. Her COPD was optimally treated according to the current international guidelines - she received long term oxygen therapy and noninvasive positive pressure ventilation. She had participated in seven comprehensive inpatient pulmonary rehabilitation programmes. In 2000 , she had lung volume reduction surgery. She had recently deteriorated, despite an intensive patient tailored interdisciplinary management programme. Lung transplantation was not possible because she smoked.

She also mentioned that dyspnoea and pain contributed to her suffering. In the days after her request for euthanasia, her dosage of opioids was increased until the pain and dyspnoea were optimally treated. However, her wish for euthanasia became stronger every day. The optimal management of pain and dyspnea did not improve her physical functioning and did not reduce her dependency. In the days before her death, her physical functioning declined quickly so that leaving her bed became harder every day.

\section{Independent opinion}

The attending doctor must have consulted at least one other independent doctor, who must have seen the patient and given a written opinion on the due care criteria, as mentioned above. Twelve days after our patient's request for euthanasia, she was visited by an independent doctor - a general practitioner trained in performing 
consultation for euthanasia. He assessed the four due care criteria explained above and reported that these criteria were met.

\section{Medical care at termination}

The attending physician must terminate the patient's life with due medical care and attention. After the independent doctor's visit, the euthanasia was planned for the next day. Once the plans were made our patient seemed to be quiet and peaceful. She said she had finished everything she wanted to do and that she had completely accepted her situation. On the day of her death, her family was with her to say goodbye. In the presence of her mother, sisters, daughters and partner, she died quickly and quietly after intravenous infusion of a barbiturate to induce a coma followed by a neuromuscular relaxant, as per protocol.

\section{Outcome}

After the patient died the attending doctor completed a report and notified the municipal pathologist of this instance of death from non-natural causes. The pathologist viewed the patient. He informed the public prosecutor, who gave consent for burial. The pathologist then sent his own report, the attending doctor's report, the independent doctor's report, and the patient's living will to the regional review committee. This committee - a legal expert, a medical doctor, and an expert on ethics - used these documents to assess whether euthanasia had been carried out in accordance with the due care criteria.

Three weeks after the euthanasia was carried out, the review committee informed the attending doctor that she had met the statutory due care criteria for euthanasia and would not be prosecuted. A few weeks later the doctor discussed the patient's life course, her disease, and her death with her family and loved ones, who were grateful that her last wish had been honoured.

\section{What can we learn from this case?}

Euthanasia is defined as termination of life by a medical practitioner at the explicit request of the patient. In 2002, in the Netherlands the Euthanasia Act legalized euthanasia in a patient who is suffering unbearably with no prospect of improvement, if all the due care criteria are fulfilled. Euthanasia is used most often in patients with malignant disease. However, euthanasia may allow a patient with end stage COPD to end his or her life in dignity after having received every type of curative and palliative care available. 



\section{CHAPTER 3}

Daily symptom burden in end stage chronic organ failure:

A systematic review

Daisy J.A. Janssen, Martijn A. Spruit, Emiel F.M. Wouters and Jos M.G.A. Schols Palliat Med, 2008. 22(8): 938-48. 


\begin{abstract}
Chronic diseases are nowadays the major cause of morbidity and mortality worldwide. Patients with end-stage chronic organ failure may suffer daily from distressful physical and psychological symptoms. The objective of the present study is to systematically review studies that examined daily symptom prevalence in patients with end-stage chronic organ failure, with attention to those that included patients with either congestive heart failure (CHF), chronic obstructive pulmonary disease (COPD) or chronic renal failure (CRF). Thirty-nine articles (8 CHF, 7 COPD, 2 CHF and COPD, $22 \mathrm{CRF}$ ) have been included. The included studies used various study designs. There was a wide range of daily symptom prevalence that may be due to the heterogeneity in methodology used. Nevertheless, findings suggest significant symptom burden in these patients. This review highlights the need for further prospective and longitudinal research on symptom prevalence in patients with end-stage CHF, COPD and CRF to facilitate the development of patient-centered palliative care programs.
\end{abstract}




\section{Introduction}

Chronic diseases are presently a major cause of morbidity and mortality worldwide. ${ }^{1}$ The prevalence of congestive heart failure $(\mathrm{CHF})^{2}$, chronic obstructive pulmonary disease $(C O P D)^{3}$ and chronic renal failure $(C R F)^{4}$ is expected to rise over the next years. The prognosis of survival for patients with chronic organ failure is even poorer than that for many common malignant diseases. ${ }^{5,6}$ To date, several authors have suggested that palliative care may have an important role in chronic nonmalignant diseases. ${ }^{5-8}$ Indeed, previous research has shown that both patients with end-stage malignant and non-malignant diseases may suffer from many distressful physical and psychological symptoms such as fatigue, pain, dyspnoea, cough, lack of appetite, sadness and sleep disorders. ${ }^{9}$ Moreover, previous studies have shown that quality of life in patients with CHF, COPD or CRF is equally or even more greatly affected by their disease than those with cancer. ${ }^{6,10,11}$ However, until now palliative care has been reserved mostly for patients with malignant disease as evidenced by the limited access to palliative care for patients with non-malignant disease. ${ }^{12}$ Even with the increasing recognition of the need for palliative care for these patients, current clinical guidelines on the management of chronic disease offer little guidance on end-of-life care issues ${ }^{13,14}$ and care for patients with end-stage disease is presently prioritized by diagnosis rather than need. ${ }^{15}$ The disparity in care, despite evidence to the contrary, likely reflects the uncertainty in the prognosis in terms of survival in patients with chronic organ failure. ${ }^{7,16}$ The course of end-stage chronic organ failure is marked typically by a gradual decrease and punctuated by acute deteriorations in health status and daily functioning, especially in COPD and CHF. ${ }^{17}$ These deteriorations can be life threatening and increase the risk of hospital admission and intensive treatment. ${ }^{18}$ Thus, although there is a gradual decrease in health status and daily functioning in patients with $\mathrm{CHF}, \mathrm{COPD}$ or $\mathrm{CRF}^{17}{ }^{17}$ timing of death remains uncertain and choosing the right moment for starting palliative care is a continuous challenge for the treating physician. ${ }^{19}$ Essential to any patient-centered palliative care program is an understanding of the self-perceived daily symptoms of patients with end-stage CHF, COPD or CRF. ${ }^{20}$

In the present systematic review, we have critically appraised the currently available peer-reviewed literature that addresses daily symptom burden of patients with CHF, COPD or CRF at the end of their life. 


\section{Methods}

\section{Data sources and searches}

A computerised literature search was performed to identify relevant articles. Several databases were used: MEDLINE/PubMed (timespan: 1966 to April 2007) and Web of Science (timespan: 1988 to April 2007) with the following three groups of keywords:

1. COPD, pulmonary disease chronic obstructive, end-stage lung failure, endstage lung disease, heart failure congestive, end-stage heart disease, kidney failure chronic, dialysis, end-stage renal disease;

2. palliative care, hospice care, terminal care, terminally ill, end-of-life;

3. symptoms, pain, dyspnoea, breathlessness, cough, fatigue, anorexia, weight loss, depression, anxiety, delirium, confusion, insomnia, edema, dizziness, nausea, mouth problems, pruritus, constipation.

The three groups were combined using "and". Within each group the keywords were combined using "or". In addition, reference lists of original articles were searched by hand to identify articles that may contain information on the topic of interest and may have been missed by the search strategy. Finally, corresponding authors of articles were contacted at least twice in an effort to include all available studies.

\section{Study selection}

Articles were included that reported original data on daily symptoms in adult patients with COPD, CHF or CRF at the end of their life and if the presence of one or more of the aforementioned symptoms in patients with COPD, CHF or CRF at the end of their life was reported in the abstract. Articles not written in English were excluded. The authors included observational studies with various study designs, such as cross-sectional, longitudinal, retrospectively and/or prospectively. Abstracts, reviews, editorials, qualitative studies and case reports were considered ineligible.

\section{Data extraction and quality assessment}

Two reviewers (D.J.A.J. and M.A.S.) assessed the methodological quality of the included studies. A predesigned data extraction form was used to obtain data on study design and relevant results. For each study, authors, journal, year of publication, country of origin and studied disease(s) were recorded. For quality assessment, studies were evaluated on the following items: design of the study (prospective or 
retrospective, cross-sectional or longitudinal, patient reporting, proxy reporting or chart review), number of patients, response rate and patient characteristics (severity of the disease, prognosis, age, gender, setting). For each of the symptoms, the definition of the symptom, method of measurement (if reported) and the reported prevalence was noted. Finally, the limitations of each study were considered.

\section{Data synthesis and analysis}

The use of meta-analytic techniques for data-analysis was not possible, because of variability of design, patient characteristics, and definition and measurement of symptoms that were used. Therefore, for each symptom, minimum, maximum and median prevalence numbers are reported for each chronic disease. Prevalence numbers are reported for patients who were not identified as terminally ill and patients who were, often retrospectively, identified as terminally ill, for example the last two weeks of life, the last week of life, the last 3 days of life or the last $24 \mathrm{~h}$ of life. For CRF, discontinuation or declining of dialysis was also terminal illness defining event.

\section{Results}

In total, 595 articles were identified in the electronic searches, 515 were written in English. Of these articles, 79 were considered eligible after reading the abstract. Five case studies, letters and editorials, seven qualitative studies and 27 reviews were excluded. In addition, 14 articles were selected from reference lists of the remaining 40 articles. In total, 54 articles were reviewed in detail. Six articles were excluded because prevalence numbers were only reported for a combined group of diseases (e.g., CHF, COPD and liver disease) and three studies because symptom prevalence numbers were not mentioned. Six studies were excluded for other reasons. In total, 39 articles were considered eligible. Eight studies included patients with end-stage $\mathrm{CHF}$, seven included patients with end-stage COPD, two included both patients with end-stage CHF and patients with end-stage COPD and 22 studies included patients with end-stage CRF (Figure 3.1).

A cross-sectional design was used in 32 studies and a longitudinal design in 7 studies. Thirteen studies were retrospective, mostly bereavement studies, and 23 were prospective. Retrospective and prospective information was combined in three studies. Patient reporting was used in 19 studies, proxy reporting in 10 studies, chart review in four studies and six studies combined patient and proxy reporting or chart review (Table 3.1). 
Figure 3.1

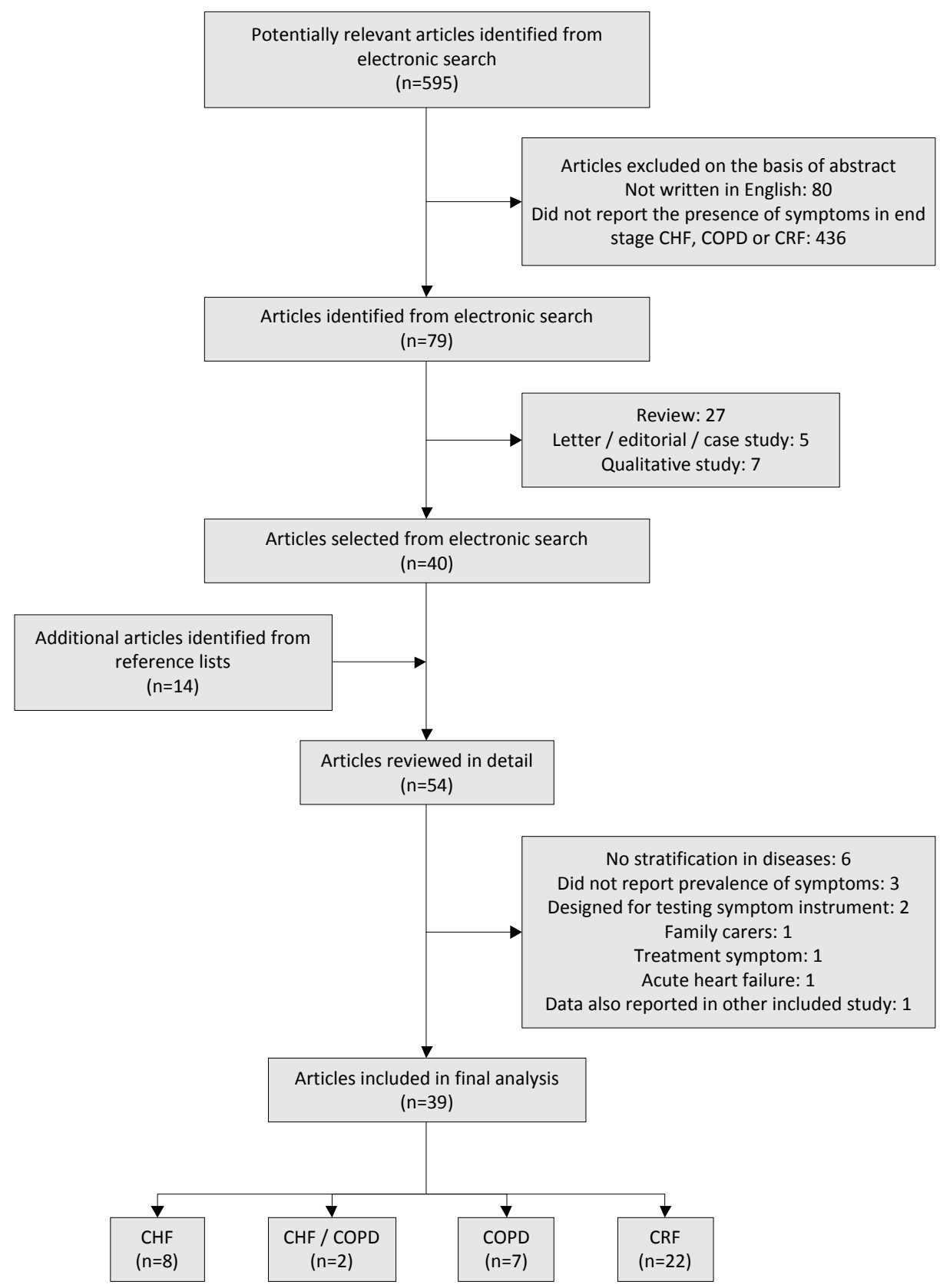

Abbreviations: $\mathrm{CHF}=$ Congestive Heart Failure; $\mathrm{COPD}=$ Chronic Obstructive Pulmonary Disease; $\mathrm{CRF}=$ Chronic Renal Failure. 


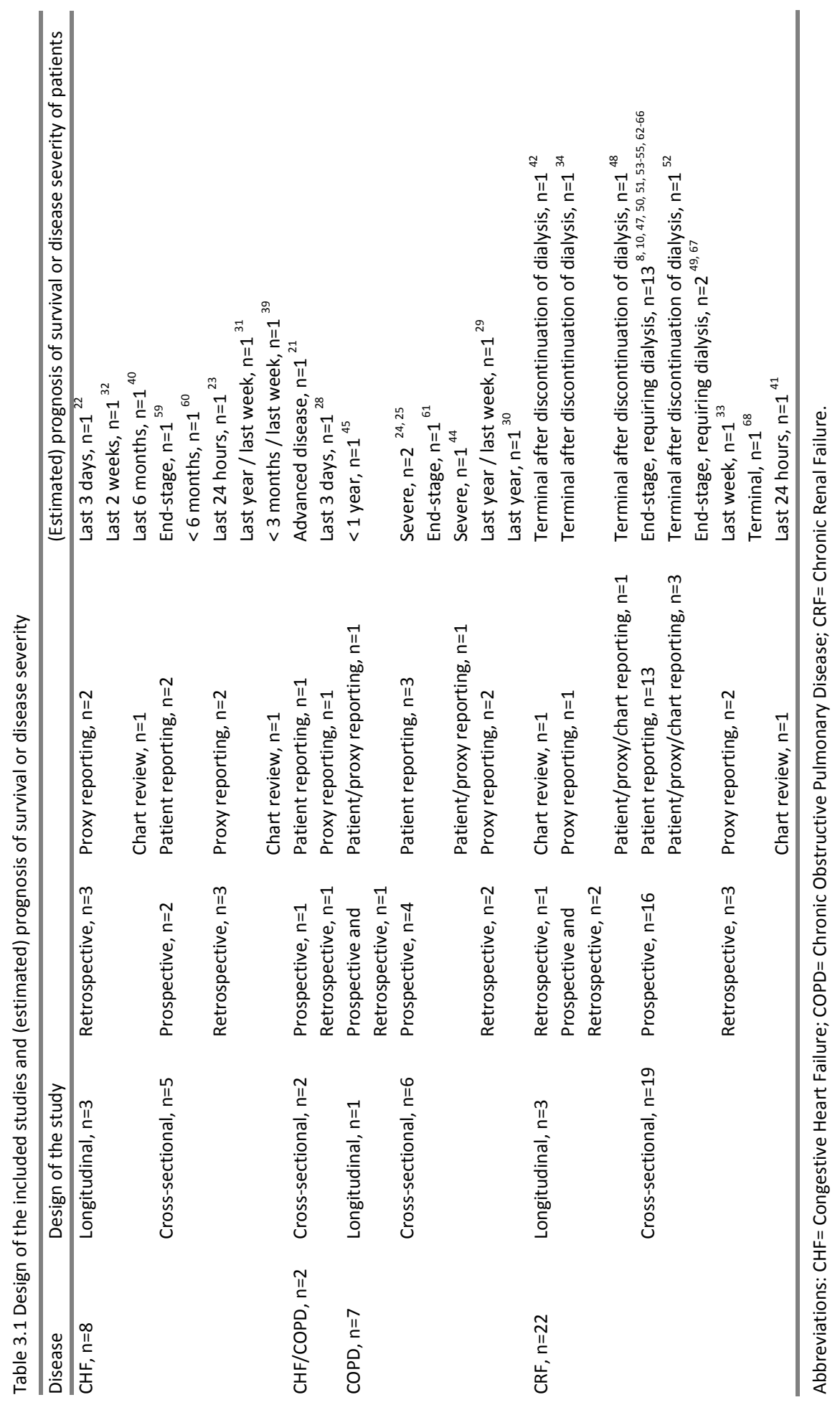


Severity of the disease and prognosis of survival varied and was sometimes unknown. Therefore, the estimated prognosis for survival and, if this was unknown, the description of disease severity have been reported in table 3.1. CHF patients with New York Heart Association (NYHA) class III or IV were included. ${ }^{21-23}$ In the studies that included patients with COPD, forced expiratory volume in the first second $\left(\mathrm{FEV}_{1}\right.$ ) was only reported in two studies (mean $\mathrm{FEV}_{1}: 34 \%$ of predicted ${ }^{24}$; median $\mathrm{FEV}_{1}: 26.3 \%$ of predicted ${ }^{25}$ ). All CRF studies included patients who needed dialysis or became terminal after discontinuation or declining of dialysis. When reported, estimated prognosis of survival ranged from 24 hours to 1 year.

Reported mean age ranged from 67 to 86 years (CHF); 65 to 75 years (CHF/COPD); 67 to 77 years (COPD) and 38 to 85 years (CRF). In the studies included in this systematic review, response rate of patients with CHF, COPD and CRF ranged from $40 \%$ to $100 \%$. Although response rate was often not reported and if reported varied in definition, it did not seem to relate to certain diseases or study designs.

For measurement of most of the symptoms, different study designs were used. This is shown for the frequently reported daily symptoms fatigue, dyspnoea, pain and insomnia (Figure 3.2).

Despite the fact that there is a wide range in the reported prevalence of symptoms, some patterns are apparent (Table 3.2). Patients with CHF, COPD and CRF are likely to experience a high daily symptom burden, with fatigue being the most common symptom. Dyspnoea, insomnia and pain are frequently reported in all three diseases (Figure 3.3).

\section{Discussion}

The present systematic review of observational studies of symptom prevalence in chronic organ failure shows that there is great heterogeneity in study designs used for studying symptoms in end-stage CHF, COPD and CRF. Daily symptom burden is likely to be high in end-stage chronic organ failure, irrespective of the underlying disease. However, to our knowledge, a comparison of symptom prevalence between patients with CHF, COPD and CRF at the end of life has not been made.

The most frequently reported symptoms in CHF, COPD and CRF were fatigue, dyspnoea, insomnia and pain. As many of the symptoms were not included in studies of patients who were terminally ill, a comparison of symptomonology of the terminally ill with those who were not was not possible. 
Figure 3.2 Study design and range of symptom prevalence

Fatigue

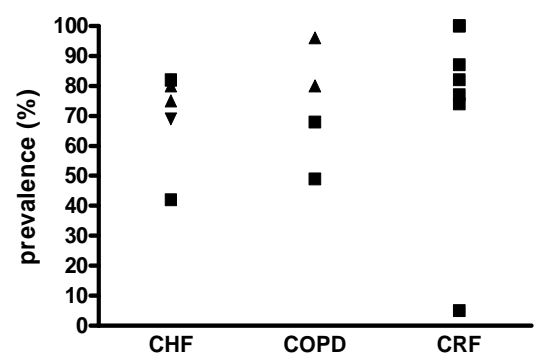

Pain

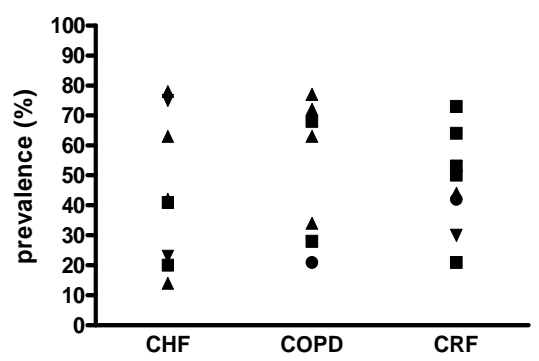

Dyspnea

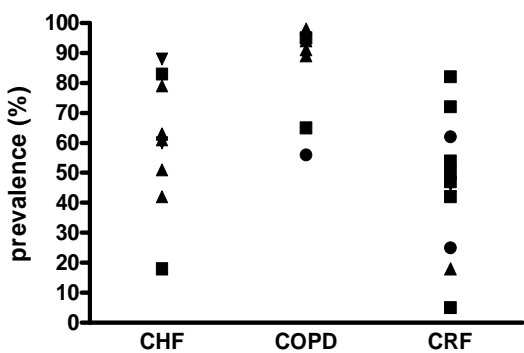

Insomnia

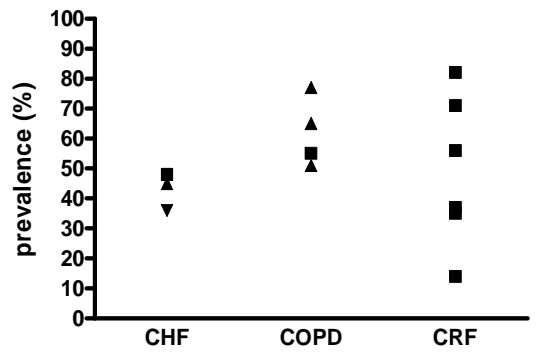

Study design and prevalence of the reported symptoms fatigue (left upper quadrant), dyspnoea (right upper quadrant), pain (left lower quadrant) and insomnia (right lower quadrant) in patients with endstage Congestive Heart Failure (CHF), Chronic Obstructive Pulmonary Disease (COPD), or Chronic Renal Failure (CRF). $\mathbf{-}$ = prospective patient reporting; $\boldsymbol{\Delta}=$ retrospective proxy reporting; $\boldsymbol{\nabla}=$ chart review; $\bullet=$ mixed patient or proxy reporting and retrospective or prospective.

Our findings are in line with the findings of Solano et al. systematic review of symptom prevalence in far advanced cancer, AIDS, CHF, COPD and CRF. ${ }^{26}$ They also found a great heterogeneity in prevalence of symptoms and a high rate of prevalence for almost all symptoms. Pain, breathlessness and fatigue were the most common reported symptoms in the diseases they reviewed. ${ }^{26} \mathrm{~A}$ recent systematic review of symptoms in end-stage CRF also found a wide variation in the prevalence of symptoms although the overall symptom burden seemed to be high, comparable with the findings in the present study. ${ }^{27}$ 







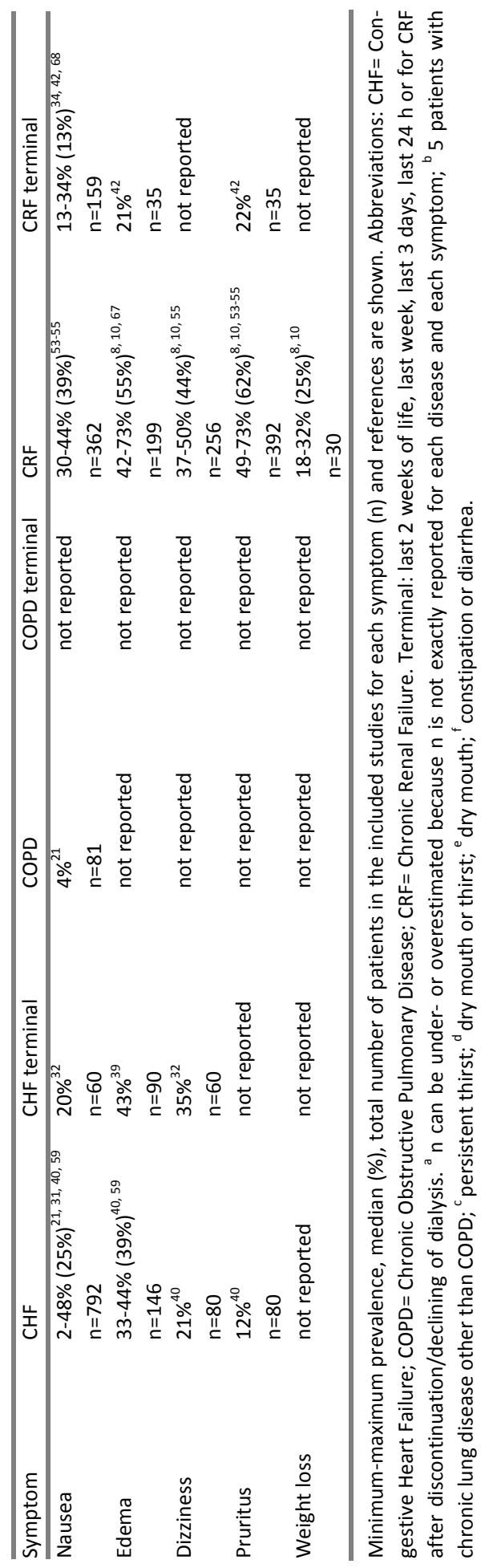


Figure 3.3 Symptom prevalence
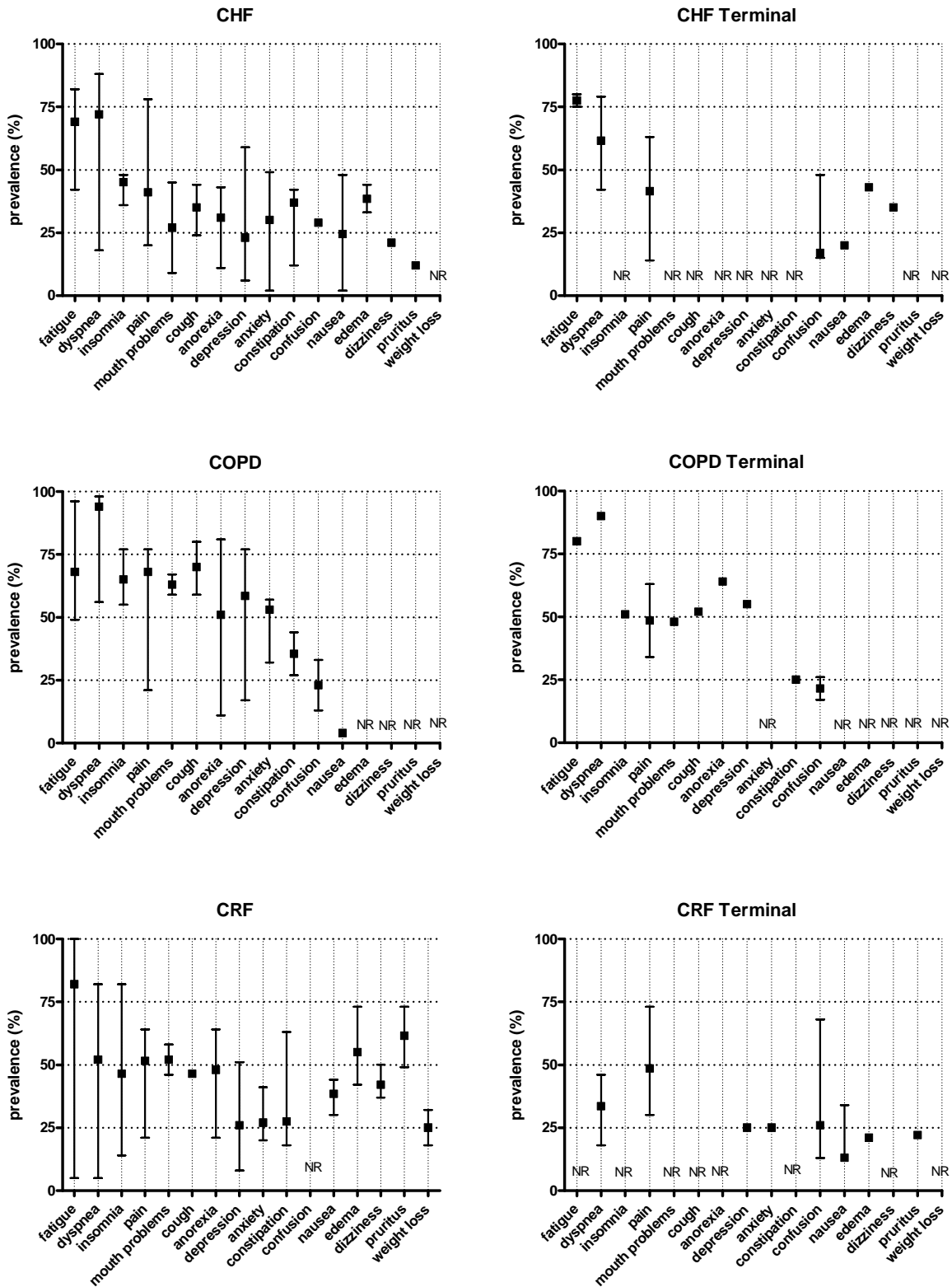

Minimum, maximum and median prevalence of reported daily symptom burden in patients with endstage Congestive Heart Failure (CHF, left upper panel), terminal CHF (right upper panel), end-stage Chronic Obstructive Pulmonary Disease (COPD, left middle panel), terminal COPD (right middle panel), Chronic Renal Failure (CRF, left lower panel) or terminal CRF (right lower panel). NR = Not Reported. 


\section{Limitations and methodological considerations}

Because it is difficult to accurately determine the prognosis for survival in patients with end-stage $\mathrm{CHF}$, COPD or CRF, authors who used prospective study designs may not have identified their patients as being at the end of life. Therefore, our search strategy may have failed to identify some relevant articles. Furthermore, some authors focused on a limited number of symptoms, and thereby our review may be underreporting some of the less commonly examined symptoms.

The variability in symptom prevalence we observed is likely the result of the heterogeneity in study design. Therefore, four causes probably contributing to the great variability will be discussed.

First, in this systematic review, studies of various designs, such as cross-sectional, longitudinal, retrospectively and/or prospectively, patient reporting, proxy reporting and chart review have been included. The reported symptom prevalence could probably be influenced by the design of the study. For example, some of the studies included in this systematic review relied on bereaved family members to act as proxies to report on the daily symptoms experienced by the patient. ${ }^{22,23,28-34}$ These proxies included relatives (partners and children), ${ }^{22,} 23,28-34$ friends, ${ }^{29}, 31,32$ neighbours ${ }^{29,31}$ or professional caregivers. ${ }^{29,} 31$ In general, proxy respondent agreement on health symptoms is better for proxies living with the patient compared with proxies not living with the patient. Children of patients have been shown to report more symptoms than partners of patients. Caregivers, like physicians, may report depression less frequently than relatives. ${ }^{35}$ This is true not only for depression, but also for pain, anxiety and other symptoms bereaved family members and medical staff have shown poor agreement. ${ }^{36}$ Previous research in patients with cancer and their relatives has shown a low agreement between family members' ratings and the patients' own ratings of their experienced symptoms. ${ }^{37}$ The low and inconsistent agreement brings into question the use of family members' or professional caregivers' views as proxies for the views of patients. Whether the study is prospective or retrospective can also have an impact. In retrospective assessment of symptoms, family members rate problems as mild or severe and avoid the midpoints of a rating scale, in contrast to what is seen in prospective assessment. ${ }^{36}$

Timing of the interview is an important consideration in post-bereavement studies because passage of time may change the perception of daily symptom burden by relatives. Studies included in this review conducted interviews within one month, ${ }^{23}$ within 5 to 10 months $^{30}$ or until 10 months after death ${ }^{31}$. It has been shown that pain and depression are reported as less severe and occurring less frequently the later the interview is conducted. ${ }^{38}$ 
Other studies relied on charts or medical records for identifying symptoms. ${ }^{39-42}$ These sources provide only indirect reporting of the daily symptom burden, potentially under representing symptoms that are not recognized by caregivers such as nurses and physicians. Moreover, these sources can also include interpretations. For example, in two of the studies the presence of depression was based upon the use of anti-depressive medication. However, this will underestimate the prevalence of depression. $^{24}$

Second, in the currently available literature, there is no clear and commonly accepted definition of end-of-life or end-stage. ${ }^{43}$ We included studies that were found by searching for the keywords 'palliative care', 'hospice care', 'terminal care', 'terminally ill' or 'end-of-life'. However, these labels signify varying degrees of prognosis. This could probably influence the reported daily symptom burden. For instance, in the study of Edmonds, et al., symptom burden of patients with COPD has been studied retrospectively in the last year and the last week of life. For all the studied symptoms a lower prevalence has been reported in the last week compared with the last year of life. ${ }^{29}$ In patients with CRF who withdrew from dialysis, Chater, et al., have shown that in the last $24 \mathrm{~h}$ of life symptom prevalence decreased. ${ }^{42}$ On the contrary, in the Study to Understand Prognoses and Preferences for Outcome and Risk of Treatments (SUPPORT), it was found that the number of CHF patients who reported symptoms like severe pain or dyspnoea increased as death came nearer. ${ }^{22}$ This could probably be partly explained by the fact that symptom burden in the last 3 days of life has only been studied by proxy reporting and in the last 6 months symptom burden has been studied by patient and proxy reporting. Although the exact relationship is not known, it is highly plausible that symptom burden is related to prognoses.

Third, patient selection criteria varied between the studies, introducing variability in patient characteristics. Some studies included only patients who were hospitalised during an acute exacerbation, ${ }^{22,44,45}$ other studies selected only outpatients. ${ }^{25} \mathrm{~Pa}$ tients included in prospective studies, those recognized as being at the end of life, could conceivably have other characteristics than patients included in retrospective studies, patients who have died. ${ }^{46}$ In some studies, considerably co-existing morbidities were present, ${ }^{8,34,45,47-50}$ while in others co-morbidity was not reported.

Fourth, definition and measurement of symptoms varied across the studies. Depression for example was defined as neurotic depression (DSM-IIIR), ${ }^{51}$ major depression (DSM-IV), ${ }^{52}$ feelings of depression, ${ }^{21}$ low mood, ${ }^{30}$ feeling sad, ${ }^{8}$ a score of $\geq 8$ points on the depression scale of Hospital Anxiety and Depression Scale (HADS), ${ }^{53}$ a score of $\geq 16$ points on the Center for Epidemiologic Study-Depression survey (CES-D), ${ }^{25}$ a score of $\geq 11$ points on the Geriatric Depression Scale (GDS) ${ }^{24}$ or Beck Depression 
Inventory $(\mathrm{BDI})^{47}$. The criteria for determining when a symptom was present and to what degree also varied. A symptom was considered as present in the various studies, if it was experienced all the time or sometimes, ${ }^{30}$ if it was mild to very severe, ${ }^{54}$ if it was moderately severe or extremely severe at least half of the time, ${ }^{22}$ a little bit, moderately, much or very much present ${ }^{55}$ or the symptom was uncontrolled. ${ }^{23}$ The length of the recall period varied from $24 \mathrm{~h}$ to one year.

\section{Conclusions and implications}

The need for palliative care for patients with end-stage chronic organ failure has been previously asserted. ${ }^{7,8,10,56}$ The degree daily symptom burden of patients with end-stage CHF, COPD or CRF that we found in this systematic review adds to such an assertion. Unfortunately, the heterogeneity and limitations of the study designs we reviewed do not permit a comparison of symptom prevalence between patients with end-stage CHF, COPD or CRF.

This limitation highlights the methodological challenges of research in end-of-life care as have been previously described. ${ }^{46,57,58}$ The resulting limited understanding of daily symptom burden in patients with CHF, COPD or CRF at the end of their life hampers efforts to develop patient-centered intensive management program aimed at reducing suffering and/or improving quality of life of patients with end-stage chronic organ failure and their families by preventing, relieving or soothing selfperceived daily symptoms. Further prospective and longitudinal research in which the views of patients, their families and their treating physician are taken into account is needed. Only then it may be possible to optimize palliative care and symptom management in patients with CHF, COPD or CRF at the end of their life. 


\section{References}

1. From the Centers for Disease Control and Prevention. Public health and aging: trends in aging-United States and worldwide. Jama. 2003;289(11):1371-3.

2. Bleumink, G.S., A.M. Knetsch, M.C. Sturkenboom, S.M. Straus, A. Hofman, J.W. Deckers, J.C. Witteman, and B.H. Stricker, Quantifying the heart failure epidemic: prevalence, incidence rate, lifetime risk and prognosis of heart failure The Rotterdam Study. Eur Heart J. 2004;25(18):1614-9.

3. Feenstra, T.L., M.L. van Genugten, R.T. Hoogenveen, E.F. Wouters, and M.P. Rutten-van Molken, The impact of aging and smoking on the future burden of chronic obstructive pulmonary disease: a model analysis in the Netherlands. Am J Respir Crit Care Med. 2001;164(4):590-6.

4. Stengel, B., S. Billon, P.C. Van Dijk, K.J. Jager, F.W. Dekker, K. Simpson, and J.D. Briggs, Trends in the incidence of renal replacement therapy for end-stage renal disease in Europe, 1990-1999. Nephrol Dial Transplant. 2003;18(9):1824-33.

5. Hauptman, P.J. and E.P. Havranek, Integrating palliative care into heart failure care. Arch Intern Med. 2005;165(4):374-8.

6. Gore, J.M., C.J. Brophy, and M.A. Greenstone, How well do we care for patients with end stage chronic obstructive pulmonary disease (COPD)? A comparison of palliative care and quality of life in COPD and lung cancer. Thorax. 2000;55(12):1000-6.

7. Curtis, J.R., Palliative and End-of-life Care for Patients with Severe COPD. Eur Respir J. 2008;32(3):796-803.

8. Weisbord, S.D., S.S. Carmody, F.J. Bruns, A.J. Rotondi, L.M. Cohen, M.L. Zeidel, and R.M. Arnold, Symptom burden, quality of life, advance care planning and the potential value of palliative care in severely ill haemodialysis patients. Nephrol Dial Transplant. 2003;18(7):1345-52.

9. Tranmer, J.E., D. Heyland, D. Dudgeon, D. Groll, M. Squires-Graham, and K. Coulson, Measuring the symptom experience of seriously ill cancer and noncancer hospitalized patients near the end of life with the memorial symptom assessment scale. J Pain Symptom Manage. 2003;25(5):420-9.

10. Saini, T., F.E. Murtagh, P.J. Dupont, P.M. McKinnon, P. Hatfield, and Y. Saunders, Comparative pilot study of symptoms and quality of life in cancer patients and patients with end stage renal disease. Palliat Med. 2006;20(6):631-6.

11. Riedinger, M.S., K.A. Dracup, and M.L. Brecht, Quality of life in women with heart failure, normative groups, and patients with other chronic conditions. Am J Crit Care. 2002;11(3):211-9.

12. Grande, G.E., M.C. Farquhar, S.I. Barclay, and C.J. Todd, The influence of patient and carer age in access to palliative care services. Age Ageing. 2006;35(3):267-73.

13. Mast, K.R., M. Salama, G.K. Silverman, and R.M. Arnold, End-of-life content in treatment guidelines for life-limiting diseases. J Palliat Med. 2004;7(6):754-73.

14. Rabe, K.F., S. Hurd, A. Anzueto, P.J. Barnes, S.A. Buist, P. Calverley, Y. Fukuchi, C. Jenkins, R. Rodriguez-Roisin, C. van Weel, and J. Zielinski, Global Strategy for the Diagnosis, Management, and Prevention of COPD - 2006 Update. Am J Respir Crit Care Med. 2007;176(6):532-555.

15. Murray, S.A., K. Boyd, M. Kendall, A. Worth, T.F. Benton, and H. Clausen, Dying of lung cancer or cardiac failure: prospective qualitative interview study of patients and their carers in the community. BMJ. 2002;325(7370):929-34.

16. Fox, E., K. Landrum-McNiff, Z. Zhong, N.V. Dawson, A.W. Wu, and J. Lynn, Evaluation of prognostic criteria for determining hospice eligibility in patients with advanced lung, heart, or liver disease. SUPPORT Investigators. Study to Understand Prognoses and Preferences for Outcomes and Risks of Treatments. Jama. 1999;282(17):1638-45.

17. Murray, S.A., M. Kendall, K. Boyd, and A. Sheikh, Illness trajectories and palliative care. Bmj. 2005;330(7498):1007-11.

18. Miravitlles, M., M. Calle, F. Alvarez-Gutierrez, E. Gobartt, F. Lopez, and A. Martin, Exacerbations, hospital admissions and impaired health status in chronic obstructive pulmonary disease. Qual Life Res. 2006;15(3):471-80. 
19. Murtagh, F.E., M. Preston, and I. Higginson, Patterns of dying: palliative care for non-malignant disease. Clin Med. 2004;4(1):39-44.

20. Janssen, D.J., E.F. Wouters, J.M. Schols, and M.A. Spruit, Self-perceived symptoms and care needs of patients with severe to very severe chronic obstructive pulmonary disease, congestive heart failure or chronic renal failure and its consequences for their closest relatives: the research protocol. BMC Palliat Care. 2008;7:5.

21. Walke, L.M., W.T. Gallo, M.E. Tinetti, and T.R. Fried, The burden of symptoms among communitydwelling older persons with advanced chronic disease. Arch Intern Med. 2004;164(21):2321-4.

22. Levenson, J.W., E.P. McCarthy, J. Lynn, R.B. Davis, and R.S. Phillips, The last six months of life for patients with congestive heart failure. J Am Geriatr Soc. 2000;48(5 Suppl):S101-9.

23. Formiga, F., C. Olmedo, A. Lopez-Soto, M. Navarro, A. Culla, and R. Pujol, Dying in hospital of terminal heart failure or severe dementia: the circumstances associated with death and the opinions of caregivers. Palliat Med. 2007;21(1):35-40.

24. Lacasse, Y., L. Rousseau, and F. Maltais, Prevalence of depressive symptoms and depression in patients with severe oxygen-dependent chronic obstructive pulmonary disease. J Cardiopulm Rehabil. 2001;21(2):80-6.

25. Stapleton, R.D., E.L. Nielsen, R.A. Engelberg, D.L. Patrick, and J.R. Curtis, Association of depression and life-sustaining treatment preferences in patients with COPD. Chest. 2005;127(1):328-34.

26. Solano, J.P., B. Gomes, and I.J. Higginson, A comparison of symptom prevalence in far advanced cancer, AIDS, heart disease, chronic obstructive pulmonary disease and renal disease. J Pain Symptom Manage. 2006;31(1):58-69.

27. Murtagh, F.E., J. Addington-Hall, and I.J. Higginson, The prevalence of symptoms in end-stage renal disease: a systematic review. Adv Chronic Kidney Dis. 2007;14(1):82-99.

28. Lynn, J., J.M. Teno, R.S. Phillips, A.W. Wu, N. Desbiens, J. Harrold, M.T. Claessens, N. Wenger, B. Kreling, and A.F. Connors, Jr., Perceptions by family members of the dying experience of older and seriously ill patients. SUPPORT Investigators. Study to Understand Prognoses and Preferences for Outcomes and Risks of Treatments. Ann Intern Med. 1997;126(2):97-106.

29. Edmonds, P., S. Karlsen, S. Khan, and J. Addington-Hall, A comparison of the palliative care needs of patients dying from chronic respiratory diseases and lung cancer. Palliat Med. 2001;15(4):287-95.

30. Elkington, H., P. White, J. Addington-Hall, R. Higgs, and P. Edmonds, The healthcare needs of chronic obstructive pulmonary disease patients in the last year of life. Palliat Med. 2005;19(6):485-91.

31. McCarthy, M., M. Lay, and J. Addington-Hall, Dying from heart disease. J R Coll Physicians Lond. 1996;30(4):325-8.

32. Sullivan, M.D. and E.S. O'Meara, Heart failure at the end of life: symptoms, function, and medical care in the Cardiovascular Health Study. Am J Geriatr Cardiol. 2006;15(4):217-25.

33. Cohen, L.M., M.J. Germain, A.L. Woods, A. Mirot, and J.A. Burleson, The family perspective of ESRD deaths. Am J Kidney Dis. 2005;45(1):154-61.

34. Cohen, L.M., M. Germain, D.M. Poppel, A. Woods, and C.M. Kjellstrand, Dialysis discontinuation and palliative care. Am J Kidney Dis. 2000;36(1):140-4.

35. Klinkenberg, M., J.H. Smit, D.J. Deeg, D.L. Willems, B.D. Onwuteaka-Philipsen, and G. van der Wal, Proxy reporting in after-death interviews: the use of proxy respondents in retrospective assessment of chronic diseases and symptom burden in the terminal phase of life. Palliat Med. 2003;17(2):191201.

36. Higginson, I., P. Priest, and M. McCarthy, Are bereaved family members a valid proxy for a patient's assessment of dying? Soc Sci Med. 1994;38(4):553-7.

37. Higginson, I., A. Wade, and M. McCarthy, Palliative care: views of patients and their families. BMJ. 1990;301(6746):277-81.

38. McPherson, C.J. and J.M. Addington-Hall, How do proxies' perceptions of patients' pain, anxiety, and depression change during the bereavement period? J Palliat Care. 2004;20(1):12-9.

39. Zambroski, C.H., D.K. Moser, L.P. Roser, S. Heo, and M.L. Chung, Patients with heart failure who die in hospice. Am Heart J. 2005;149(3):558-64. 
40. Nordgren, L. and S. Sorensen, Symptoms experienced in the last six months of life in patients with end-stage heart failure. Eur J Cardiovasc Nurs. 2003;2(3):213-7.

41. Brunier, G., D.M. Naimark, and M.A. Hladunewich, Meeting the guidelines for end-of-life care. Adv Perit Dial. 2006;22:175-9.

42. Chater, S., S.N. Davison, M.J. Germain, and L.M. Cohen, Withdrawal from dialysis: a palliative care perspective. Clin Nephrol. 2006;66(5):364-72.

43. Lorenz, K.A., J. Lynn, S.M. Dy, L.R. Shugarman, A. Wilkinson, R.A. Mularski, S.C. Morton, R.G. Hughes, L.K. Hilton, M. Maglione, S.L. Rhodes, C. Rolon, V.C. Sun, and P.G. Shekelle, Evidence for improving palliative care at the end of life: a systematic review. Ann Intern Med. 2008;148(2):147-59.

44. Claessens, M.T., J. Lynn, Z. Zhong, N.A. Desbiens, R.S. Phillips, A.W. Wu, F.E. Harrell, Jr., and A.F. Connors, Jr., Dying with lung cancer or chronic obstructive pulmonary disease: insights from SUPPORT. Study to Understand Prognoses and Preferences for Outcomes and Risks of Treatments. J Am Geriatr Soc. 2000;48(5 Suppl):S146-53.

45. Lynn, J., E.W. Ely, Z. Zhong, K.L. McNiff, N.V. Dawson, A. Connors, N.A. Desbiens, M. Claessens, and E.P. McCarthy, Living and dying with chronic obstructive pulmonary disease. J Am Geriatr Soc. 2000;48(5 Suppl):S91-100.

46. Bach, P.B., D. Schrag, and C.B. Begg, Resurrecting treatment histories of dead patients: a study design that should be laid to rest. JAMA. 2004;292(22):2765-70.

47. Wuerth, D., S.H. Finkelstein, and F.O. Finkelstein, The identification and treatment of depression in patients maintained on dialysis. Semin Dial. 2005;18(2):142-6.

48. Cohen, L.M., J.D. McCue, M. Germain, and C.M. Kjellstrand, Dialysis discontinuation. A 'good' death? Arch Intern Med. 1995;155(1):42-7.

49. Lopes, A.A., J. Bragg, E. Young, D. Goodkin, D. Mapes, C. Combe, L. Piera, P. Held, B. Gillespie, and F.K. Port, Depression as a predictor of mortality and hospitalization among hemodialysis patients in the United States and Europe. Kidney Int. 2002;62(1):199-207.

50. Iliescu, E.A., H. Coo, M.H. McMurray, C.L. Meers, M.M. Quinn, M.A. Singer, and W.M. Hopman, Quality of sleep and health-related quality of life in haemodialysis patients. Nephrol Dial Transplant. 2003;18(1):126-32.

51. Aghanwa, H.S. and O. Morakinyo, Psychiatric complications of hemodialysis at a kidney center in Nigeria. J Psychosom Res. 1997;42(5):445-51.

52. Cohen, L.M., S.K. Dobscha, K.C. Hails, P.S. Pekow, and H.M. Chochinov, Depression and suicidal ideation in patients who discontinue the life-support treatment of dialysis. Psychosom Med. 2002;64(6):889-96

53. McCann, K. and J.R. Boore, Fatigue in persons with renal failure who require maintenance haemodialysis. J Adv Nurs. 2000;32(5):1132-42.

54. Parfrey, P.S., H.M. Vavasour, S. Henry, M. Bullock, and M.H. Gault, Clinical features and severity of nonspecific symptoms in dialysis patients. Nephron. 1988;50(2):121-8.

55. Merkus, M.P., K.J. Jager, F.W. Dekker, R.J. de Haan, E.W. Boeschoten, and R.T. Krediet, Physical symptoms and quality of life in patients on chronic dialysis: results of The Netherlands Cooperative Study on Adequacy of Dialysis (NECOSAD). Nephrol Dial Transplant. 1999;14(5):1163-70.

56. Pantilat, S.Z. and A.E. Steimle, Palliative care for patients with heart failure. Jama. 2004;291(20):247682.

57. Teno, J.M., Measuring end-of-life care outcomes retrospectively. J Palliat Med. 2005;8 Suppl 1:S42-9.

58. Fowler, F.J., Jr., K.M. Coppola, and J.M. Teno, Methodological challenges for measuring quality of care at the end of life. J Pain Symptom Manage. 1999;17(2):114-9.

59. Anderson, H., C. Ward, A. Eardley, S.A. Gomm, M. Connolly, T. Coppinger, D. Corgie, J.L. Williams, and W.P. Makin, The concerns of patients under palliative care and a heart failure clinic are not being met. Palliat Med. 2001;15(4):279-86.

60. Vig, E.K. and R.A. Pearlman, Quality of life while dying: a qualitative study of terminally ill older men. J Am Geriatr Soc. 2003;51(11):1595-601. 
61. Skilbeck, J., L. Mott, H. Page, D. Smith, S. Hjelmeland-Ahmedzai, and D. Clark, Palliative care in chronic obstructive airways disease: a needs assessment. Palliat Med. 1998;12(4):245-54.

62. Yasuda, G., K. Shibata, T. Takizawa, Y. Ikeda, Y. Tokita, S. Umemura, and O. Tochikubo, Prevalence of constipation in continuous ambulatory peritoneal dialysis patients and comparison with hemodialysis patients. Am J Kidney Dis. 2002;39(6):1292-9.

63. Kimmel, P.L., S.L. Emont, J.M. Newmann, H. Danko, and A.H. Moss, ESRD patient quality of life: symptoms, spiritual beliefs, psychosocial factors, and ethnicity. Am J Kidney Dis. 2003;42(4):713-21.

64. Craven, J.L., G.M. Rodin, L. Johnson, and S.H. Kennedy, The diagnosis of major depression in renal dialysis patients. Psychosom Med. 1987;49(5):482-92.

65. Davison, S.N., Pain in hemodialysis patients: prevalence, cause, severity, and management. Am J Kidney Dis. 2003;42(6):1239-47.

66. Martin, C.R., Thompson D.R., Prediction of quality of life in patients with end-stage renal disease. Br J of Health Psychol. 2000;5:41-55.

67. Loos, C., S. Briancon, L. Frimat, B. Hanesse, and M. Kessler, Effect of end-stage renal disease on the quality of life of older patients. J Am Geriatr Soc. 2003;51(2):229-33.

68. Noble, H. and K. Rees, Caring for people who are dying on renal wards: a retrospective study. Edtna Erca J. 2006;32(2):89-92. 



\section{CHAPTER 4}

Self-perceived symptoms and care needs of patients with severe to very severe chronic obstructive pulmonary disease, congestive heart failure or chronic renal failure and its consequences for their closest relatives:

The research protocol 


\section{Abstract}

\section{Background}

Recent research shows that the prevalence of patients with very severe chronic obstructive pulmonary disease (COPD), congestive heart failure (CHF) and chronic renal failure (CRF) continues to rise over the next years. Scientific studies concerning self-perceived symptoms and care needs in patients with severe to very severe COPD, CHF and CRF are scarce. Consequently, it will be difficult to develop an optimal patient-centred palliative care program for patients with end-stage COPD, CHF or CRF. The present study has been designed to assess the symptoms, care needs, end-of-life care treatment preferences and communication needs of patients with severe to very severe COPD, CHF or CRF. Additionally, family distress and caregiving burden of relatives of these patients will be assessed.

\section{Methods/ design}

A cross-sectional comparative and prospective longitudinal study in patients with end-stage COPD, CHF or CRF has been designed. Patients will be recruited by their treating physician specialist. Patients and their closest relatives will be visited at baseline and every 4 months after baseline for a period of 12 months. The following outcomes will be assessed during home visits: self-perceived symptoms and care needs; daily physical functioning; general health status; end-of-life care treatment preferences; end-of-life care communication and caregiver burden of family caregivers. Additionally, end-of-life care communication and prognosis of survival will be assessed with the physician primarily responsible for the management of the chronic organ failure. Finally, if patients decease during the study period, the baseline preferences with regard to life-sustaining treatments will be compared with the real end-of-life care.

\section{Discussion}

To date, the symptoms, care needs, caregiver burden, end-of-life care treatment preferences and communication needs of patients with very severe COPD, CHF or CRF remain unknown. The present study will increase the knowledge about the selfperceived symptoms, care-needs, caregiver burden, end-of-life care treatment preferences and communication needs from the views of patients, their loved ones and their treating physician. This knowledge is necessary to optimize palliative care for patients with COPD, CHF or CRF. Here, the design of the present study has been described. A preliminary analysis of the possible strengths, weaknesses and clinical consequences is outlined. 


\section{Background}

Chronic diseases like chronic obstructive pulmonary disease (COPD), congestive heart failure (CHF) or chronic renal failure (CRF) are nowadays major causes of morbidity and mortality worldwide. ${ }^{1}$ Recent research shows that the prevalence of patients with very severe $\mathrm{COPD}^{2}, \mathrm{CHF}^{3}$ and $\mathrm{CRF}^{4}$ continues to rise over the next years.

Life prolongation is not the ultimate goal of management of patients with severe to very severe COPD, CHF or CRF. Management of these patients should prevent, relieve and/or soothe self-perceived symptoms and care needs to optimise daily functioning and stabilize disease-specific health status. ${ }^{5-9}$ The management of patients with severe to very severe COPD, CHF or CRF should probably be a holistic type of care, equally concerned with physical, psychosocial and spiritual aspects of each patient. $^{10}$

To the best of the present authors' knowledge, no management/treating program is currently aiming at the self-perceived symptoms and care needs of patients with severe to very severe COPD, CHF or CRF. In fact, it is currently unknown whether and to what extent patients with severe to very severe COPD, CHF or CRF suffer from self-perceived symptoms before they enter the last phase of their life and how they develop throughout the final course of the disease. At present, it is only known that patients with end-stage COPD, CHF or CRF have suffered from incapacitating symptoms while only a minority of these symptoms/problems has been treated appropriately. ${ }^{11-16}$ In the interest of patients with severe to very severe COPD, CHF or CRF, but also in the interest of their close relatives, it is of major importance to extent the currently available knowledge concerning assessment and treatment of self-perceived symptoms and care needs to optimise existing treatment options, to develop completely new treatment options and to offer adequate relief of selfperceived symptoms and care needs.

It remains very difficult to predict survival in patients with end-stage chronic organ failure. Indeed, physicians' predictions of survival in patients with various serious chronic conditions were often erroneous and optimistic. ${ }^{17,}{ }^{18}$ Moreover, a fundamental issue affecting the prediction of survival of patients with severe to very severe COPD or CHF is the hypothetical death trajectory: a slow decline in quality of life punctuated by acute exacerbations of COPD or CHF from which patients with severe to very severe COPD or CHF will only partially recover until a final crisis occurs that can not or will not be treated. ${ }^{19-21}$

It is therefore of great importance for patients with severe to very severe COPD, CHF or CRF to get to know and discuss survival and the preferences and conse- 
quences of life-sustaining interventions (i.e. mechanical ventilation and cardiac resuscitation) with their family and the treating physician. ${ }^{22}$ In fact, finding out and honouring the treatment preferences of terminally ill patients is most probably critical for the provision of high-quality end-of-life care. Moreover, patients with severe to very severe COPD, CHF or CRF who want to spend their end-of-life period as they want, should probably leave better advance directives. For example, a recent study in patients with chronic renal failure reported that about one-third of the close relatives and about one-third of the treating physicians predicted incorrectly the current preferences for cardiopulmonary resuscitation and haemodialysis under various circumstances. ${ }^{23}$ The contents and quality of end-of-life communication between patients with severe to very severe COPD, CHF or CRF, their closest relatives and their physician remain currently unknown.

Patients with severe to very severe chronic diseases like COPD, CHF or CRF may experience problems with performing normal daily tasks. ${ }^{24}$ When the patient is still living at home, most of the care needs may be carried out by family members. ${ }^{25}$ This may involve participation in personal hygiene needs, administration of medication, attention to nutritional needs, psychological support and emergency management of problems such as excessive shortness of breath, ${ }^{26}$ but also heavy physical work of transferring a weak patient and attending needs such as laundering and cleaning. $A$ recent study in 18 patients with COPD, CHF or CRF suggests that decreased independence and social isolation imposes a considerable burden of care on the family. ${ }^{10}$ Additionally, Barnes and colleagues have shown that carers of CHF patients have other characteristics than carers of patients with cancer and need practical and emotional support. ${ }^{27}$ At present, it remains unknown whether and to what extent self-perceived symptoms and care needs of patients with severe to very severe COPD, CHF or CRF may result in an extra caregiver burden for close relatives. It is therefore reasonable to hypothesize that for the families and loved ones of patients with severe to very severe COPD, CHF or CRF there is also great distress, which may increase while the symptoms and care needs of patients with severe to very severe COPD, CHF or CRF progress over time. Indeed, standing witness of physical $^{28}$ and emotional distress of the patient, ${ }^{29}$ bearing the burdens of extra care $^{25}$ and future anticipated loss will most probably cause substantial family distress. By identifying, understanding and addressing factors that may potentially overcome patients with severe to very severe COPD and their family, the necessary preconditions for coping and managing of will be established. ${ }^{6}$

Currently, the change over time in self-perceived symptoms, care needs and preferences with regard to life-sustaining treatments and communication about end-oflife care in patients with severe to very severe COPD, CHF or CRF remain unknown too. 


\section{Aims of the study}

In the present study we aim to elaborate the currently available knowledge concerning the self-perceived symptoms, care needs, caregiver burden, preferences with regard to life-sustaining treatments and communication about end-of-life care in patients with end-stage chronic organ failure, in particular COPD, CHF or CRF. To achieve this aim we need to answer the following questions:

1.1 What are the self-perceived symptoms and care needs of patients with severe to very severe COPD, CHF or CRF and to what extent do they differ from each other?

1.2 Do these self-perceived symptoms and care needs relate to patients' daily functioning, health status and mood status?

1.3 Whether and to what extent are self-perceived symptoms and care needs different between patients with severe COPD, very severe COPD without long-term oxygen therapy or very severe COPD with long-term oxygen therapy?

2.1 How are the self-perceived symptoms of patients with severe to very severe COPD, CHF or CRF perceived by their closest relatives?

2.2 Whether and to what extent do self-perceived symptoms and care needs of patients with severe to very severe COPD, CHF or CRF affect caregiver burden?

3.1 What are the preferences with regard to life-sustaining treatments of patients with severe to very severe COPD?

3.2 Whether and to what extent do the preferences with regard to life-sustaining treatments of patients with severe to very severe COPD differ from those of patients with end-stage CHF or CRF?

4.1 How do patients with severe to very severe COPD, CHF or CRF and their closest relatives perceive end-of-life care planning (i.e. communication about survival prognosis and life-sustaining treatments) with the treating physician?

5.1 How do self-perceived symptoms, care needs, caregiver burden, preferences with regard to life-sustaining treatments, end-of-life care communication and management of patients with severe to very severe COPD, CHF and CRF change over time according to the patients and their closest relatives?

The objective of this article is to describe the design of the present study and inform others on the possibilities of performing end-of-life care research in end-stage chronic organ failure, especially in COPD, CHF or CRF. In particular, the prospective and longitudinal study design, in which the views of patients, their relatives and 
physician will be taken into account for the assessment of daily symptoms, care needs, caregiver burden, end-of-life care treatment preferences and communication needs in three groups of patients with end-stage chronic organ failure has not been described before. The described methodology will also serve as detailed reference for the method section of future publications of this study.

\section{Methods / design}

\section{Design}

A cross-sectional comparative study in patients with end-stage COPD, CHF or CRF has been designed to answer question 1.1 to 4.1. Additionally, a longitudinal followup study has been designed to answer question 5.1. Patients and their closest relatives will be visited at baseline and every 4 months after baseline for a period of 12 months (Figure 4.1).

Figure 4.1 Study design

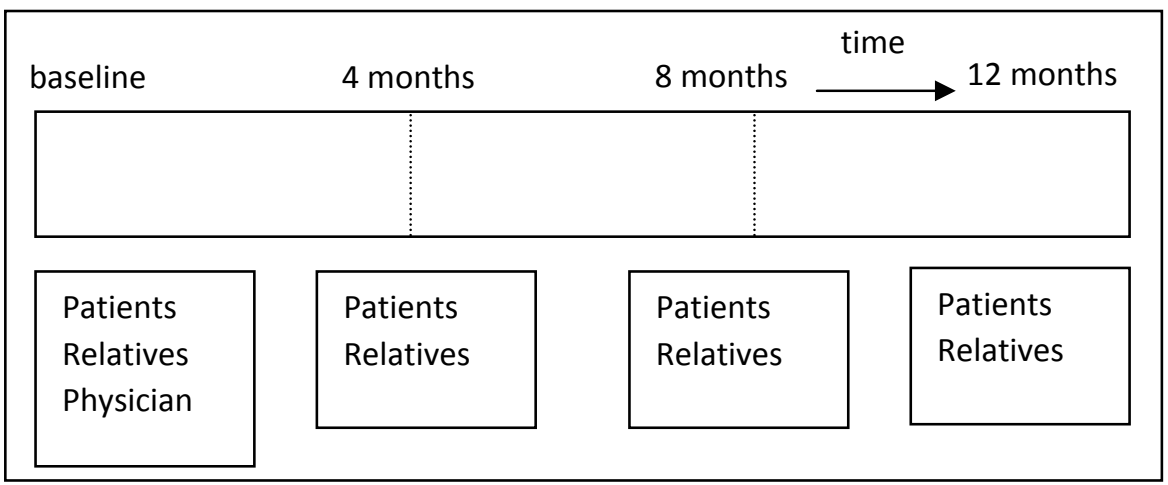

Timing of the interviews.

\section{Study population}

The study population consists of patients with severe to very severe COPD, endstage CHF and end-stage CRF. All patients will be recruited by their physician specialist ( $n=$ about 25 ) at the outpatient consultation in one academic hospital and six general hospitals throughout the southern-eastern part of the Netherlands. Patients and their closest relatives will be included. Additionally, the participating physician specialist primarily responsible for the management of the chronic organ disease of the enrolled patients will be included. 
Inclusion criteria are: patients with severe COPD (Global initiative for chronic Obstructive Lung Disease (GOLD) classification III); patients with end-stage COPD (GOLD classification IV) without long-term oxygen therapy (LTOT); patients with end-stage COPD (GOLD classification IV) with LTOT; patients with end-stage chronic heart failure (New York Heart Association (NYHA) classification III and IV) and patients with end-stage chronic renal failure (requiring dialysis).

Exclusion criteria are: the patient is not clinically stable for at least 4 weeks preceding enrolment (no hospital admission or major change in medication, according to the treating physician specialist); pharmacological therapy is not optimal (according to the current available guidelines) and stable for at least 2 months preceding enrolment and patients in a nursing home.

The lack of previous results makes it impossible to perform power calculations. The intended sample size will be 150 patients with COPD (GOLD classification III, $n=50$; GOLD classification IV without LTOT, $n=50$; GOLD classification IV with LTOT, $n=50$ ); 100 patients with CHF (NYHA class III, $n=50$; NYHA class IV, $n=50$ ) and 100 patients with CRF (haemodialysis, $n=50$; peritoneal dialysis, $n=50$ ).

\section{Instruments}

After oral and written informed consent has been given by participating patients, the following outcomes will be assessed at the patients' home-environment: demographics; current self-reported comorbidities: Charlson comorbidity index ${ }^{30}$; disease history; general health status: EuroQol-5 Dimensions (EQ-5D) ${ }^{31}$, Assessment of Quality Of Life (AQOL) ${ }^{32}$, Medical Outcomes Study 36-Item Short-Form Health Survey (SF$36)^{33}$; disease-specific health status: St. Georges Respiratory Questionnaire (SGRQ, only for COPD patients) ${ }^{34}$, Minnesota Living with Heart Failure Questionnaire (MLHFQ, only for CHF patients) ${ }^{35}$, Kidney Disease Quality Of Life questionnaire (KDQOL, only for CRF patients) ${ }^{36}$; anxiety and depression: Hospital Anxiety and Depression Scale (HADS) ${ }^{37}$; daily physical functioning: Timed 'Up and Go' test (TUG) ${ }^{38}$, Care Dependency Scale $(C D S)^{39}$; symptom checklist for the patients to determine the degree of self-perceived physical and psychological symptoms using Visual Analogue Scales (VAS); current disease management checklist; end-of-life care communication: Quality Of Communication questionnaire $(\mathrm{QOC})^{40}$, Barriers and Facilitators Questionnaire $(B F Q)^{41}$; end-of-life care treatment preferences ${ }^{42}$, Willingness to Accept Life-sustaining Treatments questionnaire (WALT) ${ }^{22}$; weight and length (only at baseline). Additionally, NT-proBNP ${ }^{43}$, creatinine and lung function (spirometry, Forced Expiratory Volume in the first second $\left(\mathrm{FEV}_{1}\right)$ ) will be measured at baseline to assess previously unrecognised co-existing morbidities. 
Patients will be asked to identify the person who spends most time with them and provides most of their care, assistance and support. ${ }^{44}$ After oral and written informed consent has been given by participating close relatives of enrolled patients, the following outcomes will be assessed at their home-environment: caregiver burden: Family Appraisal of Caregiving Questionnaire for Palliative Care (FACQ-PC) ${ }^{45}$; perception of the patient's symptoms checklist; barriers and facilitators in end-oflife care communication: $\mathrm{BFQ}^{41}$ and general well being: semi-structured interview. If possible, relatives will not be interviewed in the presence of the patient.

The participating physician specialist primarily responsible for the management of the chronic organ disease of the enrolled patients will be interviewed at baseline to assess end-of-life care communication and prognosis of survival of the patient with chronic organ disease.

If patients decease during this period, the first author will call the relatives to compare the most recent end-of-life care treatment preferences of the patient with the real end-of-life care (e.g. place of dying, the use of life-sustaining treatments like resuscitation or invasive ventilation).

Finally, for patients with COPD or CHF the number of exacerbations/acute heart decompensation during every 4-month period will be assessed using a diary, which has to be filled out every day. Complications of dialysis will be assessed every four months at the dialysis department.

From a group of non-participating patients some data like severity of disease (GOLD classification or NYHA classification), age and gender will be collected.

Questionnaires that were not available in Dutch (AQOL, QOC, BFQ, WALT and FACQ$\mathrm{PC})$ have been translated into Dutch by the procedure of forward-backward translation.

\section{Ethical considerations}

The study will be conducted according to the principles of the Declaration of Hel$\operatorname{sinki}^{46}$ and in accordance with the Medical Research Involving Human Subjects Act (WMO).

The load for patients has been tested in three volunteering patients with end-stage COPD and two relatives. The load for patients will be low, because patients will be visited at home, mainly for filling in questionnaires. This will probably not increase discomfort and sensations like dyspnea. 
All patients will be recruited at the outpatient consultation of their treating physician in one academic hospital and six general hospitals. Patients will receive the patient information letter and the informed consent form. Patients will be informed verbally by a research nurse. Patients will be asked for their consent by the research nurse after a week. If patients can not decide about their participation at that moment, the research nurse will call again after another week. Data will be handled confidentially and anonymously. The protocol of the present study has been approved by the Medical Ethical Committee of the University Hospital Maastricht (NL16264.068.07 / MEC 07-3-054).

\section{Data management and plan of statistical analysis}

Data are entered weekly in a database. Missing data will be minimized because patients will be visited at home for filling in the questionnaires and a research nurse will check if all the questions have been answered. Handling of missing data will be done according to the guidelines of the different questionnaires. For data-analysis SPSS 15.0 will be used. All operations will be stored in a SPSS-syntax file. Interim analysis will be done when each group consists of 50 patients.

Categorical variables will be described as frequencies, while continuous variables will be tested for normality and will be presented as mean and standard error of the mean (SEM) or median, inter-quartile range and minimum and maximum. Comparison of baseline results between patients with COPD, CHF and CRF will be done using parametric and non-parametric statistics and multivariate analysis, as appropriate. The presence of co-existing morbidities will be taken into account. To estimate longitudinal changes, a mixed effect model for the slopes can be used. In these analyses, covariates such as age, gender and smoking status can be included as fixed effects, whereas time can be entered as random effect. Bivariate relationships between slope changes will be analysed by using a Pearson's correlation coefficient. Comparison of baseline results between surviving patients and patients who passed away during the 1-year follow up period will be done using parametric and nonparametric statistics, as appropriate. A priori, a two-sided level of significance will be set at $p \leq 0.05 .^{47}$ Additionally, ninety-five percent confidence intervals will be provided to assist in determining the clinical significance of the differences of results between groups of patients.

\section{Discussion}

The present study has been designed to assess the self-perceived symptoms, care needs, caregiver burden, preferences with regard to life-sustaining treatments and 
communication about end-of-life care in patients with end-stage chronic organ failure, in particular COPD, CHF or CRF. Patients with moderate to severe COPD, $\mathrm{CHF}$, or CRF have been shown to suffer from exercise intolerance, muscle weakness and abnormal changes in body composition, irrespective of the degree of primary organ failure. ${ }^{48-51}$ Therefore, it seems reasonable to hypothesize that patients with end-stage CHF, COPD and CRF have comparable daily symptom burden and care needs. This study has several strengths and weaknesses, which will be described below.

\section{Strengths}

The present study concerns patients with end-stage chronic, non-malignant, diseases: COPD, CHF and CRF. To the present authors' knowledge, this study is the first to assess symptoms, care needs, caregiver burden, end-of-life care treatment preferences and communication needs from the views of patients with severe to very severe COPD, patients with end-stage CHF and patients with end-stage CRF, their loved ones and their treating physician. Previously have been described the methodological challenges of research in end-of-life care, like the difficult task of prospectively identifying the terminally ill. ${ }^{52}$ To date, many studies concerning end-oflife care have a cross-sectional and retrospective design. Barnes and colleagues have previously described the importance of prospective and longitudinal research in chronic diseases. ${ }^{53}$ The prospective and longitudinal design of this study will allow studying end-of-life care in patients who are not previously identified as terminally ill. Moreover, the longitudinal and prospective design is less vulnerable for measurement error, which is a risk of cross-sectional or retrospective studies. ${ }^{54,55}$ The intended sample size and the involvement of multiple hospitals (six general and one academic hospital) will improve the reliability of the results. The present study will provide valuable data to an area that has only scarcely been studied before.

\section{Weaknesses}

Patients will be recruited by their treating physician at the outpatient consultation. The external validity of the results of the study may be limited due to the exclusion criteria. For example, patients who are not clinically stable for four weeks will not be included. However, the exclusion of patients who are not clinically stable has the major advantage that all patients are clinically stable at baseline which improves the internal validity of the study.

Additionally, it is possible that participating patients have other clinical characteristics than non-participating patients. For example, it is possible that participating patients will be patients who talk more easily about end-of-life care than patients 
who do not want to take part in the study. Moreover, it is possible that physicians do not want to ask their terminally ill patients to participate in the study.

Nevertheless, the risk for selection bias will be reduced by the participation of seven hospitals and about 25 physicians in the recruitment of patients. Additionally, we will collect some data from a group of non-participating patients as mentioned before.

A part of the included patients will probably have co-existing morbidities, not included in the Charlson comorbidity index, like osteoarthritis, which could possibly affect symptom experience, care needs, health status and caregiver burden. Therefore, patients will be asked to report co-existing morbidities not included in the Charlson comorbidity index.

The lack of previous results makes it impossible to perform power calculations. Therefore a lack of power of this study may be possible.

Finally, previous authors described the challenges of performing prospective longitudinal research in patients with end-stage chronic diseases. ${ }^{44,53}$ However, the recruitment in the present study will be stimulated by the involvement of about 25 physicians of 7 hospitals and the active role of the research nurses in recruitment. The home visits by a research nurse or researcher will stimulate sustaining participation of patients and caregivers. This will provide patients and caregivers the most convenient setting for data collection.

\section{Clinical consequences}

The present study will identify the daily symptoms experienced by patients with severe to very severe COPD, CHF and CRF. The present study will identify the care needs which should receive attention in the development of management programs for patients with severe to very severe COPD, CHF or CRF. Additionally, the present study will reveal the end-of-life care treatment preferences and, if present, the changes in treatment preferences of patients with end-stage COPD, CHF or CRF, which will identify which and when treatment preferences should be discussed with the individual patient and his or her loved ones. The communication needs and barriers and facilitators of end-of-life care communication which will be found in this study may give recommendations for improvement of end-of-life care communication between patients with end-stage COPD, CHF or CRF, their loved ones and treating physician. Finally, the present study will identify the factors affecting caregiver burden, which may increase the possibilities to influence caregiver burden in future management programs. 


\section{Conclusion}

To date, the symptoms, care needs, caregiver burden, end-of-life care treatment preferences and end-of-life care communication of patients with very severe COPD, CHF or CRF have been studied scarcely. The present study will increase the knowledge about the symptoms, care needs, caregiver burden, end-of-life care treatment preferences and communication needs from the views of patients, their families and their treating physician. This knowledge is necessary to optimize palliative care for patients with COPD, CHF or CRF. Here, the study protocol is described and a preliminary analysis of the possible strengths, weaknesses and clinical consequences is outlined. 


\section{References}

1. Murray, C.J. and A.D. Lopez, Alternative projections of mortality and disability by cause 1990-2020: Global Burden of Disease Study. Lancet. 1997;349(9064):1498-504.

2. Feenstra, T.L., M.L. van Genugten, R.T. Hoogenveen, E.F. Wouters, and M.P. Rutten-van Molken, The impact of aging and smoking on the future burden of chronic obstructive pulmonary disease: a model analysis in the Netherlands. Am J Respir Crit Care Med. 2001;164(4):590-6.

3. Jaarsma, T., F.M. Haaijer-Ruskamp, H. Sturm, and D.J. Van Veldhuisen, Management of heart failure in The Netherlands. Eur J Heart Fail. 2005;7(3):371-5.

4. Gansevoort, R.T., B. van der Heij, C.A. Stegeman, F.T. de Charro, M.G. Nieuwenhuizen, D. de Zeeuw, and P.E. de Jong, Trends in the incidence of treated end-stage renal failure in The Netherlands: hope for the future? Kidney Int Suppl. 2004;(92):S7-10.

5. Weisbord, S.D., S.S. Carmody, F.J. Bruns, A.J. Rotondi, L.M. Cohen, M.L. Zeidel, and R.M. Arnold, Symptom burden, quality of life, advance care planning and the potential value of palliative care in severely ill haemodialysis patients. Nephrol Dial Transplant. 2003;18(7):1345-52.

6. Wouters, E.F., Management of severe COPD. Lancet. 2004;364(9437):883-95.

7. Ward, C., The need for palliative care in the management of heart failure. Heart. 2002;87(3):294-8.

8. Hauptman, P.J. and E.P. Havranek, Integrating palliative care into heart failure care. Arch Intern Med. 2005;165(4):374-8.

9. Curtis, J.R., Palliative and End-of-life Care for Patients with Severe COPD. Eur Respir J. 2008;32(3):796-803.

10. Fitzsimons, D., D. Mullan, J.S. Wilson, B. Conway, B. Corcoran, M. Dempster, J. Gamble, C. Stewart, S. Rafferty, M. McMahon, J. MacMahon, P. Mulholland, P. Stockdale, E. Chew, L. Hanna, J. Brown, G. Ferguson, and D. Fogarty, The challenge of patients' unmet palliative care needs in the final stages of chronic illness. Palliat Med. 2007;21(4):313-22.

11. Elkington, H., P. White, J. Addington-Hall, R. Higgs, and P. Edmonds, The healthcare needs of chronic obstructive pulmonary disease patients in the last year of life. Palliat Med. 2005;19(6):485-91.

12. Tranmer, J.E., D. Heyland, D. Dudgeon, D. Groll, M. Squires-Graham, and K. Coulson, Measuring the symptom experience of seriously ill cancer and noncancer hospitalized patients near the end of life with the memorial symptom assessment scale. J Pain Symptom Manage. 2003;25(5):420-9.

13. Levenson, J.W., E.P. McCarthy, J. Lynn, R.B. Davis, and R.S. Phillips, The last six months of life for patients with congestive heart failure. J Am Geriatr Soc. 2000;48(5 Suppl):S101-9.

14. Lynn, J., J.M. Teno, R.S. Phillips, A.W. Wu, N. Desbiens, J. Harrold, M.T. Claessens, N. Wenger, B. Kreling, and A.F. Connors, Jr., Perceptions by family members of the dying experience of older and seriously ill patients. SUPPORT Investigators. Study to Understand Prognoses and Preferences for Outcomes and Risks of Treatments. Ann Intern Med. 1997;126(2):97-106.

15. Saini, T., F.E. Murtagh, P.J. Dupont, P.M. McKinnon, P. Hatfield, and Y. Saunders, Comparative pilot study of symptoms and quality of life in cancer patients and patients with end stage renal disease. Palliat Med. 2006;20(6):631-6.

16. Walke, L.M., A.L. Byers, M.E. Tinetti, J.A. Dubin, R. McCorkle, and T.R. Fried, Range and severity of symptoms over time among older adults with chronic obstructive pulmonary disease and heart failure. Arch Intern Med. 2007;167(22):2503-8.

17. Christakis, N.A. and E.B. Lamont, Extent and determinants of error in doctors' prognoses in terminally ill patients: prospective cohort study. Bmj. 2000;320(7233):469-72.

18. Glare, P., K. Virik, M. Jones, M. Hudson, S. Eychmuller, J. Simes, and N. Christakis, A systematic review of physicians' survival predictions in terminally ill cancer patients. Bmj. 2003;327(7408):195.

19. Murray, S.A., M. Kendall, K. Boyd, and A. Sheikh, Illness trajectories and palliative care. Bmj. 2005;330(7498):1007-11. 
20. Miravitlles, M., M. Calle, F. Alvarez-Gutierrez, E. Gobartt, F. Lopez, and A. Martin, Exacerbations, hospital admissions and impaired health status in chronic obstructive pulmonary disease. Qual Life Res. 2006;15(3):471-80.

21. Murtagh, F.E., M. Preston, and I. Higginson, Patterns of dying: palliative care for non-malignant disease. Clin Med. 2004;4(1):39-44.

22. Fried, T.R., E.H. Bradley, V.R. Towle, and H. Allore, Understanding the treatment preferences of seriously ill patients. N Engl J Med. 2002;346(14):1061-6.

23. Miura, Y., A. Asai, M. Matsushima, S. Nagata, M. Onishi, T. Shimbo, T. Hosoya, and S. Fukuhara, Families' and physicians' predictions of dialysis patients' preferences regarding life-sustaining treatments in Japan. Am J Kidney Dis. 2006;47(1):122-30.

24. Guccione, A.A., D.T. Felson, J.J. Anderson, J.M. Anthony, Y. Zhang, P.W. Wilson, M. Kelly-Hayes, P.A. Wolf, B.E. Kreger, and W.B. Kannel, The effects of specific medical conditions on the functional limitations of elders in the Framingham Study. Am J Public Health. 1994;84(3):351-8.

25. Fried, T.R., E.H. Bradley, J.R. O'Leary, and A.L. Byers, Unmet desire for caregiver-patient communication and increased caregiver burden. J Am Geriatr Soc. 2005;53(1):59-65.

26. Doyle, D., G. Hanks, N. Cherny, and K. Calman, Palliative Medicine. Third ed. 2005, New York: Oxford University Press.

27. Barnes, S., M. Gott, S. Payne, C. Parker, D. Seamark, S. Gariballa, and N. Small, Characteristics and views of family carers of older people with heart failure. Int J Palliat Nurs. 2006;12(8):380-9.

28. Gore, J.M., C.J. Brophy, and M.A. Greenstone, How well do we care for patients with end stage chronic obstructive pulmonary disease (COPD)? A comparison of palliative care and quality of life in COPD and lung cancer. Thorax. 2000;55(12):1000-6.

29. Andenaes, R. and M.H. Kalfoss, Psychological distress in hospitalized patients with chronic obstructive pulmonary disease. Eur J Epidemiol. 2004;19(9):851-9.

30. Charlson, M.E., P. Pompei, K.L. Ales, and C.R. MacKenzie, A new method of classifying prognostic comorbidity in longitudinal studies: development and validation. J Chronic Dis. 1987;40(5):373-83.

31. Dolan, P., Modeling valuations for EuroQol health states. Med Care. 1997;35(11):1095-108.

32. Holland, R., R.D. Smith, I. Harvey, L. Swift, and E. Lenaghan, Assessing quality of life in the elderly: a direct comparison of the EQ-5D and AQoL. Health Econ. 2004;13(8):793-805.

33. Ware, J.E., K.K. Snow, and M. Kosinski, SF-36 health survey manual and interpretation guide. 1993, Boston MA: The Health Institute, New England Medical Center Hospitals.

34. Jones, P.W., F.H. Quirk, C.M. Baveystock, and P. Littlejohns, A self-complete measure of health status for chronic airflow limitation. The St. George's Respiratory Questionnaire. Am Rev Respir Dis. 1992;145(6):1321-7.

35. Riegel, B., D.K. Moser, D. Glaser, B. Carlson, C. Deaton, R. Armola, K. Sethares, M. Shively, L. Evangelista, and N. Albert, The Minnesota Living With Heart Failure Questionnaire: sensitivity to differences and responsiveness to intervention intensity in a clinical population. Nurs Res. 2002;51(4):209-18.

36. Korevaar, J.C., M.P. Merkus, M.A. Jansen, F.W. Dekker, E.W. Boeschoten, and R.T. Krediet, Validation of the KDQOL-SF: a dialysis-targeted health measure. Qual Life Res. 2002;11(5):437-47.

37. Zigmond, A.S. and R.P. Snaith, The hospital anxiety and depression scale. Acta Psychiatr Scand. 1983;67(6):361-70.

38. Ng, S.S. and C.W. Hui-Chan, The timed up \& go test: its reliability and association with lower-limb impairments and locomotor capacities in people with chronic stroke. Arch Phys Med Rehabil. 2005;86(8):1641-7.

39. Dijkstra, A., L.J. Tiesinga, W.T. Goossen, and T.W. Dassen, Further psychometric testing of the Dutch Care Dependency Scale on two different patient groups. Int J Nurs Pract. 2002;8(6):305-14.

40. Curtis, J.R., R.A. Engelberg, E.L. Nielsen, D.H. Au, and D.L. Patrick, Patient-physician communication about end-of-life care for patients with severe COPD. Eur Respir J. 2004;24(2):200-5.

41. Knauft, E., E.L. Nielsen, R.A. Engelberg, D.L. Patrick, and J.R. Curtis, Barriers and facilitators to end-oflife care communication for patients with COPD. Chest. 2005;127(6):2188-96. 
42. Stapleton, R.D., E.L. Nielsen, R.A. Engelberg, D.L. Patrick, and J.R. Curtis, Association of depression and life-sustaining treatment preferences in patients with COPD. Chest. 2005;127(1):328-34.

43. Rutten, F.H., K.G. Moons, M.J. Cramer, D.E. Grobbee, N.P. Zuithoff, J.W. Lammers, and A.W. Hoes, Recognising heart failure in elderly patients with stable chronic obstructive pulmonary disease in primary care: cross sectional diagnostic study. Bmj. 2005;331(7529):1379.

44. Steinhauser, K.E., E.C. Clipp, J.C. Hays, M. Olsen, R. Arnold, N.A. Christakis, J.H. Lindquist, and J.A. Tulsky, Identifying, recruiting, and retaining seriously-ill patients and their caregivers in longitudinal research. Palliat Med. 2006;20(8):745-54.

45. Cooper, B., G.J. Kinsella, and C. Picton, Development and initial validation of a family appraisal of caregiving questionnaire for palliative care. Psychooncology. 2006;15(7):613-22.

46. World Medical Association declaration of Helsinki. Recommendations guiding physicians in biomedical research involving human subjects. Jama. 1997;277(11):925-6.

47. Altman, D.G., S.M. Gore, M.J. Gardner, and S.J. Pocock, Statistical guidelines for contributors to medical journals. Br Med J (Clin Res Ed). 1983;286(6376):1489-93.

48. Gosker, H.R., N.H. Lencer, F.M. Franssen, G.J. van der Vusse, E.F. Wouters, and A.M. Schols, Striking similarities in systemic factors contributing to decreased exercise capacity in patients with severe chronic heart failure or COPD. Chest. 2003;123(5):1416-24.

49. Franssen, F.M., E.F. Wouters, and A.M. Schols, The contribution of starvation, deconditioning and ageing to the observed alterations in peripheral skeletal muscle in chronic organ diseases. Clin Nutr. 2002;21(1):1-14.

50. van den Ham, E.C., J.P. Kooman, A.M. Schols, F.H. Nieman, J.D. Does, M.A. Akkermans, P.P. Janssen, H.R. Gosker, K.A. Ward, J.H. MacDonald, M.H. Christiaans, K.M. Leunissen, and J.P. van Hooff, The functional, metabolic, and anabolic responses to exercise training in renal transplant and hemodialysis patients. Transplantation. 2007;83(8):1059-68.

51. van den Ham, E.C., J.P. Kooman, A.M. Schols, F.H. Nieman, J.D. Does, F.M. Franssen, M.A. Akkermans, P.P. Janssen, and J.P. van Hooff, Similarities in skeletal muscle strength and exercise capacity between renal transplant and hemodialysis patients. Am J Transplant. 2005;5(8):1957-65.

52. Teno, J.M., Measuring end-of-life care outcomes retrospectively. J Palliat Med. 2005;8 Suppl 1:S42-9.

53. Barnes, S., M. Gott, S. Payne, C. Parker, D. Seamark, S. Gariballa, and N. Small, Recruiting older people into a large, community-based study of heart failure. Chronic Illn. 2005;1(4):321-9.

54. Hudson, J.I., H.G. Pope, Jr., and R.J. Glynn, The cross-sectional cohort study: an underutilized design. Epidemiology. 2005;16(3):355-9.

55. White, E., J.R. Hunt, and D. Casso, Exposure measurement in cohort studies: the challenges of prospective data collection. Epidemiol Rev. 1998;20(1):43-56. 



\section{CHAPTER 5}

Symptoms, comorbidities and healthcare in advanced chronic obstructive pulmonary disease or chronic heart failure

Daisy J.A. Janssen, Martijn A. Spruit, Nicole H. Uszko-Lencer, Jos M.G.A. Schols and Emiel F.M. Wouters

J Palliat Med, 2011. 14 (6): 735-43. 


\section{Abstract}

\section{Background}

Patients with advanced Chronic Obstructive Pulmonary Disease (COPD) or Chronic Heart Failure (CHF) may experience significant symptom distress. For development of palliative care programs which adequately address symptoms of patients with COPD or CHF, it is necessary to know severity of symptom distress and to gain insight in comorbidities and current provision of health care. Objective of the present cross-sectional observational study was to assess severity of symptoms, presence of comorbidities and current provision of health care in outpatients with advanced COPD or CHF.

\section{Methods}

A total of 105 outpatients with clinically stable but advanced COPD (Global initiative for chronic obstructive lung disease (GOLD) stage III or IV) and 80 patients with advanced CHF (New York Heart Association (NYHA) class III or IV) were assessed for demographics, clinical characteristics, self-reported comorbidities, and severity of symptoms using visual analogue scales. In addition, current health care and symptom-related interventions have been assessed.

\section{Results}

Comorbidities were reported by $96.3 \%$ of the CHF patients and $61.9 \%$ of the COPD patients. Patients suffered from multiple symptoms, like dyspnea, fatigue, muscle weakness, coughing, low mood, sleeplessness and frequent micturition. For most symptoms, only the minority of patients had received symptom-related treatment. Involvement of allied health care professionals was low. The majority of COPD and CHF patients had received home adaptation and medical aids.

\section{Conclusions}

Patients with advanced COPD or CHF experience comorbidities and suffer from multiple symptoms, which are often under treated. Further development and implementation of palliative care programs, consisting of regular assessment of the patients' comorbidities and symptoms as well as the provision of patient-tailored interventions is needed. 


\section{Introduction}

Chronic Obstructive Pulmonary Disease (COPD) and Chronic Heart Failure (CHF) are major causes of morbidity and mortality worldwide. ${ }^{1}$ The palliative care needs of patients with advanced COPD or CHF are increasingly being recognized. ${ }^{2-4}$ Recent studies suggest that burden of symptoms in patients with advanced COPD or CHF is high and is associated with impairment of quality of life..$^{4-6}$ However, it remains unknown whether and to what extent the burden of symptoms is comparable between patients with advanced COPD and $\mathrm{CHF}^{7}$

In addition, little is known regarding symptom-related interventions and the current utilization of health care for patients with advanced COPD or CHF. A retrospective study of COPD patients in their last year of life suggests that the frequency of contact with health care professionals is low and that the care provided by health and social services is inadequate. ${ }^{8}$ Furthermore, elderly COPD patients may receive less support from health care professionals and social services than similarly disabled persons without COPD. ${ }^{9}$

For development of palliative care programs for patients with advanced COPD or CHF which adequately address symptoms, it is necessary to know the severity of symptoms, the presence of symptom-related interventions and utilization of health care.

Furthermore, while recent studies concerning symptom burden in COPD and CHF excluded patients with life-threatening comorbidities, ${ }^{5,6}$ comorbidities in these patients may be common. ${ }^{4,10,11}$ Presence of comorbidities may influence the palliative care needs and insight in the presence of comorbidities is necessary to understand how models of palliative care should be developed for these patients.

Therefore, the aim of the present study was to assess severity of symptoms, presence of comorbidities and current provision of health care in patients with advanced COPD or CHF.

We hypothesized a priori that comorbidities in advanced COPD or CHF are highly prevalent and that the experience of symptoms is similar, irrespective of the underlying disease. In addition, we hypothesized that symptoms are not adequately considered in treatment regimens for advanced COPD or CHF. 


\section{Methods}

\section{Design}

This cross-sectional observational study is part of a longitudinal study concerning self-perceived symptoms and care needs in patients with severe to very severe COPD or $\mathrm{CHF}$ and the consequences for their closest relatives. ${ }^{12}$ Details of the methodology of this study and data concerning advance care planning have been published before. ${ }^{12,13}$

\section{Study population}

The study population consists of a convenience sample of outpatients with severe COPD or CHF. Patients were recruited by their physician specialist at the outpatient clinic of one academic and five general hospitals in the Netherlands in 2008 and 2009. Patients were eligible if they had a diagnosis of advanced COPD (Global initiative for chronic Obstructive Lung Disease (GOLD) stage III or IV) or advanced CHF (New York Heart Association (NYHA) class III or IV, as assessed by the referring cardiologist). For patients who were contacted for the study but refused participation, data including severity of disease, age and gender were collected in order to compare characteristics of participating and non-participating patients. All participating patients have given written informed consent. The Medical Ethical Commission of the Maastricht University Medical Centre + (MUMC+), Maastricht, the Netherlands, approved this study (MEC 07-3-054).

\section{Instruments}

Patients were visited by a member of the research team in their home environment. The following outcomes were assessed: demographics; weight and height; current self-reported comorbidities (Charlson comorbidity index ${ }^{14}$ ); and Forced Expiratory Volume in the first second $\left(F E V_{1}\right)$. FEV 1 was calculated from the flow-volume curve measured by a handheld pulmonary spirometer. ${ }^{15}$ NT-proBNP levels have been measured. NT-proBNP levels equal to or greater than $15 \mathrm{pmol} / \mathrm{L}$ may indicate the presence of $\mathrm{CHF}$ in COPD patients. ${ }^{16}$

Severity of 20 self-perceived physical and psychological symptoms was assessed using a Visual Analogue Scale (VAS) for every symptom. VAS is a horizontal straight line, ranging from 0 (no symptom) to $100 \mathrm{~mm}$ (maximum severity). ${ }^{17}$ The patients had to mark on the line the point that represented the self-perceived severity of the symptom during the previous two weeks. The VAS score has been determined by measuring in millimetres from the left side of the line to the point the patient 
marked. ${ }^{17}$ Symptoms were selected based on previous research. ${ }^{7}$ The initial version of the VAS symptom checklist was reviewed by physician specialists of the project team and a physician specialist who was not involved in the project. Based on their expert opinion, several symptoms were added to the VAS symptom checklist.

In addition to rating severity of symptoms, patients were asked, if they had received symptom-related treatment (response options: 'yes' or 'no') for each reported symptom. Patients who reported that they received symptom-related treatment had to rate their satisfaction with this treatment using VAS. VAS for satisfaction with treatment of the symptom ranged from 0 (not satisfied) to $100 \mathrm{~mm}$ (very satisfied).

In addition, symptoms of anxiety and/or depression were assessed using the Hospital Anxiety and Depression Scale (HADS), a validated and reliable measurement instrument used widely in medically ill patients to screen for clinically relevant symptoms of anxiety and/or depression. ${ }^{18}$ The HADS is divided into an anxiety subscale (HADS-A) and a depression subscale (HADS-D). Total scores for each subscale can range from 0 (=optimal) to 21 (=worst) points. A score equal to or greater than 10 for anxiety and/or depression has been defined as abnormally high and may indicate the presence of clinically relevant symptoms of anxiety and/or depression. $^{18}$

Finally, use of medication, contacts with health care professionals (general practitioner, physician specialist, nurse, and allied health care professionals), use of longterm oxygen therapy, non-invasive positive pressure ventilation, home adaptation and availability of medical aids were assessed using a health care checklist. Satisfaction with medical treatment was assessed using VAS.

The VAS symptom checklist and health care checklist are available from the authors upon request.

\section{Statistics}

All statistics were done using SPSS 17.0 (SPSS Inc. Chicago, IL). Categorical variables are described as frequencies, while continuous variables were tested for normality and are presented as mean and standard deviation (SD) or median and interquartile range (IQR). Categorical variables were compared between patients with COPD and $\mathrm{CHF}$ using Chi square tests. Continuous variables were compared between patients with COPD and CHF using an independent sample $t$ test or Mann-Whitney $U$ test, as appropriate. A priori, a two-sided level of significance has been set at $p \leq 0.05$. $^{19}$ 


\section{Results}

\section{General patient characteristics and comorbidities}

In total, 105 COPD patients and $80 \mathrm{CHF}$ patients were included. The proportion of eligible patients who participated in the study was $62.9 \%$ for COPD and $46.0 \%$ for CHF patients $(p<0.05)$. Participating patients differed from patients who refused participation in some respects. COPD and CHF participants were younger than nonparticipants. Mean age of non-participants was 69.7 (9.7) years for COPD and 78.5 (9.0) years for CHF $(p<0.05)$. In addition, COPD participants had more advanced disease than patients who refused participation. Only $38.7 \%$ of non-participants was classified as GOLD-stage IV ( $p<0.05)$. Finally, CHF participants were more often male (67.5\%) than non-participants $(40.4 \% ; p<0.05)$.

Most COPD patients had very severe COPD (GOLD stage IV, $n=77$ (73.3\%)). CHF patients were mainly classified as NYHA III ( $n=74,92.5 \%)$. COPD patients were younger than CHF patients (Table 5.1). Comorbidities were reported by almost all CHF patients and the majority of COPD patients. The most frequently reported comorbidity was myocardial infarction $(n=51,63.8 \%)$ for $\mathrm{CHF}$ patients and diabetes (without end organ damage; $n=20,19.0 \%$ ) for COPD patients (Table 5.1). Nine COPD patients (8.6\%) reported CHF as co-morbidity, while 47 patients $(46.1 \%)$ had a NTproBNP level equal to or greater than $15 \mathrm{pmol} / \mathrm{L}$, indicating the possible presence of CHF.

\section{Severity of symptoms}

Patients experienced multiple symptoms. The mean number of symptoms with VASscore $>30 \mathrm{~mm}$ (representing moderate severity ${ }^{20}$ ) was comparable for COPD and CHF patients (8.1 (3.7) and 9.1 (3.5), respectively, $p>0.05)$. The number of experienced symptoms did not show a correlation with age $(r=0.04, p=0.64)$. Dyspnea, fatigue and muscle weakness were the most severe symptoms in both diseases (Figure 5.1). The mean VAS score for dyspnea was higher for patients with COPD than CHF $(p<0.05)$. Severe dyspnea (mean VAS score $>54 \mathrm{~mm}^{20}$ ) was reported by $57.1 \%$ of COPD patients. Other important symptoms in both diseases were coughing, sleeplessness, low mood and frequent micturition. Mean VAS scores for panic attacks, anxiety, oedema, mouth problems, muscle cramps, restless legs, angina pectoris and dizziness were below $30 \mathrm{~mm}$ in both COPD and CHF. 
Table 5.1 General patient characteristics and comorbidities

\begin{tabular}{|c|c|c|c|}
\hline & $\begin{array}{l}\text { COPD } \\
(n=105)\end{array}$ & $\begin{array}{l}\text { CHF } \\
(n=80)\end{array}$ & p-value \\
\hline Gender (male), n (\%) & 65 (61.9\%) & $54(67.5 \%)$ & 0.53 \\
\hline Age (years), mean (SD) & $66.3(9.2)$ & $76.2(8.3)$ & $<0.005$ \\
\hline BMI $\left(\mathrm{kg} / \mathrm{m}^{2}\right)$, mean $(\mathrm{SD})^{\mathrm{a}}$ & $26.3(6.7)$ & $28.6(5.6)$ & $<0.005$ \\
\hline Low BMI $\left(<21.0 \mathrm{~kg} / \mathrm{m}^{2}\right), \mathrm{n}(\%)$ & $25(23.8 \%)$ & $6(7.5 \%)$ & 0.01 \\
\hline Obese BMI ( $\left.\geq 30.0 \mathrm{~kg} / \mathrm{m}^{2}\right), \mathrm{n}(\%)$ & $24(22.9 \%)$ & $28(35.0 \%)$ & 0.10 \\
\hline Marital status (married / living with partner), n (\%) & $78(74.3 \%)$ & $45(56.3 \%)$ & 0.02 \\
\hline Current smokers, n (\%) & $26(24.8 \%)$ & $11(13.8 \%)$ & 0.04 \\
\hline Dependent in personal care, $\mathrm{n}(\%)$ & $47(44.8 \%)$ & $48(60.0 \%)$ & 0.06 \\
\hline Self-perceived mobility problems, $n(\%)$ & $89(84.8 \%)$ & $72(90.0 \%)$ & 0.41 \\
\hline $\mathrm{FEV}_{1}(\%$ predicted $)$, mean $(\mathrm{SD})^{\mathrm{a}}$ & $34.1(13.5)$ & $75.5(24.5)$ & $<0.005$ \\
\hline NT-proBNP (pmol/L), mean (SD) ${ }^{a}$ & $48.7(135.0)^{b}$ & $279.9(340.3)^{c}$ & $<0.005$ \\
\hline Charlson index (pts), mean (SD) & $2.5(1.7)$ & $4.4(2.0)$ & $<0.005$ \\
\hline Proportion of patients with $\geq 1$ co-morbidity, $\mathrm{n}(\%)$ & $65(61.9 \%)$ & 77 (96.3\%) & $<0.005$ \\
\hline Myocardial infarction, $\mathrm{n}(\%)$ & $10(9.5 \%)$ & $51(63.8 \%)$ & $<0.005$ \\
\hline Chronic heart failure, $\mathrm{n}(\%)$ & $9(8.6 \%)$ & $80(100 \%)$ & $<0.005$ \\
\hline Peripheral vascular disease, $\mathrm{n}(\%)$ & $10(9.5 \%)$ & $24(30.0 \%)$ & $<0.005$ \\
\hline Cerebrovascular disease, $\mathrm{n}(\%)$ & $8(7.6 \%)$ & $23(28.8 \%)$ & $<0.005$ \\
\hline Dementia, n (\%) & $1(1.0 \%)$ & $1(1.3 \%)$ & 0.85 \\
\hline COPD, n (\%) & $105(100 \%)$ & $29(36.3 \%)$ & $<0.005$ \\
\hline Connective tissue disease, $\mathrm{n}(\%)$ & $9(8.6 \%)$ & $14(17.5 \%)$ & 0.11 \\
\hline Ulcer disease, n (\%) & $13(12.4 \%)$ & $13(16.3 \%)$ & 0.59 \\
\hline Mild liver disease, $\mathrm{n}(\%)$ & $2(1.9 \%)$ & $1(1.3 \%)$ & 0.73 \\
\hline Moderate or severe liver disease, $\mathrm{n}(\%)$ & $1(1.0 \%)$ & $0(0 \%)$ & 0.38 \\
\hline Diabetes, n (\%) & $20(19.0 \%)$ & $16(20.0 \%)$ & 0.87 \\
\hline Diabetes with end organ damage, $\mathrm{n}(\%)$ & $5(4.8 \%)$ & $7(8.8 \%)$ & 0.43 \\
\hline Hemiplegia, n (\%) & $3(2.9 \%)$ & $2(2.5 \%)$ & 0.88 \\
\hline Moderate or severe renal disease, $\mathrm{n}(\%)$ & $4(3.8 \%)$ & $12(15.0 \%)$ & 0.02 \\
\hline Any tumor, leukemia or lymphoma, n (\%) & $18(17.1 \%)$ & $29(36.3 \%)$ & 0.005 \\
\hline Metastatic solid tumor, n (\%) & $2(1.9 \%)$ & $0(0 \%)$ & 0.60 \\
\hline AIDS, n (\%) & $0(0 \%)$ & $0(0 \%)$ & - \\
\hline
\end{tabular}

Values expressed as mean (SD) or number of patients (\%). Abbreviations: BMI= Body Mass Index; $C O P D=$ Chronic Obstructive Pulmonary Disease; $\mathrm{CHF}=$ Chronic Heart Failure; $\mathrm{FEV}_{1}=$ Forced Expiratory Volume in the first second. ${ }^{a}$ non-parametric statistical tests have been used because of skewed data; ${ }^{b} n=102$; ${ }^{c} n=78$.

HADS scores for anxiety were similar between patients with COPD and CHF (mean $5.9(4.5)$ and $5.6(4.3)$, respectively, $p>0.05)$. Also HADS scores for depression were similar between patients with COPD and CHF (mean 6.3 (4.0) and 6.9 (4.0), respectively, $p>0.05)$. Prevalence of clinically relevant symptoms of anxiety was also similar between COPD patients (22.9\%) and CHF patients (16.3\%) ( $p>0.05)$. In addition, prevalence of clinically relevant symptoms of depression was similar for patients with COPD (27.6\%) or CHF (25.0\%) ( $p>0.05)$. 
Figure 5.1 Severity of symptoms
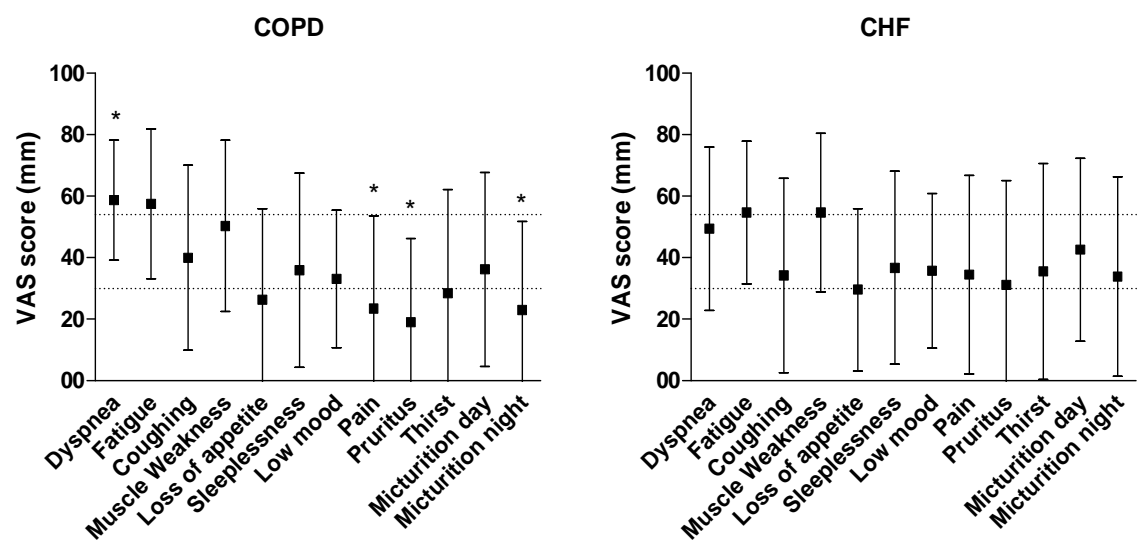

Mean (SD) Visual Analogue Scale (VAS) score of symptoms in patients with advanced Chronic Obstructive Pulmonary Disease (COPD, left panel) and advanced Chronic Heart Failure (CHF, right panel). Mean VAS scores $>30 \mathrm{~mm}$ (dotted line) represent moderate severity while mean VAS scores $>54 \mathrm{~mm}$ (dotted line) represent severe symptom burden. ${ }^{*} \mathrm{p}<0.05$ vs. CHF.

\section{Health care provision}

\section{Medical care}

A considerable number of patients with advanced COPD (45.7\%) and CHF (68.8\%) reported seeing their general practitioner only once a year or less because of their chronic disease $(p<0.05)$. COPD and CHF patients usually had contact with their physician specialist once every 3 months $(42.9 \%$ and $36.3 \%$ of the COPD and CHF patients, respectively) or once every 6 months $(41.9 \%$ and $38.8 \%$ of the COPD and CHF patients, respectively).

Median number of physician prescribed drugs was somewhat higher for CHF patients (10.0 (8.0-13.0)) than for COPD patients (8.0 (5.5-11.0)) ( $p<0.05)$. Prescriptions were mainly for medication to treat the underlying disease, while the use of antidepressants, anxiolytics, analgesics and opioids was relatively low (Table 5.2). A minority of the COPD (20.7\%) and CHF (25.0\%) patients with clinically relevant symptoms of depression used antidepressant drugs $(p>0.05)$. Maintenance oral corticosteroids had been prescribed to $32(30.5 \%)$ of the COPD patients. Of these, 17 patients used bisphosphonate drugs (53.1\%). Long-term oxygen therapy was used by 62 COPD patients (59.0\%). Non-invasive positive pressure ventilation was used by 28 COPD patients (26.7\%). 
Table 5.2 Use of medication

\begin{tabular}{lll}
\hline & COPD & CHF \\
& $(n=105)$ & $(n=80)$ \\
\hline Anticoagulant (oral) & $6(5.7 \%)^{a}$ & $44(55.0 \%)$ \\
Antiplatelet drugs & $23(21.9 \%)^{a}$ & $31(38.8 \%)$ \\
Diuretics & $44(41.9 \%)^{a}$ & $79(98.8 \%)$ \\
ACE-inhibitors/ Angiotensin receptor antagonists & $35(33.3 \%)^{a}$ & $58(72.5 \%)$ \\
Beta-receptor blocker & $15(14.3 \%)^{a}$ & $60(75.0 \%)$ \\
Hypolipidaemic agents & $24(22.9 \%)^{a}$ & $53(66.3 \%)$ \\
Nitrate & $6(5.7 \%)^{a}$ & $40(50.0 \%)$ \\
Calcium channel blockers & $22(21.0 \%)$ & $10(12.5 \%)$ \\
Short-acting $\beta 2-a g o n i s t s$ & $66(62.9 \%)^{a}$ & $16(20.0 \%)$ \\
Long-acting $\beta 2-$ agonists & $88(83.8 \%)^{a}$ & $18(22.5 \%)$ \\
Short-acting Anticholinergics & $55(52.4 \%)^{a}$ & $14(17.5 \%)$ \\
Long-acting Anticholinergics & $56(53.3 \%)^{a}$ & $18(22.5 \%)$ \\
Inhaled steroids & $92(87.6 \%)^{a}$ & $19(23.8 \%)$ \\
Oral corticosteroids (maintenance) & $32(30.5 \%)^{a}$ & $2(2.5 \%)$ \\
Theophylline & $27(25.7 \%)^{a}$ & $4(5.0 \%)$ \\
Bisphosphonate drug & $32(30.5 \%)^{a}$ & $5(6.3 \%)$ \\
Antibiotics (maintenance) & $21(20.0 \%)^{a}$ & $1(1.3 \%)$ \\
Antidepressant & $15(14.3 \%)$ & $11(13.8 \%)$ \\
Anxiolytic/hypnotic & $22(21.0 \%)^{a}$ & $28(35.0 \%)$ \\
Non-opioid analgesics & $10(9.5 \%)$ & $16(20.0 \%)$ \\
Weak opioids (like tramadol) & $5(4.8 \%)$ & $2(2.5 \%)$ \\
Strong opioids (like morphine) & $2(1.9 \%)$ & $4(5.0 \%)$ \\
\hline
\end{tabular}

Values expressed as number of patients (\%). Abbreviations: COPD= Chronic Obstructive Pulmonary Disease; $\mathrm{CHF}=$ Chronic Heart Failure. ${ }^{a} \mathrm{p}<0.05$ vs. CHF.

\section{Care provided by nurse specialist}

Approximately one third of the COPD patients (35.2\%) received care from a respiratory nurse specialist, while the majority of CHF patients in this study (88.8\%) received care from a heart failure nurse specialist. Only a minority of COPD patients $(10.8 \%)$ were visited by their respiratory nurse specialist in their home environment, while $46.5 \%$ of the CHF patients were visited by their heart failure nurse specialist at home. Assistance with personal care was provided by professional caregivers in $21.9 \%$ of COPD patients and $40.0 \%$ of CHF patients $(p<0.05)$. Relatives provided assistance with personal care in $22.9 \%$ of COPD patients and $20.0 \%$ of CHF patients ( $p>0.05)$.

\section{Treatment by allied health care professionals}

In general, involvement of allied health care professionals was low. Physiotherapy was more frequently offered to COPD patients (53.3\%) than to CHF patients $(30.0 \%)$ $(p<0.05)$. Only a few patients received treatment from a dietician, psychologist, social worker or occupational therapist (Figure 5.2). Indeed, 6.9\% of the COPD patients and $10.0 \%$ of the CHF patients with clinically relevant symptoms of depression reported treatment by a psychologist ( $p>0.05)$. 
Figure 5.2 Treatment by allied health care professionals

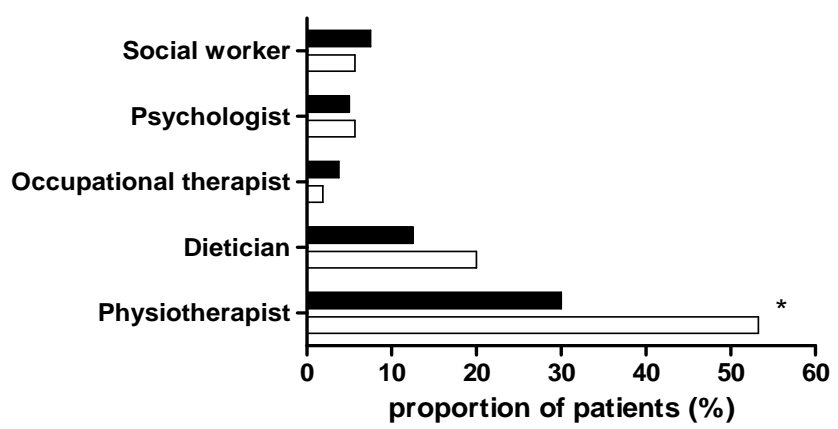

Proportion of patients with advanced Chronic Obstructive Pulmonary Disease (COPD, $\square$ ) and advanced Chronic Heart Failure $(\mathrm{CHF}, \mathbf{a})$ receiving treatment from allied health care professionals. * $\mathrm{p}<0.05$.

\section{Medical aids and home adaptation}

Home adaptation was provided to $61.0 \%$ of COPD patients and $72.5 \%$ of CHF patients ( $p>0.05$ ). Furthermore, $66.7 \%$ of COPD patients and $77.5 \%$ of $\mathrm{CHF}$ patients had medical aids $(p>0.05)$. Adaptations at home most frequently offered were grab bars in bathroom or toilet, while the most frequently provided medical aids were rollators (Table 5.3).

Table 5.3 Provision of home adaptation and aids

\begin{tabular}{lll}
\hline & $\begin{array}{l}\text { COPD } \\
(\mathrm{n}=105)\end{array}$ & $\begin{array}{l}\text { CHF } \\
(\mathrm{n}=80)\end{array}$ \\
\hline Stair lift & $16(15.2 \%)$ & $8(10.0 \%)$ \\
Doorsteps removed & $25(23.8 \%)^{\mathrm{a}}$ & $34(42.5 \%)$ \\
Bath or shower seat & $44(41.9 \%)$ & $38(47.5 \%)$ \\
Grab bars in bathroom or toilet & $41(39.0 \%)^{\mathrm{a}}$ & $49(61.3 \%)$ \\
Rollator & $48(45.7 \%)$ & $43(53.8 \%)$ \\
Cane & $7(6.7 \%)^{\mathrm{a}}$ & $23(28.8 \%)$ \\
Wheelchair & $23(21.9 \%)$ & $18(22.5 \%)$ \\
Scooter & $33(31.4 \%)$ & $19(23.8 \%)$ \\
Toilet chair & $4(3.8 \%)$ & $1(1.3 \%)$ \\
Raised toilet seat & $14(13.3 \%)$ & $12(15.0 \%)$ \\
Tripple chair & $4(3.8 \%)$ & $3(3.8 \%)$ \\
Lift chair & $5(4.8 \%)^{\mathrm{a}}$ & $16(20.0 \%)$ \\
Bed positioning aids & $1(1.0 \%)^{\mathrm{a}}$ & $5(6.3 \%)$ \\
Helping hand & $2(1.9 \%)$ & $2(2.5 \%)$ \\
\hline
\end{tabular}

Values expressed as number of patients (\%). Abbreviations: COPD= Chronic Obstructive Pulmonary Disease; $\mathrm{CHF}=$ Chronic Heart Failure. ${ }^{a} \mathrm{p}<0.05$ vs. CHF. 


\section{Satisfaction with treatment}

In general, patients were satisfied with the medical treatment they received for their COPD (median VAS score 78mm (71-85)) or CHF (median VAS score 80mm (7293)) ( $p>0.05)$. However, despite the fact that many patients suffered from multiple symptoms, for most symptoms only a minority of patients were aware of symptomrelated interventions. Furthermore, patients who reported symptom-related interventions were only moderately satisfied with these interventions (Table 5.4).

\section{Discussion}

\section{Key findings}

The present study shows that comorbidities are highly prevalent in patients with advanced COPD or CHF. Furthermore, patients with advanced COPD or CHF experience multiple symptoms. Attention for symptom management for these patients seems to be limited in current Dutch health care.

\section{Comorbidities}

The majority of clinically stable outpatients with advanced COPD or CHF report comorbidities. The high prevalence of COPD in CHF patients in the present study is in line with previous findings of Buist and colleagues who showed high prevalence of COPD in the general elderly population. ${ }^{21}$ The mean $\mathrm{FEV}_{1}$ of $\mathrm{CHF}$ patients shown in this study is in line with previous findings. ${ }^{22}$ While only a few COPD patients report CHF as comorbidity, NT-proBNP levels suggest that about half of the patients with advanced COPD may have CHF. The concurrent existence of CHF in COPD patients has been shown before in elderly COPD patients. ${ }^{10}$ This study shows that in patients with advanced COPD or CHF regular assessment of comorbidities is necessary.

\section{Symptom distress and health care provision}

Patients suffered from multiple symptoms including dyspnea, fatigue, muscle weakness, coughing, low mood, sleeplessness and frequent micturition. The fact that fatigue and dyspnea are distressing symptoms in advanced COPD or CHF is in line with previous findings. 5, 6, 23 


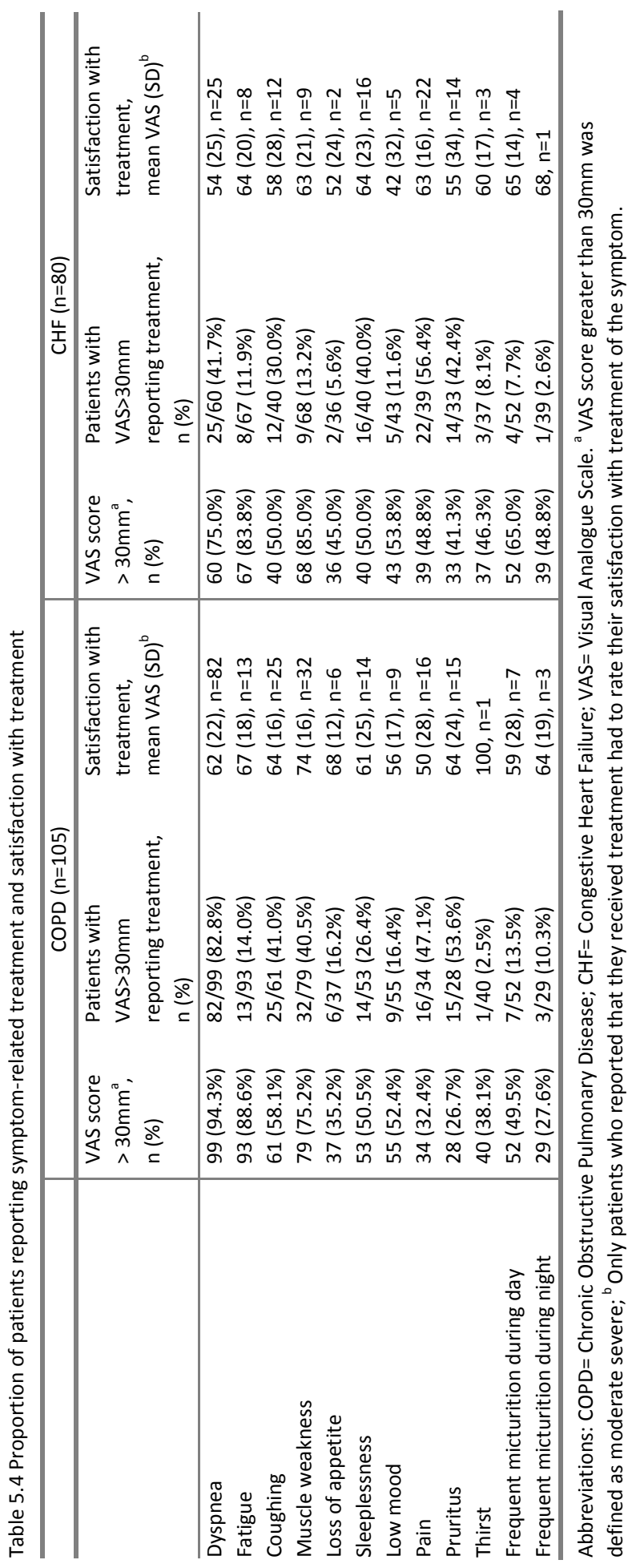


Previously, the retrospective study of Elkington and colleagues suggested that health care is blind to the palliative care needs of COPD patients. ${ }^{8}$ The present prospective study shows that patients with advanced COPD or CHF suffer from multiple symptoms, while attention for symptom management seems to be limited. While in general patients are satisfied with their medical treatment, symptom distress is high and for most symptoms only a small minority of patients report that their symptoms are addressed. Furthermore, if symptoms are addressed, patients only report moderate satisfaction with symptom treatment. Therefore, the present study confirms the previous findings of Elkington and colleagues in advanced COPD and CHF.

A majority of the patients had infrequent contact with their general practitioner for their chronic disease. The infrequent general practitioner contact of the current sample suggest that general practitioners do not offer these patients treatment with an integrative and anticipatory approach. Therefore, it's unlikely that management of these patients in primary care focuses on prevention and early recognition and treatment of physical, psychosocial and spiritual problems.

Only a few patients used medication for palliation of symptoms, like opioids. Although use of opioids for treatment of severe dyspnea in COPD is recommended in the most recent Official American Thoracic Society Clinical Policy Statement: Palliative Care for Patients with Respiratory Diseases and Critical Illnesses, ${ }^{24}$ in the present study only $1.9 \%$ of COPD patients used strong opioids like morphine while $57.1 \%$ reported severe dyspnea. Au and colleagues have shown in a retrospective study that only $25 \%$ of COPD patients in their last six months of life received opioids, while $49 \%$ of patients with lung cancer received opioids in their last six months of life. ${ }^{25}$ Randomized controlled trials regarding the use of opioids for the palliation of severe dyspnea in advanced COPD or CHF are scarce ${ }^{26-28}$ and further research is needed to determine which patients should get opioids prescribed to treat their dyspnea. ${ }^{29}$

Previous studies have shown that symptoms of depression are frequently under treated in patients with COPD. ${ }^{30,31}$ This is supported by the present study. Only a minority of the patients with advanced COPD or CHF reporting clinically relevant symptoms of depression received counseling by a psychologist or used antidepressant drugs. In patients with clinically relevant symptoms of depression, further assessment is warranted to identify those patients needing medical treatment for a depression. $^{31}$

Almost one third of the COPD patients used maintenance systemic corticosteroids which is not in line with the currently available guidelines for management of COPD. ${ }^{32}$ Physicians should pay careful attention to the use of maintenance oral 
corticosteroids. Indeed, systemic corticosteroids have been shown to be associated with lower limb muscle weakness and increased mortality risk. ${ }^{33,34}$

Care needs of patients with advanced COPD or CHF demand an interdisciplinary approach. ${ }^{3,24}$ Nevertheless, this study shows limited involvement of allied health care professionals. Provision of physiotherapy is highest for COPD patients, probably reflecting the Dutch physiotherapy guidelines for COPD. ${ }^{35}$ However, symptoms such as muscle weakness and fatigue are also frequently reported by CHF patients, but only a minority of these patients are treated by a physiotherapist. This probably reflects a need for physical exercise training in patients with advanced $\mathrm{CHF}^{36,37}$

\section{Limitations of the present study}

The study population consisted of a convenience sample of patients. While the majority of eligible COPD patients were willing to participate, the response rate for CHF patients was below $50 \%$. The current response rate confirms the previously reported difficulty of recruitment of older patients with $\mathrm{CHF}^{38}$ and may limit the generalizability of the results. In addition, some differences were present between patients with COPD and CHF, which could have influenced the results of this study. Although age differences in this study are statistically significant, the clinical relevance for the present study may be limited, as is shown by the lack of correlation between number of experienced symptoms and age. There is no consensus about standardization of symptom assessment in palliative medicine and multiple instruments are available. ${ }^{39}$ We have chosen the use of VAS to assess severity of symptoms because of the previously shown validity, test-retest reliability and clinical utility. ${ }^{17,40}$ Furthermore, VAS is continuous, approximates a ratio scale, and is more independent from language than verbal scales. ${ }^{41}$ However, the choice of the instrument might have influenced the results of this study. Finally, the present study is a cross-sectional study and symptom distress and health care provision are likely to change during the course of the disease. A longitudinal follow-up is needed to know how symptom distress and health care provision change over time in patients with advanced COPD or CHF.

\section{Conclusions and implications}

Patients with advanced COPD or CHF suffer from comorbidities and multiple symptoms. For most symptoms, only a minority of patients are aware of symptomrelated interventions such as symptom-related medication and treatment by allied health care professionals. If treated, patients are only moderately satisfied with symptom treatment. While recent statements concerning palliative care for patients with COPD or CHF describe the need for offering palliative care concurrently with 
curative-restorative treatment during the course of the disease to adequately address symptoms and improve or maintain quality of life, ${ }^{3,24}$ the degree to which symptom management is addressed in current Dutch health care is limited. Further development and implementation of palliative care programs which consist of regular assessment of the patients' comorbidities and symptom distress is warranted. Future studies should assess the value of specialized interdisciplinary teams providing patient-tailored care to patients with advanced COPD or CHF. 


\section{References}

1. Murray, C.J. and A.D. Lopez, Alternative projections of mortality and disability by cause 1990-2020: Global Burden of Disease Study. Lancet. 1997;349(9064):1498-504.

2. Curtis, J.R., Palliative and end-of-life care for patients with severe COPD. Eur Respir J. 2008;32(3):796-803.

3. Jaarsma, T., J.M. Beattie, M. Ryder, F.H. Rutten, T. McDonagh, P. Mohacsi, S.A. Murray, T. Grodzicki, I. Bergh, M. Metra, I. Ekman, C. Angermann, M. Leventhal, A. Pitsis, S.D. Anker, A. Gavazzi, P. Ponikowski, K. Dickstein, E. Delacretaz, L. Blue, F. Strasser, and J. McMurray, Palliative care in heart failure: a position statement from the palliative care workshop of the Heart Failure Association of the European Society of Cardiology. Eur J Heart Fail. 2009;11(5):433-43.

4. Bausewein, C., S. Booth, M. Gysels, R. Kuhnbach, B. Haberland, and I.J. Higginson, Understanding breathlessness: cross-sectional comparison of symptom burden and palliative care needs in chronic obstructive pulmonary disease and cancer. J Palliat Med. 2010 13(9):1109-18.

5. Blinderman, C.D., P. Homel, J. Andrew Billings, S. Tennstedt, and R.K. Portenoy, Symptom Distress and Quality of Life in Patients with Advanced Chronic Obstructive Pulmonary Disease. J Pain Symptom Manage. 2009;38(1):115-23.

6. Blinderman, C.D., P. Homel, J.A. Billings, R.K. Portenoy, and S.L. Tennstedt, Symptom distress and quality of life in patients with advanced congestive heart failure. J Pain Symptom Manage. 2008;35(6):594-603.

7. Janssen, D.J., M.A. Spruit, E.F. Wouters, and J.M. Schols, Daily symptom burden in end-stage chronic organ failure: a systematic review. Palliat Med. 2008;22(8):938-48.

8. Elkington, H., P. White, J. Addington-Hall, R. Higgs, and P. Edmonds, The healthcare needs of chronic obstructive pulmonary disease patients in the last year of life. Palliat Med. 2005;19(6):485-91.

9. Yohannes, A.M., J. Roomi, and M.J. Connolly, Elderly people at home disabled by chronic obstructive pulmonary disease. Age Ageing. 1998;27(4):523-5.

10. Rutten, F.H., M.J. Cramer, D.E. Grobbee, A.P. Sachs, J.H. Kirkels, J.W. Lammers, and A.W. Hoes, Unrecognized heart failure in elderly patients with stable chronic obstructive pulmonary disease. Eur Heart J. 2005;26(18):1887-94.

11. Sin, D.D., N.R. Anthonisen, J.B. Soriano, and A.G. Agusti, Mortality in COPD: Role of comorbidities. Eur Respir J. 2006;28(6):1245-57.

12. Janssen, D.J., E.F. Wouters, J.M. Schols, and M.A. Spruit, Self-perceived symptoms and care needs of patients with severe to very severe chronic obstructive pulmonary disease, congestive heart failure or chronic renal failure and its consequences for their closest relatives: the research protocol. BMC Palliat Care. 2008;7:5.

13. Janssen, D.J., M.A. Spruit, J.M. Schols, and E.F. Wouters, A call for high-quality advance care planning in outpatients with severe COPD or chronic heart failure. Chest. 2011;139(5):1081-88.

14. Charlson, M.E., P. Pompei, K.L. Ales, and C.R. MacKenzie, A new method of classifying prognostic comorbidity in longitudinal studies: development and validation. J Chronic Dis. 1987;40(5):373-83.

15. Standardization of Spirometry, 1994 Update. American Thoracic Society. Am J Respir Crit Care Med. 1995;152(3):1107-36.

16. Rutten, F.H., M.J. Cramer, N.P. Zuithoff, J.W. Lammers, W. Verweij, D.E. Grobbee, and A.W. Hoes, Comparison of B-type natriuretic peptide assays for identifying heart failure in stable elderly patients with a clinical diagnosis of chronic obstructive pulmonary disease. Eur J Heart Fail. 2007;9(6-7):6519.

17. Jensen, M.P., P. Karoly, and S. Braver, The measurement of clinical pain intensity: a comparison of six methods. Pain. 1986;27(1):117-26.

18. Zigmond, A.S. and R.P. Snaith, The hospital anxiety and depression scale. Acta Psychiatr Scand. 1983;67(6):361-70. 
19. Altman, D.G., S.M. Gore, M.J. Gardner, and S.J. Pocock, Statistical guidelines for contributors to medical journals. Br Med J (Clin Res Ed). 1983;286(6376):1489-93.

20. Collins, S.L., R.A. Moore, and H.J. McQuay, The visual analogue pain intensity scale: what is moderate pain in millimetres? Pain. 1997;72(1-2):95-7.

21. Buist, A.S., M.A. McBurnie, W.M. Vollmer, S. Gillespie, P. Burney, D.M. Mannino, A.M. Menezes, S.D. Sullivan, T.A. Lee, K.B. Weiss, R.L. Jensen, G.B. Marks, A. Gulsvik, and E. Nizankowska-Mogilnicka, International variation in the prevalence of COPD (the BOLD Study): a population-based prevalence study. Lancet. 2007;370(9589):741-50.

22. Witte, K.K. and A.L. Clark, Beta-blockers and inspiratory pulmonary function in chronic heart failure. J Card Fail. 2005;11(2):112-6.

23. Falk, K., H. Patel, K. Swedberg, and I. Ekman, Fatigue in patients with chronic heart failure - a burden associated with emotional and symptom distress. Eur J Cardiovasc Nurs. 2009;8(2):91-6.

24. Lanken, P.N., P.B. Terry, H.M. Delisser, B.F. Fahy, J. Hansen-Flaschen, J.E. Heffner, M. Levy, R.A. Mularski, M.L. Osborne, T.J. Prendergast, G. Rocker, W.J. Sibbald, B. Wilfond, and J.R. Yankaskas, An official American Thoracic Society clinical policy statement: palliative care for patients with respiratory diseases and critical illnesses. Am J Respir Crit Care Med. 2008;177(8):912-27.

25. Au, D.H., E.M. Udris, S.D. Fihn, M.B. McDonell, and J.R. Curtis, Differences in health care utilization at the end of life among patients with chronic obstructive pulmonary disease and patients with lung cancer. Arch Intern Med. 2006;166(3):326-31.

26. Johnson, M.J., T.A. McDonagh, A. Harkness, S.E. McKay, and H.J. Dargie, Morphine for the relief of breathlessness in patients with chronic heart failure--a pilot study. Eur J Heart Fail. 2002;4(6):753-6.

27. Abernethy, A.P., D.C. Currow, P. Frith, B.S. Fazekas, A. McHugh, and C. Bui, Randomised, double blind, placebo controlled crossover trial of sustained release morphine for the management of refractory dyspnoea. BMJ. 2003;327(7414):523-8.

28. Poole, P.J., A.G. Veale, and P.N. Black, The effect of sustained-release morphine on breathlessness and quality of life in severe chronic obstructive pulmonary disease. Am J Respir Crit Care Med. 1998;157(6 Pt 1):1877-80.

29. Currow, D.C., J. Plummer, P. Frith, and A.P. Abernethy, Can we predict which patients with refractory dyspnea will respond to opioids? J Palliat Med. 2007;10(5):1031-6.

30. Lacasse, Y., L. Rousseau, and F. Maltais, Prevalence of depressive symptoms and depression in patients with severe oxygen-dependent chronic obstructive pulmonary disease. J Cardiopulm Rehabil. 2001;21(2):80-6.

31. Janssen, D.J., M.A. Spruit, C. Leue, C. Gijsen, H. Hameleers, J.M. Schols, and E.F. Wouters, Symptoms of anxiety and depression in COPD patients entering pulmonary rehabilitation. Chron Respir Dis. 2010;7(3):147-57.

32. Rabe, K.F., S. Hurd, A. Anzueto, P.J. Barnes, S.A. Buist, P. Calverley, Y. Fukuchi, C. Jenkins, R. Rodriguez-Roisin, C. van Weel, and J. Zielinski, Global strategy for the diagnosis, management, and prevention of chronic obstructive pulmonary disease: GOLD executive summary. Am J Respir Crit Care Med. 2007;176(6):532-55.

33. Decramer, M., L.M. Lacquet, R. Fagard, and P. Rogiers, Corticosteroids contribute to muscle weakness in chronic airflow obstruction. Am J Respir Crit Care Med. 1994;150(1):11-6.

34. Schols, A.M., G. Wesseling, A.D. Kester, G. de Vries, R. Mostert, J. Slangen, and E.F. Wouters, Dose dependent increased mortality risk in COPD patients treated with oral glucocorticoids. Eur Respir J. 2001;17(3):337-42.

35. Langer, D., E. Hendriks, C. Burtin, V. Probst, C. van der Schans, W. Paterson, M. Verhoef-de Wijk, R. Straver, M. Klaassen, T. Troosters, M. Decramer, V. Ninane, P. Delguste, J. Muris, and R. Gosselink, A clinical practice guideline for physiotherapists treating patients with chronic obstructive pulmonary disease based on a systematic review of available evidence. Clin Rehabil. 2009;23(5):445-62.

36. Spruit, M.A., R.M. Eterman, V.A. Hellwig, P.P. Janssen, E.F. Wouters, and N.H. Uszko-Lencer, Effects of moderate-to-high intensity resistance training in patients with chronic heart failure. Heart. 2009;95(17):1399-408. 
37. Rees, K., R.S. Taylor, S. Singh, A.J. Coats, and S. Ebrahim, Exercise based rehabilitation for heart failure. Cochrane Database Syst Rev. 2004(3):CD003331.

38. Barnes, S., M. Gott, S. Payne, C. Parker, D. Seamark, S. Gariballa, and N. Small, Recruiting older people into a large, community-based study of heart failure. Chronic Illn. 2005;1(4):321-9.

39. Kirkova, J., D. Walsh, M. Russel, K. Hauser, and W. Lasheen, Symptom assessment in palliative medicine: complexities and challenges. Am J Hosp Palliat Care. 2010;27(1):75-83.

40. Dorman, S., A. Byrne, and A. Edwards, Which measurement scales should we use to measure breathlessness in palliative care? A systematic review. Palliat Med. 2007;21(3):177-91.

41. Caraceni, A., N. Cherny, R. Fainsinger, S. Kaasa, P. Poulain, L. Radbruch, and F. De Conno, Pain measurement tools and methods in clinical research in palliative care: recommendations of an Expert Working Group of the European Association of Palliative Care. J Pain Symptom Manage. 2002;23(3):239-55. 


\section{CHAPTER 6}

Impaired health status and care dependency in patients with advanced COPD or chronic heart failure

Daisy J.A. Janssen, Frits M.E. Franssen, Emiel F.M. Wouters, Jos M.G.A. Schols and Martijn A. Spruit

Qual Life Res, 2011. 20 (10): 1679-88. 


\section{Abstract}

\section{Purpose}

Aims of this cross-sectional study were to assess health status and care dependency in patients with advanced chronic obstructive pulmonary disease (COPD) or chronic heart failure (CHF) and to identify correlates of an impaired health status.

\section{Methods}

The following outcomes were assessed in outpatients with advanced COPD $(n=105)$ or CHF $(n=80)$ : clinical characteristics; general health status (EuroQol-5 Dimensions (EQ-5D); Assessment of Quality of Life instrument (AQoL); Medical Outcomes Study 36-Item Short-Form Health Survey (SF-36)); disease-specific health status (St. Georges Respiratory Questionnaire (SGRQ), Minnesota Living with Heart Failure Questionnaire (MLHFQ)); physical mobility (timed 'Up and Go' test); and care dependency (Care Dependency Scale).

\section{Results}

Patients with advanced COPD or CHF have an impaired health status and may be confronted with care dependency. Multiple regression analyses have shown that physical and psychological symptoms, care dependency and number of drugs were correlated with impaired health status in advanced COPD or CHF, while demographic and clinical characteristics like age, gender, disease severity and comorbidities were not correlated.

\section{Conclusions}

Clinical care should regularly assess symptom burden and care dependency to identify patients with advanced COPD or CHF at risk for an impaired health status. 


\section{Introduction}

Patient's self-reported health status, defined as the impact of health on a person's ability to perform and derive fulfilment from the activities of daily life, is an important outcome. ${ }^{1}$ Patients with advanced chronic obstructive pulmonary disease (COPD) and chronic heart failure (CHF) often have an impaired health status. ${ }^{2,3}$ Previous studies suggest that health status of patients with advanced COPD or CHF is equally or even more affected than health status of patients with incurable cancer. ${ }^{4,5}$ Furthermore, a decreased disease-specific health status is associated with reduced rates of survival in COPD and $\mathrm{CHF}^{6-8}$

Management plans of patients with advanced COPD or CHF should strive to optimize daily functioning and stabilize disease-specific health status. ${ }^{9-11}$ Identifying clinical correlates of an impaired health status may allow clinicians to better monitor health status and intervene more effectively in patients with advanced COPD or CHF. Several correlates of diminished general or disease-specific health status in COPD or CHF have been suggested before, like gender, age, educational level, symptoms, psychological symptoms, disease severity, body mass index (BMI), comorbidities, smoking status and number of physician-prescribed drugs. ${ }^{2,3,12-19}$ However, currently available literature does not provide definitive evidence; hence, it is still unknown whether and to what extent these clinical correlates are interrelated in advanced COPD or CHF.

Health status includes patient's self-reported quality of life and functional status. ${ }^{1}$ Functional impairment may have significant consequences for patients and their families, such as social isolation of the patient and their loved ones in the case of impaired mobility. ${ }^{20,21}$ One observational study showed that patients with COPD or CHF admitted to the hospital may experience disability in basic and instrumental activities of daily living. ${ }^{22}$ Impairment in the ability to perform normal daily tasks can lead to patients becoming dependent on caregivers. ${ }^{20}$ A qualitative study of patients with end-stage COPD, CHF or renal disease and their family caregivers showed that increased dependency may lead to frustration, depression and social isolation and increases the burden on family caregivers. ${ }^{20}$ Finally, there is some suggestion that care dependency is associated with increased mortality in patients hospitalized for an acute exacerbation of COPD. ${ }^{8}$ However, quantitative studies comparing care dependency in clinically stable outpatients with advanced COPD or CHF are lacking. Moreover, it remains unknown whether and to what extent care dependency and health status are interrelated in patients with advanced COPD or CHF.

Aims of this cross-sectional study were to assess health status and care dependency in patients with advanced COPD or CHF and to identify correlates of impaired health 
status. The present authors hypothesized a priori that care dependency is an important correlate of general and disease-specific health status in patients with advanced COPD or CHF, irrespective of the underlying disease.

\section{Methods}

\section{Design}

This cross-sectional study is part of a longitudinal study concerning self-perceived symptoms and care needs in patients with severe to very severe COPD or CHF and the consequences for their closest relatives. ${ }^{23}$ Details of the methodology of this study and data on advance care planning and symptom burden have been published before. $^{23-25}$ The study was registered at the Dutch Trial Register (NTR 1552).

\section{Study population}

Patients with advanced COPD or CHF were recruited by their physician specialist during an outpatient consultation of one academic and five general hospitals in the Netherlands in 2008 and 2009. Patients were eligible if they had a diagnosis of advanced COPD (Global initiative for chronic Obstructive Lung Disease (GOLD) stage III or IV) or CHF (New York Heart Association (NYHA) class III or IV). For patients who were referred for the study but refused participation, data like severity of their disease, age and gender were collected to compare characteristics of participating and non-participating patients. All participating patients gave written informed consent. The Medical Ethical Commission of the Maastricht University Medical Centre + (MUMC+), Maastricht, the Netherlands, approved this study (MEC 07-3-054).

\section{Instruments}

Patients were visited by a member of the research team in their home environment. The following outcomes were assessed: demographics; weight and height; selfreported co-morbidities (Charlson comorbidity inde ${ }^{26}{ }^{2}$ ); current medication; and forced expiratory volume in the first second $\left(\mathrm{FEV}_{1}\right)$. $\mathrm{FEV}_{1}$ was calculated from the flow-volume curve measured by a handheld pulmonary spirometer. ${ }^{27}$ Symptoms in the previous 2 weeks were assessed using visual analogue scales (VAS). ${ }^{23,24}$ Severity of dyspnea was measured using the modified Borg scale (range 0 (nothing at all) to 10 (maximal)). ${ }^{28}$ Symptoms of anxiety and depression were studied using the Hospital Anxiety and Depression Scale (HADS). ${ }^{29}$ The HADS is divided into an anxiety subscale (HADS-A) and a depression subscale (HADS-D). Total scores for each subscale range from 0 (optimal) to 21 (worst) points. 


\section{General health status}

General health status was assessed using the self-administered questionnaires EuroQol-5 Dimensions (EQ-5D) ${ }^{30}$, Assessment of Quality of Life instrument (AQoL) ${ }^{31}$ and the Medical Outcomes Study 36-Item Short-Form Health Survey (SF-36) ${ }^{32}$.

EQ-5D is a five-item questionnaire consisting of mobility, self-care, usual activity, pain/discomfort and anxiety/depression. ${ }^{30}$ Each item has three levels: no problems, some problems and extreme problems. An index score is provided which ranges from -0.59 (worst) to 1.0 (best). ${ }^{30}$ In addition, patients rated their current health using VAS. VAS scores range from 0 (death or worst possible health) to 100 (best possible health).

AQoL consists of 15 items divided into five domains: illness; independent living; social relationships; physical senses; and psychological well-being. ${ }^{31}$ Total score ranges from -0.04 (worst) to +1.00 (best). ${ }^{33}$

SF-36 consists of 36 items divided into eight domains: physical functioning; rolephysical; bodily pain; general health; vitality; social functioning; role-emotional; and mental health. For each domain, scores range from 0 (worst) to 100 points (best). ${ }^{32}$ A physical component summary measure and mental component summary measure are provided using norm-based methods with scores from a Dutch general population. ${ }^{34}$ These summary measure scores are transformed to make a minimum and maximum possible score of 0 and 100 points. All scores below 50 points can be interpreted as below the general population norm. ${ }^{32}$

\section{Disease-specific health status}

Disease-specific health status was assessed in COPD patients using the St. Georges Respiratory Questionnaire (SGRQ). ${ }^{35}$ SGRQ provides three domain scores (symptoms; activities; and impact) and a total score, ranging from 0 (optimal) to 100 points (worst). ${ }^{35}$

In CHF patients, disease-specific health status was assessed using the Minnesota Living with Heart Failure Questionnaire (MLHFQ). ${ }^{36}$ MLHFQ consists of two domains: physical (ranges from 0 (best) to 40 points (worst)) and emotional (ranges from 0 (best) to 25 points (worst)). Total score ranges from 0 (best) to 105 points (worst). ${ }^{36}$ A total score $>45$ points is defined as poor health status, 24 to 45 points as moderate health status, while $<24$ points represents good health status. ${ }^{37}$ 


\section{Physical mobility}

Physical mobility was assessed using the timed 'Up and Go' (TUG) test. ${ }^{38}$ TUG test measures in seconds the time needed to stand up from a chair, walk a distance of three metres, turn and walk back to the chair and sit down again. ${ }^{38}$

\section{Care dependency}

Care dependency was assessed using the Care Dependency Scale (CDS). CDS consists of 15 items regarding basic and instrumental activities of daily living, like personal care, household activities, social and recreational activities. ${ }^{39}$ The score ranges from 15 (worst) to 75 points (best). Patients with a CDS score $\leq 68$ points are considered as care dependent. ${ }^{40}$

\section{Statistics}

Categorical variables are described as frequencies, while continuous variables have been tested for normality and are presented as mean and standard deviation (SD) or median and inter-quartile range (IQR). Categorical variables were compared between patients with COPD and CHF using Chi-square test. Continuous variables were compared between patients with COPD and CHF using independent sample $T$-test or Mann-Whitney $U$ test, as appropriate. CDS score was compared between COPD and $\mathrm{CHF}$ after adjusting for age, gender, BMI and Charlson comorbidity index score using linear regression analysis with robust standard errors. To study correlates of general and disease-specific health status, multiple regression analysis models were developed for EQ-5D index score; AQoL total score; SGRQ total score; and MLHFQ total score. The following possible variables were tested for correlation with the dependent variables: age, gender, disease, Charlson comorbidity index score, FEV $1, \mathrm{BMI}$, smoking status, marital status, level of education, modified Borg scale, number of self-perceived symptoms with VAS score greater than $30 \mathrm{~mm}$, long-term oxygen therapy (LTOT), TUG score, HADS-A score, HADS-D score, CDS score, presence of a family caregiver, need for assistance with personal care by a professional caregiver and the number of physician-prescribed drugs. The variables that showed bivariate correlation with the dependent variables (Pearson correlation coefficient $>0.30$ ) were entered as independent variables in the standard multiple regression analysis models. Statistical analyses were performed using SPSS 17.0. STATA 11.1 was used for linear regression with robust standard errors. A priori, a two-sided level of significance was set at $\mathrm{p} \leq 0.05$. $^{41}$ 


\section{Results}

\section{General patient characteristics}

In total, 105 COPD patients and $80 \mathrm{CHF}$ patients were included. The proportion of eligible patients who participated in the study was $62.9 \%$ for COPD and $46.0 \%$ for CHF patients, $p<0.05$. Most COPD patients had very severe COPD (GOLD stage IV: $n=77,73.3 \%)$. CHF patients were mainly classified as NYHA III ( $n=74,92.5 \%)$. On average, CHF patients were older and more often living alone than COPD patients (Table 6.1).

Table 6.1 Patient characteristics

\begin{tabular}{lll}
\hline & $\begin{array}{l}\text { COPD } \\
(\mathrm{n}=105)\end{array}$ & $\begin{array}{l}\mathrm{CHF} \\
(\mathrm{n}=80)\end{array}$ \\
\hline Gender (male), $\mathrm{n}(\%)$ & $65(61.9 \%)$ & $54(67.5 \%)$ \\
Age (years), mean (SD) & $66.3(9.2)^{*}$ & $76.2(8.3)$ \\
BMI (kg/m2), mean (SD) & $26.3(6.7)^{*}$ & $28.6(5.6)$ \\
Marital status (married/living with partner), $\mathrm{n}(\%)$ & $78(74.3 \%)^{*}$ & $45(56.3 \%)$ \\
Current smokers, $\mathrm{n}(\%)$ & $26(24.8 \%)^{*}$ & $11(13.8 \%)$ \\
FEV1 (\% predicted), mean (SD) & $34.1(13.5)^{*}$ & $75.5(24.5)$ \\
Charlson index (pts), mean (SD) & $2.5(1.7)^{*}$ & $4.4(2.0)$ \\
Long-term oxygen therapy, $\mathrm{n}(\%)$ & $62(59.0 \%)^{*}$ & $10(12.5 \%)$ \\
Need for professional caregiver, $\mathrm{n}(\%)$ & $23(21.9 \%)^{*}$ & $32(40.0 \%)$ \\
Family caregiver, $\mathrm{n}$ (\%) & $90(85.7 \%)$ & $61(76.3 \%)$ \\
Number of symptoms, mean (SD) & $8.1(3.7)$ & $9.1(3.5)$ \\
Borg scale (points), mean (SD) & $4.8(2.0)^{*}$ & $4.0(2.5)$ \\
HADS-A score (points), mean (SD) & $5.9(4.5)$ & $5.6(4.3)$ \\
HADS-D score (points), mean (SD) & $6.3(4.0)$ & $6.9(4.0)$ \\
Number of physician prescribed drugs, mean (SD) & $8.5(3.9)^{*}$ & $10.8(3.7)$ \\
\hline
\end{tabular}

Abbreviations: $\mathrm{BMI}=$ Body Mass Index; $\mathrm{COPD}=$ Chronic Obstructive Pulmonary Disease; $\mathrm{CHF}=$ Chronic Heart Failure; $\mathrm{FEV}_{1}=$ Forced Expiratory Volume in the first second; HADS-A= Hospital Anxiety and Depression Scale, Anxiety subscale; HADS-D = Hospital Anxiety and Depression Scale, Depression subscale. ${ }^{*} p<0.05$; ${ }^{*}$ non-parametric statistical tests were used because of skewed data.

Participating patients differed from patients who refused participation in some respects. COPD and CHF participants were younger than non-participants. Mean age of non-participants was 69.7 (9.7) years for COPD and 78.5 (9.0) years for CHF, $\mathrm{p}<0.05$. In addition, COPD participants had more advanced disease than patients who refused participation. Only $38.7 \%$ of non-participants was classified as GOLDstage IV, $p<0.05$. Finally, CHF participants were more often men compared to nonparticipants $(40.4 \%), p<0.05$. 


\section{General health status}

General health status was considerably impaired in patients with advanced COPD or CHF. Indeed, mean (SD) EQ-5D index score was 0.51 (0.33) for COPD patients and 0.47 (0.32) for CHF patients, $p>0.05$. A higher proportion of CHF compared to COPD patients reported problems regarding pain/discomfort (Table 6.2).

Table 6.2 General health status assessed with EuroQol-5 Dimensions (EQ-5D)

\begin{tabular}{|c|c|c|c|}
\hline & & $\begin{array}{l}\text { COPD } \\
(n=105)\end{array}$ & $\begin{array}{l}\text { CHF } \\
(n=80)\end{array}$ \\
\hline EQ-5D index score, mean (SD) & & $0.51(0.33)$ & $0.47(0.32)$ \\
\hline EQ-5D VAS, mean (SD) ${ }^{\#}$ & & $62.6(14.0)$ & $62.1(13.5)$ \\
\hline \multirow[t]{3}{*}{ EQ-5D Mobility, n (\%) } & No problems & $16(15.2 \%)$ & $8(10.0 \%)$ \\
\hline & Some problems & $87(82.9 \%)$ & $69(86.2 \%)$ \\
\hline & Extreme problems & $2(1.9 \%)$ & $3(3.8 \%)$ \\
\hline \multirow[t]{3}{*}{ EQ-5D Self care, n (\%) } & No problems & $43(41.0 \%)$ & $27(33.8 \%)$ \\
\hline & Some problems & $50(47.6 \%)$ & $38(47.4 \%)$ \\
\hline & Extreme problems & $12(11.4 \%)$ & $15(18.8 \%)$ \\
\hline \multirow[t]{3}{*}{ EQ-5D Usual activities, n (\%) } & No problems & $18(17.1 \%)$ & $12(15.0 \%)$ \\
\hline & Some problems & $61(58.1 \%)$ & $50(62.5 \%)$ \\
\hline & Extreme problems & $26(24.8 \%)$ & $18(22.5 \%)$ \\
\hline \multirow[t]{3}{*}{ EQ-5D Pain/discomfort*, n (\%) } & No problems & $57(54.3 \%)$ & $29(36.2 \%)$ \\
\hline & Some problems & $38(36.2 \%)$ & $43(53.8 \%)$ \\
\hline & Extreme problems & $10(9.5 \%)$ & $8(10.0 \%)$ \\
\hline \multirow[t]{3}{*}{ EQ-5D Anxiety/depression, n (\%) } & No problems & $62(59.1 \%)$ & $44(55.0 \%)$ \\
\hline & Some problems & $33(31.4 \%)$ & $29(36.2 \%)$ \\
\hline & Extreme problems & 10 (9.5\%) & $7(8.8 \%)$ \\
\hline
\end{tabular}

Abbreviations: $\mathrm{COPD}=$ Chronic Obstructive Pulmonary Disease; $\mathrm{CHF}=$ Congestive Heart Failure; $\mathrm{EQ} 5 \mathrm{D}=$ EuroQol-5 Dimensions; VAS= Visual Analogue Scale. ${ }^{*} \mathrm{p}<0.05 ;{ }^{*}$ non-parametric statistical tests have been used because of skewed data.

In addition, AQoL scores showed impairment in general health status for both diseases. However, mean (SD) total AQoL score was worse for CHF than COPD patients (0.35 (0.26) vs. $0.46(0.28)$, respectively, p<0.05) (Table 6.3). AQoL physical senses score was higher (better) for COPD than CHF patients. Other AQoL domain scores were comparable for COPD and CHF. The SF-36 showed impaired physical health status compared with a Dutch standard population. ${ }^{34}$ Mean (SD) SF-36 physical component summary measure scores were comparable for COPD and CHF: 22.4 (9.6) and 22.2 (10.1) points, respectively, p>0.05. Mean (SD) SF-36 mental component summary measure scores were 47.3 (14.5) points for COPD and 47.5 (14.6) points for $\mathrm{CHF}$, respectively, $\mathrm{p}>0.05$. For most SF-36 domains, impairment was comparable for COPD and CHF patients. However, some differences were present. COPD patients reported more impairment in the domain 'general health', while CHF patients reported more impairment in the domain 'pain' (Figure 6.1). 
Table 6.3 General health status assessed with Assessment of Quality of Life (AQoL)

\begin{tabular}{lll}
\hline & $\begin{array}{l}\text { COPD } \\
(n=105)\end{array}$ & $\begin{array}{l}\text { CHF } \\
(n=80)\end{array}$ \\
\hline AQoL illness & $0.17(0.17)$ & $0.18(0.14)$ \\
AQoL independent living & $0.58(0.30)$ & $0.50(0.30)$ \\
AQoL social relationships $^{\#}$ & $0.83(0.20)$ & $0.78(0.27)$ \\
AQoL physical senses $^{\#}$ & $0.92(0.11)^{*}$ & $0.84(0.15)$ \\
AQoL psychological well-being & $0.87(0.13)$ & $0.85(0.15)$ \\
AQoL total & $0.46(0.28)^{*}$ & $0.35(0.26)$ \\
\hline
\end{tabular}

Values expressed as mean (SD). Abbreviations: AQoL= Assessment of Quality of Life instrument; COPD= Chronic Obstructive Pulmonary Disease; $\mathrm{CHF}=$ Congestive Heart Failure. ${ }^{*} \mathrm{p}<0.05$; ${ }^{\#}$ non-parametric statistical tests have been used because of skewed data.

Figure 6.1 General health status assessed with Medical Outcomes Study 36-Item Short-Form Health Survey (SF-36)

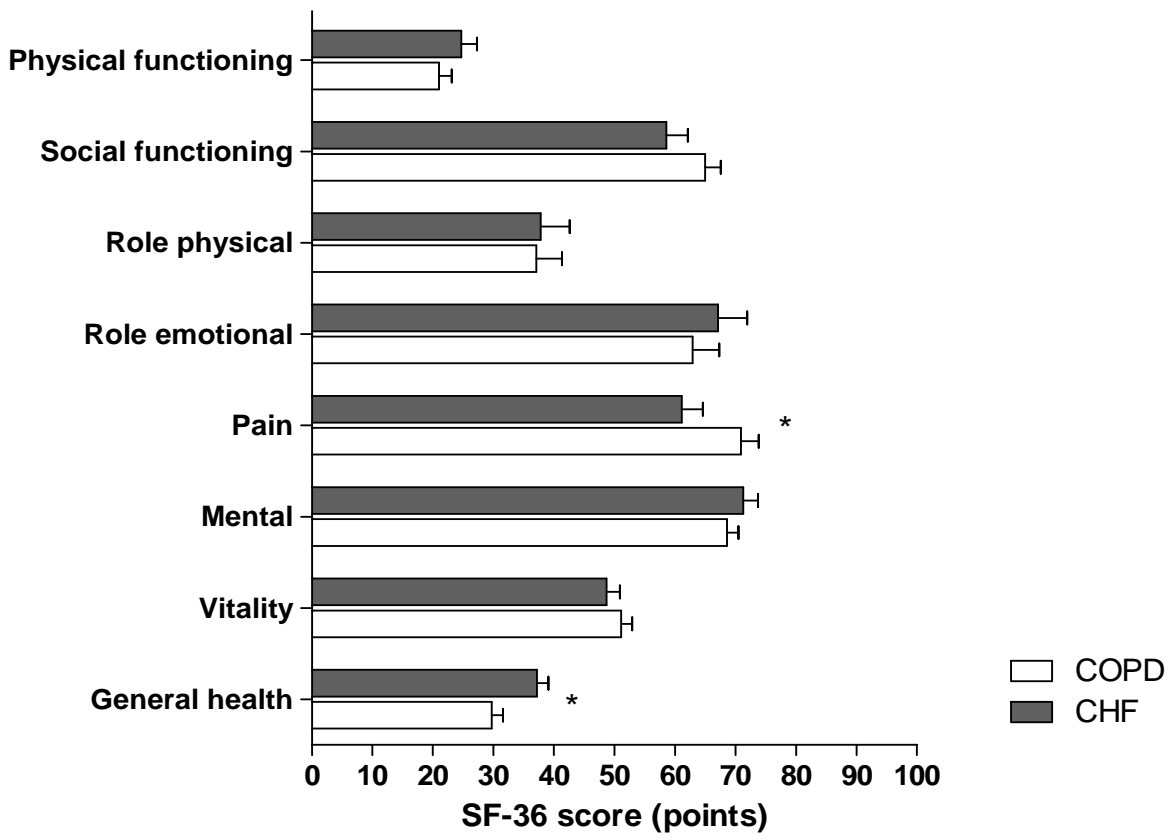

Mean (SEM) domain scores of the Medical Outcomes Study 36-Item Short-Form Health Survey (SF-36) in patients with advanced chronic obstructive pulmonary disease (COPD, $n=105$ ) or chronic heart failure (CHF, $n=80) .{ }^{*} p<0.05$.

\section{Disease-specific health status}

SGRQ scores and MLHFQ scores are shown in Figure 6.2. Poor health status ( $>45$ points) was reported by $43 \mathrm{CHF}$ patients $(53.7 \%)$, moderate health status (24-45 
points) by 25 CHF patients (31.3\%) and good health status ( $<24$ points) by 12 patients (15.0\%) with advanced CHF.

Figure 6.2 Disease-specific health status assessed with St. Georges Respiratory Questionnaire (SGRQ) and Minnesota Living with Heart Failure Questionnaire (MLHFQ)
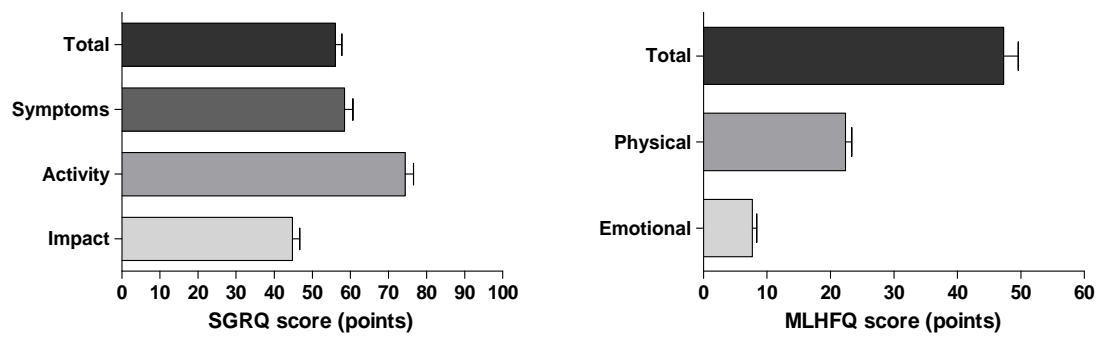

Mean (SEM) total and domain scores of the St. Georges Respiratory Questionnaire (SGRQ) in patients with advanced chronic obstructive pulmonary disease (COPD, $n=104$ ) (left panel) and mean (SEM) total and domain scores of the Minnesota Living with Heart Failure Questionnaire (MLHFQ) in patients with advanced chronic heart failure ( $\mathrm{CHF}, \mathrm{n}=80$ ) (right panel).

\section{Care dependency}

CHF patients had a lower (worse) median (IQR) CDS score than COPD patients: 65.0 (58.3-71.0) points vs. 70.0 (63.0-73.0) points, respectively, $p<0.05$. However, CDS score was comparable for COPD and CHF, after adjusting for age, gender, $\mathrm{BMI}$ and Charlson comorbidity index score (adjusted $p=0.57$ ). The linear regression model showed an association between age and CDS score (adjusted $p=0.03$ ) and Charlson comorbidity index score and CDS score (adjusted $\mathrm{p}=0.02$ ). Older patients and patients with a higher Charlson comorbidity index score had lower CDS scores.

\section{Correlates of general health status}

The number of self-perceived symptoms, TUG test, HADS-A score, HADS-D score, Borg scale, CDS score, need for assistance by a professional caregiver and the number of physician-prescribed drugs showed bivariate correlation with EQ-5D index score (Pearson correlation coefficient $>0.30$ ). Age, gender, disease, Charlson comorbidity index score, $\mathrm{FEV}_{1}, \mathrm{BMI}$, smoking status, marital status, level of education, LTOT and presence of a family caregiver did not show a bivariate correlation (Pearson correlation coefficient $\leq 0.30$ ). The multiple regression analysis model, with EQ-5D index score as dependent variable and the aforementioned variables that showed bivariate correlation as independent variables, was able to explain $56.4 \%$ of the variance in EQ-5D index score. Patients who experienced more symptoms, impair- 
ment in physical mobility, more symptoms of anxiety, a higher level of care dependency, the need for a professional caregiver to assist with personal care or patients who were using a higher number of physician-prescribed drugs reported worse general health status, as assessed with EQ-5D (Table 6.4).

The number of self-perceived symptoms, TUG test, HADS-A score, HADS-D score, Borg scale, CDS score, need for a professional caregiver and the number of physician-prescribed drugs also showed a bivariate correlation with AQoL total score, while the other variables did not show correlation. The standard multiple regression model showed that the number of symptoms, HADS-D score, CDS score, the need for a professional caregiver and the number of physician-prescribed drugs explained $66.1 \%$ of the variance in AQoL total score. Patients who experienced more symptoms, more symptoms of depression, a higher level of care dependency, the need for a professional caregiver or patients who were using more physician-prescribed drugs reported worse general health status, as assessed with AQoL (Table 6.4).

Table 6.4 Correlates of general health status: results of standard multiple regression models

\begin{tabular}{llll}
\hline Model & Correlates & Standardized Beta & p-value \\
\hline EQ-5D index score & Number of symptoms & -0.149 & 0.022 \\
$\left(\mathrm{R}^{2}=0.564, \mathrm{p}<0.0005\right)$ & TUG test & -0.228 & 0.000 \\
& HADS-A & -0.182 & 0.007 \\
& HADS-D & -0.033 & 0.640 \\
& Borg scale & -0.096 & 0.083 \\
& CDS & 0.253 & 0.000 \\
\hline AQoL total score & Need professional caregiver & -0.157 & 0.006 \\
$\left(\mathrm{R}^{2}=0.661, \mathrm{p}<0.0005\right)$ & Number of drugs & -0.124 & 0.024 \\
& TUG test & -0.192 & 0.001 \\
& HADS-A & -0.006 & 0.914 \\
& HADS-D & -0.072 & 0.228 \\
& Borg scale & -0.170 & 0.006 \\
& CDS & -0.086 & 0.078 \\
& Need professional caregiver & -0.225 & 0.000 \\
& Number of drugs & -0.137 & 0.000 \\
& Numptoms & 0.005
\end{tabular}

Abbreviations: $A Q o L=$ Assessment of Quality of Life instrument; CDS= Care Dependency Scale; EQ5D= EuroQol-5 Dimensions; HADS-A= Hospital Anxiety and Depression Scale, Anxiety subscale; HADS-D= Hospital Anxiety and Depression Scale, Depression subscale; TUG test= Timed 'Up and Go' test. $\mathrm{n}=185$.

\section{Correlates of disease-specific health status}

The number of self-perceived symptoms, HADS-A score, HADS-D score, Borg scale and CDS score showed bivariate correlation with SGRQ total score (Pearson correlation coefficient $>0.30$ ). A bivariate correlation was not found for age, gender, Charlson comorbidity index score, $\mathrm{FEV}_{1}, \mathrm{BMI}$, smoking status, marital status, level of edu- 
cation, TUG test, LTOT, presence of a family caregiver, the need for a professional caregiver or the number of medications the subject was using. The multiple regression analysis model showed that the number of symptoms, HADS-D score, Borg scale and CDS score were able to explain $57.5 \%$ of the variance in SGRQ total score in advanced COPD (Table 6.5). COPD patients who experienced increased symptoms, increased symptoms of depression, increased severe dyspnea or a higher level of care dependency reported more severe impairment in disease-specific health status.

The number of self-perceived symptoms, HADS-A score, HADS-D score, Borg scale and CDS score were shown to exhibit bivariate correlation with MLHFQ total score in patients with advanced CHF (Pearson correlation coefficient $>0.30$ ). The multiple regression analysis model showed that the number of symptoms, HADS-A score and CDS score were statistically significant correlated with disease-specific health status. These variables predicted $52.9 \%$ of the variance in MLHFQ score. Patients with advanced $\mathrm{CHF}$, who experienced a higher number of symptoms, more anxiety and a higher level of care dependency reported more impairment in disease-specific health status (Table 6.5).

Table 6.5 Correlates of disease-specific health status: results of standard multiple regression models

\begin{tabular}{lllll}
\hline & Model & Correlates & Standardized Beta & p-value \\
\hline COPD & SGRQ total score & Number of symptoms & 0.259 & 0.003 \\
$\mathrm{n}=104^{*}$ & $\left(\mathrm{R}^{2}=0.575, \mathrm{p}<0.0005\right)$ & HADS-A & -0.027 & 0.768 \\
& & HADS-D & 0.213 & 0.018 \\
& & Borg scale & 0.358 & 0.000 \\
& & CDS & -0.225 & 0.004 \\
\hline $\mathrm{CHF}$ & MLHFQ total score & Number of symptoms & 0.251 & 0.020 \\
$\mathrm{n}=80$ & $\left(\mathrm{R}^{2}=0.529, \mathrm{p}<0.0005\right)$ & HADS-A & 0.311 & 0.005 \\
& & HADS-D & 0.074 & 0.511 \\
& & Borg scale & 0.165 & 0.076 \\
& & CDS & -0.212 & 0.020 \\
\hline
\end{tabular}

Abbreviations: $C D S=$ Care Dependency Scale; $C O P D=$ Chronic Obstructive Pulmonary Disease; $C H F=$ Congestive Heart Failure; HADS-A= Hospital Anxiety and Depression Scale, Anxiety subscale; HADS-D= Hospital Anxiety and Depression Scale, Depression subscale; MLHFQ= Minnesota Living with Heart Failure Questionnaire; SGRQ= St. Georges Respiratory Questionnaire; TUG test= Timed 'Up and Go' test. * 1 patient excluded because of missing values. 


\section{Discussion}

\section{Key findings}

The present study shows that patients with advanced COPD or CHF have an impaired health status, irrespective of the underlying disease. A substantial number of these patients are confronted with care dependency. Symptom burden, symptoms of anxiety and/or depression and care dependency are correlates of general and disease-specific health status in advanced COPD and/or CHF. In addition, the number of physician-prescribed drugs is correlated with general health status in advanced COPD and/or CHF. Demographic and clinical characteristics like age, gender, disease severity and co-morbidities are not correlated with general or diseasespecific health status.

\section{Health status, care dependency and correlates of health status}

The present study has shown that age, gender, co-morbidities, lung function, smoking status, marital status, level of education, LTOT and presence of a family caregiver were not correlated with general and/or disease-specific health status in patients with advanced COPD or CHF. These findings conflict with some of the currently available literature. Previously, it was suggested that impaired general health status is associated with female gender and higher age in patients with $\mathrm{CHF}^{13,16}$ However, most patients in these studies had mild to moderate $\mathrm{CHF}^{13,16}$ while the present study included only patients with severe to very severe CHF. Spencer and colleagues showed an association between smoking status and SGRQ total score in patients with COPD. ${ }^{17}$ We did not confirm these findings in our sample of patients with advanced COPD. Other studies suggested an association between $\mathrm{FEV}_{1}$ and total SGRQ score in patients with severe COPD, ${ }^{14,15}$ another finding that was not confirmed in the present study. Indeed, the present study showed lack of correlation between FEV 1 and SGRQ total score (Spearman's rho $-0.093(p=0.354)$ ). Then again, the present study showed also lack of correlation between FEV $\mathrm{F}_{1}$ and EQ-5D index score (Spearman's rho $0.087(p=0.387)$ ) or AQoL total score (Spearman's rho $0.161(p=0.107))$ in patients with advanced COPD. Oga and colleagues have shown that change in health status and change in pulmonary function were not related. ${ }^{42}$ In a recent study in clinically stable patients with COPD, severity of airflow limitation was poorly related to health status. ${ }^{43}$ Thus, there is substantial evidence that $\mathrm{FEV}_{1}$ is not appropriate for identifying patients with advanced COPD at increased risk for an impaired health status.

Clinical correlates, like symptom burden, symptoms of anxiety and/or depression, care dependency and number of physician-prescribed drugs were able to explain 
$56 \%$ and $66 \%$ of EQ-5D index score and AQoL total score, respectively. Higher symptom burden is associated with worse general and disease-specific health status in patients with advanced COPD or CHF. The correlation between severity of dyspnea and disease-specific health status in COPD confirms previous findings. ${ }^{14,15,18,44}$ Furthermore, the correlation between symptom distress and health status has been shown before in patients with COPD or CHF and emphasizes again the importance of addressing symptom burden in patients with advanced COPD or CHF., 2, 19, 45

The present study shows that care dependency is a major correlate of general and disease-specific health status in patients with advanced COPD or CHF. Regular assessment of care dependency should be part of routine clinical care for patients with advanced COPD or CHF. Management programmes aimed at optimizing health status of patients with advanced COPD or CHF should assess impairments in basic and instrumental activities of daily living and should try to minimize care dependency.

\section{Limitations of the present study}

The study population consisted of a convenience sample of patients. While the majority of eligible COPD patients were willing to participate, the response rate for CHF patients was below $50 \%$. The current response rate confirms the previously reported difficulty of recruitment of older patients with $\mathrm{CHF}^{46}$ and may limit the generalizability of the results.

Some differences were present between COPD and CHF patients. Although differences between COPD and CHF patients in age, marital status and smoking status are statistically significant, the clinical relevance for the present study may be limited, as is shown by the lack of correlation between health status and age, marital status or smoking status. Furthermore, patients with co-morbidities were not excluded from the analyses. Indeed, co-morbidities in patients with COPD and CHF are common $^{47-49}$ and might have influenced the results of the present study. Finally, the present study is a cross-sectional study, and health status and care dependency are likely to change during the course of the disease. ${ }^{7,50}$ A longitudinal follow-up study is warranted to further reveal how health status and care dependency change over time in patients with advanced COPD or CHF.

\section{Conclusions and implications}

This study demonstrates that health status is considerably impaired in patients with advanced COPD or CHF and confirms our hypothesis that care dependency is an important correlate of general and disease-specific health status. Patients con- 
fronted with care dependency, patients who experience more physical and psychological symptoms or patients who are using a higher number of physician-prescribed drugs are at risk for having an impaired health status. Therefore, clinicians should routinely assess symptom burden as well as care dependency in patients with advanced COPD or CHF. 


\section{References}

1. Curtis, J.R. and D.L. Patrick, The assessment of health status among patients with COPD. Eur Respir J Suppl. 2003;41:36s-45s.

2. Blinderman, C.D., P. Homel, J. Andrew Billings, S. Tennstedt, and R.K. Portenoy, Symptom Distress and Quality of Life in Patients with Advanced Chronic Obstructive Pulmonary Disease. J Pain Symptom Manage. 2009;38(1):115-23.

3. Blinderman, C.D., P. Homel, J.A. Billings, R.K. Portenoy, and S.L. Tennstedt, Symptom distress and quality of life in patients with advanced congestive heart failure. J Pain Symptom Manage. 2008;35(6):594-603.

4. Gore, J.M., C.J. Brophy, and M.A. Greenstone, How well do we care for patients with end stage chronic obstructive pulmonary disease (COPD)? A comparison of palliative care and quality of life in COPD and lung cancer. Thorax. 2000;55(12):1000-6.

5. O'Leary, N., N.F. Murphy, C. O'Loughlin, E. Tiernan, and K. McDonald, A comparative study of the palliative care needs of heart failure and cancer patients. Eur J Heart Fail. 2009;11(4):406-12.

6. Iqbal, J., L. Francis, J. Reid, S. Murray, and M. Denvir, Quality of life in patients with chronic heart failure and their carers: a 3-year follow-up study assessing hospitalization and mortality. Eur J Heart Fail. 2010;12(9):1002-8.

7. Habraken, J.M., W.M. van der Wal, G. Ter Riet, E.J. Weersink, F. Toben, and P.J. Bindels, Healthrelated quality of life and functional status in end-stage COPD: longitudinal study. Eur Respir J. 2011;37(2):280-8.

8. Almagro, P., E. Calbo, A. Ochoa de Echaguen, B. Barreiro, S. Quintana, J.L. Heredia, and J. Garau, Mortality after hospitalization for COPD. Chest. 2002;121(5):1441-8.

9. Curtis, J.R., Palliative and end-of-life care for patients with severe COPD. Eur Respir J. 2008;32(3):796-803.

10. Jaarsma, T., J.M. Beattie, M. Ryder, F.H. Rutten, T. McDonagh, P. Mohacsi, S.A. Murray, T. Grodzicki, I. Bergh, M. Metra, I. Ekman, C. Angermann, M. Leventhal, A. Pitsis, S.D. Anker, A. Gavazzi, P. Ponikowski, K. Dickstein, E. Delacretaz, L. Blue, F. Strasser, and J. McMurray, Palliative care in heart failure: a position statement from the palliative care workshop of the Heart Failure Association of the European Society of Cardiology. Eur J Heart Fail. 2009;11(5):433-43.

11. Lanken, P.N., P.B. Terry, H.M. Delisser, B.F. Fahy, J. Hansen-Flaschen, J.E. Heffner, M. Levy, R.A. Mularski, M.L. Osborne, T.J. Prendergast, G. Rocker, W.J. Sibbald, B. Wilfond, and J.R. Yankaskas, An official American Thoracic Society clinical policy statement: palliative care for patients with respiratory diseases and critical illnesses. Am J Respir Crit Care Med. 2008;177(8):912-27.

12. Janssen, D.J., M.A. Spruit, C. Leue, C. Gijsen, H. Hameleers, J.M. Schols, and E.F. Wouters, Symptoms of anxiety and depression in COPD patients entering pulmonary rehabilitation. Chron Respir Dis. 2010;7(3):147-57.

13. Azevedo, A., P. Bettencourt, M. Alvelos, E. Martins, C. Abreu-Lima, H.W. Hense, and H. Barros, Health-related quality of life and stages of heart failure. Int J Cardiol. 2008;129(2):238-44.

14. Hajiro, T., K. Nishimura, M. Tsukino, A. Ikeda, and T. Oga, Stages of disease severity and factors that affect the health status of patients with chronic obstructive pulmonary disease. Respir Med. 2000;94(9):841-6.

15. Miravitlles, M., J.L. Alvarez-Sala, R. Lamarca, M. Ferrer, F. Masa, H. Verea, R. Zalacain, C. Murio, and F. Ros, Treatment and quality of life in patients with chronic obstructive pulmonary disease. Qual Life Res. 2002;11(4):329-38.

16. de Rivas, B., G. Permanyer-Miralda, C. Brotons, J. Aznar, and E. Sobreviela, Health-related quality of life in unselected outpatients with heart failure across Spain in two different health care levels. Magnitude and determinants of impairment: the INCA study. Qual Life Res. 2008;17(10):1229-38.

17. Spencer, S., P.M. Calverley, P. Sherwood Burge, and P.W. Jones, Health status deterioration in patients with chronic obstructive pulmonary disease. Am J Respir Crit Care Med. 2001;163(1):122-8. 
18. de Torres, J.P., C. Casanova, C. Hernandez, J. Abreu, A. Montejo de Garcini, A. Aguirre-Jaime, and B.R. Celli, Gender associated differences in determinants of quality of life in patients with COPD: a case series study. Health Qual Life Outcomes. 2006;4:72.

19. Heo, S., D.K. Moser, T.A. Lennie, C.H. Zambroski, and M.L. Chung, A comparison of health-related quality of life between older adults with heart failure and healthy older adults. Heart Lung. 2007;36(1):16-24.

20. Fitzsimons, D., D. Mullan, J.S. Wilson, B. Conway, B. Corcoran, M. Dempster, J. Gamble, C. Stewart, S. Rafferty, M. McMahon, J. MacMahon, P. Mulholland, P. Stockdale, E. Chew, L. Hanna, J. Brown, G. Ferguson, and D. Fogarty, The challenge of patients' unmet palliative care needs in the final stages of chronic illness. Palliat Med. 2007;21(4):313-22.

21. Habraken, J.M., J. Pols, P.J. Bindels, and D.L. Willems, The silence of patients with end-stage COPD: a qualitative study. Br J Gen Pract. 2008;58(557):844-9.

22. Incalzi, R.A., A. Corsonello, C. Pedone, F. Corica, P. Carbonin, and R. Bernabei, Construct validity of activities of daily living scale: a clue to distinguish the disabling effects of COPD and congestive heart failure. Chest. 2005;127(3):830-8.

23. Janssen, D.J., E.F. Wouters, J.M. Schols, and M.A. Spruit, Self-perceived symptoms and care needs of patients with severe to very severe chronic obstructive pulmonary disease, congestive heart failure or chronic renal failure and its consequences for their closest relatives: the research protocol. BMC Palliat Care. 2008;7:5.

24. Janssen, D.J., M.A. Spruit, N.H. Uszko-Lencer, J.M. Schols, and E.F. Wouters, Symptoms, comorbidities and healthcare in advanced COPD or chronic heart failure. J Palliat Med. 2011;14(6):73543.

25. Janssen, D.J., M.A. Spruit, J.M. Schols, and E.F. Wouters, A call for high-quality advance care planning in outpatients with severe COPD or chronic heart failure. Chest. 2011;139(5):1081-88.

26. Charlson, M.E., P. Pompei, K.L. Ales, and C.R. MacKenzie, A new method of classifying prognostic comorbidity in longitudinal studies: development and validation. J Chronic Dis. 1987;40(5):373-83.

27. Standardization of Spirometry, 1994 Update. American Thoracic Society. Am J Respir Crit Care Med. 1995;152(3):1107-36.

28. Wilson, R.C. and P.W. Jones, A comparison of the visual analogue scale and modified Borg scale for the measurement of dyspnoea during exercise. Clin Sci (Lond). 1989;76(3):277-82.

29. Zigmond, A.S. and R.P. Snaith, The hospital anxiety and depression scale. Acta Psychiatr Scand. 1983;67(6):361-70.

30. Dolan, P., Modeling valuations for EuroQol health states. Med Care. 1997;35(11):1095-108.

31. Hawthorne, G., J. Richardson, and R. Osborne, The Assessment of Quality of Life (AQoL) instrument: a psychometric measure of health-related quality of life. Qual Life Res. 1999;8(3):209-24.

32. Ware, J.E., K.K. Snow, and M. Kosinski, SF-36 health survey manual and interpretation guide. 1993, Boston MA: The Health Institute, New England Medical Center Hospitals.

33. Hawthorne, G. and R. Osborne, Population norms and meaningful differences for the Assessment of Quality of Life (AQoL) measure. Aust N Z J Public Health. 2005;29(2):136-42.

34. Kruijshaar, M.E., N. Hoeymans, R.V. Bijl, J. Spijker, and M.L. Essink-Bot, Levels of disability in major depression: findings from the Netherlands Mental Health Survey and Incidence Study (NEMESIS). J Affect Disord. 2003;77(1):53-64.

35. Jones, P.W., F.H. Quirk, C.M. Baveystock, and P. Littlejohns, A self-complete measure of health status for chronic airflow limitation. The St. George's Respiratory Questionnaire. Am Rev Respir Dis. 1992;145(6):1321-7.

36. Riegel, B., D.K. Moser, D. Glaser, B. Carlson, C. Deaton, R. Armola, K. Sethares, M. Shively, L. Evangelista, and N. Albert, The Minnesota Living With Heart Failure Questionnaire: sensitivity to differences and responsiveness to intervention intensity in a clinical population. Nurs Res. 2002;51(4):209-18. 
37. Behlouli, H., D.E. Feldman, A. Ducharme, M. Frenette, N. Giannetti, F. Grondin, C. Michel, R. Sheppard, and L. Pilote, Identifying relative cut-off scores with neural networks for interpretation of the minnesota living with heart failure questionnaire. Conf Proc IEEE Eng Med Biol Soc. 2009;1:62426.

38. Podsiadlo, D. and S. Richardson, The timed "Up \& Go": a test of basic functional mobility for frail elderly persons. J Am Geriatr Soc. 1991;39(2):142-8.

39. Dijkstra, A., L.J. Tiesinga, W.T. Goossen, and T.W. Dassen, Further psychometric testing of the Dutch Care Dependency Scale on two different patient groups. Int J Nurs Pract. 2002;8(6):305-14.

40. Dijkstra, A., L.J. Tiesinga, L. Plantinga, G. Veltman, and T.W. Dassen, Diagnostic accuracy of the care dependency scale. J Adv Nurs. 2005;50(4):410-6.

41. Altman, D.G., S.M. Gore, M.J. Gardner, and S.J. Pocock, Statistical guidelines for contributors to medical journals. Br Med J (Clin Res Ed). 1983;286(6376):1489-93.

42. Oga, T., K. Nishimura, M. Tsukino, T. Hajiro, S. Sato, A. Ikeda, C. Hamadas, and M. Mishima, Longitudinal changes in health status using the chronic respiratory disease questionnaire and pulmonary function in patients with stable chronic obstructive pulmonary disease. Qual Life Res. 2004;13(6):1109-16.

43. Agusti, A., P.M. Calverley, B. Celli, H.O. Coxson, L.D. Edwards, D.A. Lomas, W. MacNee, B.E. Miller, S. Rennard, E.K. Silverman, R. Tal-Singer, E. Wouters, J.C. Yates, and J. Vestbo, Characterisation of COPD heterogeneity in the ECLIPSE cohort. Respir Res. 2010;11:122.

44. Spruit, M.A., H.J. Pennings, P.P. Janssen, J.D. Does, S. Scroyen, M.A. Akkermans, R. Mostert, and E.F. Wouters, Extra-pulmonary features in COPD patients entering rehabilitation after stratification for MRC dyspnea grade. Respir Med. 2007;101(12):2454-63.

45. Bekelman, D.B., J.S. Rumsfeld, E.P. Havranek, T.E. Yamashita, E. Hutt, S.H. Gottlieb, S.M. Dy, and J.S. Kutner, Symptom burden, depression, and spiritual well-being: a comparison of heart failure and advanced cancer patients. J Gen Intern Med. 2009;24(5):592-8.

46. Barnes, S., M. Gott, S. Payne, C. Parker, D. Seamark, S. Gariballa, and N. Small, Recruiting older people into a large, community-based study of heart failure. Chronic IIIn. 2005;1(4):321-9.

47. Rutten, F.H., M.J. Cramer, D.E. Grobbee, A.P. Sachs, J.H. Kirkels, J.W. Lammers, and A.W. Hoes, Unrecognized heart failure in elderly patients with stable chronic obstructive pulmonary disease. Eur Heart J. 2005;26(18):1887-94.

48. Sin, D.D., N.R. Anthonisen, J.B. Soriano, and A.G. Agusti, Mortality in COPD: Role of comorbidities. Eur Respir J. 2006;28(6):1245-57.

49. Bausewein, C., S. Booth, M. Gysels, R. Kuhnbach, B. Haberland, and I.J. Higginson, Understanding breathlessness: cross-sectional comparison of symptom burden and palliative care needs in chronic obstructive pulmonary disease and cancer. J Palliat Med. 2010 13(9):1109-18.

50. Oga, T., K. Nishimura, M. Tsukino, S. Sato, T. Hajiro, and M. Mishima, Longitudinal deteriorations in patient reported outcomes in patients with COPD. Respir Med. 2007;101(1):146-53. 


\section{CHAPTER 7}

\section{Family caregiving in advanced chronic organ failure}

Daisy J.A. Janssen, Martijn A. Spruit, Emiel F.M. Wouters and Jos M.G.A. Schols JAMDA, 2011. Published online ahead of print. 


\section{Abstract}

\section{Objectives}

To assess caregiver burden as well as positive aspects of family caregiving in advanced Chronic Obstructive Pulmonary Disease (COPD), Chronic Heart Failure (CHF) and Chronic Renal Failure (CRF).

\section{Design}

Cross-sectional observational study.

\section{Setting}

Patients recruited at the outpatient clinics of academic and general hospitals in the Netherlands.

\section{Participants}

Patients with advanced COPD $(n=73), \operatorname{CHF}(n=45)$ and CRF $(n=41)$ and their family caregivers.

\section{Measurements}

Caregiver burden and positive aspects of caregiving were assessed using the Family Appraisal of Caregiving Questionnaire for Palliative Care (FACQ-PC) and were compared among family caregivers of patients with COPD, CHF, or CRF using linear regression analysis while controlling for characteristics of patients and family caregivers.

\section{Results}

Most family caregivers were female partners of participating patients. Caregiver distress and caregiver strain scores were relatively low, whereas scores for positive caregiving appraisals and family well-being were relatively positive. Caregiver strain, positive caregiving appraisals and family well-being were comparable for family caregivers of patients with COPD, CHF or CRF. Caregiver distress was higher for family caregivers of patients with COPD than CHF. The experience of caregiving was influenced by being the patient's spouse, patient's psychological symptoms and the presence of co-morbidities.

\section{Conclusions}

Family caregiving for patients with COPD, CHF or CRF should not only be seen as a burden, but also as a positive experience. To support family caregivers, attention should be paid to caregiver burden and the positive aspects of family caregiving. 


\section{Introduction}

Patients with advanced chronic organ failure, like Chronic Obstructive Pulmonary Disease (COPD), Chronic Heart Failure (CHF) and Chronic Renal Failure (CRF) often experience impairment in performing normal daily tasks leading to care dependency. ${ }^{1-4}$ Family caregivers have a crucial role in providing care for patients with advanced chronic organ failure..$^{5-7}$

Caring for a loved one with advanced disease may have significant consequences for the family caregiver(s). ${ }^{8-13}$ Indeed, a decline in patients' health status can lead to a range of physical, social, and emotional consequences for family caregivers of patients with COPD, CHF or CRF. ${ }^{1,14-16}$ A recent study has shown that caregiver burden is common in family caregivers of patients with advanced COPD or CHF. ${ }^{17}$

Family caregiving may not only cause a burden, but may also be a positive experience for family caregivers. ${ }^{18}$ Positive aspects of caregiving may enhance quality of life of family caregivers of cancer patients. ${ }^{19}$ Relatives of CHF patients have reported that they experience positive aspects of their role as a caregiver. ${ }^{8}$ However, the currently available literature concerning family caregivers of patients with advanced chronic organ failure has mainly focused on caregiver burden. ${ }^{1,9,13,17,20}$ Therefore, insight into positive aspects of caregiving for patients with advanced COPD, CHF or CRF remains scarce. In addition, quantitative ratings comparing both caregiver burden and positive aspects of family caregiving among advanced COPD, CHF and CRF are lacking. Further understanding of positive aspects of caregiving is important to support family caregivers with achieving or maintaining an optimal balance in burden and positive aspects of caregiving.

The present study aimed to assess caregiver burden and positive aspects of caregiving in family caregivers of patients with advanced COPD, CHF, or CRF. A priori, we hypothesized that positive caregiving appraisals are important aspects of caregiving for family caregivers of patients with advanced COPD, CHF or CRF.

\section{Methods}

\section{Design}

This cross-sectional study is part of a longitudinal study concerning self-perceived symptoms and care needs in patients with advanced COPD, CHF, or CRF and the consequences for their closest relatives. ${ }^{21}$ The Medical Ethical Committee of the 
Maastricht University Medical Centre, Maastricht, the Netherlands, approved this study (MEC 07-3-054). Details of study design and data on advance care planning, symptom burden and health status have been published before. ${ }^{4,21}$ The study was registered at the Dutch Trial Register (NTR 1552).

\section{Study population}

Patients with advanced COPD, CHF, or CRF were recruited by their physician specialist at the outpatient clinic of one academic and six general hospitals in the Netherlands in 2008 and 2009. Patients were eligible if they had a diagnosis of severe to very severe COPD (Global initiative for chronic Obstructive Lung Disease (GOLD) stage III or IV); advanced CHF (New York Heart Association (NYHA) class III or IV) or advanced CRF (requiring dialysis). Patients were asked to identify the person who spent the most time with them and/or provided most of their care, assistance and support. ${ }^{24}$ All participating patients and their participating family caregivers have given written informed consent.

\section{Instruments}

The following patient-related outcomes were assessed during home visits: demographics; current self-reported co-morbidities (Charlson comorbidity index ${ }^{25}$ ); longterm oxygen therapy (LTOT); need for assistance with personal care; self-perceived mobility problems; NT-proBNP ${ }^{26}$; and creatinine. Blood samples were taken before start of dialysis in CRF patients. Forced Expiratory Volume in the first second $\left(\mathrm{FEV}_{1}\right)$ was calculated from the flow-volume curve measured by a handheld pulmonary spirometer. $^{27}$

Patients' general health status was assessed using the self-administered questionnaire EuroQol-5 Dimensions (EQ-5D). ${ }^{28}$ EQ-5D index score ranges from -0.59 (worst) to 1.0 (best). ${ }^{28}$ Symptoms of anxiety and depression were studied using the Hospital Anxiety and Depression Scale (HADS). ${ }^{29}$ The HADS is divided into an anxiety subscale (HADS-A) and a depression subscale (HADS-D). Total scores for each subscale range from 0 (optimal) to 21 (worst) points. Severity of dyspnea was measured using the modified Borg scale (range 0 (nothing at all) to 10 (maximal)). ${ }^{30}$

Care dependency was assessed using the Care Dependency Scale (CDS). ${ }^{31}$ CDS consists of 15 items regarding basic and instrumental activities of daily living. Score ranges from 15 (worst) to 75 points (best). ${ }^{32}$

General characteristics of family caregivers, such as gender, age and relationship with the patient were recorded. Family caregivers were asked to rate the severity of 
dyspnea of the patient using the modified Borg scale (range 0 (nothing at all) to 10 (maximal)). ${ }^{30}$

Caregiver burden and positive aspects of caregiving were assessed using the Family Appraisal of Caregiving Questionnaire for Palliative Care (FACQ-PC). ${ }^{33}$ The FACQ-PC consists of 25 items and provides four subscales: caregiver strain, positive caregiving appraisals, caregiver distress, and family well-being. For each scale the score ranges from 0 to 5 points. The midpoint of the scale indicates a neutral position and higher scores on each subscale indicate a greater amount of the variable being measured. ${ }^{33}$

\section{Statistics}

Categorical variables are described as frequencies, while continuous variables were tested for normality and are presented as mean and standard deviation (SD). Comparison of continuous variables among patients with COPD, CHF, or CRF were done using a one-way analysis of variances (ANOVA) with LSD as post hoc test or KruskallWallis followed by Mann-Whitney $U$ tests, as appropriate. Categorical variables were compared among patients with COPD, CHF and CRF using Chi-square tests. Linear regression analysis was used to compare FACQ-PC subscales among family caregivers of patients with COPD, CHF or CRF, while adjusting for characteristics of patients and family caregivers. Because limited data are available on potential predictors of caregiver burden or positive aspects of caregiving, models were constructed by including variables that were possible confounders, defined as a $p$-value less than or equal to 0.10 . In the final regression models the following covariates were included: co-morbidities (none vs. one or more); CDS score; EQ-5D score; HADS-A score; HADS-D score and relationship of family caregiver to patient (spouse vs. other). The following variables did not confound the relationship between disease of the patient and FACQ subscales $(p>0.10)$ and were not included in the final regression models: sex of the patient; age of the patient; marital status; smoking status; presence of professional caregiver; self-perceived mobility problems; selfperceived poor health; severity of dyspnea as perceived by the patient; severity of dyspnea as perceived by the family caregiver; need for assistance with personal care; age of the caregiver; and sex of the caregiver. Statistics were performed using SPSS 17.0 (SPSS Inc., Chicago, IL). STATA 11.1 (StataCorp LP, College Station, TX) was used for linear regression analysis. A priori, a two-sided level of significance was set at $\mathrm{p}$ less than or equal to $0.05 .^{34}$ 


\section{Results}

\section{Characteristics of patients and family caregivers}

In total, $105 \mathrm{COPD}, 80 \mathrm{CHF}$, and $80 \mathrm{CRF}$ patients were asked to identify a family caregiver for participation in the study. Family caregivers of 73 COPD (69.5\%), 45 CHF (56.3\%) and 41 CRF (51.3\%) patients agreed to participate. The most frequent reasons for no participating family caregiver were: 'no family caregiver present' and 'patient was afraid of the extra burden of the study for the family caregiver' (Table 7.1).

Table 7.1 Reason no participating caregiver

\begin{tabular}{llll}
\hline & $\begin{array}{l}\text { COPD } \\
(\mathrm{n}=32)\end{array}$ & $\begin{array}{l}\text { CHF } \\
(\mathrm{n}=35)\end{array}$ & $\begin{array}{l}\text { CRF } \\
(\mathrm{n}=39)\end{array}$ \\
\hline No relative / family caregiver present & $14(43.7 \%)$ & $16(45.7 \%)$ & $10(25.6 \%)$ \\
Patient is afraid of burden for family caregiver & $14(43.8 \%)$ & $10(28.6 \%)$ & $18(46.2 \%)$ \\
Family caregiver refuses participation & $3(9.4 \%)$ & $6(17.1 \%)$ & $5(12.8 \%)$ \\
Participation not possible because of physical or & $1(3.1 \%)$ & $3(8.6 \%)$ & $6(15.4 \%)$ \\
cognitive impairment of relative & & &
\end{tabular}

Values reported as number of participants (\%). Abbreviations: COPD= Chronic Obstructive Pulmonary Disease; $\mathrm{CHF}=$ Chronic Heart Failure; $\mathrm{CRF}=$ Chronic Renal failure. $\mathrm{p}>0.05$.

Significant differences were found between populations for outcomes such as age, marital status, co-morbidities, care dependency, support from a professional caregiver, mobility problems, and symptoms of depression (Table 7.2). Most CRF patients $(n=39(95.1 \%))$ performed haemodialysis and 2 patients $(4.9 \%)$ performed peritoneal dialysis. Most family caregivers were female partners of the participating patients. In general, family caregivers of CHF patients were the oldest (Table 7.2).

\section{FACQ-PC domain scores}

FACQ-PC caregiver distress and caregiver strain scores were somewhat lower than the midpoint (midpoint indicating a neutral position), whereas scores for positive caregiving appraisals and family well-being approached about 4 on the 5-point rating scale.

Mean scores for caregiver strain, positive caregiving appraisals and family wellbeing were comparable for family caregivers of patients with COPD, CHF, or CRF (unadjusted $\mathrm{p}>0.05$ ) (Table 7.3). 
Table 7.2 General characteristics of patients and their family caregivers

\begin{tabular}{|c|c|c|c|}
\hline & $\begin{array}{l}\text { COPD } \\
(n=73)\end{array}$ & $\begin{array}{l}\text { CHF } \\
(n=45)\end{array}$ & $\begin{array}{l}\text { CRF } \\
(n=41)\end{array}$ \\
\hline \multicolumn{4}{|l|}{ Patients } \\
\hline Gender (male), n (\%) & $50(68.5 \%)$ & $34(75.6 \%)$ & $23(56.1 \%)$ \\
\hline Age (years), mean (SD) & $67.0(9.1)^{*}$ & $74.8(8.1)^{\#}$ & $61.7(14.6)$ \\
\hline $\begin{array}{l}\text { Marital status (married / living with } \\
\text { partner), n (\%) }\end{array}$ & $68(93.2 \%)^{* \#}$ & $35(77.8 \%)$ & $31(75.6 \%)$ \\
\hline Current smokers, n (\%) & $18(24.7 \%)$ & $6(13.3 \%)$ & $6(14.6 \%)$ \\
\hline $\mathrm{FEV}_{1}\left(\%\right.$ predicted), mean $(\mathrm{SD})^{\dagger}$ & $33.8(11.5)^{* \# \#}$ & $75.0(23.8)^{\#}$ & $85.0(20.9)$ \\
\hline NT-proBNP (pmol/L), mean (SD) ${ }^{\dagger}$ & $57.3(157.9)^{* \# \S}$ & $287.7(339.9)^{\# \uparrow}$ & $1396.4(3804.7)$ \\
\hline Creatinine, $(\mu \mathrm{mol} / \mathrm{L})$, mean $(\mathrm{SD})$ & $89.4(28.0)^{* \# \S}$ & $147.3(63.9)^{\# \uparrow 1}$ & $741.2(257.9)$ \\
\hline $\begin{array}{l}\text { Charlson comorbidity index (pts), mean } \\
\text { (SD) }\end{array}$ & $2.5(1.6)^{*^{\#}}$ & $4.5(2.0)$ & $4.2(2.1)$ \\
\hline Patients with $\geq 1$ co morbidity, $\mathrm{n}(\%)$ & $46(63.0 \%)^{*}$ & $43(95.6 \%)^{\#}$ & $30(73.2 \%)$ \\
\hline Long-term oxygen therapy, n (\%) & $42(57.5 \%)^{* \#}$ & $6(13.3 \%)^{\#}$ & $0(0 \%)$ \\
\hline Care dependency score (pts), mean (SD) & $66.5(9.2)^{*}$ & $61.6(11.1)^{\#}$ & $69.3(6.2)$ \\
\hline Needing help with personal care, $\mathrm{n}(\%)$ & $34(46.6 \%)$ & $28(62.2 \%)^{\#}$ & $13(31.7 \%)$ \\
\hline Professional caregiver present, n (\%) & $13(17.8 \%)$ & $14(31.1 \%)^{\#}$ & $3(7.3 \%)$ \\
\hline Self-perceived mobility problems, n (\%) & $61(83.6 \%)$ & $41(91.1 \%)^{\#}$ & $27(65.9 \%)$ \\
\hline Self-perceived poor health, n (\%) & $12(16.4 \%)$ & $9(20.0 \%)$ & $5(12.2 \%)$ \\
\hline EQ-5D score (pts), mean (SD) & $0.51(0.33)^{\#}$ & $0.48(0.33)^{\#}$ & $0.69(0.26)$ \\
\hline HADS-A score (pts), mean (SD) & $5.9(3.9)$ & $5.4(4.1)$ & $4.3(3.3)$ \\
\hline HADS-D score (pts), mean (SD) & $6.2(4.1)^{\#}$ & $6.6(3.7)^{\#}$ & $3.9(2.8)$ \\
\hline $\begin{array}{l}\text { Borg score perceived by patient (pts), } \\
\text { mean (SD) }\end{array}$ & $4.8(1.9)^{* \#}$ & $4.0(2.4)^{\#}$ & $1.3(1.6)$ \\
\hline $\begin{array}{l}\text { Borg score perceived by caregiver (pts), } \\
\text { mean (SD) }\end{array}$ & $5.2(1.9)^{* \#}$ & $3.5(2.2)^{\#}$ & $2.0(2.0)$ \\
\hline \multicolumn{4}{|l|}{ Family caregivers } \\
\hline \multicolumn{4}{|l|}{ Relationship to patient, n (\%) } \\
\hline Spouse & $66(90.4 \%)$ & $35(77.8 \%)$ & $31(75.6 \%)$ \\
\hline Child & $6(8.2 \%)$ & $8(17.8 \%)$ & $5(12.2 \%)$ \\
\hline Other $^{f}$ & $1(1.4 \%)$ & $2(4.4 \%)$ & $5(12.2 \%)$ \\
\hline Gender (male), n (\%) & $17(23.3 \%)$ & $9(20.0 \%)$ & $17(41.5 \%)$ \\
\hline Age (years), mean (SD) ${ }^{+}$ & $62.9(11.5)^{*}$ & $67.3(11.5)^{\#}$ & $59.1(15.2)$ \\
\hline
\end{tabular}

Abbreviations: $C D S=$ Care Dependency Scale; $C O P D=$ Chronic Obstructive Pulmonary Disease; $C H F=$

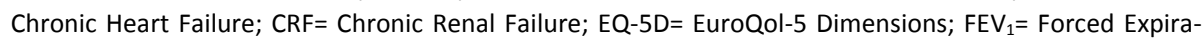
tory Volume in the first second; HADS-A= Hospital Anxiety and Depression Scale, Anxiety subscale; HADS$D=$ Hospital Anxiety and Depression Scale, Depression subscale. ${ }^{*} p<0.05$ vs. CHF; ${ }^{*} p<0.05$ vs. CRF; ${ }^{\dagger}$ nonparametric statistical tests have been used because of skewed data; ${ }^{\ddagger} n=70 ;{ }^{\S} n=71 ;{ }^{\natural} n=44 ;{ }^{f}$ other= brother, sister, parent, daughter-in-law, son-in-law. 
Table 7.3 Family Appraisal of Caregiving Questionnaire for Palliative Care (FACQ-PC) domain scores

\begin{tabular}{llll}
\hline & $\begin{array}{l}\text { COPD } \\
(n=73)\end{array}$ & $\begin{array}{l}\text { CHF } \\
(n=45)\end{array}$ & $\begin{array}{l}\text { CRF } \\
(n=41)\end{array}$ \\
\hline Caregiver strain & $1.9(1.0)$ & $2.1(1.0)$ & $1.8(0.8)$ \\
Positive caregiving appraisals & $3.8(1.2)$ & $4.0(1.1)$ & $3.9(0.9)$ \\
Caregiver distress & $2.5(1.1)^{* \#}$ & $2.1(1.1)$ & $2.1(0.9)$ \\
Family well-being & $3.7(0.8)$ & $3.7(0.9)$ & $3.8(0.8)$ \\
\hline
\end{tabular}

Values reported as mean (SD). Abbreviations: $\mathrm{COPD}=$ Chronic Obstructive Pulmonary Disease; $\mathrm{CHF}=$ Chronic Heart Failure; CRF $=$ Chronic Renal failure. ${ }^{*} p<0.05$ vs. CHF; ${ }^{*} p<0.05$ vs. CRF.

This was confirmed by linear regression analysis after adjusting for caregiver being the patient's spouse, co-morbidities, CDS score, EQ-5D score, HADS-A score, and HADS-D score (adjusted $p>0.05$ ) (Table 7.4). Caregiver strain was positively related to being the spouse of the patient (adjusted $p=0.02$ ) and HADS-D score (adjusted $p=0.04)$.

Univariate analysis suggested that caregiver distress was higher for family caregivers of patients with COPD than for family caregivers of patients with CHF or CRF (unadjusted $p<0.05$ ) (Table 7.3). After adjusting for caregiver being the patient's spouse; co-morbidities; CDS score; EQ-5D score; HADS-A score; and HADS-D score by using linear regression analysis, caregiver distress was higher for family caregivers of patients with COPD than for family caregivers of patients with CHF (adjusted $p=0.02$ ). Caregiver distress was comparable for caregivers of patients with COPD or CRF and caregivers of patients with CHF or CRF (adjusted $\mathrm{p}>0.05$ ). Caregiver distress was positively related to the presence of one or more co-morbidities (adjusted $p=0.04$ ). There was no association between CDS score, EQ-5D score, HADS-A score and any of the FACQ-PC subscales (Table 7.4).

\section{Discussion}

\section{Key findings}

The present study in family caregivers of outpatients with advanced COPD, CHF, and CRF shows the importance of positive aspects of family caregiving. Caregiver distress and caregiver strain scores were somewhat lower than the midpoint, whereas scores for positive caregiving appraisals and family well-being were relatively positive. $^{33}$ 
Table 7.4 Family Appraisal of Caregiving Questionnaire for Palliative Care (FACQ-PC) domain scores: Linear regression analysis

\begin{tabular}{lllllllll}
\hline & \multicolumn{2}{l}{ Caregiver strain } & \multicolumn{2}{l}{$\begin{array}{l}\text { Positive care- } \\
\text { giving appraisals }\end{array}$} & Caregiver distress & \multicolumn{2}{l}{$\begin{array}{l}\text { Family } \\
\text { wellbeing }\end{array}$} \\
\hline & Beta & p-value & Beta & p-value & Beta & p-value & Beta & p-value \\
COPD vs. CHF & -0.14 & 0.45 & -0.06 & 0.79 & 0.49 & 0.02 & -0.02 & 0.90 \\
COPD vs. CRF & -0.15 & 0.42 & 0.01 & 0.97 & 0.36 & 0.10 & -0.11 & 0.53 \\
CHF vs. CRF & -0.01 & 0.97 & 0.07 & 0.79 & -0.13 & 0.58 & -0.09 & 0.65 \\
Caregiver being spouse & 0.48 & 0.02 & -0.36 & 0.13 & 0.06 & 0.79 & 0.11 & 0.53 \\
Presence of & 0.16 & 0.36 & 0.09 & 0.68 & 0.43 & 0.04 & 0.03 & 0.87 \\
co-morbiditie(s) & & & & & & & 0.03 & \\
CDS score & -0.00 & 0.90 & -0.02 & 0.22 & 0.01 & 0.36 & 0.00 & 0.97 \\
EQ-5D score & -0.16 & 0.59 & 0.05 & 0.88 & -0.24 & 0.48 & 0.13 & 0.64 \\
HADS-A score & 0.02 & 0.41 & -0.03 & 0.31 & 0.02 & 0.49 & -0.03 & 0.20 \\
HADS-D score & 0.05 & 0.04 & -0.04 & 0.21 & 0.02 & 0.46 & -0.01 & 0.59 \\
\hline
\end{tabular}

Abbreviations: $C D S=$ Care Dependency Scale; $C O P D=$ Chronic Obstructive Pulmonary Disease; $C H F=$ Chronic Heart Failure; $C R F=$ Chronic Renal Failure; EQ-5D= EuroQol-5 Dimensions; HADS-A= Hospital Anxiety and Depression Scale, Anxiety subscale; HADS-D= Hospital Anxiety and Depression Scale, Depression subscale. $n=159$.

Caregiver strain, positive caregiving appraisals and family wellbeing are comparable for family caregivers of patients with COPD, CHF, or CRF. Caregiver distress may be higher for family caregivers of patients with COPD than CHF. The experience of caregiving is influenced by being the patient's spouse, patient's psychological symptoms and presence of co-morbidities.

\section{Characteristics of family caregivers}

The fact that most family caregivers in the present study are female partners of patients confirms previous findings. ${ }^{8,9,13}$ Caregiver strain may be higher for family caregivers being the partner of patients. A previous study on family caregivers of older patients with $\mathrm{CHF}$ did not show an association between relationship of the caregiver to the patient and caregiver strain. However, this study did show that being a patient's spouse was associated with lower health-related quality of life of the family caregiver. ${ }^{8}$ Especially for spouses, adopting the role of a caregiver may have a major impact on the relationship with the patient. ${ }^{8,16,35,36}$ Partners are often confronted with new tasks, restriction of social activities and major changes in life. ${ }^{1,}$ 12, 16 This may explain why caregiving strain may be higher in partners of patients. Therefore, healthcare professionals need to pay attention to the emotional and practical needs of partners of patients with advanced chronic organ failure. 


\section{Caregiving and relationship with patient characteristics}

The experience of caregiving was not related to patient characteristics such as sex; age; marital status; smoking status; self-perceived mobility problems; self-perceived poor health; and severity of dyspnea. Surprisingly, caregiver strain or caregiver distress did not show an association with the level of care dependency or the presence of a professional caregiver. Other patient and caregiver characteristics seem to have more impact on the experience of caregiving. Indeed, in the present study, caregiver strain has shown a relationship with symptoms of depression of the patient. Psychological distress is highly prevalent in patients with advanced chronic organ failure and their caregivers. ${ }^{15,37,38}$ Dealing with moodiness of the patient and providing emotional support may be one of the most challenging tasks for family caregivers. ${ }^{12,}$ ${ }^{35,}{ }^{36}$ However, patients without informal caregiver may even be more confronted with anxiety than patients with a family caregiver. ${ }^{15}$ Therefore, careful attention needs to be paid to family caregivers of patients with psychological symptoms.

A qualitative study of family caregivers of patients with moderate to severe COPD has suggested that the presence of co-morbidities may cause additional caregiver burden. $^{35}$ This is confirmed by the present study. Because co-morbidities are highly prevalent in patients with advanced chronic organ failure, ${ }^{23}$ this may be an important factor to consider in assessment of the impact of family caregiving.

\section{Positive aspects of caregiving}

The qualitative study of Barnes and colleagues ${ }^{8}$ suggested that positive aspects of caregiving, such as having someone close to talk to and sharing of problems are relevant for family caregivers of CHF patients. Our study confirms that positive aspects of caregiving are important for family caregivers of patients with advanced COPD, CHF or CRF. Indeed, positive aspects of caregiving and family wellbeing are rated relatively positive.

\section{Limitations}

The present study has some limitations. First, some of the patients refused to identify a family caregiver because they were afraid of the extra burden for family caregivers caused by participation in the study. In addition, some of the eligible family caregivers refused to participate. It may be possible that these family caregivers experienced a higher level of caregiver burden than family caregivers who were willing to participate. This confirms the previously reported challenge of recruiting family caregivers of patients with advanced chronic diseases. ${ }^{39}$ Second, most participating caregivers were female partners of patients. The present study did not 
show an association between the experience of caregiving and sex of the family caregiver. Also, previous studies in caregivers of COPD, CHF or cancer patients did not show this association. ${ }^{9,} 17$ However, the experience of male family caregivers may be underrepresented in this study and further studies are necessary to explore the experience of caregiving in male family caregivers. Third, most CRF patients in the present study performed haemodialysis. Caregiver burden may be higher in CRF patients performing peritoneal dialysis than in patients performing haemodialysis. ${ }^{13}$ Therefore, the results of the present study may not be representative for CRF patients performing peritoneal dialysis. Fourth, we did not study psychosocial symptoms and coping strategies of the family caregiver, although previous studies have shown a relationship between psychosocial symptoms, coping and caregiver burden. ${ }^{8,9,40}$ Finally, the present study is a cross-sectional study and the experience of caregiving may change during the course of the disease. However, a recent study showed little change in caregiver burden over one year in caregivers of patients with COPD, CHF or cancer. ${ }^{17}$

\section{Conclusion}

Caregiver strain, positive caregiving appraisals and family wellbeing are comparable for family caregivers of patients with COPD, CHF or CRF. Caregiver distress may be higher for family caregivers of patients with COPD than CHF. Positive caregiving appraisals are important aspects of the experience of family caregiving in outpatients with advanced COPD, CHF and CRF. Healthcare providers of patients with advanced chronic organ failure should therefore pay attention to caregiver burden as well as positive aspects of family caregiving. Partners of patients, family caregivers of patients with psychological symptoms, and caregivers of patients suffering from co-morbidities need careful attention. 


\section{References}

1. Fitzsimons, D., D. Mullan, J.S. Wilson, B. Conway, B. Corcoran, M. Dempster, J. Gamble, C. Stewart, S. Rafferty, M. McMahon, J. MacMahon, P. Mulholland, P. Stockdale, E. Chew, L. Hanna, J. Brown, G. Ferguson, and D. Fogarty, The challenge of patients' unmet palliative care needs in the final stages of chronic illness. Palliat Med. 2007;21(4):313-22.

2. Incalzi, R.A., A. Corsonello, C. Pedone, F. Corica, P. Carbonin, and R. Bernabei, Construct validity of activities of daily living scale: a clue to distinguish the disabling effects of COPD and congestive heart failure. Chest. 2005;127(3):830-8.

3. Annegarn, J., K. Meijer, V.L. Passos, K. Stute, J. Wiechert, H.H. Savelberg, A.M. Schols, E.F. Wouters, and M.A. Spruit, Problematic Activities of Daily Life are Weakly Associated With Clinical Characteristics in COPD. J Am Med Dir Assoc. 2011 Published online ahead of print. DOI:10.1016/j.jamda. 2011.01.002

4. Janssen, D.J., F.M. Franssen, E.F. Wouters, J.M. Schols, and M.A. Spruit, Impaired health status and care dependency in patients with advanced COPD or chronic heart failure. Qual Life Res. 2011;20(10):1679-88.

5. Hwang, B., M.L. Luttik, K. Dracup, and T. Jaarsma, Family caregiving for patients with heart failure: types of care provided and gender differences. J Card Fail.16(5):398-403.

6. Emanuel, E.J., D.L. Fairclough, J. Slutsman, H. Alpert, D. Baldwin, and L.L. Emanuel, Assistance from family members, friends, paid care givers, and volunteers in the care of terminally ill patients. $\mathrm{N}$ Engl J Med. 1999;341(13):956-63.

7. Elkington, H., P. White, J. Addington-Hall, R. Higgs, and P. Edmonds, The healthcare needs of chronic obstructive pulmonary disease patients in the last year of life. Palliat Med. 2005;19(6):485-91.

8. Barnes, S., M. Gott, S. Payne, C. Parker, D. Seamark, S. Gariballa, and N. Small, Characteristics and views of family carers of older people with heart failure. Int J Palliat Nurs. 2006;12(8):380-9.

9. Pinto, R.A., M.A. Holanda, M.M. Medeiros, R.M. Mota, and E.D. Pereira, Assessment of the burden of caregiving for patients with chronic obstructive pulmonary disease. Respir Med. 2007;101(11):24028.

10. Dracup, K., L.S. Evangelista, L. Doering, D. Tullman, D.K. Moser, and M. Hamilton, Emotional wellbeing in spouses of patients with advanced heart failure. Heart Lung. 2004;33(6):354-61.

11. Luttik, M.L., T. Jaarsma, I. Lesman, R. Sanderman, and M. Hagedoorn, Quality of life in partners of people with congestive heart failure: gender and involvement in care. J Adv Nurs. 2009;65(7):144251.

12. Pressler, S.J., I. Gradus-Pizlo, S.D. Chubinski, G. Smith, S. Wheeler, J. Wu, and R. Sloan, Family caregiver outcomes in heart failure. Am J Crit Care. 2009;18(2):149-59.

13. Belasco, A., D. Barbosa, A.R. Bettencourt, S. Diccini, and R. Sesso, Quality of life of family caregivers of elderly patients on hemodialysis and peritoneal dialysis. Am J Kidney Dis. 2006;48(6):955-63.

14. Hasson, F., A. Spence, M. Waldron, G. Kernohan, D. McLaughlin, B. Watson, and B. Cochrane, Experiences and needs of bereaved carers during palliative and end-of-life care for people with chronic obstructive pulmonary disease. J Palliat Care. 2009;25(3):157-63.

15. Boyd, K.J., S.A. Murray, M. Kendall, A. Worth, T. Frederick Benton, and H. Clausen, Living with advanced heart failure: a prospective, community based study of patients and their carers. Eur J Heart Fail. 2004;6(5):585-91.

16. Luttik, M.L., A. Blaauwbroek, A. Dijker, and T. Jaarsma, Living with heart failure: partner perspectives. J Cardiovasc Nurs. 2007;22(2):131-7.

17. Garlo, K., J.R. O'Leary, P.H. Van Ness, and T.R. Fried, Burden in caregivers of older adults with advanced illness. J Am Geriatr Soc. 2010;58(12):2315-22.

18. Yamamoto-Mitani, N., K. Ishigaki, M. Kuniyoshi, N. Kawahara-Maekawa, K. Hayashi, K. Hasegawa, and C. Sugishita, Subjective quality of life and positive appraisal of care among Japanese family caregivers of older adults. Qual Life Res. 2004;13(1):207-21. 
19. Kim, Y., F. Baker, and R.L. Spillers, Cancer caregivers' quality of life: effects of gender, relationship, and appraisal. J Pain Symptom Manage. 2007;34(3):294-304.

20. Luttik, M.L., T. Jaarsma, N. Veeger, J. Tijssen, R. Sanderman, and D.J. van Veldhuisen, Caregiver burden in partners of Heart Failure patients; limited influence of disease severity. Eur J Heart Fail. 2007;9(6-7):695-701.

21. Janssen, D.J., E.F. Wouters, J.M. Schols, and M.A. Spruit, Self-perceived symptoms and care needs of patients with severe to very severe chronic obstructive pulmonary disease, congestive heart failure or chronic renal failure and its consequences for their closest relatives: the research protocol. BMC Palliat Care. 2008;7:5.

22. Janssen, D.J., M.A. Spruit, J.M. Schols, and E.F. Wouters, A call for high-quality advance care planning in outpatients with severe COPD or chronic heart failure. Chest. 2011;139(5):1081-88.

23. Janssen, D.J., M.A. Spruit, N.H. Uszko-Lencer, J.M. Schols, and E.F. Wouters, Symptoms, comorbidities and healthcare in advanced COPD or chronic heart failure. J Palliat Med. 2011;14(6):73543.

24. Steinhauser, K.E., E.C. Clipp, J.C. Hays, M. Olsen, R. Arnold, N.A. Christakis, J.H. Lindquist, and J.A. Tulsky, Identifying, recruiting, and retaining seriously-ill patients and their caregivers in longitudinal research. Palliat Med. 2006;20(8):745-54.

25. Charlson, M.E., P. Pompei, K.L. Ales, and C.R. MacKenzie, A new method of classifying prognostic comorbidity in longitudinal studies: development and validation. J Chronic Dis. 1987;40(5):373-83.

26. Rutten, F.H., M.J. Cramer, N.P. Zuithoff, J.W. Lammers, W. Verweij, D.E. Grobbee, and A.W. Hoes, Comparison of B-type natriuretic peptide assays for identifying heart failure in stable elderly patients with a clinical diagnosis of chronic obstructive pulmonary disease. Eur J Heart Fail. 2007;9(6-7):6519.

27. Standardization of Spirometry, 1994 Update. American Thoracic Society. Am J Respir Crit Care Med. 1995;152(3):1107-36.

28. Dolan, P., Modeling valuations for EuroQol health states. Med Care. 1997;35(11):1095-108.

29. Zigmond, A.S. and R.P. Snaith, The hospital anxiety and depression scale. Acta Psychiatr Scand. 1983;67(6):361-70.

30. Wilson, R.C. and P.W. Jones, A comparison of the visual analogue scale and modified Borg scale for the measurement of dyspnoea during exercise. Clin Sci (Lond). 1989;76(3):277-82.

31. Dijkstra, A., L.J. Tiesinga, W.T. Goossen, and T.W. Dassen, Further psychometric testing of the Dutch Care Dependency Scale on two different patient groups. Int J Nurs Pract. 2002;8(6):305-14.

32. Dijkstra, A., L.J. Tiesinga, L. Plantinga, G. Veltman, and T.W. Dassen, Diagnostic accuracy of the care dependency scale. J Adv Nurs. 2005;50(4):410-6.

33. Cooper, B., G.J. Kinsella, and C. Picton, Development and initial validation of a family appraisal of caregiving questionnaire for palliative care. Psychooncology. 2006;15(7):613-22.

34. Altman, D.G., S.M. Gore, M.J. Gardner, and S.J. Pocock, Statistical guidelines for contributors to medical journals. Br Med J (Clin Res Ed). 1983;286(6376):1489-93.

35. Simpson, A.C., J. Young, M. Donahue, and G. Rocker, A day at a time: caregiving on the edge in advanced COPD. Int J Chron Obstruct Pulmon Dis.5:141-51.

36. Gysels, M.H. and I.J. Higginson, Caring for a person in advanced illness and suffering from breathlessness at home: threats and resources. Palliat Support Care. 2009;7(2):153-62.

37. Janssen, D.J., M.A. Spruit, E.F. Wouters, and J.M. Schols, Daily symptom burden in end-stage chronic organ failure: a systematic review. Palliat Med. 2008;22(8):938-48.

38. Janssen, D.J., M.A. Spruit, C. Leue, C. Gijsen, H. Hameleers, J.M. Schols, and E.F. Wouters, Symptoms of anxiety and depression in COPD patients entering pulmonary rehabilitation. Chron Respir Dis.7(3):147-57.

39. Barnes, S., M. Gott, S. Payne, C. Parker, D. Seamark, S. Gariballa, and N. Small, Recruiting older people into a large, community-based study of heart failure. Chronic IIIn. 2005;1(4):321-9. 
40. Riedijk, S.R., M.E. De Vugt, H.J. Duivenvoorden, M.F. Niermeijer, J.C. Van Swieten, F.R. Verhey, and A. Tibben, Caregiver burden, health-related quality of life and coping in dementia caregivers: a comparison of frontotemporal dementia and Alzheimer's disease. Dement Geriatr Cogn Disord. 2006;22(5-6):405-12. 


\section{CHAPTER 8}

A call for high-quality advance care planning

\section{in outpatients with severe COPD or chronic heart failure}




\section{Abstract}

\section{Background}

Patients with severe COPD or Chronic Heart Failure (CHF) are often confronted with decisions concerning life-sustaining treatments. The aim of this prospective observational study was to assess life-sustaining treatment preferences, advance care planning, and the quality of end-of-life care communication in Dutch outpatients with clinically stable but severe COPD or CHF.

\section{Methods}

The following outcomes were assessed in outpatients with severe COPD $(n=105)$ or CHF ( $n=80$ ): life-sustaining treatment preferences (CPR and mechanical ventilation; Willingness to Accept Life-sustaining Treatment instrument); advance care planning, and quality of end-of-life care communication (Quality of Communication questionnaire).

\section{Results}

Most patients asserted that in their current health status, they would prefer CPR (COPD, 70.5\%; CHF, 62.5\%) and/or mechanical ventilation (COPD, 70.5\%; CHF, 66.3\%). Patients' treatment preferences were influenced by burden of treatment, outcome of treatment and likelihood of outcome. Advance directives were discussed with the physician specialist by $5.9 \%$ of patients with COPD and $3.9 \%$ of patients with CHF. Patients rated quality of patient-physician end-of-life care communication as poor. Physicians rarely discussed prognosis, dying, and palliative care.

\section{Conclusions}

Despite the fact that patients are able to indicate their preferences regarding lifesustaining treatments, based on burden of treatment, outcome of treatment and likelihood of outcome, these preferences are rarely discussed with their physician specialist. This study shows a need for advance care planning, taking into account the burden of treatment, outcome of treatment and likelihood of outcome, in patients with severe COPD or CHF. Finally, the quality of patient-physician end-of-life care communication needs to improve. 


\section{Introduction}

Patients with life-limiting chronic diseases, their loved ones, and their physicians are often confronted with decisions concerning life-sustaining treatments. ${ }^{1}$ Indeed, the unpredictable disease trajectories of COPD and chronic heart failure (CHF) increase the need for early patient-physician communication regarding life-sustaining treatments. $^{2,3}$

Predicting patients' preferences regarding life-sustaining treatments often remains difficult. $^{4-6}$ This, in turn, may limit the provision of care at the end of life according to the patient's wishes. ${ }^{1,7}$ Therefore, physicians need to know their patients' preferences regarding life-sustaining treatments, such as CPR and mechanical ventilation (MV). In fact, most patients with severe COPD or CHF appear to have lifesustaining treatment preferences. ${ }^{6,8,9}$

Preferences regarding life-sustaining treatments may depend not only on the specific treatment, but also on treatment burden, expected outcome, and likelihood of outcome as has been shown in patients with COPD or CHF with a limited life expectancy in the United States. ${ }^{10,11}$ To date, European data are lacking.

Recent studies have shown the benefits to patients and their loved ones of advance care planning. ${ }^{12,13}$ A randomized controlled trial showed that end-of-life wishes of patients receiving advance care planning were much more likely to be known and followed than in the control group. Advance care planning reduced stress, anxiety, and depression in family members of deceased patients. ${ }^{13}$

Patients have identified communication as one of the most important skills of physicians in providing adequate end-of-life care. ${ }^{14}$ Next to discussing life-sustaining treatment preferences, patient-physician end-of-life care communication needs to include prognosis, process of dying, and preferred place of terminal care. ${ }^{5,15-17}$ Currently, patient-physician end-of-life care communication remains rare. ${ }^{16}$

Previous studies concerning quality of end-of-life care communication have mainly been performed in COPD patients in the United States. ${ }^{16}$ Because regional differences may exist in patient-physician communication, ${ }^{16,18}$ the quality of patientphysician end-of-life care communication remains unknown in European patients with severe COPD or CHF.

Therefore, we aimed to explore life-sustaining treatment preferences, advance care planning, and quality of end-of-life care communication in Dutch outpatients with clinically stable, but severe COPD or CHF. A priori, we hypothesized that patients 
with severe COPD or CHF are able to report their life-sustaining treatment preferences, but that advance care planning and end-of-life care communication remain inadequate.

\section{Materials and Methods}

\section{Design}

This prospective cross-sectional study is part of a longitudinal study concerning selfperceived symptoms and care needs in patients with severe COPD or CHF, and the consequences for their closest relatives. ${ }^{19}$ The methodology of this study was described previously. ${ }^{19}$ The Medical Ethical Commission of the Maastricht University Medical Centre + (MUMC+), Maastricht, the Netherlands, approved this study (MEC 07-3-054).

\section{Study population}

The study population consisted of a convenience sample of outpatients with severe COPD or CHF, recruited by physician specialists at the outpatient consultation of one academic and five general hospitals in the Netherlands in 2008 and 2009. Patients were eligible if they had a diagnosis of severe COPD (Global initiative for chronic Obstructive Lung Disease (GOLD) stage III or IV) or CHF (New York Heart Association (NYHA) class III or IV). Demographics were collected from eligible patients who refused participation in the study for comparison with participating patients. All participating patients gave written informed consent. In addition, the chest physicians and cardiologists of the participating patients were asked to participate. Chest physicians of 101 patients with COPD (96.2\%) and cardiologists of 51 patients with CHF (63.8\%) volunteered to participate $(p<0.05)$.

\section{Instruments}

The following factors were assessed during home visits: weight and height, lung function, and previous CPR or MV. Patients reported co-morbidities using the Charlson comorbidity index. ${ }^{20}$ Patients' preferences in their current health status for CPR and MV were assessed using two validated questions. ${ }^{4}$ In addition, the presence of advance care planning and the preferred site of terminal care were studied.

Patients' life-sustaining treatment preferences were elaborated using the Willingness to Accept Life-sustaining Treatment instrument (WALT), which consists of six scenarios in which patients weigh treatment burden against treatment outcome, 
expressed in likelihood of different health states and length of life following treatment. $^{10,11}$ Scenario 1 concerned low-burden therapy and likelihood of death vs return to current health. Scenario 2 concerned low-burden therapy and length of life following therapy. Scenario 3 concerned high-burden therapy and likelihood of death vs return to current health. Scenario 4 concerned high-burden therapy and length of life following therapy. Scenario 5 concerned low-burden therapy and likelihood of functional impairment (being bedbound) vs return to current health. Scenario 6 concerned low-burden therapy and likelihood of cognitive impairment (not recognizing family members) vs return to current health. ${ }^{11}$

Quality of communication with the physician specialist was assessed using the Quality of Communication (QOC) questionnaire. ${ }^{16,21}$ The QOC questionnaire consisted of two domains (general communication and end-of-life care communication). ${ }^{21}$ Scores ranged from 0 (worst) to 10 (best)..$^{21}$ Finally, for each participating patient, the physician specialist was asked to complete a written questionnaire concerning expected prognosis of survival and advance care planning.

\section{Statistics}

Statistics were compiled using SPSS, version 17.0 (SPSS, Inc; Chicago, Illinois) and Stata 11.1 (StataCorp LP; College Station, Texas). Categorical variables were described as frequencies, whereas continuous variables were tested for normality and are presented as mean and SD or median and interquartile range. Comparison of continuous variables between patients with COPD and CHF was done using independent sample $t$ tests or Mann-Whitney $U$ tests, as appropriate. Categorical variables were compared between patients with COPD and CHF using Chi square tests. The influence of general and clinical patient characteristics on preferences regarding CPR and MV was determined using univariate analysis, followed by logistic regression analysis. A log-rank test was used to compare life-sustaining treatment preferences for COPD and CHF for each WALT scenario. To analyze whether and to what extent patients' treatment preferences are influenced by burden of treatment and likelihood of treatment outcome, scenario 3, 5, and 6 were compared with scenario 1 using a log-rank test. ${ }^{10} \mathrm{QOC}$ domain scores were compared between patients with COPD and patients with CHF using linear regression analysis, with robust standard errors and clustered by physician, while controlling for general and clinical patient characteristics. A priori, a two-sided level of significance was set at $p \leq 0.05$. $^{22}$ 


\section{Results}

\section{General patient characteristics}

One hundred five patients with COPD and 80 patients with $\mathrm{CHF}$ were included. The proportion of eligible patients who participated in the study was $62.9 \%$ for patients with COPD and $46.0 \%$ for patients with CHF $(p<0.05)$. Chest physicians referred a median of 5 (one to 10) patients and cardiologists referred 2 (one to three) participating patients. Most patients with COPD had very severe COPD (GOLD stage IV, 73.3\%). Patients with CHF were classified mainly as NYHA class III (92.5\%). On average, patients with $\mathrm{CHF}$ were older, had a higher BMI and were expected to have a worse prognosis of survival compared with patients with COPD (Table 8.1).

Table 8.1 General patient characteristics

\begin{tabular}{|c|c|c|}
\hline Characteristic & $\begin{array}{l}\text { COPD } \\
(n=105)\end{array}$ & $\begin{array}{l}\mathrm{CHF} \\
(n=80)\end{array}$ \\
\hline Age, years & $66.3(9.2)^{a}$ & $76.2(8.3)$ \\
\hline $\mathrm{BMI}, \mathrm{kg} / \mathrm{m}^{2 \mathrm{~b}}$ & $26.3(6.7)^{a}$ & $28.6(5.6)$ \\
\hline Charlson index, points & $2.5(1.7)^{a}$ & $4.4(2.0)$ \\
\hline Proportion of patients with $\geq 1$ co morbidity & $65(61.9 \%)^{\mathrm{a}}$ & 77 (96.3\%) \\
\hline $\mathrm{FEV}_{1}, \%$ predicted $^{\mathrm{b}}$ & $34.1(13.5)^{\mathrm{a}}$ & $75.5(24.5)$ \\
\hline Male gender & $65(61.9 \%)$ & $54(67.5 \%)$ \\
\hline Marital status, married / living with partner & $78(74.3 \%)^{\mathrm{a}}$ & $45(56.3 \%)$ \\
\hline Current smoker & $26(24.8 \%)^{a}$ & $11(13.8 \%)$ \\
\hline LTOT & $62(59.0 \%)^{\mathrm{a}}$ & $10(12.5 \%)$ \\
\hline NPPV & $28(26.7 \%)^{a}$ & $1(1.3 \%)$ \\
\hline Dependent in personal care & $47(44.8 \%)$ & $48(60.0 \%)$ \\
\hline Self-perceived mobility problems & $89(84.8 \%)$ & $72(90.0 \%)$ \\
\hline Self-perceived poor health & $18(17.1 \%)$ & $14(17.5 \%)$ \\
\hline Previous CPR & $5(4.9 \%)^{\mathrm{a}}$ & $12(16.2 \%)$ \\
\hline Previous $\mathrm{MV}^{\mathrm{c}}$ & $20(19.4 \%)$ & $19(25.7 \%)$ \\
\hline Visits general practitioner at least every 6 months & $57(54.3 \%)^{\mathrm{a}}$ & $25(31.3 \%)$ \\
\hline Visits physician specialist at least every 6 months & $91(86.7 \%)$ & $62(77.5 \%)$ \\
\hline \multicolumn{3}{|l|}{ Expected prognosis of survival ${ }^{d}$} \\
\hline$<6$ months & $0(0 \%)^{a}$ & $2(3.9 \%)$ \\
\hline 6-12 months & $15(14.9 \%)$ & $12(23.5 \%)$ \\
\hline$>12$ months & $86(85.1 \%)^{a}$ & $33(64.7 \%)$ \\
\hline unknown & $0(0 \%)^{a}$ & $4(7.8 \%)$ \\
\hline
\end{tabular}

Data are presented as mean (SD) or number of patients (\%). Abbreviations: $\mathrm{CHF}=$ Chronic Heart Failure (CHF); LTOT= Long-Term Oxygen Therapy; MV= Mechanical Ventilation; NPPV= Non-invasive Positive Pressure Ventilation. ${ }^{\mathrm{a}} \mathrm{p}<0.05 \mathrm{vs} \mathrm{CHF} ;{ }^{\mathrm{b}}$ non-parametric statistical tests were used because of skewed data; ${ }^{c}$ COPD: $n=103 ;$ CHF: $n=74 ;{ }^{d}$ COPD: $n=101 ; C H F: n=51$.

Participating patients were younger than those who refused participation. Moreover, participants with COPD had more advanced disease, whereas participants with CHF were more often men than were nonparticipants. 


\section{Preferences regarding life-sustaining treatments}

\section{Preferences regarding CPR and MV}

Most patients reported that they preferred CPR (COPD, 70.5\%; CHF, 62.5\%; $p>0.05$ ) and/or MV (COPD, 70.5\%; CHF, 66.3\%, p>0.05). Only a minority of patients were not able to indicate preferences regarding CPR (COPD, 1.9\%; CHF, 3.7\%; $>>0.05$ ) or MV (COPD, 3.8\%; $\mathrm{CHF}, 3.7 \%$; $>0.05$ ). Univariate analysis of the relationship of general and clinical patient characteristics with a preference regarding CPR or MV suggested an association between living alone, dependency on personal care, and refusing CPR and/or MV. None of the other patient characteristics shown in Table 8.1 was related to preference regarding CPR or MV $(p \geq 0.10)$. Logistic regression analysis confirmed these findings. Patients who were living alone were more likely to refuse CPR or MV. Furthermore, patients who needed help with personal care were more likely to refuse CPR or MV (Table 8.2).

Table 8.2 Influence of general patient characteristics on preferences for CPR and MV

\begin{tabular}{lllll}
\hline CPR & & $\mathrm{n}$ & Prefers CPR, $\mathrm{n}(\%)$ & Odds ratio (95\% Cl) \\
\hline Marital status & $\begin{array}{l}\text { Married / living with } \\
\text { partner }\end{array}$ & 120 & $94(75.8)$ & 1.0 \\
& $\begin{array}{l}\text { Living alone } \\
\text { Personal care }\end{array}$ & 60 & $30(24.2)$ & $3.68(1.87-7.28)$ \\
& Not dependent & 88 & $68(54.8)$ & 1.0 \\
& Dependent & 92 & $56(45.2)$ & $2.25(1.14-4.44)$ \\
\hline MV & & $\mathrm{n}$ & Prefers MV, $\mathrm{n}(\%)$ & Odds ratio (95\% Cl) \\
\hline Marital status & Married / living with & 120 & $92(72.4)$ & 1.0 \\
& partner & & & \\
& Living alone & 58 & $35(27.6)$ & $2.17(1.09-4.30)$ \\
Personal care & Not dependent & 86 & $68(53.5)$ & 1.0 \\
& Dependent & 92 & $59(46.5)$ & $2.12(1.07-4.19)$ \\
\hline
\end{tabular}

Abbreviation: $\mathrm{MV}=$ Mechanical Ventilation.

\section{Life-sustaining treatment preferences according to treatment burden, treatment outcome, and likelihood of outcome}

Most patients were able to report their treatment preferences according to treatment burden and treatment outcome as assessed with the WALT (Tables 8.3 and 8.4). The proportion of patients with COPD or CHF choosing treatment decreased as the likelihood of death or functional or cognitive impairment as the outcome of treatment increased. The proportion of patients choosing treatment did not change when the likelihood of an adverse outcome was $<10 \%$ (Table 8.3).

In addition, the proportion of patients with COPD or CHF choosing treatment increased when life extension following treatment increased (Table 8.4). 


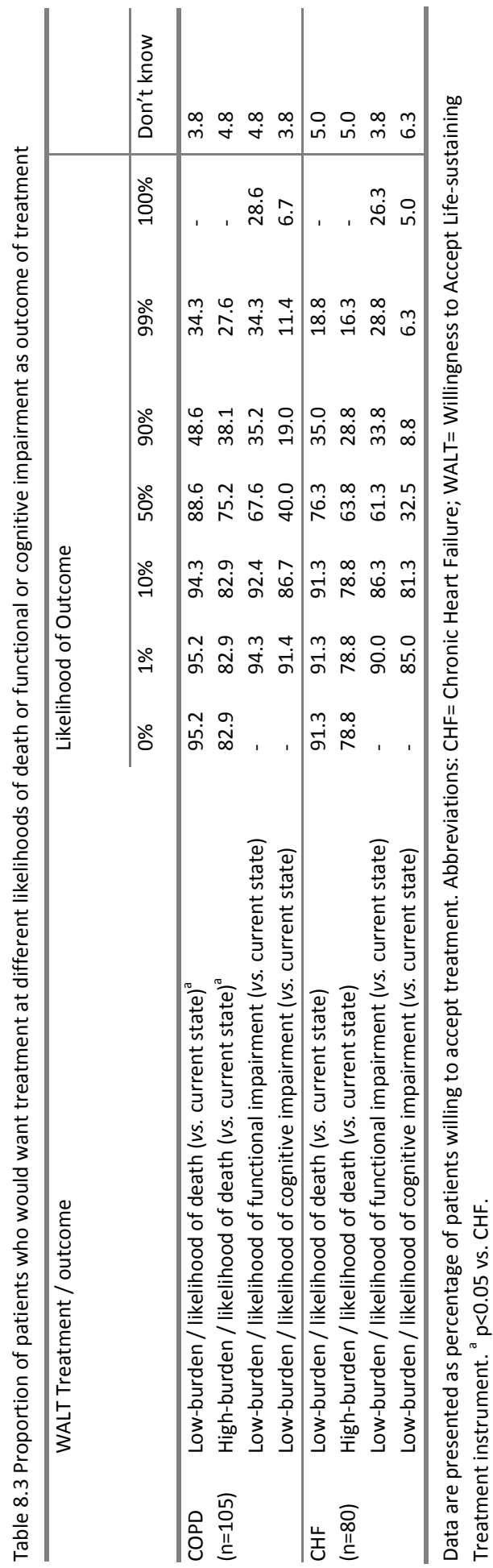


Table 8.4 Proportion of patients who would want treatment with outcome of different degrees of life extension

\begin{tabular}{llllll|l}
\hline & WALT Treatment & \multicolumn{2}{l|}{ Life extension } & \\
& & & & \\
\cline { 3 - 7 } & & & & & \\
\hline COPD & Low-burden & 34.3 & 52.4 & 83.8 & 90.5 & 1.9 \\
(n=105) & High-burden & 25.7 & 39.0 & 69.5 & 76.2 & 4.8 \\
\hline CHF & Low-burden & 22.5 & 47.5 & 67.5 & 85.0 & 2.5 \\
$(n=80)$ & High-burden & 17.5 & 38.8 & 65.0 & 76.3 & 2.5 \\
\hline
\end{tabular}

Data are presented as percentage of patients willing to accept treatment. Abbreviations: $\mathrm{CHF}=\mathrm{Chronic}$ Heart Failure (CHF); WALT= Willingness to Accept Life-sustaining Treatment instrument. COPD vs CHF $p>0.05$.

Patients with CHF were less willing to accept treatment scenario 1 (low-burden / likelihood of death) and scenario 3 (high-burden / likelihood of death) than were patients with COPD $(p<0.05)$ (Table 8.3). Other outcomes were comparable between patients with COPD or CHF. The proportion of patients choosing treatment was different for scenario 3 (high-burden / likelihood of death) and scenario 6 (lowburden / likelihood of cognitive impairment) compared with scenario 1 (low-burden / likelihood of death) ( $p<0.05$ for each comparison) (Figure 8.1).

Figure 8.1 Treatment preferences according to burden of treatment and likelihood of an adverse outcome

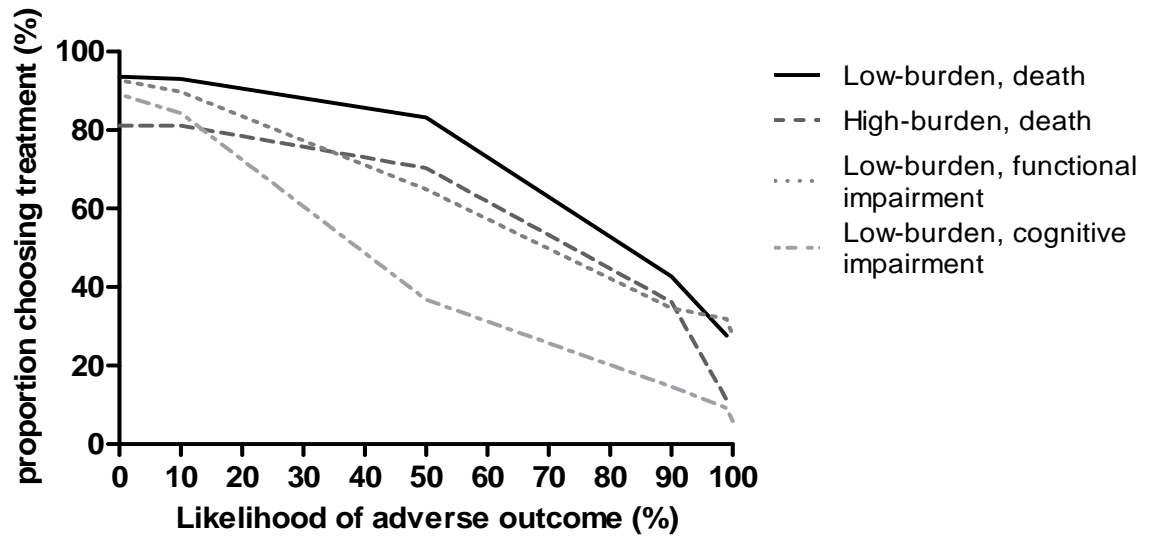

Proportion of COPD or Chronic Heart Failure patients who accepts treatment according to burden of treatment and likelihood of an adverse outcome. $p<0.05$ for comparison scenario 3 (high burden, death) and 6 (low burden, cognitive impairment) with scenario 1 (low burden, death). $\mathrm{n}=185$. 


\section{Preferences for site of dying}

Most patients with COPD (91.4\%) and patients with CHF $(86.3 \%)$ expressed a preferred site for care when they were likely to die. Preferences were comparable for COPD and CHF (Table 8.5). No statistically significant differences existed in preference for dying at home according to preference for MV or CPR ( $p>0.05)$.

Table 8.5 Preferences for place of dying

\begin{tabular}{lll}
\hline & COPD $(n=105)$ & CHF $(n=80)$ \\
\hline Home & $54(51.4)$ & $45(56.3)$ \\
Hospital & $30(28.6)$ & $16(20.0)$ \\
Hospice & $4(3.8)$ & $2(2.5)$ \\
Care home & $8(7.6)$ & $6(7.5)$ \\
Don't know & $9(8.6)$ & $11(13.7)$ \\
\hline
\end{tabular}

Data are presented as number of patients (\%). Abbreviation: $\mathrm{CHF}=$ Chronic Heart Failure. COPD vs CHF $p>0.05$.

\section{Advance care planning}

Chest physicians and cardiologists reported communication regarding CPR or MV with $19.8 \%$ and $15.7 \%$ of their patients, respectively. However, in only $5.9 \%$ of the COPD group and $3.9 \%$ of CHF group did the patient and physician specialist both report having discussed preferences regarding CPR or MV. The process of dying or palliative care was rarely discussed in both diseases (Table 8.6).

Table 8.6 Advance care planning according to physicians of patients with severe COPD or CHF

\begin{tabular}{lll}
\hline Advance care planning & COPD (n=101) & CHF $(n=51)$ \\
\hline $\begin{array}{l}\text { Preferences for CPR or MV discussed according to physician } \\
\text { Preferences for CPR or MV discussed according to patient and }\end{array}$ & $20(19.8)$ & $8(15.7)$ \\
physician & $6(5.9)$ & $2(3.9)$ \\
Prognosis of survival discussed & $16(15.8)$ & $6(11.8)$ \\
Process of dying discussed & $15(14.9)$ & $7(13.7)$ \\
Palliative care discussed & $11(10.9)$ & $7(13.7)$ \\
\hline
\end{tabular}

Data are presented as number of patients (\%). Abbreviations: $\mathrm{CHF}=$ Chronic Heart Failure; $\mathrm{MV}=\mathrm{Mechani}$ cal Ventilation. COPD vs $\mathrm{CHF} p>0.05$.

\section{Quality of patient-physician end-of-life care communication}

Patients with COPD and patients with CHF usually contacted their physician specialist once every 3 months (42.9\% and 36.3\%, respectively, $p>0.05$ ) or once every 6 months (41.9\% and $38.8 \%$, respectively, $p>0.05$ ). Patients with COPD and patients with $\mathrm{CHF}$ rated the general communication skills of their physician specialist high on the QOC questionnaire (median score 8.0 (7.0-9.0) points for chest physicians; 8.0 (7.0-8.7) points for cardiologists), whereas quality of end-of-life care communication was rated very low (median score 0.0 (0.0-2.3) points for chest physicians; 0.0 (0.0-1.3) points for cardiologists) (Figure 8.2). Quality of general communication and 
end-of-life care communication was comparable for COPD and CHF when controlling for patient characteristics and clustering for physician (adjusted $p=0.73$ and $\mathrm{p}=0.94$, respectively).

Figure 8.2 Quality of patient-physician general and end-of-life care communication

General communication skills

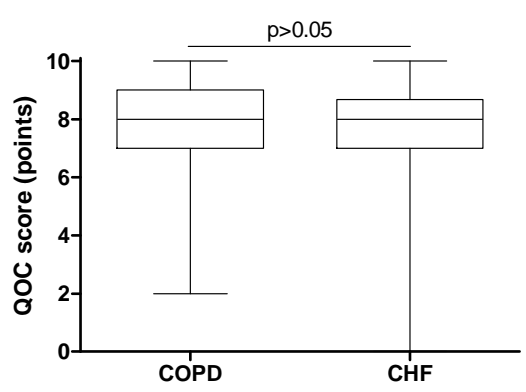

End-of-life care communication

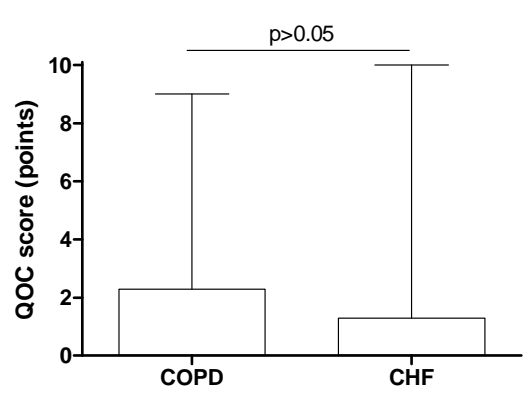

Median Quality of Communication (QOC) questionnaire scores and range for the domains general communication skills (left panel) and end-of-life care communication (right panel) in patients with severe COPD $(n=105)$ or CHF (Chronic Heart Failure) $(n=80)$.

Low median scores for end-of-life care communication were given mainly because most patients reported that items concerning end-of-life care were not discussed. Indeed, a majority of the physicians did not address 'talking about how long you have to live' (88.6\%), 'talking about what dying might be like' (88.6\%), 'asking about spiritual or religious beliefs' (93.4\%), 'involving you in treatment discussions about your care' (84.9\%) and 'asking you about important things in life' (83.2\%).

\section{Discussion}

The present study shows that the majority of Dutch outpatients with clinically stable severe COPD or CHF are able to indicate their preferences regarding life-sustaining treatments, depending on burden of treatment, outcome of treatment and likelihood of outcome. Despite the fact that patients can indicate preferences regarding life-sustaining treatments and end-of-life care, these preferences are rarely discussed with their physician specialist. Indeed, patients rate quality of patientphysician end-of-life care communication as low.

The finding that most patients with severe COPD or CHF prefer MV and CPR is in line with previous studies. ${ }^{4-6,8,23}$ However, the present study shows that most patients 
with severe COPD or CHF do not want highly burdensome interventions with a low likelihood of success. Indeed, the burden of MV or CPR and likelihood of an adverse outcome may be considerable in these patients. ${ }^{23-26}$ Therefore, patients may underestimate their likelihood of an adverse outcome. ${ }^{27}$ Because patients' prognosis of survival and life-sustaining treatment preferences are infrequently discussed by their physicians, the reported preferences for CPR and MV probably do not reflect informed and deliberated decisions taking into account treatment burden and likelihood of treatment outcome.

Previously, Fried and colleagues showed that treatment preferences of patients with COPD, CHF and cancer with a high probability of death in the next 6 month in the United States were influenced by burden of treatment, outcome of treatment and likelihood of outcome. ${ }^{10,11}$ In general, patients in the present study had a better estimated prognosis of survival. Only two patients were expected by their physician to die within 6 months. Nevertheless, our study in Dutch outpatients with severe COPD or CHF confirms the findings of Fried and colleagues and emphasizes again that the complexity of patients' life-sustaining treatment preferences asks for a thorough elaboration of these preferences.

Even though currently available statements regarding palliative care in COPD and CHF recommend advance care planning early in the course of the disease, ${ }^{2,3}$ this study shows a lack of advance care planning in outpatients with severe COPD or CHF. The general communication skills of physicians are rated high, whereas end-oflife care communication is rated very low. The present QOC questionnaire scores are somewhat lower than those of oxygen-dependent COPD patients in the United States. ${ }^{21}$ The finding that Dutch chest physicians and cardiologists do not address 'talking about how long you have to live', 'talking about what dying might be like' and 'asking about spiritual or religious beliefs' is in line with previous findings in the United States. ${ }^{16}$ The fact that prognosis of survival and end-of-life care are rarely discussed may arise from the fact that most physicians overestimate the survival of their patients. ${ }^{28}$ Furthermore, physicians may be afraid to take away patients' hope. ${ }^{29}$ However, a previous study by Curtis and colleagues ${ }^{30}$ has shown that patients and their families differ in their needs and desires for hope and explicit prognostic information. Therefore, patient-physician end-of-life care communication should be tailored to the patient's needs.

\section{Limitations}

The study population consists of a convenience sample. Although most eligible patients with COPD were willing to participate, the response rate for patients with $\mathrm{CHF}$ was $<50 \%$. It may be possible that eligible patients who refused participation in this 
study were less willing to discuss issues concerning end-of-life care. The current response rate confirms the previously reported difficulty of recruitment of older patients with $\mathrm{CHF}^{31}$ and may limit the generalizability of the results.

In addition, there were some small but significant differences between patients with COPD and CHF in some of the scenarios of the WALT. This may be due to differences in general characteristics of patients with COPD or CHF, such as the lower proportion of COPD patients who were living alone. Other general patient characteristics that differed between COPD and CHF did not show a relationship with lifesustaining treatment preferences.

Patients also receive care from their general practitioner and may have discussed end-of-life care with their general practitioner instead of their physician specialist. This was not assessed in the present study. However, patients had less frequent contact with their general practitioner than with their physician specialist. Therefore, the role of the physician specialist seems to be more prominent in care for the current sample.

Patients who suffer from co-morbidities were not excluded from the analyses. In turn, this may have influenced the results of the study. However, co-morbidities in patients with COPD or CHF are very common ${ }^{32}$ and this increases the general validity of the current findings. Furthermore, preferences regarding CPR or MV did not show a relationship with the presence of co-morbidities.

Finally, the present study is a cross-sectional study and treatment preferences may change during the course of the disease. ${ }^{6,33-35}$ A longitudinal follow-up is needed to study change of life-sustaining treatment preferences over time in patients with severe COPD or CHF.

\section{Conclusions}

To conclude, the current findings emphasize the lack of advance care planning in Dutch clinically stable outpatients with severe COPD or CHF. Increased awareness among chest physicians and cardiologists that advance care planning is an essential component of care for patients with severe COPD or CHF is necessary. Finally, the quality of patient-physician end-of-life care communication needs to improve. 


\section{References}

1. Lynn, J., J.M. Teno, R.S. Phillips, A.W. Wu, N. Desbiens, J. Harrold, M.T. Claessens, N. Wenger, B. Kreling, and A.F. Connors, Jr., Perceptions by family members of the dying experience of older and seriously ill patients. SUPPORT Investigators. Study to Understand Prognoses and Preferences for Outcomes and Risks of Treatments. Ann Intern Med. 1997;126(2):97-106.

2. Lanken, P.N., P.B. Terry, H.M. Delisser, B.F. Fahy, J. Hansen-Flaschen, J.E. Heffner, M. Levy, R.A. Mularski, M.L. Osborne, T.J. Prendergast, G. Rocker, W.J. Sibbald, B. Wilfond, and J.R. Yankaskas, An official American Thoracic Society clinical policy statement: palliative care for patients with respiratory diseases and critical illnesses. Am J Respir Crit Care Med. 2008;177(8):912-27.

3. Jaarsma, T., J.M. Beattie, M. Ryder, F.H. Rutten, T. McDonagh, P. Mohacsi, S.A. Murray, T. Grodzicki, I. Bergh, M. Metra, I. Ekman, C. Angermann, M. Leventhal, A. Pitsis, S.D. Anker, A. Gavazzi, P. Ponikowski, K. Dickstein, E. Delacretaz, L. Blue, F. Strasser, and J. McMurray, Palliative care in heart failure: a position statement from the palliative care workshop of the Heart Failure Association of the European Society of Cardiology. Eur J Heart Fail. 2009;11(5):433-43.

4. Stapleton, R.D., E.L. Nielsen, R.A. Engelberg, D.L. Patrick, and J.R. Curtis, Association of depression and life-sustaining treatment preferences in patients with COPD. Chest. 2005;127(1):328-34.

5. Formiga, F., D. Chivite, C. Ortega, S. Casas, J.M. Ramon, and R. Pujol, End-of-life preferences in elderly patients admitted for heart failure. QJM. 2004;97(12):803-8.

6. Krumholz, H.M., R.S. Phillips, M.B. Hamel, J.M. Teno, P. Bellamy, S.K. Broste, R.M. Califf, H. Vidaillet, R.B. Davis, L.H. Muhlbaier, A.F. Connors, Jr., J. Lynn, and L. Goldman, Resuscitation preferences among patients with severe congestive heart failure: results from the SUPPORT project. Study to Understand Prognoses and Preferences for Outcomes and Risks of Treatments. Circulation. 1998;98(7):648-55.

7. Tanvetyanon, T. and J.C. Leighton, Life-sustaining treatments in patients who died of chronic congestive heart failure compared with metastatic cancer. Crit Care Med. 2003;31(1):60-4.

8. Gaber, K.A., M. Barnett, Y. Planchant, and C.R. McGavin, Attitudes of 100 patients with chronic obstructive pulmonary disease to artificial ventilation and cardiopulmonary resuscitation. Palliat Med. 2004;18(7):626-9.

9. Heffner, J.E., B. Fahy, L. Hilling, and C. Barbieri, Attitudes regarding advance directives among patients in pulmonary rehabilitation. Am J Respir Crit Care Med. 1996;154(6 Pt 1):1735-40.

10. Fried, T.R., E.H. Bradley, V.R. Towle, and H. Allore, Understanding the treatment preferences of seriously ill patients. N Engl J Med. 2002;346(14):1061-6.

11. Fried, T.R., E.H. Bradley, and V.R. Towle, Assessment of patient preferences: integrating treatments and outcomes. J Gerontol B Psychol Sci Soc Sci. 2002;57(6):S348-54.

12. Silveira, M.J., S.Y. Kim, and K.M. Langa, Advance directives and outcomes of surrogate decision making before death. N Engl J Med. 2010;362(13):1211-8.

13. Detering, K.M., A.D. Hancock, M.C. Reade, and W. Silvester, The impact of advance care planning on end of life care in elderly patients: randomised controlled trial. BMJ. 2010;340:c1345.

14. Curtis, J.R., M.D. Wenrich, J.D. Carline, S.E. Shannon, D.M. Ambrozy, and P.G. Ramsey, Understanding physicians' skills at providing end-of-life care perspectives of patients, families, and health care workers. J Gen Intern Med. 2001;16(1):41-9.

15. Curtis, J.R., M.D. Wenrich, J.D. Carline, S.E. Shannon, D.M. Ambrozy, and P.G. Ramsey, Patients' perspectives on physician skill in end-of-life care: differences between patients with COPD, cancer, and AIDS. Chest. 2002;122(1):356-62.

16. Curtis, J.R., R.A. Engelberg, E.L. Nielsen, D.H. Au, and D.L. Patrick, Patient-physician communication about end-of-life care for patients with severe COPD. Eur Respir J. 2004;24(2):200-5.

17. Fried, T.R., C. van Doorn, J.R. O'Leary, M.E. Tinetti, and M.A. Drickamer, Older persons' preferences for site of terminal care. Ann Intern Med. 1999;131(2):109-12. 
18. Schoen, C., R. Osborn, S.K. How, M.M. Doty, and J. Peugh, In chronic condition: experiences of patients with complex health care needs, in eight countries, 2008. Health Aff (Millwood). 2009;28(1):w1-16.

19. Janssen, D.J., E.F. Wouters, J.M. Schols, and M.A. Spruit, Self-perceived symptoms and care needs of patients with severe to very severe chronic obstructive pulmonary disease, congestive heart failure or chronic renal failure and its consequences for their closest relatives: the research protocol. BMC Palliat Care. 2008;7:5.

20. Charlson, M.E., P. Pompei, K.L. Ales, and C.R. MacKenzie, A new method of classifying prognostic comorbidity in longitudinal studies: development and validation. J Chronic Dis. 1987;40(5):373-83.

21. Engelberg, R., L. Downey, and J.R. Curtis, Psychometric characteristics of a quality of communication questionnaire assessing communication about end-of-life care. J Palliat Med. 2006;9(5):1086-98.

22. Altman, D.G., S.M. Gore, M.J. Gardner, and S.J. Pocock, Statistical guidelines for contributors to medical journals. Br Med J (Clin Res Ed). 1983;286(6376):1489-93.

23. Claessens, M.T., J. Lynn, Z. Zhong, N.A. Desbiens, R.S. Phillips, A.W. Wu, F.E. Harrell, Jr., and A.F. Connors, Jr., Dying with lung cancer or chronic obstructive pulmonary disease: insights from SUPPORT. Study to Understand Prognoses and Preferences for Outcomes and Risks of Treatments. J Am Geriatr Soc. 2000;48(5 Suppl):S146-53.

24. Pochard, F., J.J. Lanore, F. Bellivier, I. Ferrand, J.P. Mira, M. Belghith, F. Brunet, and J.F. Dhainaut, Subjective psychological status of severely ill patients discharged from mechanical ventilation. Clin Intensive Care. 1995;6(2):57-61.

25. Hill, A.T., R.B. Hopkinson, and D.E. Stableforth, Ventilation in a Birmingham intensive care unit 19931995: outcome for patients with chronic obstructive pulmonary disease. Respir Med. 1998;92(2):156-61.

26. Seneff, M.G., D.P. Wagner, R.P. Wagner, J.E. Zimmerman, and W.A. Knaus, Hospital and 1-year survival of patients admitted to intensive care units with acute exacerbation of chronic obstructive pulmonary disease. JAMA. 1995;274(23):1852-7.

27. Nava, S., C. Santoro, M. Grassi, and N. Hill, The influence of the media on COPD patients' knowledge regarding cardiopulmonary resuscitation. Int J Chron Obstruct Pulmon Dis. 2008;3(2):295-300.

28. Christakis, N.A. and E.B. Lamont, Extent and determinants of error in doctors' prognoses in terminally ill patients: prospective cohort study. Bmj. 2000;320(7233):469-72.

29. Knauft, E., E.L. Nielsen, R.A. Engelberg, D.L. Patrick, and J.R. Curtis, Barriers and facilitators to end-oflife care communication for patients with COPD. Chest. 2005;127(6):2188-96.

30. Curtis, J.R., R. Engelberg, J.P. Young, L.K. Vig, L.F. Reinke, M.D. Wenrich, B. McGrath, E. McCown, and A.L. Back, An approach to understanding the interaction of hope and desire for explicit prognostic information among individuals with severe chronic obstructive pulmonary disease or advanced cancer. J Palliat Med. 2008;11(4):610-20.

31. Barnes, S., M. Gott, S. Payne, C. Parker, D. Seamark, S. Gariballa, and N. Small, Recruiting older people into a large, community-based study of heart failure. Chronic IIIn. 2005;1(4):321-9.

32. Rutten, F.H., M.J. Cramer, J.W. Lammers, D.E. Grobbee, and A.W. Hoes, Heart failure and chronic obstructive pulmonary disease: An ignored combination? Eur J Heart Fail. 2006;8(7):706-11.

33. Fried, T.R., J. O'Leary, P. Van Ness, and L. Fraenkel, Inconsistency over time in the preferences of older persons with advanced illness for life-sustaining treatment. J Am Geriatr Soc. 2007;55(7):100714.

34. Levenson, J.W., E.P. McCarthy, J. Lynn, R.B. Davis, and R.S. Phillips, The last six months of life for patients with congestive heart failure. J Am Geriatr Soc. 2000;48(5 Suppl):S101-9.

35. Lynn, J., E.W. Ely, Z. Zhong, K.L. McNiff, N.V. Dawson, A. Connors, N.A. Desbiens, M. Claessens, and E.P. McCarthy, Living and dying with chronic obstructive pulmonary disease. J Am Geriatr Soc. 2000;48(5 Suppl):S91-100. 



\section{CHAPTER 9 \\ Predicting changes in preferences for life- sustaining treatment among patients with advanced chronic organ failure}

Daisy J.A. Janssen, Martijn A. Spruit, Jos M.G.A. Schols, Bianca Cox, Tim S. Nawrot, J. Randall Curtis and Emiel F.M. Wouters

Chest, 2011. Published online ahead of print. 


\section{Abstract}

\section{Background}

For clinicians discussing advance care planning with patients with life-limiting illness, it is important to understand the stability of patients' preferences for life-sustaining treatments and the factors that predict a change in preferences. Our objectives were to investigate one-year stability of preferences regarding cardiopulmonary resuscitation (CPR) and mechanical ventilation (MV) for outpatients with advanced chronic obstructive pulmonary disease (COPD), chronic heart failure (CHF) or chronic renal failure (CRF) and to identify predictors of changes in preferences.

\section{Methods}

265 clinically stable outpatients with advanced COPD, CHF or CRF were visited at baseline and then every four months for one year, to assess preferences regarding $\mathrm{CPR}$ and MV in their current health status. Generalized estimating equations were used to examine the association between change in life-sustaining treatment preferences and several potential predictors, including changes in co-morbidities, hospital admissions, generic health status, care dependency, mobility and symptoms of anxiety or depression.

\section{Results}

One-year follow-up was completed by $77.7 \%$ of patients. Preferences regarding CPR or MV changed in $38.3 \%$ of the patients during follow-up. Changes over time in generic health status, mobility, symptoms of anxiety and depression, and marital status were associated with changes in life-sustaining treatment preferences.

\section{Conclusions}

More than a third of the outpatients with advanced COPD, CHF or CRF change their preferences regarding CPR and/or MV at least once during one year. Regular reevaluation of advance care planning is necessary, in particular when patients experience a change in health status, mobility, symptoms of anxiety or depression, or marital status. 


\section{Introduction}

Patients with advanced chronic organ failure are often able to specify their preferences for life-sustaining treatments, like preferences regarding cardiopulmonary resuscitation (CPR) or mechanical ventilation (MV). ${ }^{1}$ Discussing these preferences is an important component of advance care planning in patients with chronic obstructive pulmonary disease (COPD), chronic heart failure (CHF) or chronic renal failure (CRF). ${ }^{1,2}$ Effective advance care planning can result in improved outcomes for patients and their loved ones. ${ }^{3,4}$ Patients who have prepared a living will receive care that is more strongly associated with their preferences than those without a living will. ${ }^{5}$ Moreover, a randomized trial demonstrates that advance care planning results in increased documentation of end-of-life care wishes and improved concordance between treatment preferences and treatments received for elderly hospitalized patients as well as significantly less stress, anxiety and depression among family members and increased patient and family satisfaction with care. ${ }^{6}$

For clinicians discussing advance care planning, it is important to understand the stability of patients' life-sustaining treatment preferences. Some studies show a consistent pattern in life-sustaining treatment preferences of different patient populations over a period of $12-30$ months, ${ }^{7,8}$ while other studies report changes during a two-year follow up. ${ }^{9-13}$ Life-sustaining treatment preferences of patients with COPD or CHF may be less stable compared to cancer patients. ${ }^{11}$ Stability of preferences regarding CPR and $\mathrm{MV}$ in patients on dialysis is currently unknown.

The identification of potential predictors of changes in life-sustaining treatment preferences may allow clinicians to better understand and monitor these preferences and provides the opportunity for timely re-evaluation of advance care planning. To date, declines in health status and/or psychological functioning appear to result in decreased interest in life-sustaining treatments. ${ }^{10,14}$ However, a study of physicians did not show an association between their life-sustaining treatment preferences and declines in physical and mental health status during three-year follow-up. ${ }^{15}$ Therefore, the currently available literature does not offer clear guidance concerning potential predictors of changes in preferences regarding CPR and/or MV in patients with advanced chronic organ failure.

Objectives of the present study were to investigate one-year stability of preferences regarding CPR and MV in outpatients with advanced COPD, CHF or CRF and to identify potential predictors of changes in preferences regarding CPR and MV. A priori, we hypothesized that life-sustaining treatment preferences of outpatients with advanced chronic organ failure change during one year follow up and that a de- 
crease in generic health status is associated with less willingness to undergo CPR and/or MV.

\section{Methods and materials}

\section{Study design}

The current data are part of a multi-centre prospective longitudinal study concerning self-perceived symptoms and care needs in patients with advanced COPD, CHF or CRF. ${ }^{16}$ Patients were visited in their home environment at baseline and every four months after baseline for a period of one year. Baseline data concerning advance care planning, symptom distress, health status and care dependency were published previously. ${ }^{1,17,18}$ The Medical Ethical Committee of the Maastricht University Medical Centre + (MUMC+), Maastricht, the Netherlands, approved this study (MEC 07-3-054). The study was registered at the Dutch Trial Register (NTR 1552).

\section{Patients}

A convenience sample of clinically stable outpatients with advanced COPD, CHF or CRF was recruited by their physician specialist at the outpatient clinic of one academic and six general hospitals in the Netherlands between January 2008 and June 2009. Patients were eligible if they had a diagnosis of severe to very severe COPD (Global initiative for chronic Obstructive Lung Disease (GOLD) stage III or IV); advanced CHF (New York Heart Association (NYHA) class III or IV); or advanced CRF (requiring dialysis). All patients provided written informed consent.

\section{Measurements}

The following outcomes were assessed at each visit: demographics; current selfreported co-morbidities (Charlson comorbidity index ${ }^{19}$ ); the number of hospital admissions since the previous visit; patients' preferences in their current health status for CPR and invasive $\mathrm{MV}^{20}$ (Table 9.1); symptoms of anxiety and depression using the Hospital Anxiety and Depression Scale (HADS ${ }^{21}$; generic health status using the self-administered questionnaires EuroQol-5 Dimensions (EQ-5D) ${ }^{22}$ and the Medical Outcomes Study 36-Item Short-Form Health Survey (SF-36) ${ }^{23}$; physical mobility using the timed ' Up and Go' (TUG) test ${ }^{24}$; and care dependency using the Care Dependency Scale (CDS) ${ }^{25}$. All instruments have been described before. ${ }^{16}$ 
Table 9.1 Questions asked to patients about their treatment preferences

\begin{tabular}{ll}
\hline Treatment & Question \\
\hline MV & 'The first treatment is short-term mechanical ventilation. You would be in an ICU, and a \\
& tube would be placed through your mouth or nose into your lungs. This tube would be \\
& attached to a breathing machine for a few days. During that time, you would have to be \\
& continuously on the breathing machine and would be unable to talk. If you were in your \\
& current health and were unable to breathe on your own, would you want to be on a \\
& breathing machine for a few days? There would be no guarantee that you would be able \\
& to come off the breathing machine and be able to breathe on your own.' \\
& 'The second treatment is CPR, which consists of electric shocks to the heart, pumping on \\
& the chest, help with breathing and heart medications given through the veins. Possible \\
& side effects of CPR include broken ribs and memory loss. Because you would be uncon- \\
Scious, other people would need to make the decision for you regarding your treatment. & In your current health, would you want resuscitation (CPR) if your heart were to stop \\
beating?'
\end{tabular}

Abbreviations: $\mathrm{CPR}=$ Cardiopulmonary Resuscitation; $\mathrm{MV}=$ Mechanical Ventilation.

\section{Statistical analysis}

Statistics were done using SPSS 18.0 (SPSS Inc, Chicago, IL) and SAS 9.2 (SAS Institute, Cary, NC). Categorical variables were described as frequencies, while continuous variables were tested for normality and are presented as mean and standard deviation (SD). We used frequencies to describe one-year stability of preferences regarding CPR and $M V$ in patients who completed all visits $(n=206)$. We defined the following categories: unchanged preference (patient provided the same response at each interview); decreased willingness (preference changed from preferred treatment into refused treatment during follow up visits); increased willingness (preference changed from refused treatment into preferred treatment during follow up visits); and variable preference (inconsistent pattern of preferences or 'don't know' responses). We used generalized estimating equations (GEE), with autoregressive correlation structure ${ }^{26}$ to identify longitudinal predictors of change in preferences regarding CPR or MV. We developed two models for both CPR and MV: one model including change from refuses to prefers versus no change as dependent variable and a second model including change from prefers to refuses versus no change as dependent variable. We took this approach because, a priori, we anticipated that the predictors of a change from prefers to refuses life-sustaining treatment would be different from a change from refuses to prefers. Possible predictor variables, including number of hospital admissions (one or more versus none), marital status (single versus living with a spouse), co-morbidities (Charlson comorbidity index score), generic health status (EQ-5D score, SF-36 physical component summary measure score and SF-36 mental component summary measure score), care dependency (CDS score), symptoms of anxiety and depression (HADS-A and HADS-D score), and mobility problems (TUG test in seconds) and the interaction of each 
variable with time, were subsequently modelled as possible explanatory variables. Results are presented as odds ratios (OR) and 95\% confidence intervals. For continuous variables, the OR represents the OR for an inter-quartile range increase of the variable. A priori, a two-sided level of significance was set at $p \leq 0.05 .^{27}$

\section{Results}

\section{Patient characteristics}

105 Patients with COPD, 80 patients with CHF and 80 patients with CRF were included. The proportion of eligible patients who participated in the study was $58.9 \%$. Most patients with COPD had very severe COPD (73.3\% GOLD stage IV). Patients with CHF were mainly classified as NYHA class III (92.5\%). Most patients with CRF performed haemodialysis $(96.2 \%)$ and only three patients $(3.8 \%)$ performed peritoneal dialysis. Participants were younger than non-participants (mean age: 68.0 (12.6) versus $74.0(10.9)$ years, $p<0.01)$. In addition, participants were more often male than non-participants ( $63.0 \%$ versus $49.2 \%, p<0.05$ ). Finally, COPD participants had more advanced disease than patients with COPD who refused participation (proportion GOLD stage IV: $73.3 \%$ versus $38.7 \%, p<0.05$ ).

All study visits were completed by 206 patients (77.7\% of enrolled patients). During the study period of 12 months, 59 patients (22.3\%) were withdrawn from the study: 24 patients (9.1\%) died, 7 patients (2.6\%) underwent renal transplantation, and 28 patients $(10.6 \%)$ withdrew from the study for other reasons (burden of the study, $n=14$; too ill, $n=10$; lost interest in the study, $n=3$; cognitive decline, $n=1$ ). Patients who died during the study were older at baseline, had a lower EQ-5D score, experienced more care dependency and needed more time to perform the TUG test than patients who completed the study (Table 9.2).

\section{Instability of life-sustaining treatment preferences}

During the study period, preferences regarding CPR and/or MV changed at least once in $38.3 \%$ of the patients.

At baseline, 152 patients (73.8\%) preferred CPR (Figure 9.1). This remained unchanged over time in 110 patients (53.4\%), while 29 patients $(14.1 \%)$ reported a decreased willingness to undergo CPR and 13 patients (6.3\%) reported a variable preference. At baseline, 51 patients (24.8\%) refused CPR. This remained unchanged in 17 patients $(8.3 \%)$, while 23 patients (11.2\%) reported an increased willingness and 11 patients showed a variable preference $(5.3 \%)$. Three patients $(1.4 \%)$ were 
unable to report a preference for CPR at baseline, but did report a preference at follow-up interviews.

A similar pattern emerges for preferences regarding MV (Figure 9.2). At baseline, 156 patients (75.7\%) preferred MV. This remained unchanged in 114 patients (55.3\%), while 28 patients (13.6\%) reported a decreased willingness to undergo MV and 14 patients $(6.8 \%)$ reported a variable preference. At baseline, 44 patients $(21.4 \%)$ refused MV. This remained unchanged in 13 patients $(6.3 \%)$, while 19 patients $(9.2 \%)$ reported an increased willingness and 12 patients showed a variable preference $(5.9 \%)$. Six patients $(2.9 \%)$ were unable to report a preference for MV at baseline, but did report a preference at follow-up interviews.

Table 9.2 Baseline patient characteristics

\begin{tabular}{|c|c|c|c|}
\hline & $\begin{array}{l}\text { Completed } \\
\text { study } \\
n=206\end{array}$ & $\begin{array}{l}\text { Died } \\
n=24\end{array}$ & $\begin{array}{l}\text { Withdrawn } \\
n=35\end{array}$ \\
\hline Age (years), mean (SD) & $67.2(13.1)^{\mathrm{a}}$ & $74.0(7.8)$ & $69.0(11.2)$ \\
\hline $\mathrm{BMI}\left(\mathrm{kg} / \mathrm{m}^{2}\right)$, mean $(\mathrm{SD})^{\mathrm{c}}$ & $26.7(6.2)$ & $27.5(8.1)$ & $26.6(4.8)$ \\
\hline Charlson index (points), mean (SD) & $3.4(2.0)$ & $3.9(2.4)$ & $3.7(1.7)$ \\
\hline Gender (male), n (\%) & $132(64.1 \%)$ & $14(58.3 \%)$ & $21(60.0 \%)$ \\
\hline Marital status (married / living with partner), n (\%) & $135(65.5 \%)$ & $17(70.8 \%)$ & $23(65.7)$ \\
\hline Current smokers, n (\%) & $41(19.9 \%)$ & $4(16.7 \%)$ & $4(11.4 \%)$ \\
\hline Dependent in personal care, $\mathrm{n}(\%)$ & $82(39.8 \%)^{a}$ & $17(70.8 \%)$ & $15(42.9 \%)$ \\
\hline Self-perceived mobility problems, $n(\%)$ & $161(78.2 \%)$ & $23(95.8 \%)^{b}$ & $22(62.9 \%)$ \\
\hline Self-perceived poor health, n (\%) & $29(14.1 \%)$ & $4(16.7 \%)$ & $6(17.1 \%)$ \\
\hline Prefers CPR at baseline, $\mathrm{n}(\%)$ & $152(73.8 \%)$ & $13(54.2 \%)$ & $25(71.4 \%)$ \\
\hline Prefers MV at baseline, $\mathrm{n}(\%)$ & $156(75.7 \%)$ & $14(58.3 \%)$ & $22(62.9 \%)$ \\
\hline Previous CPR, $\mathrm{n}(\%)^{\mathrm{d}}$ & $21(10.4 \%)$ & $2(10.5 \%)$ & $1(3.2 \%)$ \\
\hline Previous MV, $\mathrm{n}(\%)^{\mathrm{d}}$ & $46(22.8 \%)$ & $4(21.1 \%)$ & $6(19.4 \%)$ \\
\hline EQ-5D index score (points), mean (SD) & $0.58(0.30)^{\mathrm{a}}$ & $0.41(0.33)$ & $0.56(0.37)$ \\
\hline SF-36 physical component score (points), mean (SD) & $25.7(11.7)$ & $22.8(10.3)$ & 25.5 (12.9) \\
\hline SF-36 mental component score (points), mean (SD) & $48.4(13.1)$ & $45.3(15.7)$ & $48.2(12.7)$ \\
\hline Care Dependency Scale (points), mean (SD) ${ }^{c}$ & $68.1(7.5)^{\mathrm{a}}$ & $57.9(12.0)^{b}$ & $67.1(7.1)$ \\
\hline HADS-A score (points), mean (SD) & $5.1(4.0)$ & $6.0(5.6)$ & $5.5(4.5)$ \\
\hline HADS-D score (points), mean (SD) & $5.6(4.0)$ & $6.8(3.8)$ & $6.8(3.5)$ \\
\hline Timed 'Up and Go' test (sec), mean (SD) ce & $12.3(6.4)^{\mathrm{a}}$ & $18.6(13.3)^{b}$ & $12.6(5.4)$ \\
\hline
\end{tabular}

Abbreviations: $\mathrm{BMI}=$ Body Mass Index; $\mathrm{CPR}=$ Cardiopulmonary Resuscitation; $\mathrm{EQ}-5 \mathrm{D}=$ EuroQol-5 Dimensions; HADS-A= Hospital Anxiety and Depression Scale, Anxiety subscale; HADS-D= Hospital Anxiety and Depression Scale, Depression subscale; $M V=$ Mechanical Ventilation; SF-36=Short Form $36 .{ }^{a} p<0.05$ versus died; ${ }^{b} p<0.05$ versus withdrawn; ${ }^{c}$ non-parametric statistical tests have been used because of skewed data; ${ }^{d}$ completed: $n=202$, died: $n=19$, withdrawn: $n=31 ;{ }^{e}$ completed: $n=196$, died: $n=20$, withdrawn: $n=30$. 
Figure 9.1 Preferences regarding CPR at baseline, 4, 8 and 12 months

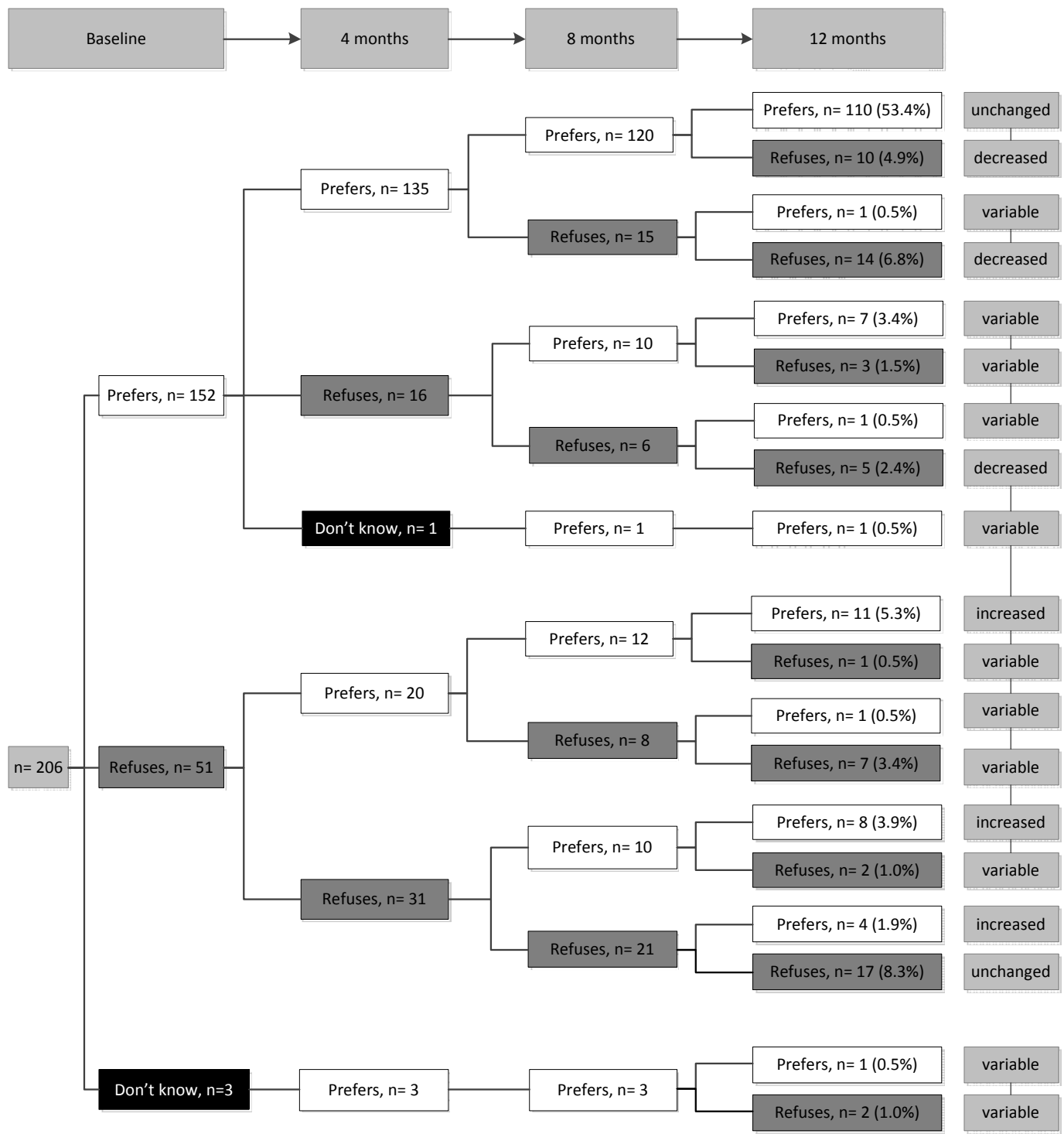

The sum of the individual proportions does not equal $100 \%$ due to rounding. 
Figure 9.2 Preferences regarding mechanical ventilation at baseline, 4, 8 and 12 months

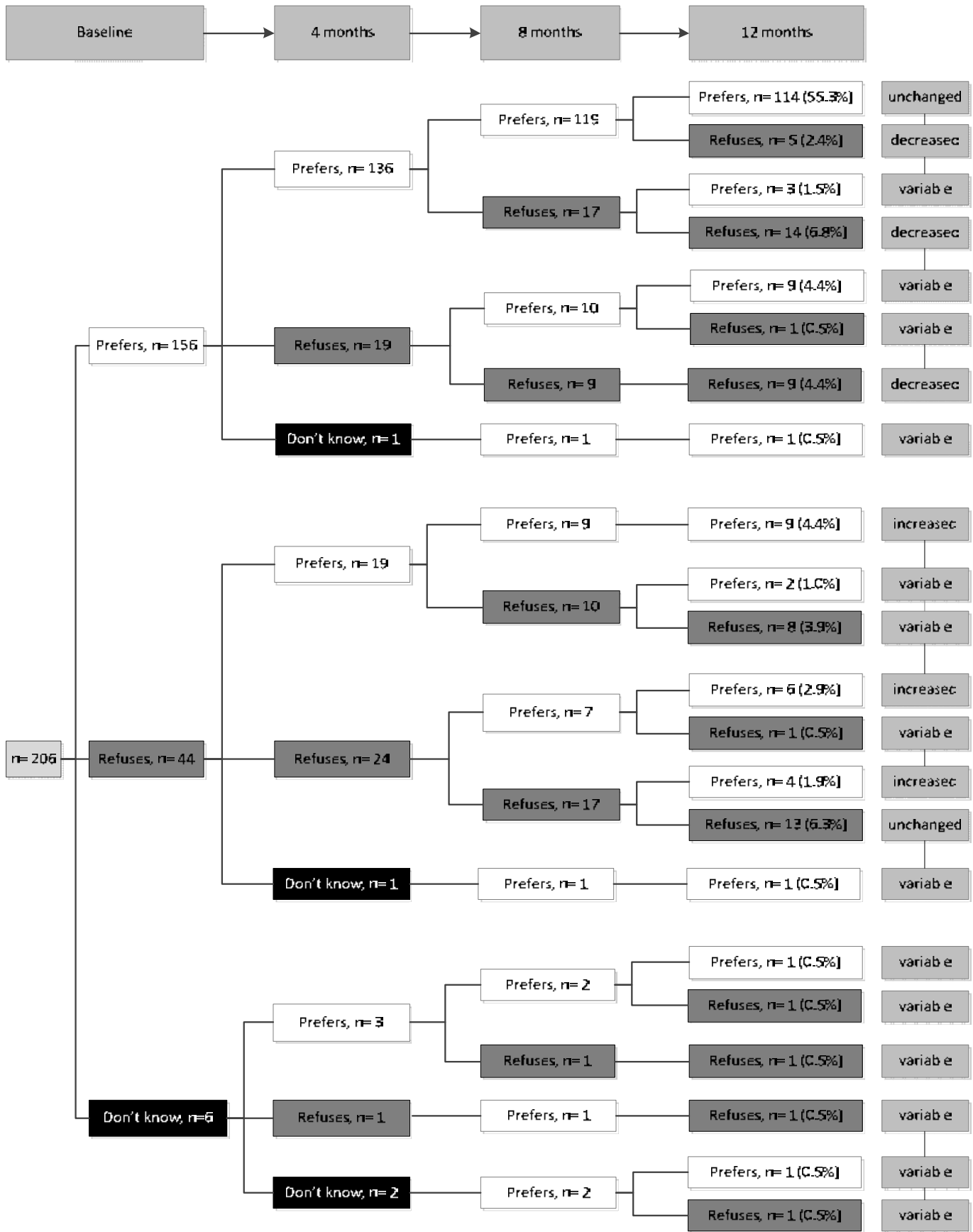

The sum of the individual proportions does not equal $100 \%$ due to rounding. 


\section{Predictors of changes in life-sustaining treatment preferences}

The GEE model identified several predictors for changes from preferring CPR and/or MV to refusing CPR and/or MV (Table 9.3). A decrease in EQ-5D index score or SF-36 physical component summary measure score (both worsening of generic health status) was associated with an increasing probability to change the preference regarding CPR or MV from prefers to refuses. A decrease in SF-36 mental component summary measure score was associated with an increasing probability to change preference regarding CPR from prefers to refuses. In addition, an increase in symptoms of anxiety (HADS-A score) or depression (HADS-D score) was associated with an increasing probability to change preference regarding CPR or MV from prefers to refuses. Furthermore, an increase in time needed to perform TUG test was associated with a change in preference regarding MV from prefers to refuses.

The GEE model also identified several predictors for changes from refusing CPR and/or MV to preferring CPR and/or MV (Table 9.3). Patients who went from living with a spouse to living alone were more likely to change from refusing to preferring CPR. In addition, a decrease in SF-36 physical component summary measure score was associated with an increasing probability to change from refuses to prefers MV. Finally, an increase in time needed to perform TUG test was associated with a change from refuses to prefers MV.

There was no association between change in preferences regarding CPR or MV and hospital admissions, changes in Charlson comorbidity index score or care dependency.

\section{Discussion}

The present study has two important findings. First, 38\% of the clinically stable outpatients with advanced COPD, CHF or CRF changed their preferences regarding CPR and/or MV at least once during one year follow up. Second, changes over time in generic health status, mobility, symptoms of anxiety and depression, and marital status were associated with changes in life-sustaining treatment preferences. Decreasing health status and increasing symptoms of anxiety or depression were associated with an increased likelihood of changing from prefer CPR and MV to refuse CPR and MV. Decreasing mobility was associated with an increased likelihood of changing from prefer MV to refuse MV. However, decreased health status and mobility were also associated with an increased likelihood of changing from refuse to prefer MV. 


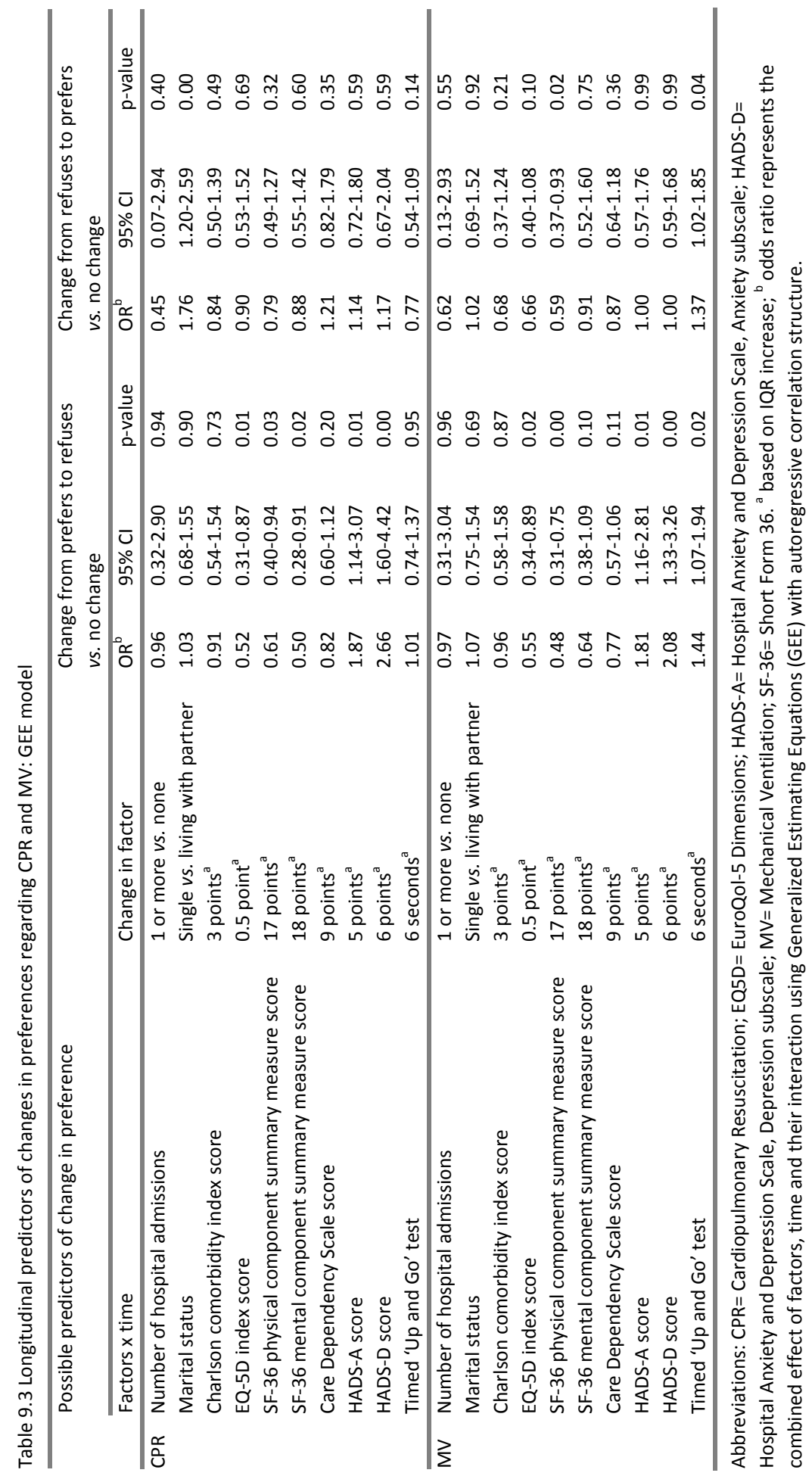


Previous studies have suggested that preferences for life-sustaining treatments show a stable pattern. ${ }^{9,28}$ For example, a study including a broad range of primary care patients showed that $75 \%$ of the patients who decided to forego CPR at study enrollment, also decided to forego CPR at follow-up at two years. ${ }^{9}$ Furthermore, $71 \%$ of the patients who decided at baseline to forego MV, had a stable preference at two years. ${ }^{9}$ In addition, a previous study of elderly persons showed that about $70 \%$ did not change their preferences for $\mathrm{CPR}, \mathrm{MV}$ or tube feeding during two years. $^{28}$

However, other authors have stated that life-sustaining treatment preferences are influenced by transient factors, rather than representing stable core values. ${ }^{11}$ In a longitudinal study, a large proportion of patients with advanced cancer, COPD or $\mathrm{CHF}$, were found to have inconsistent trajectories of willingness to undergo burdensome therapy. ${ }^{11}$ In this study, a variable health status was associated with inconsistent preferences regarding life-sustaining treatments. ${ }^{11}$ Our study shows an interesting relationship between change in health status and change in preferences for life-sustaining treatments. Deterioration in health status was associated with a change from prefers to refuses CPR and/or MV. This confirms our hypothesis and is in line with previous findings. ${ }^{14}$ However, deterioration in health status or mobility was also associated with increased willingness to undergo MV. These findings show the complex relationship of health status and life-sustaining treatment preferences. While for some patients a deterioration in health status is associated with a decreased willingness to undergo life-sustaining treatments, ${ }^{14}$ for other patients a deterioration in health status results in a greater willingness to undergo lifesustaining treatments. ${ }^{12}$ This likely reflects the complexity of decision-making. ${ }^{29}$ The reported preferences for $\mathrm{CPR}$ or MV may be influenced by transient factors like the affective state, as well as situational and environmental factors at the moment of the interview. ${ }^{30}$ Therefore, advance care planning should not be limited to discussing preferences for CPR or MV, but should include discussing patient's general goals, values and beliefs. ${ }^{31}$ Indeed, repeated assessments of preferences for CPR or MV, without discussing patient's general goals, values and beliefs, will increase the risk of decision fatigue, ${ }^{32}$ and as a result, may increase the likelihood that patient's responses don't reflect their true preferences. However, discussing general goals of care will facilitate the process of advance care planning and may be more stable over time. Nonetheless, it may be important to discuss life-sustaining treatment preferences with a change in health status. Since the course of chronic organ failure are typically marked by a gradual decline in health status and punctuated by unpredictable acute deteriorations in health status, ${ }^{33,34}$ this variable and unpredictable course may influence life-sustaining treatment preferences in these patients. 
We found that an increase in depression scores was associated with a change in preference regarding CPR and MV from prefers to refuses. A previous study in primary care patients suggested the opposite. An increase in depressive symptoms was associated with a desire for life-sustaining treatments. ${ }^{9}$ In contrast, among hospitalized patients refusing CPR at admission, a substantial improvement in depression was associated with increased preference for CPR at two months followup. ${ }^{13}$ Cross-sectional data have not shown a relationship between depressive symptoms and preferences regarding CPR or MV among veterans with COPD. ${ }^{35}$ It is difficult to reconcile these prior studies, but our longitudinal study shows that a change in mood status is associated with changes in preferences regarding CPR and/or MV in patients with advanced COPD, CHF or CRF.

Since changes in life-sustaining treatment preferences are related to changes in clinical outcomes, like health status and symptoms of anxiety or depression, it might be reasonable to assume that interventions designed to improve health status or symptoms of anxiety or depression can alter life-sustaining treatment preferences. Indeed, previous studies have shown that treatment of depression in elderly persons may result in an increased desire for life-sustaining treatments. ${ }^{36,37}$ Therefore, clinicians should be aware of the fact that improvement in clinical outcomes after interventions may result in change in life-sustaining treatment preferences.

\section{Methodological considerations}

Several limitations of the study should be considered in interpreting the results. First, our study consists of a convenience sample of patients. Although the majority of eligible patients with COPD or CRF were willing to participate, the response rate for patients with $\mathrm{CHF}$ was below $50 \%$. Moreover, there were some differences between participants and non-participants. The current response rate confirms the previously reported difficulty of recruitment of older patients with $\mathrm{CHF}^{38}$ and may limit the generalizability of the results. Second, $22.3 \%$ of the patients did not complete the study. Drop-out is to be expected in a longitudinal study of patients with an advanced chronic disease. Indeed, $11.7 \%$ of the included patients died or withdrew because of renal transplant. The remaining $10.6 \%$ withdrew from the study for other reasons. It remains unknown whether and to what extent this has influenced the current results. However, since the baseline characteristics and preferences of patients who withdrew from the study were similar to those of the patients who completed all visits, this suggests these individuals may be similar to those who completed all study visits. Third, the present study focused on specific life-sustaining interventions: CPR and MV. Preferences for life-sustaining interventions may not always reflect preferences for general goals of care. ${ }^{39}$ In fact, living wills that include acceptable health states may be better suited to patients' end-of-life care goals 
than those that focus on specific medical interventions. ${ }^{40}$ We did not study stability of health values or preferences for general goals of care. It may be possible that preferences for general goals of care show a more stable pattern than preferences for CPR and/or MV. Indeed, the Study to Understand Prognoses and Preferences for Outcomes and Risks of Treatments (SUPPORT) has shown that health values of seriously ill patients have excellent test-retest reliability and construct validity. However, this study also showed that health values may change over time, and therefore need to be evaluated regularly. ${ }^{41}$ Fourth, preferences for life-sustaining treatments are influenced by burden of treatment, expected outcome of treatment and the likelihood of an adverse outcome. ${ }^{1}$ We don't know which information concerning burden and expected outcome of CPR and MV physicians provided during the study period to participating patients that may have influenced their preferences for MV and CPR. Finally, it may be possible that participants reconsidered their lifesustaining treatment preferences due to the repeated assessments of their preferences during the study period.

\section{Conclusions and implications}

The present study shows that more than one-third of the outpatients with advanced chronic organ failure changed their preferences regarding CPR or MV at least once during one year follow up. Moreover, only a minority of the patients who decided at baseline to forego CPR or MV, had a stable preference during one year. A change in generic health status, mobility, symptoms of anxiety and depression, and marital status was associated with changes in preferences regarding life-sustaining treatments, including changes toward more and less aggressive life-sustaining treatments. This instability of life-sustaining treatment preferences suggests that advance care planning must be regularly re-evaluated, especially after changes in health status, mobility, symptoms of anxiety and depression, or marital status. Regular re-evaluation of advance care planning is likely to strengthen the value of advance directives. Our findings also have policy implications, supporting reimbursement for regular re-evaluation of advance care planning and advance directives. 


\section{References}

1. Janssen, D.J., M.A. Spruit, J.M. Schols, and E.F. Wouters, A call for high-quality advance care planning in outpatients with severe COPD or chronic heart failure. Chest. 2011;139(5):1081-88.

2. Davison, S.N., End-of-life care preferences and needs: perceptions of patients with chronic kidney disease. Clin J Am Soc Nephrol. 2010;5(2):195-204.

3. Teno, J.M., A. Gruneir, Z. Schwartz, A. Nanda, and T. Wetle, Association between advance directives and quality of end-of-life care: a national study. J Am Geriatr Soc. 2007;55(2):189-94.

4. Wright, A.A., B. Zhang, A. Ray, J.W. Mack, E. Trice, T. Balboni, S.L. Mitchell, V.A. Jackson, S.D. Block, P.K. Maciejewski, and H.G. Prigerson, Associations between end-of-life discussions, patient mental health, medical care near death, and caregiver bereavement adjustment. JAMA. 2008;300(14):166573.

5. Silveira, M.J., S.Y. Kim, and K.M. Langa, Advance directives and outcomes of surrogate decision making before death. N Engl J Med. 2010;362(13):1211-8.

6. Detering, K.M., A.D. Hancock, M.C. Reade, and W. Silvester, The impact of advance care planning on end of life care in elderly patients: randomised controlled trial. BMJ. 2010;340:c1345.

7. Patrick, D.L., R.A. Pearlman, H.E. Starks, K.C. Cain, W.G. Cole, and R.F. Uhlmann, Validation of preferences for life-sustaining treatment: implications for advance care planning. Ann Intern Med. 1997;127(7):509-17.

8. Emanuel, L.L., E.J. Emanuel, J.D. Stoeckle, L.R. Hummel, and M.J. Barry, Advance directives. Stability of patients' treatment choices. Arch Intern Med. 1994;154(2):209-17.

9. Danis, M., J. Garrett, R. Harris, and D.L. Patrick, Stability of choices about life-sustaining treatments. Ann Intern Med. 1994;120(7):567-73.

10. Ditto, P.H., W.D. Smucker, J.H. Danks, J.A. Jacobson, R.M. Houts, A. Fagerlin, K.M. Coppola, and R.M. Gready, Stability of older adults' preferences for life-sustaining medical treatment. Health Psychol. 2003;22(6):605-15.

11. Fried, T.R., J. O'Leary, P. Van Ness, and L. Fraenkel, Inconsistency over time in the preferences of older persons with advanced illness for life-sustaining treatment. J Am Geriatr Soc. 2007;55(7):100714.

12. Fried, T.R., A.L. Byers, W.T. Gallo, P.H. Van Ness, V.R. Towle, J.R. O'Leary, and J.A. Dubin, Prospective study of health status preferences and changes in preferences over time in older adults. Arch Intern Med. 2006;166(8):890-5.

13. Rosenfeld, K.E., N.S. Wenger, R.S. Phillips, A.F. Connors, N.V. Dawson, P. Layde, R.M. Califf, H. Liu, J. Lynn, and R.K. Oye, Factors associated with change in resuscitation preference of seriously ill patients. The SUPPORT Investigators. Study to Understand Prognoses and Preferences for Outcomes and Risks of Treatments. Arch Intern Med. 1996;156(14):1558-64.

14. Fried, T.R., P.H. Van Ness, A.L. Byers, V.R. Towle, J.R. O'Leary, and J.A. Dubin, Changes in preferences for life-sustaining treatment among older persons with advanced illness. J Gen Intern Med. 2007;22(4):495-501.

15. Wittink, M.N., K.H. Morales, L.A. Meoni, D.E. Ford, N.Y. Wang, M.J. Klag, and J.J. Gallo, Stability of preferences for end-of-life treatment after 3 years of follow-up: the Johns Hopkins Precursors Study. Arch Intern Med. 2008;168(19):2125-30.

16. Janssen, D.J., E.F. Wouters, J.M. Schols, and M.A. Spruit, Self-perceived symptoms and care needs of patients with severe to very severe chronic obstructive pulmonary disease, congestive heart failure or chronic renal failure and its consequences for their closest relatives: the research protocol. BMC Palliat Care. 2008;7:5.

17. Janssen, D.J., M.A. Spruit, N.H. Uszko-Lencer, J.M. Schols, and E.F. Wouters, Symptoms, comorbidities, and health care in advanced chronic obstructive pulmonary disease or chronic heart failure. J Palliat Med. 2011;14(6):735-43. 
18. Janssen, D.J., F.M. Franssen, E.F. Wouters, J.M. Schols, and M.A. Spruit, Impaired health status and care dependency in patients with advanced COPD or chronic heart failure. Qual Life Res. 2011;20(10):1679-88.

19. Charlson, M.E., P. Pompei, K.L. Ales, and C.R. MacKenzie, A new method of classifying prognostic comorbidity in longitudinal studies: development and validation. J Chronic Dis. 1987;40(5):373-83.

20. Stapleton, R.D., E.L. Nielsen, R.A. Engelberg, D.L. Patrick, and J.R. Curtis, Association of depression and life-sustaining treatment preferences in patients with COPD. Chest. 2005;127(1):328-34

21. Zigmond, A.S. and R.P. Snaith, The hospital anxiety and depression scale. Acta Psychiatr Scand. 1983;67(6):361-70.

22. Dolan, P., Modeling valuations for EuroQol health states. Med Care. 1997;35(11):1095-108.

23. Ware, J.E., K.K. Snow, and M. Kosinski, SF-36 health survey manual and interpretation guide. 1993, Boston MA: The Health Institute, New England Medical Center Hospitals.

24. Podsiadlo, D. and S. Richardson, The timed "Up \& Go": a test of basic functional mobility for frail elderly persons. J Am Geriatr Soc. 1991;39(2):142-8.

25. Dijkstra, A., L.J. Tiesinga, W.T. Goossen, and T.W. Dassen, Further psychometric testing of the Dutch Care Dependency Scale on two different patient groups. Int J Nurs Pract. 2002;8(6):305-14.

26. Diggle, P.J., K.Y. Liang, and S.L. Zeger, Analysis of Longitudinal Data. 1994: Oxford: Clarendon Press.

27. Altman, D.G., S.M. Gore, M.J. Gardner, and S.J. Pocock, Statistical guidelines for contributors to medical journals. Br Med J (Clin Res Ed). 1983;286(6376):1489-93.

28. Carmel, S. and E.J. Mutran, Stability of elderly persons' expressed preferences regarding the use of life-sustaining treatments. Soc Sci Med. 1999;49(3):303-11.

29. Slovic, P., The Construction of Preference. American Psychologist. 2005;50(5):364-71.

30. Loewenstein, G., Projection bias in medical decision making. Med Decis Making. 2005;25(1):96-105.

31. Janssen, D.J., R.A. Engelberg, E.F. Wouters, and J.R. Curtis, Advance care planning for patients with COPD: Past, present and future. Patient Educ Couns. 2011 Published online ahead of print. DOI:10.1016/j.pec.2011.01.007.

32. Vohs, K.D., R.F. Baumeister, B.J. Schmeichel, J.M. Twenge, N.M. Nelson, and D.M. Tice, Making choices impairs subsequent self-control: a limited-resource account of decision making, selfregulation, and active initiative. J Pers Soc Psychol. 2008;94(5):883-98.

33. Murtagh, F.E., E. Murphy, and N.S. Sheerin, Illness trajectories: an important concept in the management of kidney failure. Nephrol Dial Transplant. 2008;23(12):3746-8.

34. Murray, S.A., M. Kendall, K. Boyd, and A. Sheikh, Illness trajectories and palliative care. Bmj. 2005;330(7498):1007-11.

35. Reinke, L.F., C.G. Slatore, E.M. Udris, B.R. Moss, E.A. Johnson, and D.H. Au, The Association of Depression and Preferences for Life-Sustaining Treatments in Veterans with Chronic Obstructive Pulmonary Disease. J Pain Symptom Manage. 2011;41(2):402-11.

36. Ganzini, L., M.A. Lee, R.T. Heintz, J.D. Bloom, and D.S. Fenn, The effect of depression treatment on elderly patients' preferences for life-sustaining medical therapy. Am J Psychiatry. 1994;151(11):16316.

37. Eggar, R., A. Spencer, D. Anderson, and L. Hiller, Views of elderly patients on cardiopulmonary resuscitation before and after treatment for depression. Int J Geriatr Psychiatry. 2002;17(2):170-4.

38. Barnes, S., M. Gott, S. Payne, C. Parker, D. Seamark, S. Gariballa, and N. Small, Recruiting older people into a large, community-based study of heart failure. Chronic Illn. 2005;1(4):321-9.

39. McCarthy, E.P., M.J. Pencina, M. Kelly-Hayes, J.C. Evans, E.J. Oberacker, R.B. D'Agostino, Sr., R.B. Burns, and J.M. Murabito, Advance care planning and health care preferences of communitydwelling elders: the Framingham Heart Study. J Gerontol A Biol Sci Med Sci. 2008;63(9):951-9.

40. Rodriguez, K.L. and A.J. Young, Patients' and healthcare providers' understandings of life-sustaining treatment: are perceptions of goals shared or divergent? Soc Sci Med. 2006;62(1):125-33.

41. Tsevat, J., E.F. Cook, M.L. Green, D.B. Matchar, N.V. Dawson, S.K. Broste, A.W. Wu, R.S. Phillips, R.K. Oye, and L. Goldman, Health values of the seriously ill. SUPPORT investigators. Ann Intern Med. 1995;122(7):514-20. 


\section{CHAPTER 10 \\ Patient-clinician communication about end- of-life care for Dutch and US patients with COPD}

Daisy J.A. Janssen, J. Randall Curtis, David H. Au, Martijn A. Spruit, Lois Downey, Jos M.G.A. Schols, Emiel F.M. Wouters and Ruth A. Engelberg

Eur Resp J, 2011. 38(2): 268-276. 


\section{Abstract}

Improving patient-clinician communication about end-of-life care is important in order to enhance quality of care for patients with chronic obstructive pulmonary disease (COPD). Our objective was to compare quality of patient-clinician communication about end-of-life care, and endorsement of barriers and facilitators to this communication in the Netherlands and the USA.

The present study was an analysis of survey data from 122 Dutch and 391 US outpatients with COPD. We compared quality of patient-clinician communication about end-of-life care (Quality of Communication questionnaire) and barriers and facilitators to communication about end-of-life care (Barriers and Facilitators questionnaire) between the Netherlands and the USA, controlling for patients' demographic and illness characteristics.

Although Dutch patients in this study had worse lung function and disease-specific health status than US patients, Dutch patients reported lower quality of communication about end-of-life care (median score (interquartile range): 0.0 (0.0-2.0) versus $1.4(0.0-3.6)$, adjusted $p<0.005)$. Clinicians in both countries rarely discussed lifesustaining treatment preferences, prognoses, dying processes or spiritual issues.

Quality of communication about end-of-life care needs to improve in the Netherlands and the USA. Future studies to improve this communication should be designed to take into account international differences and patient-specific barriers and facilitators to communication about end-of-life care. 


\section{Introduction}

Because Chronic Obstructive Pulmonary Disease (COPD) is a major cause of mortality worldwide, ${ }^{1}$ the provision of high quality palliative care to these patients is an important priority. Understanding and improving patient-clinician communication about end-of-life care is one way to ensure the delivery of high-quality palliative care. ${ }^{2}$ Studies of patient-clinician communication about end-of-life care in COPD have been performed primarily in the USA. These studies have identified areas for improvement in communication about end-of-life care as well as barriers and facilitators to communication about end-of-life care in COPD. ${ }^{3,4}$

Important regional differences may exist in patient-clinician communication about end-of-life care. ${ }^{3}$ Indeed, patient involvement in decisions about life-sustaining treatments differs between North America and Europe ${ }^{5}$, and international differences exist in the provision of end-of-life care. For example, a higher proportion of US than European patients die in the intensive care unit (ICU) ${ }^{6}$ and participation of palliative care teams in European ICUs remains uncommon, while it occurs more frequently in the USA. ${ }^{7,8}$ Furthermore, Dutch patients with chronic diseases are more informed about treatment options and more involved in treatment decisions than US patients. ${ }^{9}$ Lastly, a recent report concerning the quality of death across the world ranked the Netherlands higher than the USA. ${ }^{10}$ These studies would suggest that communication about end-of-life care may be better in the Netherlands than in the USA.

Future efforts to improve communication about end-of-life care for patients with COPD may benefit from an understanding of international differences in quality of communication about end-of-life care and the barriers and facilitators to this communication. Based on the prior research, we hypothesized that Dutch patients with COPD would be more involved in decision making about their care at the end of life and report higher quality of patient-clinician communication about end-of-life care.

We sought to compare the quality of patient-clinician communication about end-oflife care and the endorsement of barriers and facilitators to patient-clinician communication about end-of-life care in patients with COPD in the Netherlands and the USA. 


\section{Materials and Methods}

\section{Study design}

The present study is an analysis of baseline data from three studies: 1) a Dutch longitudinal observational study of self-perceived symptoms and care needs of patients with severe COPD ${ }^{11,12}$; 2) a randomised controlled trial designed to improve quality of communication for patients with COPD in the USA ${ }^{13}$; and 3) a cross-sectional observational study concerning quality of communication in patients with severe COPD in the USA. ${ }^{3}$

\section{Study population}

The study population consisted of 513 outpatients with COPD. Diagnosis of COPD was based on airflow obstruction as defined by the Global initiative for Chronic Obstructive Lung Disease (GOLD) criteria. ${ }^{14}$ The Dutch dataset consisted of 124 outpatients with moderate to very severe COPD. ${ }^{12}$ Patients were recruited by their clinician specialist at one university and two general hospitals, and data were collected in 2008 and 2009. The first US dataset consisted of 376 patients with COPD from the Veterans Affairs (VA) Puget Sound Health Care System (Seattle, WA, USA), recruited between 2004 and $2007 .{ }^{13}$ The second US dataset consisted of 115 patients with severe COPD. ${ }^{3}$ These patients were identified through ambulatory pulmonary clinics in three hospitals (one university hospital, one university-affiliated hospital and one VA Medical Center) and through an oxygen delivery company between 1999 and 2002 in Seattle. The final sample included 122 Dutch and 391 US patients with COPD who had valid responses for the primary outcome measure (Quality of Communication (QOC) questionnaire) and the covariates included in the regression models at study enrollment ( $83.4 \%$ of the original datasets). All procedures were approved by institutional review boards at all institutions.

\section{Outcome measures}

\section{QOC questionnaire}

The primary outcome of interest was quality of communication, assessed with the QOC questionnaire. ${ }^{3,15}$ The QOC questionnaire consists of 13 items that form two domains (general communication and communication about end-of-life care). Patients were asked to rate how good their doctor is at each of these items on a scale of 0 to 10, with 0 indicating "the very worst" and 10 indicating "the very best." Patients were offered two additional response options: "my doctor did not do this" and "don't know". Domain scores were the average from all endorsed items and 
were calculated for patients who had at least three valid items for the general communication domain and at least four valid items for the end-of-life communication domain. Scores for both domains range from 0 (worst) to 10 (best). The answer "my doctor did not do this" was replaced by a score of ' 0 ', while "don't know" was replaced by the median domain score of the valid items for the individual, as suggested by the QOC questionnaire developers. ${ }^{3,15}$

\section{Life-sustaining treatment preferences}

Patients' preferences in their current health state for cardiopulmonary resuscitation (CPR) and invasive mechanical ventilation (MV) were assessed using two validated questions, previously used in patients with COPD. ${ }^{16}$ Response options were 'yes', 'no', or 'don't know'. In addition, patients reported whether they had discussed their treatment preferences with their clinician, using a previously developed question. $^{15}$

\section{Barriers and Facilitators Questionnaire}

Barriers and facilitators to communication about end-of-life care were assessed using the Barriers and Facilitators Questionnaire (BFQ). ${ }^{4}$ The BFQ consists of 15 barriers and 11 facilitators to communication about end-of-life care. For each barrier and facilitator, the respondent was asked if the item applied to his/her situation and it was scored dichotomously ( 0 if not applicable and 1 if applicable). ${ }^{4}$

\section{Covariates}

The following patient characteristics were obtained by self-report: age, sex, marital status, race, education and co-morbidities (myocardial infarction, congestive heart failure, stomach ulcer, diabetes, cancer and liver disease). We also collected data on the specialty of the treating clinician. All patients had spirometry performed. Forced expiratory volume in $1 \mathrm{~s}\left(\mathrm{FEV}_{1}\right)$ was expressed as \% predicted reference values. ${ }^{17}$ Patients were asked to rate their health status on a five-point scale (excellent, very good, good, fair and poor). ${ }^{18}$ For assessment of disease-specific health status, participants completed the St. George's Respiratory Questionnaire (SGRQ). ${ }^{19}$ The SGRQ provides a total score and three domain scores (symptoms, activities and impact) ranging from 0 (optimal) to 100 points (worst).

\section{Statistics}

Analyses included descriptive statistics using frequencies for categorical variables, and means and standard deviations or medians and interquartile ranges (IQRs) for continuous variables, depending on the variable distribution. Patient characteristics were compared using unpaired t-tests or Mann-Whitney U-tests (as appropriate) for continuous variables and Chi-squared tests for categorical variables. Our first step 
was to compare the two US study samples to ensure that they were similar for the primary outcome. QOC end-of-life care domain scores were similar in these two US samples, after adjusting for patient characteristics and clustering for clinician, allowing us to combine them for analyses.

In order to examine the association of country with the quality of patient-clinician communication about end-of-life care, we used linear regression analysis with robust standard errors, adjusting for patient's demographic and clinical characteristics. Since limited data are available on potential predictors of quality of communication about end-of-life care in COPD, models were constructed by including variables that were possible confounders, defined as a $p$-value $\leq 0.20$. A priori, sex was included as a covariate because it was unequally represented in our comparison samples. The variables entered in the final regression models were age, sex, race (Caucasian and non-Caucasian), marital status (living alone or living with a partner), $\mathrm{FEV}_{1}$, SGRQ total score, and medical history of myocardial infarction, congestive heart failure or diabetes. There were several covariates that did not confound the relationship between country and communication scores $(p>0.20)$ and were not included in the final model, including educational level (less than high school or high school or more), speciality of the treating clinician (chest clinician or primary care clinician/geriatrician) and other comorbidities. Since clinicians could have referred more than one patient, this analysis was clustered by clinician.

We also compared individual QOC item scores between Dutch and US patients using the same analytic approach: linear regression analysis with robust standard errors, clustered by clinician and adjusting for the same patient characteristics identified above. Finally, because BFQ items and preferences for life-sustaining treatments were scored dichotomously, we modelled logistic regression analyses, controlling for the same patient characteristics identified for the primary QOC questionnaire analyses and clustered by clinician. SPSS 17.0 (IBM, Somers, NY, USA) was used to develop descriptive statistics; STATA 11.1 (StataCorp, College Station, TX, USA) was used for the regression analyses. A two-sided level of significance was set at $p \leq$ $0.05^{20}$

\section{Results}

\section{Patient characteristics}

The current study includes 122 Dutch and 391 US patients with COPD. The majority of the patients had severe to very severe COPD (GOLD stage III or IV). Dutch patients had lower $\mathrm{FEV}_{1}$ and worse disease-specific health status. All Dutch patients were 
Caucasian. Most US patients were male and a lower proportion of US patients were married or living with a partner. All patients in the Dutch sample rated care and communication from a chest clinician, as compared with $44 \%$ of the US patients; the rest of the US patients rated care and communication from geriatricians or primary care clinicians. Finally, a higher proportion of patients from the US sample reported myocardial infarction or liver disease (Table 10.1).

Table 10.1 Demographic and clinical patient characteristics

\begin{tabular}{|c|c|c|c|}
\hline & $\begin{array}{l}\text { Dutch patients } \\
(\mathrm{n}=122)\end{array}$ & $\begin{array}{l}\text { US patients } \\
(n=391)\end{array}$ & p-value* \\
\hline Age (years) & $66.7(9.3)$ & $68.7(10.0)$ & 0.05 \\
\hline Sex (male) & $75(61.5)$ & $360(92.1)$ & $<0.001$ \\
\hline Marital status (married / living with partner) & $88(72.1)$ & $188(48.1)$ & $<0.001$ \\
\hline Race (Caucasian) & $122(100)$ & $339(86.7)$ & $<0.001$ \\
\hline Education (high school or more) & $93(76.2)$ & $325(83.1)$ & 0.12 \\
\hline Receiving treatment by chest clinician & $122(100)$ & $171(44.5)^{\#}$ & $<0.001$ \\
\hline $\mathrm{FEV}_{1}(\%$ predicted $)$ & $37.8(15.5)$ & $43.3(20.2)$ & $<0.01$ \\
\hline \multicolumn{4}{|l|}{ GOLD stage } \\
\hline GOLD stage I or II & $25(20.5)$ & $125(32.0)$ & 0.02 \\
\hline GOLD stage III or IV & $97(79.5)$ & $266(68.0)$ & \\
\hline \multicolumn{4}{|l|}{ Comorbid illnesses } \\
\hline Myocardial infarction & $13(10.7)$ & 75 (19.2) & 0.04 \\
\hline Congestive heart failure & $12(9.8)$ & $61(15.6)$ & 0.15 \\
\hline Stomach ulcer & $14(11.5)$ & $60(15.3)$ & 0.36 \\
\hline Diabetes & $28(23.0)$ & $94(24.0)$ & 0.90 \\
\hline Cancer & $23(18.9)$ & $72(18.4)$ & 1.00 \\
\hline Liver disease & $3(2.5)$ & $36(9.8)^{\dagger}$ & 0.02 \\
\hline \multicolumn{4}{|l|}{ Self-perceived health status } \\
\hline Excellent & $0(0)$ & $4(1.0)^{\S}$ & $<0.001$ \\
\hline Very good & $2(1.6)$ & $46(11.9)^{\S}$ & \\
\hline Good & $21(17.2)$ & $128(33.0)^{\S}$ & \\
\hline Fair & $80(65.6)$ & $139(35.8)^{\S}$ & \\
\hline Poor & $19(15.6)$ & $71(18.3)^{\S}$ & \\
\hline \multicolumn{4}{|l|}{ Disease-specific health status } \\
\hline SGRQ symptoms score & $58.6(22.6)$ & $57.6(23.4)$ & 0.68 \\
\hline SGRQ activity score & 72.9 (22.9) & $68.5(21.5)$ & 0.06 \\
\hline SGRQ impact score & $43.8(19.1)$ & $39.7(18.1)$ & 0.03 \\
\hline SGRQ total score & $55.1(17.7)$ & $51.4(17.5)$ & 0.04 \\
\hline
\end{tabular}

Data are presented as mean (SD) or $\mathrm{n}(\%)$. Bold indicates statistically significant $\mathrm{p}$-values. Abbreviations: $\mathrm{FEV}_{1}=$ Forced Expiratory Volume in the first second; GOLD= Global initiative for chronic Obstructive Lung Disease; SGRQ= St. George's Respiratory Questionnaire. * p-values based on Chi squared or independent sample t-test; ${ }^{\#} \mathrm{n}=384 ;^{+} \mathrm{n}=368 ;^{\S} \mathrm{n}=388$. 


\section{Communication about end-of-life care}

General communication domain scores were rated high, while communication about end-of-life care domain scores were rated low (Figure 10.1). Dutch patients reported statistically significant lower QOC general and end-of-life care domain scores than US patients. After controlling for country, three other patient characteristics were also statistically significant predictors for higher QOC end-of-life care scores: 1 ) younger age; 2 ) worse disease-specific health status, as assessed with the SGRQ; and 3) having a history of myocardial infarction (Table 10.2). QOC end-of-life care domain scores were comparable for patients with mild to moderate COPD (GOLD Stage I-II) and patients with severe to very severe COPD (GOLD Stage III-IV) with median score 1.1 (IQR 0.0-2.9) versus $1.4(0.0-3.4)$, respectively $(p=0.42)$.

Figure 10.1 QOC domain scores for Dutch and US patients
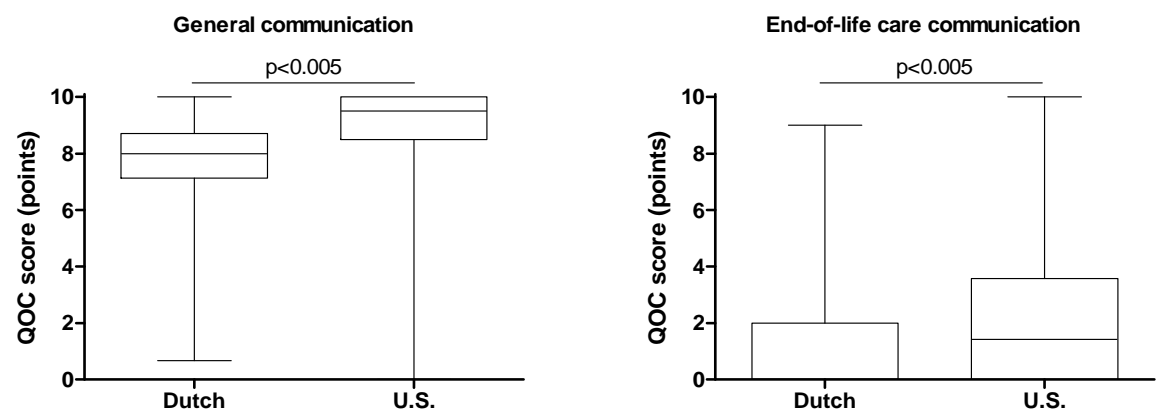

Median (interquartile range, minimum and maximum) Quality of Communication (QOC) questionnaire scores for the domain 'general communication' (left panel) and the domain 'communication about endof-life care' (right panel) reported by Dutch $(n=122)$ and US $(n=391)$ patients with COPD. P-values are based on linear regression analysis clustered by clinician (156 clusters), adjusted for age, sex, race, marital status, $\mathrm{FEV}_{1}$, SGRQ total score, medical history of myocardial infarction, congestive heart failure and diabetes.

The QOC item analyses showed that most general communication items, as well as specific end-of-life care communication items, were rated lower by Dutch than US patients (Table 10.3). However, the items 'talking about what dying might be like' and 'asking about spiritual or religious beliefs' were rated very low in both the Netherlands and the USA. These low scores for communication about end-of-life care are mainly due to the fact that patients reported that these items had not been discussed. Four specific end-of-life care items were less frequently discussed in Dutch than US patients (Table 10.4). 
Table 10.2 QOC "Communication about end-of-life care" domain score: Association with country using linear regression and clustered by clinician

\begin{tabular}{llll}
\hline & Beta & $95 \% \mathrm{Cl}$ & $\mathrm{p}$-value \\
\hline $\begin{array}{l}\text { Primary predictor } \\
\quad \text { Country (ref: the Netherlands) }\end{array}$ & $\mathbf{1 . 0 3}$ & $\mathbf{0 . 5 4 - 1 . 5 2}$ & $\mathbf{0 . 0 0}$ \\
$\begin{array}{l}\text { Demographics } \\
\text { Age }\end{array}$ & $-\mathbf{0 . 0 2}$ & $\mathbf{- 0 . 0 5 - - 0 . 0 0}$ & $\mathbf{0 . 0 3}$ \\
$\quad$ Sex (ref: male) & 0.13 & $-0.34-0.60$ & 0.58 \\
$\quad$ Marital status (ref: living alone) & 0.37 & $-0.03-0.76$ & 0.07 \\
$\quad$ Race (ref: non-Caucasian) & -0.52 & $-1.25-0.21$ & 0.16 \\
Disease severity & & & \\
$\quad$ FEV (\% predicted) & -0.01 & $-0.02-0.00$ & 0.31 \\
$\quad$ SGRQ total score & $\mathbf{0 . 0 2}$ & $\mathbf{0 . 0 0 - 0 . 0 3}$ & $\mathbf{0 . 0 2}$ \\
Comorbidities & & & $\mathbf{0 . 0 5}$ \\
$\quad$ Myocardial infarction (ref: none) & $\mathbf{0 . 6 3}$ & $\mathbf{0 . 0 1 - 1 . 2 5}$ & 0.48 \\
Congestive heart failure (ref: none) & 0.26 & $-0.46-0.97$ & 0.21 \\
$\quad$ Diabetes (ref: none ) & 0.27 & $-0.16-0.70$ & \\
\hline
\end{tabular}

$\mathrm{n}=513 ; \mathrm{R} 2=0.096, \mathrm{p}<0.00005$. Number of clusters: 156 . Bold indicates statistically significant data. Abbreviations: $\mathrm{FEV}_{1}=$ Forced Expiratory Volume in the first second; $\mathrm{SGRQ}=$ St. Georges Respiratory Questionnaire; ref= reference category.

Table 10.3 QOC items: Descriptive statistics and association with country using linear regression

\begin{tabular}{|c|c|c|c|c|}
\hline & $\begin{array}{l}\text { Dutch patients } \\
(n=122)\end{array}$ & $\begin{array}{l}\text { US patients } \\
(n=391)\end{array}$ & Beta\# & $\begin{array}{l}\text { Adjusted } \\
\text { p-value* }\end{array}$ \\
\hline \multicolumn{5}{|l|}{ General communication items } \\
\hline Using words you understand & $8.0(7.8-9.0)$ & $9.0(8.0-10.0)$ & 0.57 & 0.01 \\
\hline Looking you in eye & $8.0(7.0-9.0)$ & $10.0(9.0-10.0)$ & 1.43 & 0.00 \\
\hline Answering all questions about illness & $8.0(7.0-9.0)$ & $10.0(8.0-10.0)$ & 1.09 & 0.00 \\
\hline Listening to what you have to say & $8.0(7.0-9.0)$ & $10.0(9.0-10.0)$ & 1.05 & 0.00 \\
\hline Caring about you as a person & $8.0(7.0-9.0)$ & $10.0(9.0-10.0)$ & 1.23 & 0.00 \\
\hline Giving full attention & $8.0(7.8-9.0)$ & $10.0(9.0-10.0)$ & 1.12 & 0.00 \\
\hline \multicolumn{5}{|l|}{ Communication about end-of-life care items } \\
\hline $\begin{array}{l}\text { Talking about your feelings about getting } \\
\text { sicker }\end{array}$ & $0.0(0.0-3.8)$ & $0.0(0.0-9.0)$ & 1.64 & 0.00 \\
\hline Talking about details if you got sicker & $0.0(0.0-3.5)$ & $0.0(0.0-9.0)$ & 1.73 & 0.00 \\
\hline Talking about how long you have to live & $0.0(0.0-0.0)$ & $0.0(0.0-0.0)$ & 0.67 & 0.05 \\
\hline $\begin{array}{l}\text { Involving you in treatment discussions } \\
\text { about your care }\end{array}$ & $0.0(0.0-0.0)$ & $0.0(0.0-3.0)$ & 1.11 & 0.00 \\
\hline Asking you about important things in life & $0.0(0.0-0.0)$ & $0.0(0.0-8.0)$ & 2.00 & 0.00 \\
\hline Talking about what dying might be like & $0.0(0.0-0.0)$ & $0.0(0.0-0.0)$ & -0.20 & 0.35 \\
\hline Asking about spiritual, religious beliefs & $0.0(0.0-0.0)$ & $0.0(0.0-0.0)$ & 0.26 & 0.27 \\
\hline
\end{tabular}

Data are presented as median (interquartile range). Bold indicates statistically significant p-values." reference category was Dutch patients; * based on linear regression analysis clustered by clinician (156 clusters), adjusted for age, sex, race, marital status, FEV 1 , SGRQ total score, medical history of myocardial infarction, congestive heart failure and diabetes. 
Table 10.4 QOC "Communication about end-of-life care" items not discussed by clinicians: Descriptive statistics and association with country using logistic regression

\begin{tabular}{|c|c|c|c|c|}
\hline Communication about end-of-life care items & $\begin{array}{l}\text { Dutch patients } \\
(n=122)\end{array}$ & $\begin{array}{l}\text { US patients } \\
(\mathrm{n}=391)\end{array}$ & $\begin{array}{l}\text { Odds } \\
\text { Ratio* }\end{array}$ & $95 \% \mathrm{Cl}^{*}$ \\
\hline $\begin{array}{l}\text { Talking about your feelings about getting } \\
\text { sicker }\end{array}$ & $89(73.0 \%)$ & $208(53.2 \%)$ & 0.37 & $0.21-0.65$ \\
\hline Talking about details if you got sicker & $89(73.0 \%)$ & $221(56.5 \%)$ & 0.38 & $0.24-0.60$ \\
\hline $\begin{array}{l}\text { Involving you in treatment discussions about } \\
\text { your care }\end{array}$ & $103(84.4 \%)$ & $271(69.3 \%)$ & 0.35 & $0.19-0.66$ \\
\hline Asking you about important things in life & $98(80.3 \%)$ & 227 (58.1\%) & 0.30 & $0.16-0.54$ \\
\hline Talking about how long you have to live & $108(88.5 \%)$ & $319(81.6 \%)$ & 0.46 & $0.21-1.00$ \\
\hline Talking about what dying might be like & $108(88.5 \%)$ & $360(92.1 \%)$ & 1.24 & $0.60-2.54$ \\
\hline Asking about spiritual, religious beliefs & $111(91.0 \%)$ & $341(87.2 \%)$ & 0.79 & $0.35-1.77$ \\
\hline
\end{tabular}

Data are presented as $\mathrm{n}(\%)$ answering 'doctor didn't do'. Bold indicates statistically significant data. *based on logistic regression analysis clustered by clinician (156 clusters), adjusted for age, sex, race, marital status, $\mathrm{FEV}_{1}$, SGRQ total score, medical history of myocardial infarction, congestive heart failure and diabetes, using Dutch patients as the reference category.

\section{Life-sustaining treatment preferences}

Patients' preferences in their current health state for MV and CPR were similar in the Netherlands and the USA: $70.5 \%$ of Dutch and $58.2 \%$ of US patients reported they would accept invasive MV (adjusted $p=0.29$ ) and $69.7 \%$ of Dutch and $70.2 \%$ of US patients reported they would accept CPR (adjusted $p=0.18$ ) if needed. Although conversations about life-sustaining treatments with clinicians were not frequent in either country, Dutch patients reported having these conversations significantly less often than US patients ( $12.3 \%$ and $17.6 \%$, respectively; adjusted $p=0.02$ ).

\section{Barriers and facilitators to communication about end-of-life care}

Endorsed barriers and facilitators to end-of-life care communication were different for Dutch and US patients (Table 10.5 and 10.6). A higher proportion of Dutch than US patients reported 'I don't know what kind of care I want if I get very sick'; 'I'm not ready to talk about the care I want if I get very sick'; 'I don't want to make plans for the future'; and 'I have concerns about bringing up assisted suicide'. US patients more frequently endorsed 'I'm not sure which doctor will be taking care of me if I get very sick'; 'My ideas about the kind of medical care I want change at different times'; 'I have a living will and that means I don't need to talk with my doctor about the care I want if I'm too sick to speak for myself'; and 'Doctors look down on people who developed lung/respiratory disease because of smoking' (Table 10.5).

In addition, a higher proportion of US than Dutch patients reported the following facilitators to end-of-life care communication: 'My doctor cares about me as a person'; 'I worry that I could be a burden on my friends and family if I got very sick'; 'I 
worry about the quality of my life in the future'; 'My doctor often asks me about end-of-life care'; 'My doctor is very good at talking about end-of-life care'; and 'Someone other than my doctor has talked with me about the care I would want if I got too sick to speak for myself'. None of the facilitators was more frequently reported by Dutch patients (Table 10.6).

\section{Discussion}

\section{Overview of findings}

Despite the fact that the Dutch patients with COPD from the present sample had more severe disease, Dutch patients reported communication about end-of-life care as occurring less frequently and rated the quality of this communication lower than US patients. However, prognosis, dying and spiritual issues were rarely discussed by clinicians in both countries. Moreover, in both countries only a minority of the outpatients with COPD had discussed life-sustaining treatment preferences with their clinician. There were also differences in endorsed barriers and facilitators to communication about end-of-life care between Dutch and US patients that may provide direction for future interventions.

\section{Quality of communication about end-of-life care}

The present study shows that quality of patient-clinician communication about endof-life care was rated low in both the Netherlands and the USA. However, Dutch patients rated quality of communication about end-of-life care even lower than US patients. In contrast to our hypothesis, we found that patients with COPD in the Netherlands were less involved in decision-making about end-of-life care. Interestingly, this was different from what Schoen et al. ${ }^{9}$ reported concerning involvement in general decision-making. Although reasons for these differences are not clear, previous authors have described differences in the role of autonomy in decisionmaking between the USA and Europe. ${ }^{5,21}$ A more prominent role for autonomy in decision-making may increase the need for or perceived value of timely conversations about life-sustaining treatments in the USA.

Our study confirms the need for enhancing the quality of communication about end-of-life care in the USA and supports this as an even more pressing need for patients with COPD in the Netherlands. Patients with COPD report that clinician communication skills are an important predictor of quality of care. ${ }^{13}$ 


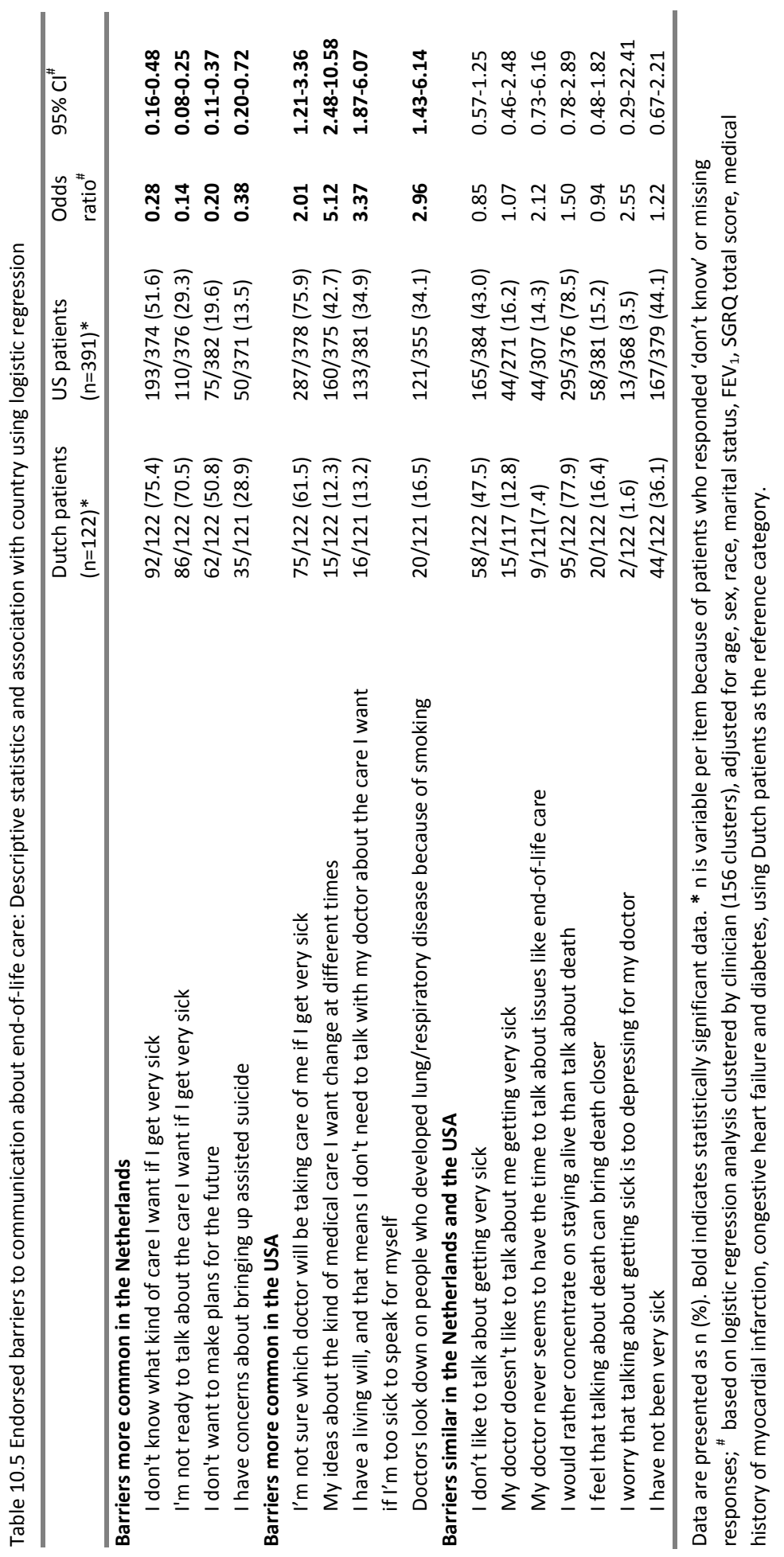




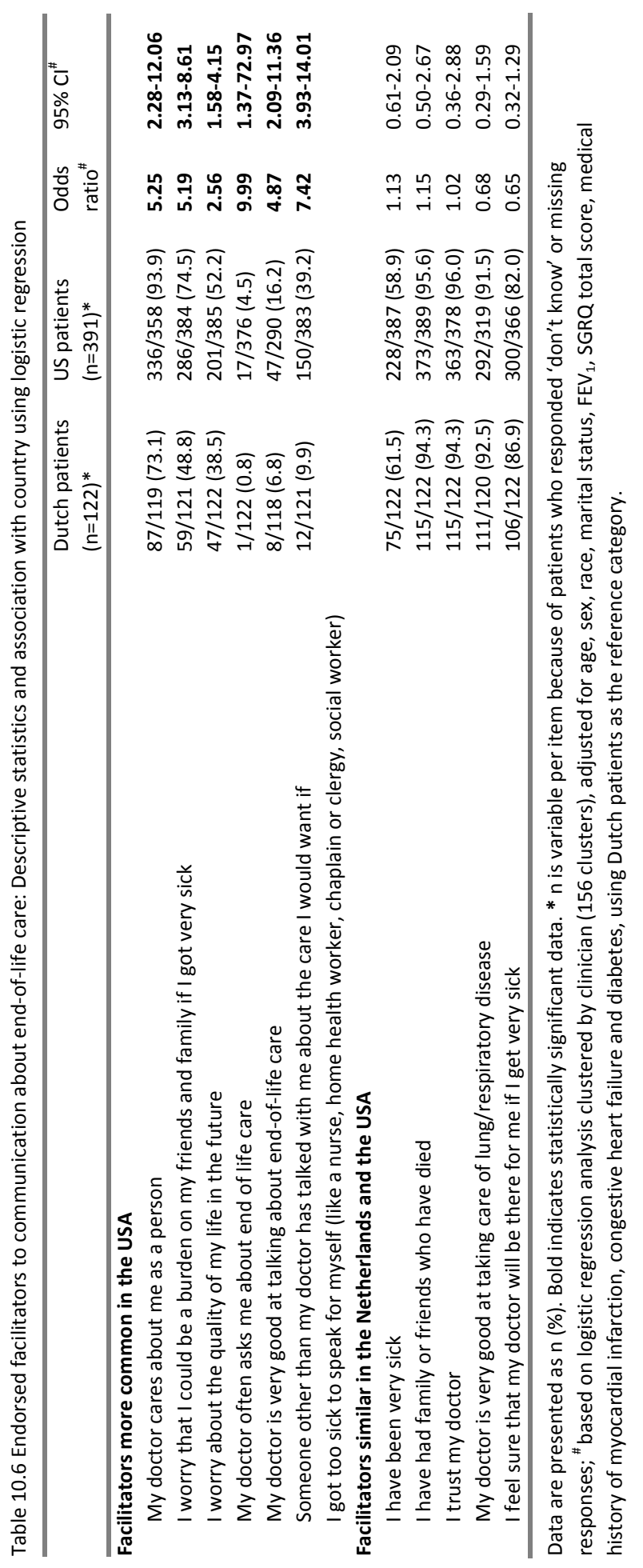


Patients with advanced COPD also report that avoidance of prolonged or unwanted life support is an important element of palliative care. ${ }^{22}$ Among patients with cancer, communication about end-of-life care has been associated with improved quality of life at the end of life and reduced intensity of care without any evidence of increased anxiety or depression. ${ }^{23}$ In addition, communication about end-of-life care is also associated with higher ratings of the quality of dying, as assessed by bereaved relatives. ${ }^{24}$ Finally, a recent randomised trial showed that advance care planning improved satisfaction of patients and families with their care, and reduced stress, anxiety, and depression in families of deceased patients. ${ }^{25}$ Our study, in the context of these prior studies, suggests that communication about end-of-life care is an important target for improving quality of care for patients with COPD.

\section{Barriers and facilitators to communication about end-of-life care}

Barriers and facilitators to communication about end-of-life care may provide direction for future interventions. We found a number of differences between the Netherlands and the USA in barriers and facilitators endorsed by patients with COPD. Even though our Dutch sample had more severe disease, a considerably higher proportion of Dutch patients reported that they were not ready to talk about care they want if they got very sick. This may reflect a difference in patients' preferences for communication about prognosis and should be considered in future studies and efforts to improve communication about end-of-life care. One potential approach for discussing prognosis and end-of-life care with patients who are uncomfortable talking about end-of-life care is an indirect approach to the discussion of prognosis. ${ }^{26}$ Conversations directed to self-efficacy around disease management as well as quality of life concerns may also enable patients uncomfortable with end-of-life care discussions to find a way to participate and plan for treatments that might be needed if they were to become very ill. ${ }^{27-29}$ Furthermore, the barrier 'I don't know what kind of care I want if I get very sick' was more frequently endorsed by Dutch patients. This latter barrier has been associated with a lower occurrence of discussions about end-of-life care ${ }^{4}$ and, therefore, may be particularly important to address in designing interventions to increase the occurrence of communication about end-of-life care. Finally, prior research has shown that media coverage can influence treatment preferences for patients with COPD and may also be related to some of the regional differences in attitudes about discussing end-of-life care. ${ }^{30}$

We found that a higher proportion of US patients reported the barrier that they are not sure which doctor would be taking care of them if they got very sick. Slatore et al. ${ }^{13}$ found that $55 \%$ of patients with COPD who received care from the same clinician for more than five years reported receiving the best possible care, while only $37 \%$ of the patients who had the same clinician for less than two years reported 
receiving the best possible care $(p=0.02)$. Therefore, continuity of care may be an important factor in enhancing quality of patient-clinician communication in the USA. We also found that US patients more frequently reported that 'Doctors look down on people who developed lung/respiratory disease because of smoking'. Recently, a qualitative study highlighted the challenge for clinicians to combine health advice on smoking cessation with non-blaming support throughout the course of COPD. ${ }^{31}$ Attention to this issue may be relatively more important in US interventions.

End-of-life care discussions occur more frequently if patients perceive that their clinician is good at talking about end-of-life issues. ${ }^{4}$ Although US patients report this more frequently than Dutch patients, in both countries only a minority of patients endorsed this facilitator. Previous studies have shown that communication skillsbuilding workshops for clinicians working in oncology can improve communication skills about end-of-life care. ${ }^{32,33}$ Therefore, this may be a useful intervention to improve communication about end-of-life care in the Netherlands and the USA.

\section{Limitations}

The current project has a number of important limitations. Perhaps most importantly, the difference between the Dutch and US samples could be due to differences other than regional variability. For example, female patients were underrepresented in the US sample, while the Dutch sample consisted only of Caucasian patients. Although we used regression analyses to adjust for known differences in patient characteristics, other differences may have been present which were not assessed in the current study, like differences in religion or psychological symptoms. Perception of quality of communication may be influenced by the presence of depression. ${ }^{3}$ However, Slatore et al. ${ }^{13}$ showed that QOC scores were not related to the presence of depression symptoms (measured by the Mental Health Inventory-5) or previous self-reported physician diagnosis of depression. Data for the US samples were collected between 1999 and 2002, and between 2004 and 2007, while the data for the Dutch sample were collected in 2008 and 2009. Because data were collected at three different time points, it is possible that effects may be due to secular trends rather than country differences. Given the absence of any overlap in time among the three samples, it is impossible to assess the extent to which observed differences were primarily functions of sample rather than functions of time. In addition, all Dutch patients were recruited by their chest clinician and rated quality of communication with their chest clinician, while some of the US patients rated quality of communication with the primary care clinician or geriatrician. Although we did not include Dutch primary care physicians, Dutch patients in our sample reported visiting their chest clinicians more frequently than their primary care clinicians. Furthermore, in our study, quality of communication about end-of-life care 
was not associated with clinician specialty and therefore seems unlikely to be an important confounder. Nevertheless, clinician specialty has been suggested to be related to willingness to discuss end-of-life care issues ${ }^{34}$ and it remains unknown whether results would have been comparable if Dutch patients rated quality of communication with their primary care clinician.

There are several other important limitations. First, participants in these studies were volunteers and we do not know whether their views are representative of all patients with COPD. This is an inherent limitation of such research, but should be considered in interpreting the results. Secondly, the present study is based on the patients' perception of quality of communication and does not include objective measures of quality of communication. However, we believe that the patients' perception of the quality of communication about end-of-life care is an important construct. Thirdly, the current project compared communication about end-of-life care between the Netherlands and the USA, and it is unknown whether the current Dutch findings are applicable to other European countries. The Netherlands has legalized euthanasia and it is difficult to determine what effect this has on communication about end-of-life care. ${ }^{35}$ Furthermore, Cartwright et al. ${ }^{34}$ showed that Dutch clinicians were more likely to discuss purpose of treatment and palliative care compared with clinicians from other European countries. Further research is necessary to study whether and to what extent quality of communication about end-oflife care is comparable between European countries. Finally, the US patients were mainly recruited in one region in the USA and it is unknown if results are comparable with other regions.

\section{Conclusions and future directions}

There is increasing realisation of the importance of communication in the provision of high quality end-of-life care. Our results suggest that improvements in communication about end-of-life care are needed in both the Netherlands and the USA. We found that conversations about advance care planning occurred for only a minority of outpatients with moderate or severe COPD. Therefore, clinicians caring for patients with COPD in both countries need to pay more attention to communication about end-of-life care. International differences were also notable, with communication about end-of-life care rated lower by Dutch than US patients. It will be important for future studies to collect data concurrently in the two countries in order to produce definitive comparisons of the two locales. Future studies are needed to develop interventions to improve patient-clinician communication about end-of-life care for patients with COPD. These interventions should take into account regional differences in barriers and facilitators to communication about end-of-life care. 


\section{References}

1. Lopez, A.D., K. Shibuya, C. Rao, C.D. Mathers, A.L. Hansell, L.S. Held, V. Schmid, and S. Buist, Chronic obstructive pulmonary disease: current burden and future projections. Eur Respir J. 2006;27(2):397412.

2. Curtis, J.R., Palliative and end-of-life care for patients with severe COPD. Eur Respir J. 2008;32(3):796-803.

3. Curtis, J.R., R.A. Engelberg, E.L. Nielsen, D.H. Au, and D.L. Patrick, Patient-physician communication about end-of-life care for patients with severe COPD. Eur Respir J. 2004;24(2):200-5.

4. Knauft, E., E.L. Nielsen, R.A. Engelberg, D.L. Patrick, and J.R. Curtis, Barriers and facilitators to end-oflife care communication for patients with COPD. Chest. 2005;127(6):2188-96.

5. Moselli, N.M., F. Debernardi, and F. Piovano, Forgoing life sustaining treatments: differences and similarities between North America and Europe. Acta Anaesthesiol Scand. 2006;50(10):1177-86.

6. Wunsch, H., W.T. Linde-Zwirble, D.A. Harrison, A.E. Barnato, K.M. Rowan, and D.C. Angus, Use of intensive care services during terminal hospitalizations in England and the United States. Am J Respir Crit Care Med. 2009;180(9):875-80.

7. Fassier, T., A. Lautrette, M. Ciroldi, and E. Azoulay, Care at the end of life in critically ill patients: the European perspective. Curr Opin Crit Care. 2005;11(6):616-23.

8. White, D.B. and J.R. Curtis, Care near the end-of-life in critically ill patients: a North American perspective. Curr Opin Crit Care. 2005;11(6):610-5.

9. Schoen, C., R. Osborn, S.K. How, M.M. Doty, and J. Peugh, In chronic condition: experiences of patients with complex health care needs, in eight countries, 2008. Health Aff (Millwood). 2009;28(1):w1-16.

10. Economist Intelligence Unit. The quality of death: Ranking end-of-life care across the world. 2010 [cited 2010 July, 31]; Available from: http://www.eiu.com/site_info.asp?info_name=qualityofdeath _lienfoundation \& page $=$ noads $\& \mathrm{rf}=0$.

11. Janssen, D.J., E.F. Wouters, J.M. Schols, and M.A. Spruit, Self-perceived symptoms and care needs of patients with severe to very severe chronic obstructive pulmonary disease, congestive heart failure or chronic renal failure and its consequences for their closest relatives: the research protocol. BMC Palliat Care. 2008;7:5.

12. Janssen, D.J., M.A. Spruit, J.M. Schols, and E.F. Wouters, A call for high-quality advance care planning in outpatients with severe COPD or chronic heart failure. Chest. 2011;139(5):1081-88.

13. Slatore, C.G., L.M. Cecere, L.F. Reinke, L. Ganzini, E.M. Udris, B.R. Moss, C.L. Bryson, J.R. Curtis, and D.H. Au, Patient-Clinician Communication: Associations with Important Health Outcomes among Veterans with COPD. Chest. 2010;138(3):628-34.

14. Rabe, K.F., S. Hurd, A. Anzueto, P.J. Barnes, S.A. Buist, P. Calverley, Y. Fukuchi, C. Jenkins, R. Rodriguez-Roisin, C. van Weel, and J. Zielinski, Global strategy for the diagnosis, management, and prevention of chronic obstructive pulmonary disease: GOLD executive summary. Am J Respir Crit Care Med. 2007;176(6):532-55.

15. Engelberg, R., L. Downey, and J.R. Curtis, Psychometric characteristics of a quality of communication questionnaire assessing communication about end-of-life care. J Palliat Med. 2006;9(5):1086-98.

16. Stapleton, R.D., E.L. Nielsen, R.A. Engelberg, D.L. Patrick, and J.R. Curtis, Association of depression and life-sustaining treatment preferences in patients with COPD. Chest. 2005;127(1):328-34.

17. Standardization of Spirometry, 1994 Update. American Thoracic Society. Am J Respir Crit Care Med. 1995;152(3):1107-36.

18. Nguyen, H.Q., D. Donesky-Cuenco, and V. Carrieri-Kohlman, Associations between symptoms, functioning, and perceptions of mastery with global self-rated health in patients with COPD: a crosssectional study. Int J Nurs Stud. 2008;45(9):1355-65. 
19. Jones, P.W., F.H. Quirk, C.M. Baveystock, and P. Littlejohns, A self-complete measure of health status for chronic airflow limitation. The St. George's Respiratory Questionnaire. Am Rev Respir Dis. 1992;145(6):1321-7.

20. Altman, D.G., S.M. Gore, M.J. Gardner, and S.J. Pocock, Statistical guidelines for contributors to medical journals. Br Med J (Clin Res Ed). 1983;286(6376):1489-93.

21. Luce, J.M. and F. Lemaire, Two transatlantic viewpoints on an ethical quandary. Am J Respir Crit Care Med. 2001;163(4):818-21.

22. Rocker, G.M., P.M. Dodek, and D.K. Heyland, Toward optimal end-of-life care for patients with advanced chronic obstructive pulmonary disease: insights from a multicentre study. Can Respir J. 2008;15(5):249-54.

23. Wright, A.A., B. Zhang, A. Ray, J.W. Mack, E. Trice, T. Balboni, S.L. Mitchell, V.A. Jackson, S.D. Block, P.K. Maciejewski, and H.G. Prigerson, Associations between end-of-life discussions, patient mental health, medical care near death, and caregiver bereavement adjustment. JAMA. 2008;300(14):166573.

24. Patrick, D.L., J.R. Curtis, R.A. Engelberg, E. Nielsen, and E. McCown, Measuring and improving the quality of dying and death. Ann Intern Med. 2003;139(5 Pt 2):410-5.

25. Detering, K.M., A.D. Hancock, M.C. Reade, and W. Silvester, The impact of advance care planning on end of life care in elderly patients: randomised controlled trial. BMJ. 2010;340:c1345.

26. Curtis, J.R., R. Engelberg, J.P. Young, L.K. Vig, L.F. Reinke, M.D. Wenrich, B. McGrath, E. McCown, and A.L. Back, An approach to understanding the interaction of hope and desire for explicit prognostic information among individuals with severe chronic obstructive pulmonary disease or advanced cancer. J Palliat Med. 2008;11(4):610-20.

27. Goldstein, N.E., A.L. Back, and R.S. Morrison, Titrating guidance: a model to guide physicians in assisting patients and family members who are facing complex decisions. Arch Intern Med. 2008;168(16):1733-9.

28. Steinhauser, K.E., S.C. Alexander, I.R. Byock, L.K. George, M.K. Olsen, and J.A. Tulsky, Do preparation and life completion discussions improve functioning and quality of life in seriously ill patients? Pilot randomized control trial. J Palliat Med. 2008;11(9):1234-40.

29. Ford, D., J. Zapka, M. Gebregziabher, C. Yang, and K. Sterba, Factors associated with illness perception among critically ill patients and surrogates. Chest. 2010;138(1):59-67.

30. Nava, S., C. Santoro, M. Grassi, and N. Hill, The influence of the media on COPD patients' knowledge regarding cardiopulmonary resuscitation. Int J Chron Obstruct Pulmon Dis. 2008;3(2):295-300.

31. Halding, A.G., K. Heggdal, and A. Wahl, Experiences of self-blame and stigmatisation for self-infliction among individuals living with COPD. Scand J Caring Sci. 2011;25(1):100-7

32. Back, A.L., R.M. Arnold, W.F. Baile, K.A. Fryer-Edwards, S.C. Alexander, G.E. Barley, T.A. Gooley, and J.A. Tulsky, Efficacy of communication skills training for giving bad news and discussing transitions to palliative care. Arch Intern Med. 2007;167(5):453-60.

33. Jenkins, V., L. Fallowfield, I. Solis-Trapala, C. Langridge, and V. Farewell, Discussing randomised clinical trials of cancer therapy: evaluation of a Cancer Research UK training programme. BMJ. 2005;330(7488):400.

34. Cartwright, C., B.D. Onwuteaka-Philipsen, G. Williams, K. Faisst, F. Mortier, T. Nilstun, M. Norup, A van der Heide, and G. Miccinesi, Physician discussions with terminally ill patients: a cross-national comparison. Palliat Med. 2007;21(4):295-303.

35. van der Heide, A., B.D. Onwuteaka-Philipsen, M.L. Rurup, H.M. Buiting, J.J. van Delden, J.E. Hanssende Wolf, A.G. Janssen, H.R. Pasman, J.A. Rietjens, C.J. Prins, I.M. Deerenberg, J.K. Gevers, P.J. van der Maas, and G. van der Wal, End-of-life practices in the Netherlands under the Euthanasia Act. N Engl J Med. 2007;356(19):1957-65. 


\section{CHAPTER 11 \\ General discussion}

Part of the General discussion was published as:

Daisy J.A. Janssen, Ruth A. Engelberg, Emiel F.M. Wouters, and J. Randall Curtis Advance care planning for patients with COPD: past, present and future.

Patient Educ Couns, 2012. 86(1): 19-24. 
174 | CHAPTER 11 


\section{General discussion}

During the last decade the need for palliative care for patients with advanced chronic organ failure has been recognized. ${ }^{1-5}$ The development of palliative management programs aimed at improving quality of life of patients with advanced chronic organ failure and their closest relatives requires a better understanding of their palliative care needs. Therefore, the central aim of this thesis was to understand the palliative care needs of patients with advanced chronic organ failure, like Chronic Obstructive Pulmonary Disease (COPD), Chronic Heart Failure (CHF) or Chronic Renal Failure (CRF) and the needs of their closest relatives. The story of our patient in chapter $\mathbf{2}$ shows the major impact of advanced chronic organ failure on the patient and her loved ones. This story clearly reveals from an individual perspective the need for palliative care. Early palliative care can improve quality of life of patients with advanced disease. ${ }^{6}$ However, the story of our patient also shows that there are limits to how much palliative care can make things right for patients. In this final chapter, the palliative care needs of patients with advanced chronic organ failure, as identified by this thesis, will be discussed. First, we will discuss the need for symptom management, followed by care needs, aspects of family caregiving, comorbidities and the need for advance care planning. Then we will discuss methodological considerations of this thesis. Finally, implications for clinical practice and recommendations for future research with the aim to improve palliative care for patients with chronic organ failure will be described.

\section{Symptom management}

A systematic review of the literature was performed to gain insight in the knowledge available at the start of this study concerning symptom burden in advanced chronic organ failure (chapter 3 ). This review showed a wide range in reported symptom prevalence in patients with advanced COPD, CHF or CRF. In general, patients with COPD, CHF and CRF are likely to experience high symptom distress. However, because of the heterogeneity in symptom prevalence and the limitations of the included studies in this review, insight in symptom distress in advanced chronic organ failure remained scarce and did not allow clear recommendations for targets for interventions. Indeed, studies of various designs were included in this systematic review. Some of the studies relied on bereaved family members to act as proxies to report on the symptoms experienced by the patient. Agreement between family members and patients may be low or inconsistent. ${ }^{7}$ Furthermore, a considerable part of the studies was retrospective and this might have contributed to the wide range of symptom prevalence. ${ }^{8}$ Other studies relied on charts or medical records for identifying symptoms. These sources provide only indirect reporting of 
symptoms, potentially under representing symptoms that are not recognized by caregivers such as nurses and physicians. Therefore, this review highlighted the need for prospective studies assessing symptom distress from the patient's perspective. Our prospective study used systematic assessment of self-perceived symptoms (chapter 4). This study has shown that patients with advanced COPD or CHF suffer from multiple symptoms, like dyspnea, fatigue, muscle weakness, coughing, low mood, sleeplessness and frequent micturition (chapter $\mathbf{5}$ ).

Patients with advanced COPD or CHF have an impaired general and disease-specific health status. Physical and psychological symptoms are important determinants of health status (chapter 6). ${ }^{9-11}$ Furthermore, chapter 7 has shown a correlation between caregiver strain and symptoms of depression as perceived by the patient. Therefore, optimal symptom management may be one way to improve health status of these patients and perhaps even influence burden for family caregivers. Nevertheless, for most symptoms, only a minority of the patients had received symptom-related treatment and if patients received symptom-related treatment, patients only reported moderate satisfaction with this treatment. Involvement of allied health care professionals was low and palliative medication was prescribed scarcely. Here we will discuss two factors which may contribute to the fact that symptoms are scarcely addressed in advanced COPD or CHF.

The first factor concerns recognition of symptom distress. Patients with advanced COPD or CHF may not actively express a wish for help for their symptoms, because they adapt to their situation, attribute their symptoms to getting older or believe that there a no possibilities to improve their situation. ${ }^{12,13}$ Therefore, a systematic assessment of symptom distress should be part of regular clinical care. Recognition and acknowledgement of symptoms might be the first step to alleviation of symptoms of patients with advanced chronic organ failure. The use of instruments for symptom assessment might have an additional value next to the regular clinical interview. ${ }^{14}$ However, nowadays there is no consensus about standardization of symptom assessment in palliative care and multiple instruments are available. ${ }^{14}$ Many instruments for symptom assessment in palliative care were previously developed for patients with cancer. ${ }^{15}$ While previous research has shown that in general, symptom distress of patients with advanced COPD or CHF is comparable with symptom distress of patients with cancer, prevalence and severity of individual symptoms may be different. ${ }^{5,16,17}$ Furthermore, disease-specific tools for patients with non-malignant disease, for example multidimensional instruments for symptom assessment in COPD, are often not validated in patients with advanced disease. ${ }^{18}$ In turn, these instruments may not be sensitive enough to detect small but significant changes that may occur in a symptom in a patient with advanced disease. ${ }^{18}$ Moreover, these instruments may not detect symptoms caused by co- 
morbid conditions. Therefore, further research is necessary to develop an instrument for multidimensional symptom assessment in patients with advanced chronic organ failure. This instrument must be easy to use on a regular basis in clinical practice and should provide a clear insight in presence and severity of symptoms with the aim to identify the need for symptom-related interventions.

A second factor contributing to under treatment of symptoms may be that many questions concerning optimal symptom management remain. This thesis identified dyspnea, fatigue, muscle weakness, coughing, low mood, sleeplessness and frequent micturition (chapter $\mathbf{5}$ ) as the most frequently reported symptoms in patients with advanced COPD or CHF. Therefore, future studies should focus on interventions to improve these symptoms. Here, we will discuss possible interventions and research questions concerning dyspnea, fatigue, muscle weakness and symptoms of depression.

A considerable part of the patients in the present study suffered from severe dyspnea and only a few patients used opioids (chapter 5 ), despite the fact that recent guidelines recommend opioids for management of severe dyspnea. ${ }^{19}$ While previous studies support the use of oral and parenteral opioids to treat dyspnea in patients with advanced disease, ${ }^{20-22}$ to date remains unknown which patients suffering from dyspnea are likely to respond to opioids. ${ }^{23}$ Furthermore, no randomized clinical trials are available comparing the effect of different opioids or administration routes on the sensation of dyspnea in advanced chronic organ failure. Therefore, adequately powered randomized clinical trials are needed to identify the patients who are likely to benefit from the prescription of opioids to treat their dyspnea and to provide recommendations about when to prescribe opioids, which opioids to prescribe, administration routes and dosage regimes.

Other frequently reported symptoms in advanced chronic organ failure are fatigue and muscle weakness. These symptoms may be relieved by pulmonary rehabilitation or cardiac rehabilitation. ${ }^{24,25}$ Pulmonary and cardiac rehabilitation are wellestablished for patients with COPD or CHF, respectively. ${ }^{24,26}$ However, uptake and adherence to rehabilitation programs may be problematic for some patients and the suitability of rehabilitation in the palliative care setting has not well be established. ${ }^{27,28}$ Recent innovations in rehabilitation interventions allow incorporation of some of these interventions into palliative care management programs for patients who are not able to participate in a pulmonary rehabilitation program because of end-stage disease. ${ }^{28}$ For example, neuromuscular electrical stimulation (NMES) may be one treatment modality that is also feasible in a palliative care setting. Indeed, NMES can improve muscle strength, exercise tolerance and health status, with acceptable increase of dyspnea or fatigue. ${ }^{29,}{ }^{30}$ Nowadays, pharmacological treatment 
options for symptomatic treatment of fatigue are limited. Although corticosteroids are frequently used in palliative care for symptomatic treatment of fatigue, the beneficial effect has not been established. ${ }^{31}$ Moreover, side-effects of systemic corticosteroids can be considerable and may limit their use. Indeed, in COPD patients systemic corticosteroids have been shown to be associated with lower limb muscle weakness and increased mortality risk. ${ }^{32,33}$ Therefore, the use of corticosteroids for symptomatic treatment of fatigue in chronic organ failure can not be recommended. Psychostimulant drugs, such as methylphenidate have been suggested to be effective for treatment of fatigue in patients with cancer. ${ }^{31}$ However, the effect and safety of methylphenidate have not been studied in patients with advanced chronic organ failure. Therefore, future studies should try to identify effective pharmacological and non-pharmacological palliative interventions for fatigue in patients with advanced chronic organ failure.

Low mood was reported by more than half of the patients with COPD or CHF and clinically relevant symptoms of depression were reported by about a quarter of the patients with COPD or CHF (chapter 5). Although symptoms of depression may occur frequently in patients with COPD or CHF, they often remain un(der)diagnosed and un(der)treated. ${ }^{34-37}$ The currently available literature does not offer guidance for management of symptoms of depression in palliative care for patients with advanced COPD or CHF. Randomized-controlled clinical trials concerning the effectiveness and safety of the use of antidepressant medication in patients with COPD or CHF are scarce. ${ }^{37,38}$ However, Selective Serotonin Reuptake Inhibitors (SSRI) have been safely used in other chronic illnesses. ${ }^{39}$ Therefore, in patients with advanced chronic organ failure suffering from a major depressive disorder, treatment with a SSRI should be considered. However, physicians need to be aware of co-morbidities and interaction with other medication. ${ }^{39}$ Non-pharmacological treatment modalities also provide an opportunity for alleviation of symptoms of depression. Previous research has shown that patients with symptoms of depression may benefit from an interdisciplinary rehabilitation program. ${ }^{37,40,41}$ Indeed, recent findings suggest that comprehensive pulmonary rehabilitation is significantly more effective than standard pharmacological care for the reduction of symptoms of depression in older patients with moderate to severe COPD. ${ }^{42}$ Furthermore, psychotherapy may be able to reduce symptoms of depression. ${ }^{43,44}$ Nevertheless, only a few patients in the present study received treatment by a psychologist (chapter 5). Therefore, clinicians need to be aware of the possible benefit of psychological treatment and counseling by a psychologist should be offered to patients with advanced chronic organ failure and symptoms of depression.

Symptom assessment and symptom management are also important components of palliative care for CRF patients. ${ }^{45}$ However, aspects of CRF, in particular the avail- 
ability of dialysis, differentiates CRF from other chronic organ failure. ${ }^{46}$ Indeed, most patients with advanced COPD or CHF follow a disease trajectory characterized by a gradual decline in health status and punctuated by acute exacerbations, ${ }^{47}$ but CRF patients can follow different trajectories. CRF patients can follow a trajectory comparable with the trajectories of patients with COPD or CHF. ${ }^{46}$ However, patients who withdraw from dialysis or who are managed conservatively, are likely to follow a trajectory characterized by a short period of rapid decline at the end of life. ${ }^{46,48}$ Then again, other CRF patients may follow a disease trajectory characterized by a steady decline. ${ }^{49}$ Palliative care needs, including the need for symptom management, may be influenced by the disease trajectory and whether or not CRF is managed using dialysis. ${ }^{46}$ Most studies concerning symptom burden in CRF included patients on dialysis and knowledge concerning symptom burden in patients managed conservatively or patients who withdraw from dialysis is scarce. ${ }^{45,50,51}$ Therefore, further research is necessary to understand symptom distress of CRF patients in different phases of different CRF disease trajectories.

\section{Care needs}

Chapter 6 shows that patients with COPD or CHF may be confronted with care dependency. Indeed, 45 percent of the patients with COPD and 60 percent of the patients with CHF needed help with personal care. Furthermore, Care Dependency Scale (CDS) scores were impaired in COPD and CHF patients. Chapter 6 also shows that care dependency is an important correlate of impaired general and diseasespecific health status. Moreover, activities of daily living may even predict survival of elderly hospitalized patients. ${ }^{52}$ Furthermore, care dependency may lead to reduction in activities of daily living, feelings of frustration, social isolation and is difficult to deal with for both the patient and their loved ones. ${ }^{53,54}$ Therefore, palliative management programs for patients with advanced COPD or CHF should assess impairments in basic and instrumental activities of daily living and should try to minimize care dependency and provide support as needed. Previous authors have described the difficulty in accessing appropriate health and social care services for patients with advanced chronic organ failure. ${ }^{3,55,56}$ Furthermore, the provision of aids and appliances could be improved, for instance by getting support earlier in the disease. ${ }^{56}$ In the present study, home adaptation, like grab bars in bathroom or toilet, were provided to the majority of COPD or CHF patients. In addition, most patients used medical aids, like rollators. However, the involvement of allied health care professionals, like occupational therapists and social workers was very limited (chapter 5). Interdisciplinary care, including occupational interventions, may have an important role in improvement of daily functioning. ${ }^{57,58}$ For example, COPD patients use a higher proportion of their peak aerobic capacity and peak ventilation to 
perform normal daily tasks than healthy elderly persons. ${ }^{59}$ The use of energyconservation techniques has been shown to reduce energy cost and perception of dyspnea during activities of daily living in patients with moderate to very severe COPD. ${ }^{60}$ Therefore, these interventions may increase the ability to perform daily tasks and should be considered for patients with advanced chronic organ failure.

\section{Family caregiving}

While 45 percent of the patients with COPD and 60 percent of the patients with CHF required help with personal care, only 22 percent of the patients with COPD and 40 percent of the patients with CHF received help from a professional caregiver. Family caregivers provided care to 86 percent and 76 percent of the patients with advanced COPD or CHF, respectively (chapter 6). This emphasizes the important role of family caregivers in advanced chronic organ failure. Qualitative studies have shown that a decline in patients' health status can lead to a range of physical, social, and emotional consequences for family caregivers of patients with chronic organ failure. $^{53,61-63}$ Previous studies have described the burden of family caregiving. Indeed, health status and emotional well-being of family caregivers of patients with chronic organ failure may be impaired. ${ }^{64-69}$ A recent study has shown that caregiver burden is common in family caregivers of patients with advanced COPD or CHF. ${ }^{70}$ However, we have shown in chapter 7 that family caregiving for patients with COPD, CHF or CRF should not only be seen as a burden, but also as a positive experience. Caregiver distress and caregiver strain scores were rated relatively low, whereas scores for positive caregiving appraisals and family well-being were rated relatively positive. Healthcare providers of patients with advanced chronic organ failure should therefore pay attention to caregiver burden as well as positive aspects of family caregiving. Partners of patients, family caregivers of patients with psychological symptoms and caregivers of patients suffering from co-morbidities are at increased risk for higher caregiver burden and therefore need careful attention. Assessment of positive aspects and burden of family caregiving provides insight in the need for support for family caregivers, like professional care and information needs. For example, family caregivers of patients with life-limiting illnesses have reported that they desire information about the expected course of the disease, physical and psychological care, information about medical aids and other resources such as hospice care and how to deal with an emergency. ${ }^{71}$ 


\section{Co-morbidities}

Co-morbidities are highly prevalent in patients with COPD or CHF (chapter 5). Comorbidities may influence palliative care needs. Indeed, we have shown that comorbidities may influence the experience of family caregiving (chapter 7). Moreover, patients with advanced chronic organ failure experience both disease-specific and general symptoms (chapter 5). It is reasonable to assume that co-morbid conditions may be associated with additional symptom burden or care needs. In fact, we have shown in chapter 6 an association between care dependency and comorbidities. Until now remains unknown whether and to what extent comorbidities have an influence on health status in advanced COPD or CHF. We did not show a relationship between health status and Charlson comorbidity index score (chapter 6). This confirmed previous findings in patients with advanced COPD or CHF. ${ }^{9,}{ }^{10}$ However, it is possible that co-morbidities which are not included in the Charlson comorbidity index may influence health status. Indeed, other studies have suggested a relationship between health status and the presence of co-morbidities in patients with COPD. ${ }^{72,73}$ In addition, chapter 5 has shown that patients with advanced COPD or CHF use a high number of physician-prescribed drugs. Moreover, a higher number of physician-prescribed drugs was correlated with impaired general health status in COPD and CHF patients (chapter 6). Therefore, careful analyses of both co-morbidities and polypharmacy is important in offering palliative care. Indeed, co-morbidities and polypharmacy need to be taken into account in symptom-related interventions. For example, CRF is highly prevalent and underdiagnosed in elderly patients with COPD. ${ }^{74}$ Because of the complex pharmacokinetics of opioids in patients with $\mathrm{CRF}^{75}$, the presence of CRF should be considered when prescribing opioids for the treatment of dyspnea in patients with COPD or CHF. Management of palliative care needs in patients with multiple medical conditions and complex polypharmacy is challenging. Therefore, coordination of care between healthcare professionals like the medical specialist, nurse specialist, general practitioner and palliative care physician is essential.

\section{Advance care planning}

Because of the trajectory of illness among patients with chronic organ failure and the prognostic uncertainty, ${ }^{47}$ advance care planning is an important component of palliative care for these patients. ${ }^{76,77}$ We have shown in chapter 8 that patients with advanced chronic organ failure are able to indicate their preferences regarding lifesustaining treatments, based on burden of treatment, outcome of treatment and likelihood of outcome. Most patients with advanced COPD or CHF prefer cardiopulmonary resuscitation and/or invasive mechanical ventilation. Clinically stable outpa- 
tients with advanced COPD or CHF are able to express a preferred site for terminal care. The majority of these patients prefers to die at home. Nevertheless, preferences for life-sustaining treatments or end-of-life care are scarcely discussed with their physician specialist (chapter 8). Although patients with severe COPD rated their clinicians' general communication skills highly (e.g., listening, answering questions), they rated their clinicians' skills at discussing end-of-life topics as poor and reported that many topics are not discussed at all (e.g., prognosis, what dying might be like, spiritual issues) (chapter 8 ).

This is in accordance with previous findings. ${ }^{78}$ Studies from both patients and their physicians suggest that advance care planning is uncommon and often poorly done, despite patients' and families' requests for increased and improved advance care planning. Only 19 percent of the patients entering pulmonary rehabilitation reported having discussed advance directives with their clinician and only 14 percent thought that their clinician understood their wishes for end-of-life care. ${ }^{79}$ Nevertheless, 94 percent of these patients had opinions about intubation and 99 percent wanted to discuss advance directives with their clinician. ${ }^{79}$ In a study of oxygendependent patients with COPD, only 32 percent of the patients reported having discussed with their clinician the care they would want if they were too sick to speak for themselves.

Clinicians have similarly reported that they often fail to discuss end-of-life care with their patients with advanced COPD. ${ }^{81}$ Despite the fact that clinicians acknowledge that the appropriate timing for these discussions is when patients are well enough to participate in decision making, these discussions are often initiated when patients are too ill to make decisions about care. ${ }^{81}$ Clinicians have also reported that patients with COPD are frequently not informed about the fact that they have a lifelimiting illness. ${ }^{81}$ Indeed, only 31 percent of the patients with advanced COPD, CHF or cancer, estimated their life-expectancy to be less than one year in the month before they died. ${ }^{82}$ This failure to understand the likelihood of death is an important barrier to initiating discussions about end-of-life care. ${ }^{81}$

Future efforts to improve communication about end-of-life care for patients with COPD may benefit from an understanding of international differences in quality of communication about end-of-life care and the barriers and facilitators to this communication. Therefore, in chapter $\mathbf{1 0}$, we have compared the quality of patientclinician communication about end-of-life care and the endorsement of barriers and facilitators to patient-clinician communication about end-of-life care in patients with COPD in the Netherlands and USA. Despite the fact that the Dutch patients with COPD in chapter $\mathbf{1 0}$ had more severe disease, Dutch patients reported communication about end-of-life care as occurring less frequently and rated the quality 
of this communication lower than US patients. However, prognosis, dying and spiritual issues were rarely discussed by clinicians in both countries. Moreover, in both countries only a minority of the outpatients with COPD had discussed life-sustaining treatment preferences with their clinician. There were also differences in endorsed barriers and facilitators to communication about end-of-life care between Dutch and US patients that are important to take into account in future interventions. Even though our Dutch sample had more severe disease, a considerably higher proportion of Dutch patients reported that they were not ready to talk about care they want if they got very sick (chapter 10). A previous study in US patients with COPD identified barriers and facilitators to patient-clinician communication about end-of-life care. ${ }^{80}$ Seventy-five percent of the patients reported "I would rather concentrate on staying alive than talk about death". ${ }^{80}$ Despite the need for conversations about end-of-life care, most patients will not initiate these discussions and will wait for their clinician to initiate these discussions. ${ }^{79}$ Therefore, clinicians need skills to communicate about a difficult topic like care at the end of life. ${ }^{80}$ Indeed, the Official American Thoracic Society Clinical Policy Statement: Palliative Care for Patients with Respiratory Diseases and Critical Illnesses has recommended communication and advance care planning as core competencies for pulmonary clinicians. ${ }^{19}$ Nevertheless, only 23 percent of the patients with severe COPD reported "my doctor is very good at talking about end-of-life care". ${ }^{80}$

We have designed an outline to guide interventions directed at improving advance care planning. The outline includes the following components: 1) preparation of the discussion; 2) content; style; and family-related aspects of the discussion; and 3) follow-up (Figure 11.1).

Preparation for an advance care planning discussion includes choosing the appropriate time and place and deciding who should be present. ${ }^{71}$ Events or perceptions that patients, their family members and their clinicians view as transitional milestones in the course of their disease can be used to trigger these discussions. ${ }^{83}$ Such events or perceptions include new or different treatments; lack of additional treatment options; limitations in activities or functional decline; initiation of long-term oxygen therapy; and exacerbations of the disease or hospitalization. Identifying these transitions may help in providing a patient-centered approach towards communication about end-of-life care. ${ }^{83}$ The relationship between the patient and the clinician is also an important factor to consider. ${ }^{71}$ Indeed, 64 percent of oxygendependent patients with COPD reported as a barrier to communication about advance care planning that they were "not sure which doctor will be taking care of me if I get very sick". ${ }^{80}$ It is also helpful to include the interdisciplinary healthcare team to ensure patients and their family receive consistent messages from all members of the healthcare team. ${ }^{84}$ 

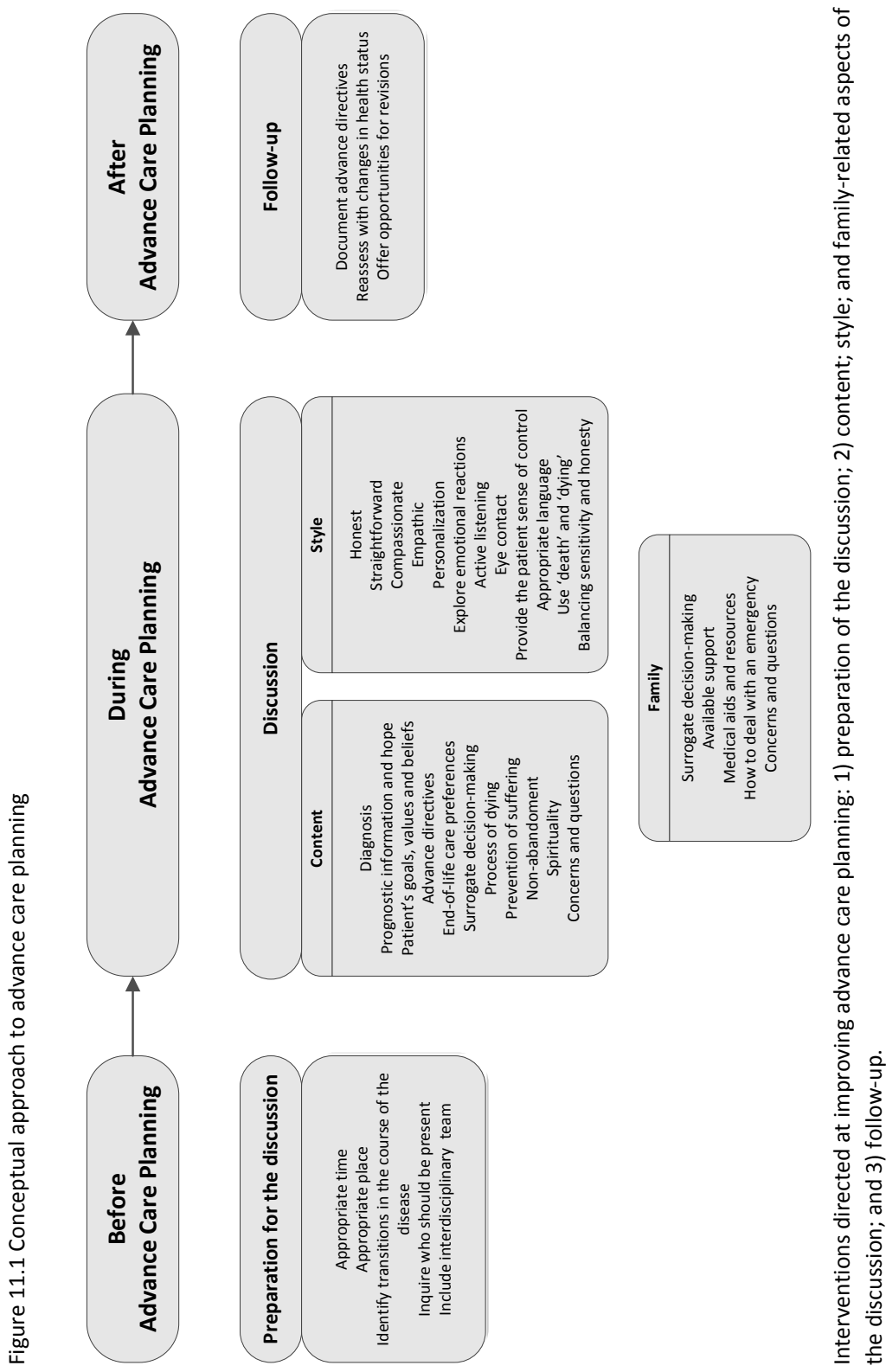
In the content component, there are a number of topics that are important to address, like diagnosis and expected disease process, treatment, prognosis, what dying might be like, and advance care planning. ${ }^{85}$ Balancing sensitivity and honesty when discussing prognosis is a central component of delivery of bad news. ${ }^{86}$ However, timing of talking about dying is a challenge for physicians. ${ }^{86}$ Patients differ in the extent to which they want to receive information regarding their prognosis. ${ }^{87}$ Some patients with COPD want to know all available information, while other patients are reluctant to receive information about worsening of their condition. ${ }^{87} \mathrm{~A}$ systematic review concerning end-of-life care communication in patients with lifelimiting illnesses has found that factors associated with wanting a high level of information include younger age, a higher level of education and patient's expectation of a worse prognosis of survival. ${ }^{71}$ However, the interaction between preferences for hope and desire for prognostic information is complex and direct questioning at one point in time about how much information patients and families desire will not fully elucidate their informational needs. ${ }^{88}$ Moreover, patients and their loved ones may differ in the extent to which they prefer to receive information and family members often appreciate the opportunity to talk directly to clinicians. ${ }^{71,89}$ Checking the patient's and family members' understanding and goals should be an ongoing process during the course of the disease ${ }^{71}$ and will facilitate the process of advance care planning. In addition, affirming non-abandonment of patients and families is important to include in conversations about end-of-life care. ${ }^{90}$ These kinds of reassurances have been shown to be associated with increased family satisfaction. $^{91}$

The manner or style in which the content is addressed is also critically important to successful advance care planning conversations. Clinicians need to communicate in an honest and straightforward way while using appropriate language. ${ }^{86}$ Information should be conveyed compassionately and empathetically. ${ }^{71}$ It is important to make eye contact, explore emotional reactions, and encourage patients to ask questions. ${ }^{71,86}$ Active listening is an essential communication skill for clinicians conducting advance care planning. ${ }^{71}$ In a study of family conferences, an increased proportion of time spent listening to family rather than talking was significantly associated with increased family satisfaction with physician communication. ${ }^{92}$ Personalizing care, acknowledging the patient as an individual, and taking into consideration the patient's social situation may help in meeting patients' needs. ${ }^{93}$ Clinicians should show willingness to talk about dying and use the words "death" and "dying". ${ }^{71,86} \mathrm{~A}$ recent study suggests there may be important variability in the way that patients would like to receive prognostic information from their clinicians and the way that this information affects their hopes for the future. ${ }^{88}$ Some patients and family members desire to hear direct and explicit information about the patient's prognosis, while other prefer a more indirect approach that describes prognosis in general 
for other patients. Understanding patients and their families' perspective on prognostic information will help clinicians match their approach to the preferences and needs of individual patients and their families. ${ }^{88}$

There are also a number of communication topics about end-of-life care that are specifically important for family members. Such topics include available support, medical aids and resources and how to deal with an emergency. ${ }^{71}$ In addition, surrogate decision-making is an important topic to discuss with family members and patients. $^{94}$ Indeed, agreement between patients and their surrogate decision makers about the acceptability of health states may be poor and surrogate decisions based on considerations of treatment outcomes may not effectively represent patients' preferences. Communication with patients and their family about these topics will improve agreement. ${ }^{94}$

Finally, because preferences for life-sustaining treatments may change during the course of the disease, repeated assessments of preferences for life-sustaining treatments are necessary. ${ }^{95-97}$ Indeed, the results of chapter 9 clearly show the need for frequent evaluation of advance care planning. More than a third of the outpatients with advanced COPD, CHF or CRF changes their preferences regarding cardiopulmonary resuscitation and/or invasive mechanical ventilation at least once during one year. A change in life-sustaining treatment preferences was predicted by a change in health status, mobility, symptoms of anxiety or depression or loss of a spouse. Therefore, re-evaluation of advance care planning is even more important when patients experience a change in health status, mobility, psychological symptoms, or marital status. The relationship between change in health status and lifesustaining treatment preferences is complex. For some patients, worsening of health status may result in decreased interest in life-sustaining treatments. For other patients, changes in their health status are associated with changes in their assessment of the outcomes that result from treatment of their illness. ${ }^{97}$ For example, patients with COPD who experience a decline in functional status may find more severe functional disability an acceptable outcome of therapy, while patients who don't experience a decline in functional status are more likely to evaluate possible severe functional disability as unacceptable. ${ }^{97}$ In addition, patients facing the need for intervention may decide to forgo life-sustaining treatments, despite having previously expressed the wish for life-sustaining treatments. ${ }^{89}$

Clinicians caring for patients with chronic organ failure will need training in order to implement these components of good advance care planning. Previous studies have shown that a communication skills-building workshop for clinicians working in oncology was successful in improving skills for communication about end-of-life care. $^{98,99}$ Therefore, a target for future studies may be to develop interventions to 
improve the skills of clinicians to communicate about end-of-life care with patients with chronic organ failure and their loved ones.

Although there is growing recognition of the importance of interdisciplinary communication and the potential role for interdisciplinary team members in supporting physicians to enhance advance care planning and communication about end-of-life care, ${ }^{84,100}$ there are limited data on exactly how best to accomplish this goal. In a recent randomized controlled trial in patients being admitted for internal medicine, cardiology or respiratory medicine services which showed that advance care planning can be effective in changing outcomes for patients and their loved ones, advance care planning was provided by a trained nurse or allied health care professional. ${ }^{101}$ Future studies should explore interdisciplinary interventions to improve advance care planning and communication about end-of-life care.

\section{Methodological considerations}

The present thesis has some important limitations that should be considered in interpreting the results. First, the included patients in this study consisted of a convenience sample. It is possible that physicians were unwilling to refer their patients with the most severe disease. While the majority of eligible COPD and CRF patients agreed to participate, the response rate for CHF patients was below 50\%. The current response rate confirms the previously reported difficulty of recruitment of older patients with $\mathrm{CHF}^{102}$ and may limit the generalizability of the results. Indeed, some differences were present between eligible patients who were willing to participate and patients who refused participation. Participants were younger and more often male than non-participants. Moreover, unknown differences between patients who agreed to participate and patients who refused to participate might have been present. For example, it may be possible that eligible patients who refused participation were less willing to discuss issues concerning end-of-life care. Second, $22.3 \%$ of the patients did not complete the longitudinal study. Drop-out is to be expected in a longitudinal study of patients with an advanced chronic disease. Indeed, $11.7 \%$ of the included patients died or withdrew because of renal transplant. The remaining $10.6 \%$ withdrew from the study for other reasons. It remains unknown whether and to what extent this has influenced the current results. However, since the baseline characteristics and life-sustaining treatment preferences of patients who withdrew from the study were similar to those of the patients who completed all visits, this suggests that these individuals may be similar to those who completed all study visits. Some differences were present between patients who completed the study and patients who died during the study. Patients who died during the study were older at baseline, had a worse general health status, more 
mobility problems and a higher level of care dependency. These differences may have influenced our results. Third, the main part of this thesis reported palliative care needs of patients with advanced COPD or CHF. Therefore, knowledge concerning the palliative care needs of CRF patients remains scarce and further research is necessary to elaborate the currently available knowledge concerning palliative care needs of patients with advanced CRF. Fourth, chapter 8 and 10 focused on advance care planning and communication with the physician specialist. We did not study advance care planning with the general practitioner, nurse specialists or other healthcare professionals. Patients may have discussed end-of-life care with their general practitioner or other healthcare professionals instead of their physician specialist. Moreover, a recent study has shown that advance care planning provided by nurses or allied health care professionals can improve end-of-life care. ${ }^{101}$ Therefore, future studies should include communication with other healthcare professionals. Finally, most chapters of this thesis were based on the cross-sectional part of the prospective study. Therefore, to date remains unknown whether and to what extent symptom distress, healthcare provision, health status, care dependency, and communication about end-of-life care change during the course of advanced chronic organ failure.

\section{Conclusions, implications for daily practice and recommendations for research}

Previous studies have tried to identify the time point for transition from curative to palliative care for patients with advanced chronic organ failure. Unfortunately, even the best models to predict six months survival or less have shown poor discrimination. ${ }^{103,104}$ Moreover, a recent qualitative study has shown that identifying a time point for transition to palliative care has little resonance with the experiences from patients, informal carers, and healthcare professionals, and may even be counterproductive if it distracts healthcare professionals from timely consideration of providing palliative care. ${ }^{55}$ This is supported by the present thesis. Only 9.1 percent of the enrolled clinically stable outpatients with advanced disease died during one year follow-up. Nevertheless, patients with advanced chronic organ failure have major palliative care needs. Therefore, the provision of palliative care to patients with advanced chronic organ failure should be based on their needs for palliative care and not on their estimated life expectancy.

This thesis has identified the following palliative care needs of patients with advanced chronic organ failure (Figure 11.2). First, patients with advanced chronic organ failure experience significant symptom distress and symptom management is 
often poor. A systematic assessment of symptom distress should be part of regular clinical care. Further research is necessary to develop and validate instruments for multidimensional symptom assessment in patients with advanced chronic organ failure. In addition, future studies should focus on interventions concerning optimal symptom management. Finally, further research is necessary to understand symptom distress of CRF patients. Second, care dependency is highly prevalent in patients with advanced chronic organ failure and may have significant consequences for patients and their closest relatives. Therefore, assessment of care dependency should be part of palliative management programs. A clear insight in care dependency will provide insight in the need for support, medical aids and appliances. Furthermore, interdisciplinary interventions may be important in reducing care dependency. Third, family caregivers have an important role in care for patients with advanced chronic organ failure. Assessment of caregiver burden and positive aspects of caregiving and support for family caregivers is needed. Fourth, comorbidities are highly prevalent in patients with advanced chronic organ failure and may influence palliative care needs. Therefore, co-morbidities need to be taken into account in the assessment and management of palliative care needs. Finally, advance care planning, including communication about end-of-life care, is of major importance for patients with chronic organ failure and their loved ones. Because of the uncertain prognosis and the frequent occurrence of unexpected declines in health status in chronic organ failure, advance care planning must be an important part of regular care for patients with advanced chronic organ failure. Unfortunately, advance care planning occurs infrequently and the quality of patient-physician communication about end-of-life care is poor for patients with chronic organ failure. Future studies should focus on interventions to facilitate advance care planning in patients with chronic organ failure with the goal of improving the quality of end-oflife care. In addition, future research should focus on interventions to improve quality of patient-physician communication about end-of-life care in chronic organ failure. 







\section{References}

1. Curtis, J.R., Palliative and End-of-life Care for Patients with Severe COPD. Eur Respir J. 2008; 32(3): 796-803.

2. Weisbord, S.D., S.S. Carmody, F.J. Bruns, A.J. Rotondi, L.M. Cohen, M.L. Zeidel, and R.M. Arnold, Symptom burden, quality of life, advance care planning and the potential value of palliative care in severely ill haemodialysis patients. Nephrol Dial Transplant. 2003;18(7):1345-52.

3. Gore, J.M., C.J. Brophy, and M.A. Greenstone, How well do we care for patients with end stage chronic obstructive pulmonary disease (COPD)? A comparison of palliative care and quality of life in COPD and lung cancer. Thorax. 2000;55(12):1000-6.

4. Hauptman, P.J. and E.P. Havranek, Integrating palliative care into heart failure care. Arch Intern Med. 2005;165(4):374-8.

5. Edmonds, P., S. Karlsen, S. Khan, and J. Addington-Hall, A comparison of the palliative care needs of patients dying from chronic respiratory diseases and lung cancer. Palliat Med. 2001;15(4):287-95.

6. Temel, J.S., J.A. Greer, A. Muzikansky, E.R. Gallagher, S. Admane, V.A. Jackson, C.M. Dahlin, C.D. Blinderman, J. Jacobsen, W.F. Pirl, J.A. Billings, and T.J. Lynch, Early Palliative Care for Patients with Metastatic Non-Small-Cell Lung Cancer. N Engl J Med. 2010;363(8):733-42.

7. Higginson, I., A. Wade, and M. McCarthy, Palliative care: views of patients and their families. Bmj. 1990;301(6746):277-81.

8. Higginson, I., P. Priest, and M. McCarthy, Are bereaved family members a valid proxy for a patient's assessment of dying? Soc Sci Med. 1994;38(4):553-7.

9. Blinderman, C.D., P. Homel, J. Andrew Billings, S. Tennstedt, and R.K. Portenoy, Symptom Distress and Quality of Life in Patients with Advanced Chronic Obstructive Pulmonary Disease. J Pain Symptom Manage. 2009;38(1):115-23.

10. Blinderman, C.D., P. Homel, J.A. Billings, R.K. Portenoy, and S.L. Tennstedt, Symptom distress and quality of life in patients with advanced congestive heart failure. J Pain Symptom Manage. 2008;35(6):594-603.

11. Opasich, C., A. Gualco, S. De Feo, M. Barbieri, G. Cioffi, A. Giardini, and G. Majani, Physical and emotional symptom burden of patients with end-stage heart failure: what to measure, how and why. J Cardiovasc Med (Hagerstown). 2008;9(11):1104-8.

12. Habraken, J.M., J. Pols, P.J. Bindels, and D.L. Willems, The silence of patients with end-stage COPD: a qualitative study. Br J Gen Pract. 2008;58(557):844-9.

13. Rogers, A.E., J.M. Addington-Hall, A.J. Abery, A.S. McCoy, C. Bulpitt, A.J. Coats, and J.S. Gibbs, Knowledge and communication difficulties for patients with chronic heart failure: qualitative study. BMJ. 2000;321(7261):605-7.

14. Kirkova, J., D. Walsh, M. Russel, K. Hauser, and W. Lasheen, Symptom assessment in palliative medicine: complexities and challenges. Am J Hosp Palliat Care. 2010;27(1):75-83.

15. Opasich, C. and A. Gualco, The complex symptom burden of the aged heart failure population. Curr Opin Support Palliat Care. 2007;1(4):255-9.

16. O'Leary, N., N.F. Murphy, C. O'Loughlin, E. Tiernan, and K. McDonald, A comparative study of the palliative care needs of heart failure and cancer patients. Eur J Heart Fail. 2009;11(4):406-12.

17. Bausewein, C., S. Booth, M. Gysels, R. Kuhnbach, B. Haberland, and I.J. Higginson, Understanding breathlessness: cross-sectional comparison of symptom burden and palliative care needs in chronic obstructive pulmonary disease and cancer. J Palliat Med. 2010 13(9):1109-18.

18. Bausewein, C., M. Farquhar, S. Booth, M. Gysels, and I.J. Higginson, Measurement of breathlessness in advanced disease: a systematic review. Respir Med. 2007;101(3):399-410.

19. Lanken, P.N., P.B. Terry, H.M. Delisser, B.F. Fahy, J. Hansen-Flaschen, J.E. Heffner, M. Levy, R.A. Mularski, M.L. Osborne, T.J. Prendergast, G. Rocker, W.J. Sibbald, B. Wilfond, and J.R. Yankaskas, An official American Thoracic Society clinical policy statement: palliative care for patients with respiratory diseases and critical illnesses. Am J Respir Crit Care Med. 2008;177(8):912-27. 
20. Jennings, A.L., A.N. Davies, J.P. Higgins, J.S. Gibbs, and K.E. Broadley, A systematic review of the use of opioids in the management of dyspnoea. Thorax. 2002;57(11):939-44.

21. Abernethy, A.P., D.C. Currow, P. Frith, B.S. Fazekas, A. McHugh, and C. Bui, Randomised, double blind, placebo controlled crossover trial of sustained release morphine for the management of refractory dyspnoea. BMJ. 2003;327(7414):523-8.

22. Currow, D.C., C. McDonald, S. Oaten, B. Kenny, P. Allcroft, P. Frith, M. Briffa, M.J. Johnson, and A.P. Abernethy, Once-Daily Opioids for Chronic Dyspnea: A Dose Increment and Pharmacovigilance Study. J Pain Symptom Manage. 2011;42(3):388-99.

23. Currow, D.C., J. Plummer, P. Frith, and A.P. Abernethy, Can we predict which patients with refractory dyspnea will respond to opioids? J Palliat Med. 2007;10(5):1031-6.

24. Lacasse, Y., R. Goldstein, T.J. Lasserson, and S. Martin, Pulmonary rehabilitation for chronic obstructive pulmonary disease. Cochrane Database Syst Rev. 2006(4):CD003793.

25. Pozehl, B., K. Duncan, and M. Hertzog, The effects of exercise training on fatigue and dyspnea in heart failure. Eur J Cardiovasc Nurs. 2008;7(2):127-32.

26. Davies, E.J., T. Moxham, K. Rees, S. Singh, A.J. Coats, S. Ebrahim, F. Lough, and R.S. Taylor, Exercise based rehabilitation for heart failure. Cochrane Database Syst Rev. (4):CD003331.

27. Davies, P., F. Taylor, A. Beswick, F. Wise, T. Moxham, K. Rees, and S. Ebrahim, Promoting patient uptake and adherence in cardiac rehabilitation. Cochrane Database Syst Rev. (7):CD007131.

28. Sachs, S. and R.L. Weinberg, Pulmonary rehabilitation for dyspnea in the palliative-care setting. Curr Opin Support Palliat Care. 2009;3(2):112-9.

29. Sillen, M.J., C.M. Speksnijder, R.M. Eterman, P.P. Janssen, S.S. Wagers, E.F. Wouters, N.H. UszkoLencer, and M.A. Spruit, Effects of neuromuscular electrical stimulation of muscles of ambulation in patients with chronic heart failure or COPD: a systematic review of the English-language literature. Chest. 2009;136(1):44-61.

30. Sillen, M.J., P.P. Janssen, M.A. Akkermans, E.F. Wouters, and M.A. Spruit, The metabolic response during resistance training and neuromuscular electrical stimulation (NMES) in patients with COPD, a pilot study. Respir Med. 2008;102(5):786-9.

31. Peuckmann, V., F. Elsner, N. Krumm, P. Trottenberg, and L. Radbruch, Pharmacological treatments for fatigue associated with palliative care. Cochrane Database Syst Rev. (11):CD006788.

32. Decramer, M., L.M. Lacquet, R. Fagard, and P. Rogiers, Corticosteroids contribute to muscle weakness in chronic airflow obstruction. Am J Respir Crit Care Med. 1994;150(1):11-6.

33. Schols, A.M., G. Wesseling, A.D. Kester, G. de Vries, R. Mostert, J. Slangen, and E.F. Wouters, Dose dependent increased mortality risk in COPD patients treated with oral glucocorticoids. Eur Respir J. 2001;17(3):337-42.

34. Lacasse, Y., L. Rousseau, and F. Maltais, Prevalence of depressive symptoms and depression in patients with severe oxygen-dependent chronic obstructive pulmonary disease. J Cardiopulm Rehabil. 2001;21(2):80-6.

35. Kunik, M.E., K. Roundy, C. Veazey, J. Souchek, P. Richardson, N.P. Wray, and M.A. Stanley, Surprisingly high prevalence of anxiety and depression in chronic breathing disorders. Chest. 2005;127(4):1205-11.

36. Anderson, H., C. Ward, A. Eardley, S.A. Gomm, M. Connolly, T. Coppinger, D. Corgie, J.L. Williams, and W.P. Makin, The concerns of patients under palliative care and a heart failure clinic are not being met. Palliat Med. 2001;15(4):279-86.

37. Yohannes, A.M., T.G. Willgoss, R.C. Baldwin, and M.J. Connolly, Depression and anxiety in chronic heart failure and chronic obstructive pulmonary disease: prevalence, relevance, clinical implications and management principles. Int J Geriatr Psychiatry.25(12):1209-21.

38. Borson, S., G.J. McDonald, T. Gayle, M. Deffebach, S. Lakshminarayan, and C. VanTuinen, Improvement in mood, physical symptoms, and function with nortriptyline for depression in patients with chronic obstructive pulmonary disease. Psychosomatics. 1992;33(2):190-201. 
39. Maurer, J., V. Rebbapragada, S. Borson, R. Goldstein, M.E. Kunik, A.M. Yohannes, and N.A. Hanania, Anxiety and depression in COPD: current understanding, unanswered questions, and research needs. Chest. 2008;134(4 Suppl):43S-56S.

40. Withers, N.J., S.T. Rudkin, and R.J. White, Anxiety and depression in severe chronic obstructive pulmonary disease: the effects of pulmonary rehabilitation. J Cardiopulm Rehabil. 1999;19(6):362-5.

41. Griffiths, T.L., M.L. Burr, I.A. Campbell, V. Lewis-Jenkins, J. Mullins, K. Shiels, P.J. Turner-Lawlor, N. Payne, R.G. Newcombe, A.A. Ionescu, J. Thomas, and J. Tunbridge, Results at 1 year of outpatient multidisciplinary pulmonary rehabilitation: a randomised controlled trial. Lancet. 2000;355(9201):362-8.

42. Coventry, P.A. and D. Hind, Comprehensive pulmonary rehabilitation for anxiety and depression in adults with chronic obstructive pulmonary disease: Systematic review and meta-analysis. J Psychosom Res. 2007;63(5):551-65.

43. de Godoy, D.V. and R.F. de Godoy, A randomized controlled trial of the effect of psychotherapy on anxiety and depression in chronic obstructive pulmonary disease. Arch Phys Med Rehabil. 2003;84(8):1154-7.

44. Kunik, M.E., U. Braun, M.A. Stanley, K. Wristers, V. Molinari, D. Stoebner, and C.A. Orengo, One session cognitive behavioural therapy for elderly patients with chronic obstructive pulmonary disease. Psychol Med. 2001;31(4):717-23.

45. Murtagh, F.E., J. Addington-Hall, and I.J. Higginson, The prevalence of symptoms in end-stage renal disease: a systematic review. Adv Chronic Kidney Dis. 2007;14(1):82-99.

46. Murtagh, F.E., E. Murphy, and N.S. Sheerin, Illness trajectories: an important concept in the management of kidney failure. Nephrol Dial Transplant. 2008;23(12):3746-8.

47. Murray, S.A., M. Kendall, K. Boyd, and A. Sheikh, Illness trajectories and palliative care. Bmj. 2005;330(7498):1007-11.

48. Murtagh, F.E., J.M. Addington-Hall, and I.J. Higginson, End-Stage Renal Disease: A New Trajectory of Functional Decline in the Last Year of Life. J Am Geriatr Soc. 2011;59(2):304-8.

49. Murtagh, F.E., M. Preston, and I. Higginson, Patterns of dying: palliative care for non-malignant disease. Clin Med. 2004;4(1):39-44.

50. Cohen, L.M., M. Germain, D.M. Poppel, A. Woods, and C.M. Kjellstrand, Dialysis discontinuation and palliative care. Am J Kidney Dis. 2000;36(1):140-4.

51. Cohen, L.M., M.J. Germain, D.M. Poppel, A.L. Woods, P.S. Pekow, and C.M. Kjellstrand, Dying well after discontinuing the life-support treatment of dialysis. Arch Intern Med. 2000;160(16):2513-8.

52. Teno, J.M., F.E. Harrell, Jr., W. Knaus, R.S. Phillips, A.W. Wu, A. Connors, Jr., N.S. Wenger, D. Wagner, A. Galanos, N.A. Desbiens, and J. Lynn, Prediction of survival for older hospitalized patients: the HELP survival model. Hospitalized Elderly Longitudinal Project. J Am Geriatr Soc. 2000;48(5 Suppl):S16-24.

53. Fitzsimons, D., D. Mullan, J.S. Wilson, B. Conway, B. Corcoran, M. Dempster, J. Gamble, C. Stewart, S. Rafferty, M. McMahon, J. MacMahon, P. Mulholland, P. Stockdale, E. Chew, L. Hanna, J. Brown, G. Ferguson, and D. Fogarty, The challenge of patients' unmet palliative care needs in the final stages of chronic illness. Palliat Med. 2007;21(4):313-22.

54. Seamark, D.A., S.D. Blake, C.J. Seamark, and D.M. Halpin, Living with severe chronic obstructive pulmonary disease (COPD): perceptions of patients and their carers. An interpretative phenomenological analysis. Palliat Med. 2004;18(7):619-25.

55. Pinnock, H., M. Kendall, S.A. Murray, A. Worth, P. Levack, M. Porter, W. MacNee, and A. Sheikh, Living and dying with severe chronic obstructive pulmonary disease: multi-perspective longitudinal qualitative study. BMJ.342:d142.

56. Habraken, J.M., D.L. Willems, S.J. de Kort, and P.J. Bindels, Health care needs in end-stage COPD: A structured literature review. Patient Educ Couns. 2007;68(2):121-30.

57. Azad, N., F. Molnar, and A. Byszewski, Lessons learned from a multidisciplinary heart failure clinic for older women: a randomised controlled trial. Age Ageing. 2008;37(3):282-7. 
58. Nici, L., C. Donner, E. Wouters, R. Zuwallack, N. Ambrosino, J. Bourbeau, M. Carone, B. Celli, M. Engelen, B. Fahy, C. Garvey, R. Goldstein, R. Gosselink, S. Lareau, N. Maclntyre, F. Maltais, M. Morgan, D. O'Donnell, C. Prefault, J. Reardon, C. Rochester, A. Schols, S. Singh, and T. Troosters, American Thoracic Society/European Respiratory Society statement on pulmonary rehabilitation. Am J Respir Crit Care Med. 2006;173(12):1390-413.

59. Vaes, A.W., E.F. Wouters, F.M. Franssen, N.H. Uszko-Lencer, K.H. Stakenborg, M. Westra, K. Meijer, A.M. Schols, P.P. Janssen, and M.A. Spruit, Task-related oxygen uptake during domestic activities of daily life in patients with COPD and healthy elderly subjects. Chest. 2011;140(4):970-9.

60. Velloso, M. and J.R. Jardim, Study of energy expenditure during activities of daily living using and not using body position recommended by energy conservation techniques in patients with COPD. Chest. 2006;130(1):126-32.

61. Hasson, F., A. Spence, M. Waldron, G. Kernohan, D. McLaughlin, B. Watson, and B. Cochrane, Experiences and needs of bereaved carers during palliative and end-of-life care for people with chronic obstructive pulmonary disease. J Palliat Care. 2009;25(3):157-63.

62. Boyd, K.J., S.A. Murray, M. Kendall, A. Worth, T. Frederick Benton, and H. Clausen, Living with advanced heart failure: a prospective, community based study of patients and their carers. Eur J Heart Fail. 2004;6(5):585-91.

63. Luttik, M.L., A. Blaauwbroek, A. Dijker, and T. Jaarsma, Living with heart failure: partner perspectives. J Cardiovasc Nurs. 2007;22(2):131-7.

64. Barnes, S., M. Gott, S. Payne, C. Parker, D. Seamark, S. Gariballa, and N. Small, Characteristics and views of family carers of older people with heart failure. Int J Palliat Nurs. 2006;12(8):380-9.

65. Pinto, R.A., M.A. Holanda, M.M. Medeiros, R.M. Mota, and E.D. Pereira, Assessment of the burden of caregiving for patients with chronic obstructive pulmonary disease. Respir Med. 2007;101(11):24028.

66. Dracup, K., L.S. Evangelista, L. Doering, D. Tullman, D.K. Moser, and M. Hamilton, Emotional wellbeing in spouses of patients with advanced heart failure. Heart Lung. 2004;33(6):354-61.

67. Luttik, M.L., T. Jaarsma, I. Lesman, R. Sanderman, and M. Hagedoorn, Quality of life in partners of people with congestive heart failure: gender and involvement in care. J Adv Nurs. 2009;65(7):144251.

68. Pressler, S.J., I. Gradus-Pizlo, S.D. Chubinski, G. Smith, S. Wheeler, J. Wu, and R. Sloan, Family caregiver outcomes in heart failure. Am J Crit Care. 2009;18(2):149-59.

69. Belasco, A., D. Barbosa, A.R. Bettencourt, S. Diccini, and R. Sesso, Quality of life of family caregivers of elderly patients on hemodialysis and peritoneal dialysis. Am J Kidney Dis. 2006;48(6):955-63.

70. Garlo, K., J.R. O'Leary, P.H. Van Ness, and T.R. Fried, Burden in caregivers of older adults with advanced illness. J Am Geriatr Soc. 2010;58(12):2315-22.

71. Parker, S.M., J.M. Clayton, K. Hancock, S. Walder, P.N. Butow, S. Carrick, D. Currow, D. Ghersi, P. Glare, R. Hagerty, and M.H. Tattersall, A systematic review of prognostic/end-of-life communication with adults in the advanced stages of a life-limiting illness: patient/caregiver preferences for the content, style, and timing of information. J Pain Symptom Manage. 2007;34(1):81-93.

72. Ferrer, M., J. Alonso, J. Morera, R.M. Marrades, A. Khalaf, M.C. Aguar, V. Plaza, L. Prieto, and J.M. Anto, Chronic obstructive pulmonary disease stage and health-related quality of life. The Quality of Life of Chronic Obstructive Pulmonary Disease Study Group. Ann Intern Med. 1997;127(12):1072-9.

73. Miravitlles, M., J.L. Alvarez-Sala, R. Lamarca, M. Ferrer, F. Masa, H. Verea, R. Zalacain, C. Murio, and F. Ros, Treatment and quality of life in patients with chronic obstructive pulmonary disease. Qual Life Res. 2002;11(4):329-38.

74. Incalzi, R.A., A. Corsonello, C. Pedone, S. Battaglia, G. Paglino, and V. Bellia, Chronic renal failure: a neglected comorbidity of COPD. Chest.137(4):831-7.

75. Nayak-Rao, S., Achieving effective pain relief in patients with chronic kidney disease: a review of analgesics in renal failure. J Nephrol.24(1):35-40.

76. Curtis, J.R., Palliative and end-of-life care for patients with severe COPD. Eur Respir J. 2008;32(3):796-803. 
77. Davison, S.N. and C. Torgunrud, The creation of an advance care planning process for patients with ESRD. Am J Kidney Dis. 2007;49(1):27-36.

78. Curtis, J.R., R.A. Engelberg, E.L. Nielsen, D.H. Au, and D.L. Patrick, Patient-physician communication about end-of-life care for patients with severe COPD. Eur Respir J. 2004;24(2):200-5.

79. Heffner, J.E., B. Fahy, L. Hilling, and C. Barbieri, Attitudes regarding advance directives among patients in pulmonary rehabilitation. Am J Respir Crit Care Med. 1996;154(6 Pt 1):1735-40.

80. Knauft, E., E.L. Nielsen, R.A. Engelberg, D.L. Patrick, and J.R. Curtis, Barriers and facilitators to end-oflife care communication for patients with COPD. Chest. 2005;127(6):2188-96.

81. Gott, M., C. Gardiner, N. Small, S. Payne, D. Seamark, S. Barnes, D. Halpin, and C. Ruse, Barriers to advance care planning in chronic obstructive pulmonary disease. Palliat Med. 2009;23(7):642-8.

82. Fried, T.R., E.H. Bradley, and J. O'Leary, Changes in prognostic awareness among seriously ill older persons and their caregivers. J Palliat Med. 2006;9(1):61-9.

83. Reinke, L.F., R.A. Engelberg, S.E. Shannon, M.D. Wenrich, E.K. Vig, A.L. Back, and J.R. Curtis, Transitions regarding palliative and end-of-life care in severe chronic obstructive pulmonary disease or advanced cancer: themes identified by patients, families, and clinicians. J Palliat Med. 2008;11(4):6019.

84. Reinke, L.F., S.E. Shannon, R.A. Engelberg, J.P. Young, and J.R. Curtis, Supporting hope and prognostic information: nurses' perspectives on their role when patients have life-limiting prognoses. J Pain Symptom Manage. 2010;39(6):982-92.

85. Curtis, J.R., M.D. Wenrich, J.D. Carline, S.E. Shannon, D.M. Ambrozy, and P.G. Ramsey, Patients' perspectives on physician skill in end-of-life care: differences between patients with COPD, cancer, and AIDS. Chest. 2002;122(1):356-62.

86. Wenrich, M.D., J.R. Curtis, S.E. Shannon, J.D. Carline, D.M. Ambrozy, and P.G. Ramsey, Communicating with dying patients within the spectrum of medical care from terminal diagnosis to death. Arch Intern Med. 2001;161(6):868-74.

87. Gardiner, C., M. Gott, N. Small, S. Payne, D. Seamark, S. Barnes, D. Halpin, and C. Ruse, Living with advanced chronic obstructive pulmonary disease: patients concerns regarding death and dying. Palliat Med. 2009;23(8):691-7.

88. Curtis, J.R., R. Engelberg, J.P. Young, L.K. Vig, L.F. Reinke, M.D. Wenrich, B. McGrath, E. McCown, and A.L. Back, An approach to understanding the interaction of hope and desire for explicit prognostic information among individuals with severe chronic obstructive pulmonary disease or advanced cancer. J Palliat Med. 2008;11(4):610-20.

89. Fried, T.R. and J.R. O'Leary, Using the experiences of bereaved caregivers to inform patient- and caregiver-centered advance care planning. J Gen Intern Med. 2008;23(10):1602-7.

90. Back, A.L., J.P. Young, E. McCown, R.A. Engelberg, E.K. Vig, L.F. Reinke, M.D. Wenrich, B.B. McGrath, and J.R. Curtis, Abandonment at the end of life from patient, caregiver, nurse, and physician perspectives: loss of continuity and lack of closure. Arch Intern Med. 2009;169(5):474-9.

91. Stapleton, R.D., R.A. Engelberg, M.D. Wenrich, C.H. Goss, and J.R. Curtis, Clinician statements and family satisfaction with family conferences in the intensive care unit. Crit Care Med. 2006;34(6):1679-85.

92. McDonagh, J.R., T.B. Elliott, R.A. Engelberg, P.D. Treece, S.E. Shannon, G.D. Rubenfeld, D.L. Patrick, and J.R. Curtis, Family satisfaction with family conferences about end-of-life care in the intensive care unit: increased proportion of family speech is associated with increased satisfaction. Crit Care Med. 2004;32(7):1484-8.

93. Wenrich, M.D., J.R. Curtis, D.A. Ambrozy, J.D. Carline, S.E. Shannon, and P.G. Ramsey, Dying patients' need for emotional support and personalized care from physicians: perspectives of patients with terminal illness, families, and health care providers. J Pain Symptom Manage. 2003;25(3):236-46.

94. Fried, T.R., E.H. Bradley, and V.R. Towle, Valuing the outcomes of treatment: do patients and their caregivers agree? Arch Intern Med. 2003;163(17):2073-8. 
95. Rosenfeld, K.E., N.S. Wenger, R.S. Phillips, A.F. Connors, N.V. Dawson, P. Layde, R.M. Califf, H. Liu, J. Lynn, and R.K. Oye, Factors associated with change in resuscitation preference of seriously ill patients. The SUPPORT Investigators. Study to Understand Prognoses and Preferences for Outcomes and Risks of Treatments. Arch Intern Med. 1996;156(14):1558-64.

96. Fried, T.R., J. O'Leary, P. Van Ness, and L. Fraenkel, Inconsistency over time in the preferences of older persons with advanced illness for life-sustaining treatment. J Am Geriatr Soc. 2007;55(7):100714.

97. Fried, T.R., A.L. Byers, W.T. Gallo, P.H. Van Ness, V.R. Towle, J.R. O'Leary, and J.A. Dubin, Prospective study of health status preferences and changes in preferences over time in older adults. Arch Intern Med. 2006;166(8):890-5.

98. Back, A.L., R.M. Arnold, W.F. Baile, K.A. Fryer-Edwards, S.C. Alexander, G.E. Barley, T.A. Gooley, and J.A. Tulsky, Efficacy of communication skills training for giving bad news and discussing transitions to palliative care. Arch Intern Med. 2007;167(5):453-60.

99. Jenkins, V., L. Fallowfield, I. Solis-Trapala, C. Langridge, and V. Farewell, Discussing randomised clinical trials of cancer therapy: evaluation of a Cancer Research UK training programme. BMJ. 2005;330(7488):400.

100.Reinke, L.F., S.E. Shannon, R. Engelberg, D. Dotolo, G.A. Silvestri, and J.R. Curtis, Nurses' identification of important yet under-utilized end-of-life care skills for patients with life-limiting or terminal illnesses. J Palliat Med.13(6):753-9.

101.Detering, K.M., A.D. Hancock, M.C. Reade, and W. Silvester, The impact of advance care planning on end of life care in elderly patients: randomised controlled trial. BMJ. 2010;340:c1345.

102.Barnes, S., M. Gott, S. Payne, C. Parker, D. Seamark, S. Gariballa, and N. Small, Recruiting older people into a large, community-based study of heart failure. Chronic IIIn. 2005;1(4):321-9.

103. Coventry, P.A., G.E. Grande, D.A. Richards, and C.J. Todd, Prediction of appropriate timing of palliative care for older adults with non-malignant life-threatening disease: a systematic review. Age Ageing. 2005;34(3):218-27.

104.Fox, E., K. Landrum-McNiff, Z. Zhong, N.V. Dawson, A.W. Wu, and J. Lynn, Evaluation of prognostic criteria for determining hospice eligibility in patients with advanced lung, heart, or liver disease. SUPPORT Investigators. Study to Understand Prognoses and Preferences for Outcomes and Risks of Treatments. Jama. 1999;282(17):1638-45. 
Summary 
$198 \mid$ 


\section{Summary}

Chronic diseases, like Chronic Obstructive Pulmonary Disease (COPD), Chronic Heart Failure (CHF) and Chronic Renal Failure (CRF) are major causes of morbidity and mortality, worldwide. During the last decade, several authors have suggested that palliative care has an important role in chronic non-malignant diseases. Palliative care aims to improve quality of life of patients confronted with a life-limiting illness and their loved ones. Indeed, quality of life of patients with chronic organ failure is equally or even more affected by the disease than quality of life of patients with cancer. However, until now palliative care has been reserved mostly for patients with malignant disease as evidenced by the limited access to palliative care for patients with non-malignant disease. Therefore, palliative care programs should be developed with the aim to improve quality of life of patients with advanced chronic organ failure and their closest relatives. For the development of such programs, it is necessary to understand the palliative care needs of patients with advanced chronic organ failure. Therefore, aim of this thesis was to understand the palliative care needs of patients with advanced chronic organ failure and the needs of their closest relatives (chapter 1).

Chapter 2 shows the need for palliative care from the perspective of a patient with advanced COPD. This chapter also shows the limitations of palliative care. Although this patient was offered every type of curative and palliative care available, she still experienced her suffering as unbearable. After fulfilment of all the due care criteria, euthanasia allowed her to end her life in dignity.

Chapter 3 describes the literature available at the start of this study concerning symptom burden in advanced COPD, CHF or CRF. A systematic review was performed of studies that examined daily symptom prevalence in patients with advanced COPD, CHF or CRF. The included studies used various study designs. There was a wide range of daily symptom prevalence that may be due to the heterogeneity and limitations in methodology used in the included studies. Findings suggest significant symptom burden, but did not allow clear recommendations for symptom management. This review highlighted the need for prospective and longitudinal research on symptom prevalence in patients with advanced CHF, COPD or CRF to facilitate the development of patient-centered palliative care programs.

A cross-sectional comparative and prospective longitudinal study of patients with advanced COPD, CHF or CRF was designed to gain insight in their palliative care needs (chapter 4). Patients were recruited by their treating physician specialist. The following outcomes were assessed during home visits at baseline and every four months after baseline for a period of 12 months: self-perceived symptoms and care 
needs; daily physical functioning; generic and disease-specific health status; end-oflife care treatment preferences; end-of-life care communication and caregiver burden and positive aspects of family caregiving. Additionally, advance care planning was assessed with the physician specialist.

Chapter 5 describes the findings of the cross-sectional part of the study concerning symptoms, presence of co-morbidities and current provision of healthcare in advanced COPD or CHF. Co-morbidities were reported by the majority of the patients. Patients suffered from multiple symptoms, like dyspnea, fatigue, muscle weakness, coughing, low mood, sleeplessness and frequent micturition. For most symptoms, only the minority of patients had received symptom-related treatment. Involvement of allied healthcare professionals was low. The majority of COPD and CHF patients had received home adaptation and medical aids. Further development and implementation of palliative care programs, consisting of regular assessment of the patients' co-morbidities and symptoms as well as the provision of patient-tailored interventions is needed.

Health status and care dependency in patients with advanced COPD or CHF were assessed in chapter 6 . We found that patients with advanced COPD or CHF have an impaired health status and may be confronted with care dependency. Physical and psychological symptoms, care dependency and number of drugs were correlated with impaired health status in advanced COPD or CHF, while demographic and clinical characteristics like age, gender, disease severity and co-morbidities were not correlated. Therefore, clinical care should regularly assess symptom burden and care dependency to identify patients with advanced COPD or CHF at risk for an impaired health status.

Caring for a loved one with advanced disease may have significant consequences for the family caregivers. Chapter 7 examined caregiver burden, as well as positive aspects of family caregiving in family caregivers of patients with advanced COPD, CHF or CRF. The majority of the family caregivers were female partners of participating patients. Caregiver distress and caregiver strain scores were relatively low, whereas scores for positive caregiving appraisals and family well-being were relatively positive. Caregiver strain, positive caregiving appraisals and family well-being were comparable for family caregivers of patients with COPD, CHF or CRF. Caregiver distress was higher for family caregivers of patients with COPD than CHF. The experience of caregiving was influenced by being the patient's spouse, patient's psychological symptoms and the presence of co-morbidities. Attention should be paid to caregiver burden as well as the positive aspects of family caregiving to support family caregivers. 
Patients with advanced COPD or CHF are often confronted with decisions concerning life-sustaining treatments. Aim of chapter 8 was to assess life-sustaining treatment preferences, advance care planning and quality of end-of-life care communication in outpatients with clinically stable, but severe COPD or CHF. Most patients asserted to prefer cardiopulmonary resuscitation and mechanical ventilation. $\mathrm{Pa}-$ tients' treatment preferences were influenced by burden of treatment, outcome of treatment and likelihood of outcome. Advance directives were discussed with the physician specialist by only a few patients with COPD or CHF. Patients rated quality of patient-clinician end-of-life care communication as poor. Physicians scarcely discussed prognosis, dying and palliative care. This chapter shows a need for advance care planning, taking into account burden of treatment, outcome of treatment and likelihood of outcome in patients with severe COPD or CHF. Finally, quality of patient-clinician end-of-life care communication needs to improve.

For clinicians discussing advance care planning with patients with life-limiting illness, it is important to understand the stability of patients' preferences for life-sustaining treatments and the factors that predict a change in preferences. Objectives of chapter 9 were to investigate one-year stability of preferences regarding cardiopulmonary resuscitation (CPR) and mechanical ventilation of outpatients with advanced COPD, CHF or CRF and to identify predictors of changes in preferences. Preferences regarding CPR or mechanical ventilation changed in more than a third of the patients at least once during one year follow-up. A change in life-sustaining treatment preferences was predicted by a change in health status, mobility, symptoms of anxiety or depression or loss of a spouse. Therefore, regular re-evaluation of advance care planning is necessary, in particular when patients experience a change in health status, mobility, psychological symptoms, or marital status.

Objective of chapter $\mathbf{1 0}$ was to compare quality of patient-clinician communication about end-of-life care in the Netherlands and USA. We compared quality of patientclinician communication about end-of-life care and barriers and facilitators to this communication between 122 Dutch and 391 US outpatients with COPD. Although Dutch patients in this study had worse lung function and disease-specific health status than US patients, Dutch patients reported lower quality of communication about end-of-life care. Clinicians in both countries rarely discussed life-sustaining treatment preferences, prognoses, dying processes, and spiritual issues. Quality of communication about end-of-life care needs to improve in the Netherlands and the USA. Future studies to improve this communication should be designed to take into account international differences and patient-specific barriers and facilitators to communication about end-of-life care. 
To conclude, this thesis has identified a spectrum of palliative care needs of patients with advanced chronic organ failure, that should be addressed in palliative care programs (chapter 11). Patients with advanced chronic organ failure experience significant symptom distress and symptom management is often poor. Furthermore, care dependency is highly prevalent and may have significant consequences for patients and their closest relatives. In addition, family caregivers have an important role in care for patients with advanced chronic organ failure. Co-morbidities are highly prevalent and may influence palliative care needs. Consequently, palliative care programs should pay attention to symptom management; care dependency; caregiver burden and positive aspects of family caregiving; and co-morbidities. Finally, advance care planning, including communication about end-of-life care, is of major importance for patients with chronic organ failure. Unfortunately, advance care planning occurs infrequently and the quality of patient-clinician communication about end-of-life care is poor for patients with chronic organ failure. Because of the uncertain prognosis and the frequent occurrence of unexpected declines in health status in chronic organ failure, advance care planning must be an important part of regular care for patients with advanced chronic organ failure. 
Samenvatting 
204 


\section{Samenvatting}

Chronisch orgaanfalen, zoals COPD, hartfalen of nierfalen, is wereldwijd een belangrijke doodsoorzaak. Tijdens het laatste decennium is duidelijk geworden dat palliatieve zorg belangrijk is voor patiënten met chronisch orgaanfalen. Palliatieve zorg is de zorg die als doel heeft het verbeteren van de kwaliteit van leven van patiënten met een levensbedreigende ziekte en hun naasten. De kwaliteit van leven van patiënten met chronisch orgaanfalen is in gelijke mate of zelfs meer beperkt dan de kwaliteit van leven van patiënten met kanker. Echter, tot nu toe wordt palliatieve zorg met name geboden aan patiënten met kanker. Daarom is het ontwikkelen van palliatieve zorgprogramma's voor patiënten met chronisch orgaanfalen noodzakelijk. Voor het ontwikkelen van palliatieve zorgprogramma's die de kwaliteit van leven van patiënten met chronisch orgaanfalen en hun naasten kunnen verbeteren, is het noodzakelijk om de behoeften aan palliatieve zorg te begrijpen. Het doel van dit proefschrift is dan ook inzicht krijgen in de behoeften aan palliatieve zorg van patiënten met gevorderd chronisch orgaanfalen en hun directe naasten (hoofdstuk 1).

Hoofdstuk 2 beschrijft het verhaal van een patiënte met zeer ernstig COPD en laat haar behoefte aan palliatieve zorg zien. Dit hoofdstuk laat tegelijkertijd ook de beperkingen van palliatieve zorg zien. Voor deze patiënte was haar lijden ondraaglijk, ondanks iedere mogelijke curatieve en palliatieve behandeling die zij had gekregen. Nadat aan alle zorgvuldigheidseisen was voldaan, werd naar haar wens haar leven beëindigd middels euthanasie.

In hoofdstuk 3 wordt een overzicht gegeven van de literatuur die beschikbaar was aan het begin van deze studie over symptomen bij patiënten met gevorderd COPD, hartfalen of nierfalen. De bestaande literatuur liet een grote spreiding zien van het voorkomen van symptomen. Deze grote variatie werd waarschijnlijk veroorzaakt door grote verschillen in studieopzet en beperkingen van de gebruikte onderzoeksmethoden. Hoewel deze studies suggereren dat patiënten met gevorderd orgaanfalen een aanzienlijke symptoomlast ervaren, konden hierdoor geen aanbevelingen voor het behandelen van symptomen worden gedaan. Verder onderzoek naar het voorkomen van symptomen was nodig om de ontwikkeling van patiëntgeoriënteerde programma's voor palliatieve zorg mogelijk te maken.

Om inzicht te krijgen in de behoeften aan palliatieve zorg van patiënten met gevorderd COPD, hartfalen of nierfalen werden patiënten aan het begin van de studie en daarna iedere vier maanden gedurende een jaar thuis bezocht (hoofdstuk 4). Tijdens deze huisbezoeken vulden patiënten vragenlijsten in en werden ze geïnterviewd over: symptomen en zorgbehoeften; het dagelijks functioneren; algemene en 
ziektespecifieke gezondheidsstatus; voorkeuren voor zorg in de laatste levensfase; communicatie over zorg in de laatste levensfase; belasting voor de mantelzorger en positieve aspecten van het zorgen voor een naaste. Tenslotte beantwoordde de medisch specialist vragen over communicatie over zorg rondom het levenseinde en levensverlengende behandelingen.

Hoofdstuk 5 laat zien dat de meeste patiënten naast hun COPD of hartfalen ook lijden aan andere ziekten. Daarnaast bleek de symptoomlast van patiënten hoog te zijn. De meest voorkomende symptomen waren kortademigheid, vermoeidheid, spierzwakte, hoesten, somberheid, slapeloosheid en vaak plassen. Patiënten gaven aan dat ze voor de meeste symptomen niet werden behandeld. Therapeuten zoals ergotherapeuten, psychologen en maatschappelijk werkers waren slechts zelden betrokken in de behandeling. De meerderheid van de patiënten had wel aanpassingen in huis en medische hulpmiddelen. Behandeling van symptomen en comorbiditeit zijn dan ook belangrijke componenten van een palliatief zorgprogramma.

We hebben in hoofdstuk 6 laten zien dat patiënten met gevorderd COPD of hartfalen een verminderde kwaliteit van leven ervaren. Daarnaast kunnen patiënten afhankelijkheid zijn van zorg van anderen. Lichamelijke en psychische klachten, zorgafhankelijkheid en het aantal voorgeschreven medicijnen bleken voorspellend te zijn voor de kwaliteit van leven. Om tijdig patiënten te identificeren die een verhoogd risico hebben op verminderde kwaliteit van leven is het belangrijk om regelmatig symptoomlast en zorgafhankelijkheid in kaart te brengen.

Het zorgen voor een naaste met een gevorderde ziekte kan belangrijke consequenties hebben voor de mantelzorger. Hoofdstuk 7 toont aan dat zorgen voor een naaste niet alleen belastend kan zijn, maar ook als positief kan worden ervaren. De meeste mantelzorgers waren de vrouwelijke partners van patiënten die deelnamen aan de studie. De belasting van het mantelzorgen leek hoger te zijn bij naasten van patiënten met COPD, dan bij naasten van patiënten met hartfalen. Positieve aspecten van het zorgen voor een naaste, spanning, en welzijn van het gezin waren vergelijkbaar voor naasten van patiënten met COPD, hartfalen of nierfalen. Hoe het zorgen voor een naaste wordt ervaren, wordt beïnvloed door de relatie met de patiënt, psychologische symptomen van de patiënt en de aanwezigheid van andere ziekten. Voor het ondersteunen van mantelzorgers is het niet alleen belangrijk om aandacht te hebben voor de belasting, maar ook voor positieve aspecten van het zorgen voor een naaste.

Patiënten met gevorderd COPD of hartfalen worden vaak geconfronteerd met besluiten over levensverlengende behandelingen. Het doel van hoofdstuk 8 was het 
onderzoeken van voorkeuren voor levensverlengende behandelingen en communicatie over deze voorkeuren en zorg rondom het levenseinde bij patiënten met gevorderd COPD of hartfalen. De meeste patiënten gaven aan dat ze indien nodig levensverlengende behandelingen, zoals reanimatie en beademing, wilden ondergaan. De voorkeuren van patiënten werden beïnvloed door belasting van de behandeling, de uitkomst van de behandeling en de kans op een negatieve uitkomst. Slechts enkele patiënten hadden hun voorkeuren besproken met hun arts. Patiënten beoordeelden de kwaliteit van communicatie over zorg in de laatste levensfase met hun medisch specialist als onvoldoende. Artsen bespraken zelden de prognose, doodgaan en palliatieve zorg. Dit hoofdstuk laat zien dat het spreken over voorkeuren voor levensverlengende behandelingen onderdeel hoort te zijn van de zorg voor patiënten met gevorderd COPD of hartfalen. Tenslotte dient de kwaliteit van communicatie over zorg rondom het levenseinde te verbeteren.

Voor artsen die met hun patiënten spreken over hun voorkeuren ten aanzien van levensverlengende behandelingen is het van groot belang om inzicht te hebben in de stabiliteit van deze voorkeuren. Daarnaast is het noodzakelijk om te begrijpen welke factoren een verandering in deze voorkeuren bepalen. Het doel van hoofdstuk 9 was dan ook om na te gaan hoe stabiel voorkeuren voor reanimatie en beademing zijn gedurende een jaar en welke factoren kunnen leiden tot een verandering van deze voorkeuren. De voorkeuren voor reanimatie en beademing veranderden in meer dan een derde van de patiënten minstens één keer gedurende één jaar. Een verandering in gezondheidsstatus, mobiliteit, angst, depressie of verlies van de partner bleek geassocieerd met een verandering in voorkeuren voor levensverlengende behandelingen. Regelmatig evalueren van deze voorkeuren is dan ook noodzakelijk, met name als de gezondheidsstatus, mobiliteit, psychologische symptomen of de burgerlijke staat verandert.

Het doel van hoofdstuk 10 was het vergelijken van de kwaliteit van communicatie tussen artsen en patiënten met COPD over zorg rondom het levenseinde in Nederland en de Verenigde Staten. Daarnaast hebben we de belemmerende en bevorderende factoren voor het spreken over zorg rondom het levenseinde vergeleken. Dit onderzoek laat zien dat patiënten met COPD in Nederland de communicatie over zorg in de laatste levensfase slechter beoordelen dan patiënten in de Verenigde Staten. Echter, in beide landen spraken artsen zelden over voorkeuren voor levensverlengende behandelingen, prognose, doodgaan en spiritualiteit of religie. De kwaliteit van communicatie over het levenseinde moet dan ook in beide landen verbeterd worden. Toekomstig onderzoek gericht op het verbeteren van communicatie dient rekening te houden met internationale verschillen in communicatie en bevorderende en belemmerende factoren voor deze communicatie. 
Dit proefschrift heeft een spectrum aan behoeften aan palliatieve zorg bij patiënten met gevorderd chronisch orgaanfalen geïdentificeerd, waar aandacht aan besteed dient te worden in programma's voor palliatieve zorg (hoofdstuk 11). Patiënten met chronisch orgaanfalen ervaren een aanzienlijke symptoomlast en behandeling van deze symptomen is vaak onvoldoende. Daarnaast komt zorgafhankelijkheid vaak voor en deze zorgafhankelijkheid heeft belangrijke consequenties voor patiënten en hun naasten. Naasten van patiënten hebben een belangrijke rol in de zorg voor patiënten met gevorderd chronisch orgaanfalen. De rol van mantelzorger kan belastend zijn, maar heeft ook positieve aspecten. Patiënten met chronisch orgaanfalen hebben vaak tevens andere ziekten en deze kunnen de behoefte aan palliatieve zorg beïnvloeden. Behandeling van symptomen en aandacht voor zorgbehoeften en co-morbiditeit zijn dan ook belangrijke onderdelen van programma's voor palliatieve zorg. Daarnaast dient aandacht besteed te worden aan belasting en positieve aspecten van het bieden van mantelzorg. Tenslotte is het proces van communicatie tussen artsen en patiënten waarbij de voorkeuren voor levensverlengende behandelingen en zorg rondom het levenseinde worden besproken van groot belang voor patiënten met gevorderd chronisch orgaanfalen. Helaas worden deze voorkeuren zelden besproken en is de kwaliteit van de communicatie over zorg rondom het levenseinde onvoldoende. Vanwege de onzekere prognose en het vaak voorkomen van onverwachte achteruitgang in gezondheidsstatus moet communicatie over zorg rondom het levenseinde onderdeel zijn van reguliere zorg voor patiënten met gevorderd chronisch orgaanfalen. 
Dankwoord 
210 


\section{Dankwoord}

De afgelopen jaren heb ik met heel veel plezier gewerkt aan dit promotieonderzoek. In dit laatste hoofdstuk wil ik de personen bedanken die dit mogelijk hebben gemaakt. De voltooiing van dit proefschrift was onmogelijk geweest zonder de bijdragen en steun van deze personen.

Allereerst heel veel dank aan mijn promotoren Prof. dr. Emiel Wouters en Prof. dr. Jos Schols en mijn copromotor Dr. Martijn Spruit. Het was een enorm voorrecht om door $u$ begeleid te worden. Martijn, je bent een fantastische begeleider voor mij geweest. Ik heb veel respect voor jou als wetenschapper en ben je dankbaar dat ik heb mogen leren van je ervaring. Jouw expertise en ideeën waren onmisbaar bij dit proefschrift. Maar ik wil je vooral danken voor je betrokkenheid bij dit project en bij mijn persoonlijke ontwikkeling. Het was een heel fijn gevoel dat ik geleidelijk aan steeds meer mijn eigen weg mocht zoeken, maar altijd voor wijze raad bij jou terecht kon en altijd met de zekerheid dat je me tijdig bij zou sturen als dat nodig was. Dank dat jij me vertrouwen hebt gegeven, juist op de momenten dat ik dat zelf even niet had. Ik mis onze inspirerende overleggen op vrijdagochtend om half acht en ik hoop dat je ook de komende jaren nog een beetje mijn mentor wilt zijn.

Prof. Wouters, ik heb heel veel waardering voor uw indrukwekkende hoeveelheid kennis, wijsheid en ervaring. Ondanks uw vele bezigheden hebt $u$ tijd gevonden om mij bij dit proefschrift op persoonlijke en inspirerende wijze te begeleiden. Ik wil $u$ hartelijk danken voor alle mogelijkheden die u mij biedt. Dank dat $u$ het mogelijk hebt gemaakt dat ik mijn vleugels uit kon slaan in Seattle. Dank voor het vertrouwen dat $u$ in mij hebt. Prof. Jos, hartelijk dank voor je enthousiaste begeleiding en je continue betrokkenheid. Er heeft geen hoofdstuk van dit proefschrift langer dan 24 uur op je bureau gelegen voordat ik je commentaren kreeg en hiermee weer verder kon. Voor mij en vele van mijn collega specialisten ouderengeneeskunde ben je het boegbeeld van ons vakgebied en steeds als ik jou hoor spreken over ons vak, kan ik er weer trots op zijn.

Dr. Randy Curtis, Dr. Ruth Engelberg, Dr. David Au, Dr. Lynn Reinke and Dr. Lois Downey: It was an honor for me to be part of your research team during my stay in Seattle. I had a great time in Seattle. You made me feel very welcome and I learned a lot about research and communication about end-of-life care. Randy, thank you very much for coming to the Netherlands for the defense of my thesis. You and your team are the best worldwide in research concerning communication about end-oflife care. I am grateful that you are one of my mentors and I hope we will continue working together in the future. 
De leden van de beoordelingscommissie dank ik voor hun kritische beoordeling en goedkeuring van het manuscript. Naast voorzitter Prof. dr. H.P. Brunner-La Rocca bestond de commissie uit Prof. dr. J.E. Ellershaw, Prof. dr. R.T.C.M. Koopmans, Prof. dr. K. Leunissen en Prof. dr. J.F.M. Metsemakers.

Ik wil de vele patiënten en hun naasten bedanken, die ondanks de ernstige ziekte en vaak ernstige beperkingen, hun kostbare tijd en energie hebben willen besteden aan ons onderzoek en ons hebben laten delen in hun ervaringen. Dank dat u bereid was om met ons te praten over de zorg rondom het levenseinde.

Daarnaast wil ik alle patiënten van het Pulmotel bedanken die ik heb mogen begeleiden in hun laatste levensfase. $U$ bent mijn dagelijkse bron van inspiratie. Dank voor alles dat ik iedere dag weer van u leer.

Dit onderzoek was niet succesvol geweest zonder onderzoeksverpleegkundigen Els Verstraeten en Jamila Dekker-Heuts. Els en Jamila, wat had ik bewondering voor het enthousiasme en geduld waarmee jullie zoveel patiënten en naasten thuis hebben bezocht en zoveel interviews en vragenlijsten hebben afgenomen. Dankzij jullie betrokkenheid en inzet hebben vele patiënten de studie voltooid. Maar nog meer bewondering heb ik ervoor dat jullie met zo'n control-freak als ik samen konden werken. Dat zal niet altijd makkelijk zijn geweest, maar dankjewel dat ik met een gerust hart zoveel aan jullie kon overlaten. Wat hebben we samen een fijne tijd gehad! Linda Koolen, dankjewel voor het zo zorgvuldig invoeren van onze data.

De medisch specialisten en verpleegkundigen die patiënten hebben verwezen voor deze studie wil ik hiervoor hartelijk bedanken.

Een speciaal woord van dank aan Ton Alsemgeest. Ton, dank dat jij het hebt gestimuleerd en mogelijk hebt gemaakt dat ik naast mijn patiëntenzorg kon promoveren. Mijn collega artsen, Vera, Gert, Marianne, Carlijn, Frédérique, Karim, Lotje, Loes en Saskia wil ik danken voor hun medewerking en begrip als mijn afdeling weer eens waargenomen moest worden omdat ik aan dit onderzoek werkte, in het buitenland was of onderwijs gaf. Het verpleegkundig team van het Pulmotel wil ik hartelijk bedanken voor de interesse in dit onderzoek. Het is heel fijn om met jullie samen voor onze patiënten te zorgen.

Dank aan mijn collega's in CIRO+ voor de oprechte interesse in dit onderzoek en de fijne samenwerking. Ik ben benieuwd of één van jullie in staat is om mijn record te breken in het aantal keren dat één artikel opnieuw gesubmit moet worden voordat het geaccepteerd is! 
Dank aan mijn paranimfen: Marie-Kathrin Breyer en Dr. Kim Verhoef. Liebste Marie, I am so happy that you came to CIRO+ for research! It is very special to have such a good friend in Vienna. I love the time we spend with talking (skyping!) about research, clinic, our families, your and mine Ivan, men (...) and ourselves. You are the only one who can make me laugh so soon after the rejection of a manuscript! Lieve Kim, wat hebben we de afgelopen jaren vele uren gekletst en de hele wereld, wetenschap en onszelf geanalyseerd. Er zijn maar weinig mensen in mijn leven waarmee ik op zo'n niveau contact maak. Dankjewel dat je er bent en ook nu naast me staat.

Mijn 'stal'-vrienden, Jori, Eric, Lara, Marc, Jo, Petra, Beate: dankjewel dat ik bij jullie ook af en toe even afstand kon nemen van dit onderzoek en met jullie en onze viervoeters fijn kon ontspannen.

Joukje en Karlien, ook al zien en spreken we elkaar soms vele maanden niet door ons drukke leven en alle diensten, als we bij elkaar zijn is het altijd weer net zo vertrouwd en gezellig als toen we studeerden. Ik hoop dat onze vriendschap voor eeuwig standhoudt.

Mijn lieve zus Fiona en ons zonnetje en mijn petekindje Jorn: dankjewel dat jullie er zijn. Oma, uw mooie hand, die symbool staat voor 91 jaar levenservaring, siert de kaft van dit proefschrift. Dank dat u "fotomodel" wilde zijn. Pap, je hebt Fiona en mij altijd gestimuleerd om het beste uit onszelf te halen en ons zoveel mogelijk te ontwikkelen. Ik weet dat je er trots op bent dat ik nu promoveer. Zonder alles wat Mam en jij mij hebben meegegeven was dat niet mogelijk geweest. Ik zal jullie daar altijd dankbaar voor zijn. Dankjewel Pap, dat je de afgelopen jaren het geduld had om mijn enthousiaste verhalen over onderzoek en de zorg rondom het sterven aan te horen. Lieve Mam+, jij hebt me laten zien hoe ongelooflijk belangrijk de zorg in het laatste stukje van het leven is. Zeker de laatste jaren waarin jij ziek was en ik studeerde hebben we een bijzonder hechte band gekregen. Lieve Mams, dank voor alles dat je me hebt meegegeven, dank voor je liefde en onvoorwaardelijke steun. Wat was het fijn geweest als je er nu bij kon zijn. Ik weet dat je trots op me was geweest. 

Curriculum vitae 
216 


\section{Curriculum vitae}

Daisy J.A. Janssen werd geboren op 16 juni 1979 in Sittard. In 1997 behaalde ze haar VWO diploma aan het Bisschoppelijk College in Echt. In hetzelfde jaar startte ze met haar studie Geneeskunde aan de Universiteit Maastricht. In 2001 behaalde ze haar doctoraal diploma met het predikaat cum laude en in 2003 behaalde ze haar artsexamen, eveneens met het predikaat cum laude. Hierna begon ze aan de opleiding tot verpleeghuisarts bij Proteion Thuis in Horn en de Vrije Universiteit in Amsterdam. Deze opleiding voltooide ze in 2005 en sindsdien werkt ze als specialist ouderengeneeskunde bij Proteion Thuis. Ze heeft zich verder ontwikkeld binnen de palliatieve zorg middels de kaderopleiding palliatieve zorg aan de Vrije Universiteit te Amsterdam en de Universiteit van Amsterdam te Amsterdam. Deze opleiding heeft

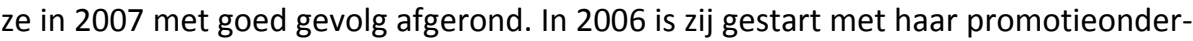
zoek naar behoeften aan palliatieve zorg bij patiënten met gevorderd chronisch orgaanfalen onder leiding van Prof. dr. E.F.M. Wouters, Prof. dr. J.M.G.A. Schols en Dr. M.A. Spruit. Tijdens een research fellowship in 2010 aan het Harborview Medical Center en de University of Washington in Seattle heeft ze zich verder verdiept in kwaliteit van communicatie tussen artsen en patiënten met COPD over zorg in de laatste levensfase onder leiding van Dr. J.R. Curtis. Sinds 2011 werkt ze als themaleider van de onderzoekslijn "Palliatieve zorg, psychologie en educatie" bij $\mathrm{ClRO}+$, expertisecentrum voor chronisch orgaanfalen in Horn. 
List of publications 
220 


\section{List of publications}

Janssen, D.J.A., Spruit, M.A., Schols, J.M.G.A., van der Sande, F.M., Frenken, L.A. and Wouters, E.F.M. Insight in advance care planning for patients on dialysis. Under review.

Janssen, D.J.A., Spruit, M.A., Wouters, E.F.M. and Schols, J.M.G.A. Symptom distress in advanced chronic organ failure: disagreement among patients and family caregivers. J Palliat Med. In press.

Janssen, D.J.A., Spruit, M.A., Schols, J.M.G.A., Cox, B., Nawrot, T.S., Curtis, J.R. and Wouters, E.F.M. Predicting changes in preferences for life-sustaining treatment among patients with advanced chronic organ failure. Chest, 2011. Published online ahead of print.

Janssen, D.J.A., Spruit, M.A., Wouters, E.F.M. and Schols, J.M.G.A. Family caregiving in advanced chronic organ failure. JAMDA, 2011. Published online ahead of print.

Patel, K., Janssen D.J.A. and Curtis, J.R., Advance Care Planning in COPD. Respirology, 2012. 17(1):72-78.

Janssen, D.J.A., Engelberg, R.A., Wouters, E.F.M. and Curtis, J.R. Advance care planning for patients with COPD: past, present and future. Patient Educ Couns, 2012. 86(1): 19-24.

Janssen, D.J.A., Franssen, F.M.E., Wouters, E.F.M., Schols, J.M.G.A. and Spruit, M.A. Impaired health status and care dependency in patients with advanced COPD or chronic heart failure. Qual Life Res, 2011. 20(10): 1679-88.

Janssen, D.J.A., Spruit, M.A., Uszko-Lencer, N.H., Schols, J.M.G.A. and Wouters, E.F.M. Symptoms, co-morbidities and healthcare in advanced COPD or chronic heart failure. J Palliat Med, 2011. 14(6): 735-43.

Janssen, D.J.A., Curtis, J.R., Au, D.H., Spruit, M.A., Downey, L., Schols, J.M.G.A., Wouters, E.F.M. and Engelberg, R.A. Patient-clinician communication about end-oflife care for Dutch and US patients with COPD. Eur Respir J, 2011. 38(2): 268-276.

Janssen, D.J.A., Spruit, M.A., Schols, J.M.G.A. and Wouters, E.F.M. A call for highquality advance care planning in outpatients with severe COPD or chronic heart failure. Chest, 2011. 139(5): 1081-88. 
Janssen, D.J.A., Engelberg, R.A., Curtis, J.R. Toward patient-tailored education in COPD. Patient Educ Couns, 2010. 81(1): 1-2.

Janssen, D.J.A., Spruit, M.A., Leue, C., Gijsen, C., Hameleers, H., Schols, J.M.G.A. and Wouters, E.F.M. Symptoms of anxiety and depression in COPD patients entering pulmonary rehabilitation. Chronic Respiratory Disease, 2010. 7(3): 147-57.

Janssen, D.J.A., Spruit, M.A., Alsemgeest, T.P.G., Does, J.D., Schols, J.M.G.A. and Wouters, E.F.M. A Patient-Centred Interdisciplinary Palliative Care Program for Patients with End-Stage Chronic Respiratory Diseases. International Journal of Palliative Nursing, 2010. 16(4): 189-94.

Janssen, D.J.A., Spruit, M.A., Does, J.D., Schols, J.M.G.A. and Wouters, E.F.M. End-oflife care in a COPD patient awaiting lung transplantation: a case report. BMC Palliat Care, 2010. 9(1):6.

Spruit, M.A., Janssen, D.J.A., Franssen, F.M.E. and Wouters, E.F.M. Rehabilitation and palliative care in lung fibrosis. Respirology, 2009. 14(6): 781-7.

Janssen, D.J.A., Alsemgeest, T.P.G., Widdershoven, G.A.M., Wouters, E.F.M., Schols, J.M.G.A. and Spruit, M.A. End stage chronic lung disease - Authors' reply. BMJ 2009;338:b45.

Janssen, D.J.A., Alsemgeest, T.P.G., Widdershoven, G.A.M., Wouters, E.F.M., Schols, J.M.G.A. and Spruit, M.A. A Patient's Journey: The last wish of a patient with end stage chronic obstructive pulmonary disease. BMJ 2008;337:a2701.

Janssen, D.J.A., Spruit, M.A., Schols, J.M.G.A. and Wouters, E.F.M. A Dosage of Opioids Should Never Exceed What Is Necessary to Relieve Symptoms. Am J Respir Crit Care Med, 2008. 178(11): 1186.

Janssen, D.J.A., Spruit, M.A., Wouters, E.F.M., and Schols, J.M.G.A. Daily symptom burden in endstage chronic organ failure: a systematic review. Palliat Med, 2008. 22(8): 938-48.

Janssen, D.J.A., Wouters, E.F.M., Schols, J.M.G.A. and Spruit, M.A. Self-perceived symptoms and care needs of patients with severe to very severe chronic obstructive pulmonary disease, congestive heart failure or chronic renal failure and its consequences for their closest relatives: the research protocol. BMC Palliat Care, 2008. 7: 5. 


\section{Nationale publicaties}

Janssen, D.J.A. en Franssen, F.M.E. Chronisch obstructief longlijden en comorbiditeit. In: Muris, J.W.M. en de Weerd-Spaetgens, C.M.E.E., Redactie. Praktische huisartsgeneeskunde, Ouderengeneeskunde. $1^{\mathrm{e}}$ druk. Houten. Bohn Stafleu van Loghum. 2012. p. 411-20.

Janssen, D.J.A., Uszko-Lencer, N.H., Wouters, E.F.M., Spruit, M.A. en Schols, J.M.G.A. Palliatieve zorg voor patiënten met chronisch hartfalen: hard nodig! Tijdschrift voor ouderengeneeskunde, 2010. 4: 144-9. 
But I have promises to keep, and miles to go before I sleep. Robert Frost 